\title{
The conservation status of birds in Laos: a review of key species
}

\author{
R. M. THEWLIS, R. J. TIMMINS, T. D. EVANS and J. W. DUCKWORTH
}

\section{Summary}

Laos is an important country for bird conservation. Bird surveys between 1992 and 1996, the first since 1949, covered 20 main areas, with incidental records from many others.

This paper reviews the status of all Lao species reported to be of elevated conservation concern (key species) in any of the following categories: Globally Threatened or Globally Near-Threatened (sensu Collar and Andrew 1988 and Collar et al. 1994), and At Risk or Rare in Thailand (sensu Round 1988 and Treesucon and Round 1990). Several additional species are covered which have clearly undergone a National Historical Decline in Laos. A comprehensive review of other Lao species was not possible, and some species which are in truth of conservation concern have doubtless been overlooked. Historical and modern records were reviewed and population trends identified where possible.

Current global status listings (Collar et al. 1994) were supported, except that consideration should be given to changing Red-collared Woodpecker Picus rabieri and Sooty Babbler Stachyris herberti from Threatened to Near-Threatened. If the Lao situation is representative of the species throughout their range, then consideration should also be given to placing Ratchet-tailed Treepie Temnurus temnurus and River Lapwing Vanellus duvaucelii as Near-Threatened.

Twenty-seven Globally Threatened species are known from Laos, of which there are recent records of 22. There are recent unconfirmed records of two more. Forty-seven Globally Near-Threatened species are known from Laos, of which there are recent records of 39; there are unconfirmed records of one further species. Five Globally Threatened and five Near-Threatened species were recorded for the first time in Laos in recent years, suggesting that further species of elevated conservation concern remain to be found.

All species reviewed were placed in one of the four categories: At Risk in Laos, Potentially At Risk in Laos, Little Known and Not At Risk in Laos. These are assessed in the light of foreseeable threats; some species may move into a higher category of threat in due course. Forty-four species are thought to be At Risk in Laos; there are no recent records of four of these. Twenty-five species are thought to be Potentially At Risk in Laos; there are no recent records of two of these. Thirty-four species considered by this review are thought to be Not At Risk in Laos at the current time, whilst there is insufficient information to make an assessment (termed Little Known) for another 32 species.

Laos retains a much higher proportion of forest cover than do most neighbours, including substantial lengths of almost pristine riverine forest in the Nam Theun and $\mathrm{X}$ Kong basins, extensive level lowland forest (especially at $\mathrm{Xe}$ Pian National Biodiversity Conservation Area and Dong Khanthung Proposed Protected Area in the South) and considerable amounts of slope forest at all altitudes. At least 27 forest 
species seem to occur in globally significant numbers. This is probably because the surveyed forests were large in relation to hunting and degradation pressures on the populations of most species. Logging of virgin areas, hydropower schemes and clearance of forest for cultivation will soon reverse this situation unless controls are established.

At least 35 of the species under consideration have declined over the past 50 years by a magnitude exceeding that of their habitat loss, so that they are now absent from large areas of suitable habitat. Twenty-four of them are associated with slow-flowing rivers and other wetlands. These areas are preferentially settled and exploited by people and their birds are thus under elevated threat from hunting, habitat clearance and disturbance. Other factors may explain the declines of several birds (Pied Kingfisher Ceryle rudis and Plain Martin Riparia paludicola) in these habitats. Most other decreasing species inhabit open deciduous forest or scrub, which also experience heavy human use. Hornbills, however, occupy dense forest but also have declined, perhaps because their conspicuousness, flocking behaviour and low reproductive rate all magnify the effects of hunting. Further species have doubtless declined, but historical data are too patchy to demonstrate this.

The major threats to birds in Laos include logging, accelerated forest clearance and fragmentation on a large scale (for subsistence and commercial purposes), intensification of wetland use and widespread unrestricted hunting. A new force with the potential to be exceedingly damaging is a proposed programme of over 50 hydropower developments. These will inundate and fragment large areas of intact habitat, force farmers to clear fresh land elsewhere and open up access to some of the nation's most remote and pristine wildlife habitats.

Conservation measures will revolve around implementing management within the recently established protected areas, resisting commercial exploitation within them, and expanding the network to cover currently under-represented habitats. For a few species, measures beyond the reserves system are imperative: these include species requiring large rivers (e.g. Great Thick-knee Esacus recurvirostris, terns and River Lapwing) and wide-ranging large waterbirds (e.g. storks, ibises and cranes). Further status surveys for all species are needed throughout Laos and are particularly urgent for large waterbirds and everywhere in North Laos.

In a global context, Laos has highly important populations of: Siamese Fireback Lophura diardi, Crested Argus Rheinardia ocellata, Green Peafowl Pavo muticus, White-winged Duck Cairina scutulata, Red-collared Woodpecker, Red-vented Barbet Megalaima lagrandieri, Brown Hornbill Anorrhinus tickellii, Rufous-necked Hornbill Aceros nipalensis, Blyth's Kingfisher Alcedo hercules, Coral-billed Ground-cuckoo Carpococcyx renauldii, Masked Finfoot Heliopais personata, Grey-headed Lapwing Vanellus cinereus, Lesser Fish-eagle Ichthyophaga humilis, White-rumped Vulture Gyps bengalensis, Long-billed Vulture Gyps indicus, Red-headed Vulture Sarcogyps calvus, Rufous-winged Buzzard Butastur liventer, White-shouldered Ibis Pseudibis davisoni, Giant Ibis P. gigantea, Greater Adjutant* Leptoptilos dubius, Blue-rumped Pitta Pitta soror, Bar-bellied Pitta P. elliotii, White-winged Magpie Urocissa whiteheadi, Yellow-breasted Magpie Cissa hypoleuca, Ratchet-tailed Treepie, Green Cochoa Cochoa viridis, Jerdon's Bushchat Saxicola jerdoni, Beautiful Nuthatch Sitta formosa, Black-hooded Laughingthrush Garrulax milleti, Grey Laughingthrush G. maesi, White-cheeked Laughingthrush G. vassali, Red-tailed Laughingthrush G. milnei, Sooty Babbler, Grey-faced Tit-babbler Macronous kelleyi, Spectacled Fulvetta Alcippe ruficapilla, Rufous-throated Fulvetta A. rufogularis, Mountain Fulvetta $A$. peracensis and Short-tailed Parrotbill Paradoxornis davidianus. These are species either on the brink of global extinction; Globally Threatened or Near-Threatened but

* See note added in proof 1, p. 131. 
occurring commonly at many sites in Laos; for which recent Lao records are more substantial than those from anywhere else in a species's range; or have limited geographical range of which Laos is a substantial part.

A revised set of key species for future use in Laos is given in Appendix 2

\section{Introduction}

The birds of Laos remain poorly known, particularly in comparison with neighbouring Thailand. Most historical records come from a small number of observers who worked in the country during 1919-1949. Thereafter, successive political upheavals and, in the 1970 s and 1980s, restrictions on visitors, meant that for 40 years no new ornithological observations were made and published. During this period there were alarming declines in many South-East Asian birds: the first edition of Birds to watch (Collar and Andrew 1988) listed 18 globally threatened species from Laos and a further 15 which were near-threatened with extinction. In view of the extensive habitat destruction in Thailand, Vietnam and southern China, it was hoped that Laos would prove to support viable populations of many of these species, although the contemporary status in Laos was not known for a single one.

The political climate relaxed considerably after 1988, when a major conservation initiative was begun by the Lao government, with the help of international conservation organisations. This has led to an extensive series of wildlife surveys and, in 1993, to the declaration of 18 protected areas at the national level, with an unknown number at the provincial level. These recent surveys have provided the information necessary for the compilation of the current paper, whose object is to review the past and present status of all bird species recorded from Laos which are known or suspected to be of conservation concern either globally, regionally or nationally. Survey sites were selected for a variety of logistical and biological reasons. Identification of areas to protect at the national level involved examination of aerial photographs and satellite imagery followed by reconnaissance visits with extensive interviews of villagers (Salter 1993, Berkmüller et al. 1995b). Areas which appeared to be particularly rich in wildlife were a high priority for survey, together with those where for a variety of reasons early management implementation was envisaged. The comprehensive overview of Laos taken at the start of the project identifying suitable areas for conservation means that it is likely that few extensive areas of largely natural habitat remain that are not figured in Berkmüller et al. (1995a).

Laos is a small country $\left(236,800 \mathrm{~km}^{2}\right)$ with a human population of only 4.58 million (National Statistical Centre 1995). In biogeographical terms it lies in the Indochinese subdivision of the Indomalayan Realm, in the three sub-units defined by MacKinnon and MacKinnon (1986) as Central Indochina (10a), North Indochina (10b) and Annam (5b). The country is still comparatively well endowed with natural habitats, although habitat clearance will inevitably accelerate, as the human population is expanding at a rate of $2.4 \%$ per year (National Statistical Centre 1995). This is one of the fastest growth rates in the world and means that population density per unit area of agricultural land is already near the regional average (Salter 1993). 
Laos is entering a period of rapid economic change. Natural resources account for about $70 \%$ of the country's foreign earnings (Salter 1993). Growth in the commercial use of these resources is expected as Laos changes from a centrally controlled economy to embrace rapid free-market expansion. As an illustration of this, the number of private foreign investment projects in Laos rose from seven in 1988 (value $\$ 4.6$ million) to 135 by 1994 (value $\$ 4,713$ million), and the total number of such projects in this period was 572 with a sum value of $\$ 8,836$ million (Foreign Investment Management Committee 1995). This rapid expansion is certain to have far-reaching effects on birds and their habitats.

\section{Methods}

\section{Status of bird habitats}

In the course of the bird surveys listed in Tables 1 and 2, a system of habitat classification was established, based on systems used in Thailand (Round 1988). Information on the status of these habitats in the study areas was gathered during the bird surveys. Information on the status of habitats elsewhere in Laos came from recent published and unpublished data from a variety of sources. Information was also reviewed on three related topics: existing conservation initiatives in Laos, planned major hydroelectric projects in Laos, and the nature of hunting pressure on Lao birds.

\section{Selection of species for consideration}

This review covers bird species of elevated conservation concern (henceforward "key species") which have occurred in Laos. They have been drawn from five categories (for purposes of clarity, from this point we capitalise phrases that stand for these and other precisely defined categories), as follows:

(1) Species listed as Globally Threatened with extinction by Collar et al. (1994).

(2) Species listed as Globally Near-Threatened with extinction by Collar et al. (1994).

(3) Species listed as Globally Threatened or Globally Near-Threatened in Collar and Andrew (1988) but which were not listed as such by Collar et al. (1994).

(4) Species At Risk in Thailand. Round (1988) and Treesucon and Round (1990) both list species At Risk in Thailand, but not all species occur in both lists. All Lao species occurring on either list are discussed in this paper. Round (1988) included some additional "Rare" species which, while not considered At Risk in Thailand, were localised enough to be of conservation concern: these are indicated here by "Rare in Thailand", and if they occur in Laos their status is also discussed.

(5) Species not listed in any of the above sources but for which a population decline, over and above the direct effects of habitat loss, was perceptible to us when comparing information in historical sources (pre-1950) with recent information. Such species are described as showing a National Historical Decline. The paucity of historical information means that this category is probably incomplete, and biased towards conspicuous birds which were easily identifiable in the field 50 years ago. Furthermore, the species in this 
category were not identified through a systematic review, but are those whose change in status was noticed incidentally while using the historical references to derive information for other purposes.

\section{Assessment of national population trends and risk status in Laos}

Lao populations of all key species were assessed to determine: (i) whether or not a decline has demonstrably occurred; (ii) the national conservation status.

Evidence for a decline between "historical" records, which cover the period up to 1949, and modern records, which commenced in 1990, was taken from a comparison of all sources mentioning the species in Laos. Only in rare cases was it possible to make direct comparison of a species's status today in the same area and at the same season as those for which a historical status assessment had been made. Some species which have not demonstrably declined in well surveyed areas of the country (principally south of $18^{\circ} 40^{\prime} \mathrm{N}$ ) may in future be shown to have declined in large areas north of this latitude. For some species (e.g. Sarus Crane [all scientific names of key species are given in 'key species accounts']), historical information from villagers was used to substantiate evidence for a historical decline.

National conservation status was assessed for all species, independent of any global assessment of status. This used a framework based on the IUCN Red List guidelines (IUCN 1994). For many species, present data are simply insufficient to provide the quantitative information those guidelines require; in these cases subjective judgements were necessary. The criteria were also amended in the following ways.

(i) Only one category of threat (At Risk) was used; species were considered to be At Risk on the basis of a likely decline of $40 \%$ in the last or the next 10 years (rather than the $20 \%$ in 10 years specified by IUCN 1994). Use of a criterion of $20 \%$ decline in to years for species widespread in Laos would lead to the inclusion of many forest species, due simply to predicted long-term habitat loss. Reliable predictions of long-term rates of habitat loss are not possible given the current state of information about Lao forests (although it seems likely that extensive losses will occur), and furthermore inclusion of such species would have compromised the ability of this review to highlight species in imminent danger.

(ii) Species were also considered as At Risk if they have a limited range in Laos ("limited" generally but not strictly being defined as present in three or fewer provinces) and are likely to decline by more than $20 \%$ in the next 10 years or to have done so in the last 10 years.

(iii) Small population size and area of occupancy were not used alone to determine status.

Any of the following types of evidence were sufficient to indicate that the Lao population of a species was At Risk:

(i) observed or presumed heavy hunting pressure;

(ii) evidence of a National Historical Decline; 
(iii) suspected or demonstrated low tolerance to human disturbance (in any form);

(iv) dependence on particularly threatened habitats (the following habitats are disproportionately vulnerable to clearance or degradation: flat lowland semi-evergreen forest; lowland mosaic forest; Fokienia forest; wet evergreen forest; large lowland rivers; marshland).

All key species were then placed in one of four categories:

(i) At Risk in Laos, which is roughly equivalent to the Threatened category of IUCN (1994) but with the above amendments which result in the exclusion of some species for which the only threat is long-term habitat loss and which might be considered "Vulnerable" following the criteria of IUCN (1994);

(ii) Potentially At Risk in Laos, which includes species suspected to be At Risk but where information about threats or species status is not clear enough to make a firm categorisation, and species on or close to the borderline (the latter case being equivalent to the Near-Threatened category used by Collar et al. 1994 and IUCN 1994);

(iii) Little Known in Laos, which provides for species difficult to assess, i.e. those with detection or identification problems; or where there has been a lack of fieldwork in their preferred range and habitats; or where threats or species status are not clear for other reasons;

(iv) Not At Risk in Laos, which covers key species for which there are no foreseeable threats to their survival in the country at the current time.

The appropriateness of current Globally Threatened and Globally NearThreatened status has been reviewed in the light of discoveries in Laos since Collar et al. (1994) was published, and in a few instances a change of designation has been recommended. These international designations were not used in the classification of species into the four-category system of level of risk in Laos; for species with a divergence of opinion on their threat status globally and risk status nationally, the global status should be reconsidered in this light.

In an ongoing analysis to be reported separately, the same review procedures are being applied to all other Lao bird species. Some species at risk in Laos have undoubtedly been overlooked in the present review, and in the interim fieldworkers should remain vigilant for these. Furthermore, many species not currently At Risk seem likely to move into this category in the future as forest loss and human population growth continue.

New information in the future will allow progressive refinement of these provisional status assessments.

Assessment of global importance of species populations and priority for action for their conservation in Laos

An attempt was made to set the Lao population of every bird species treated here in an international context, principally to assist in setting priorities for action within Laos. For species not considered to be Globally Threatened this was hampered by the lack of a readily available review of information from 
other range states, particularly for Cambodia in areas away from waterbird colonies.

Populations were considered to be of high global importance where species are either on the brink of global extinction; Globally Threatened or Near-Threatened but occurring commonly at many sites in Laos; for which recent Lao records are more substantial than those from anywhere else in their South-East Asian range; or have limited geographical range of which Laos is a substantial part. The importance of the Lao population may not be solely related to numbers: it may relate to the maintenance of the species's ancestral range.

The priority of action needed for each key species was assessed using the following factors:

(i) the global importance of the Lao population;

(ii) the degree of threat in Laos;

(iii) practicability of conservation measures;

(iv) the extent of incidental benefit to other conservation aims.

Four priority levels of urgency were distinguished: Acute, High, Mid and Zero.

As an example of how a priority level was designated, White-winged Duck is Globally Threatened and the Lao population is an important component of the global population, but it is highly threatened. The population faces a specific threat (over-harvesting), and is localised. Realistically enforceable conservation measures can thus be envisaged and, because of the location of the population, are likely to benefit other species At Risk. The species has thus been assigned an Acute urgency for action. Similarly, although Lesser Adjutant and Woolly-necked Stork have similar status in Laos, the former is Globally Threatened while the latter is not; thus the former is assigned a higher urgency for action.

\section{Summary of categorisation system adopted in this paper}

Bird species treated in this review are referred to as "key species". They were selected from outside sources (Collar and Andrew 1988, Round 1988, Treesucon and Round 1990, Collar et al. 1994), supplemented by a few species which were not on any of these lists but which have clearly declined greatly in Laos. The Lao population of each of these species was then categorised on four gradients:

(i) national population trend - species which have declined over and above the direct effects of habitat loss are referred to as showing a National Historical Decline;

(ii) national conservation status - all key species are placed in one of four categories: At Risk in Laos, Potentially At Risk in Laos, Little Known in Laos, Not At Risk in Laos;

(iii) global importance of the Lao population - all key species were categorised in one of four categories: high global importance, mid global importance, unknown global importance, presumed insignificant global importance;

(iv) priority of action - all key species were categorised into one of four priority levels for conservation action in Laos: Acute, High, Mid and Zero.

The information from the four gradients in conjunction with international 
threat designations (see Collar et al. 1994) was used to reduce the list of key species for future work in order to ensure that attention is not deflected from species in real need in Laos or globally. The recommended list of key species for future workers is given in Appendix 2; but the rest of the text of this paper uses the term "key species" to refer to all those that are reviewed in this paper, and were treated as such until the end of 1996.

\section{Sources of information}

\section{Historical information}

The ornithological bibliography of Indochina (Mlikovsky and Inskipp in prep.) and its cross-referenced species checklist index all bird records from Laos known to its compilers. This was an invaluable base for the present work. The approximately 70 historical sources concerning Lao birds, many mainly or exclusively secondary, are based on the work of a handful of ornithologists and collectors visiting between 1876 and 1949, with the bulk during 1919-1944. The most important sources are the accounts of David-Beaulieu, who lived for some years each in Savannakhet and Xiangkhouang (David-Beaulieu 1944, 1948, 19491950), of Engelbach, who lived in Salavan and Pakxe (mostly synthesised in Engelbach 1932), and of six collecting expeditions which visited Laos: the second, fourth, sixth and seventh Indochina Expeditions led by Jean Delacour (Delacour and Jabouille 1927, Delacour 1929, 1932, Delacour and Greenway 1940), the Legendre Indochina Expedition (Dickinson 1970a) and the Kelley-Roosevelts Expedition (Bangs and van Tyne 1931). Other collections from this period remain undocumented (for example that of F. R. Wulsin; see Bangs and van Tyne 1931) and specimens representing valuable information may yet be discovered in museums.

Delacour and Jabouille (1931, 1940) summarised contemporary knowledge of the avifauna of Indochina. However, some of their species distribution summaries are at variance with contemporary primary literature, suggesting that they incorporated many otherwise unpublished observations (e.g. Malayan Night-heron) or were careless: some status assessments were misleadingly exaggerated, notably Bamboo Woodpecker Gecinulus viridis (see Duckworth 1996).

King et al. (1975) synthesised all distributional information of birds in Laos to form a convenient summary, although some records were omitted (see, e.g., Evans and Timmins 1998).

All significant historical records of a species from Laos which are known to the compilers are included in the species accounts, except for a few species where recent reviews of their status in Laos have been published in detail elsewhere (Green Peafowl, White-winged Duck, Giant Ibis, River Lapwing, Jerdon's Bushchat). Where one reference merely duplicates another, usually only one has been cited.

\section{Modern information}

From October 1992 a series of wildlife surveys has been carried out in many areas of Laos (Tables 1 and 2). All known records of key species from then until 
Table 1. Summary of recent survey work in Laos

\begin{tabular}{|c|c|c|c|c|}
\hline Paper & $\begin{array}{l}\text { Dates } \\
\text { covered }\end{array}$ & $\begin{array}{l}\text { Main study } \\
\text { sites } \\
\text { discussed }\end{array}$ & $\begin{array}{l}\text { Other study } \\
\text { sites visited }\end{array}$ & $\begin{array}{l}\text { Minor sites with records used in } \\
\text { the current paper }\end{array}$ \\
\hline $\begin{array}{l}\text { Thewlis et al. } \\
\text { (1996) }\end{array}$ & $\begin{array}{l}\text { October } 1992 \\
\text { to October } \\
1993\end{array}$ & $\begin{array}{l}\mathrm{HN}, \mathrm{XP}, \\
\mathrm{PXH}, \mathrm{DHS}\end{array}$ & SMK, PKK & $\begin{array}{l}\text { Lao Pako, Ban Thadua, Ban Xot } \\
\text { (S of XP), Attapu town, Xe Kong } \\
\text { river, Ban Thangon reservoir, } \\
\text { Mekong at Vientiane }\end{array}$ \\
\hline $\begin{array}{l}\text { Evans and } \\
\text { Timmins } \\
\text { (1998) }\end{array}$ & $\begin{array}{l}\text { January } 1994 \\
\text { to August } \\
1994\end{array}$ & $\begin{array}{l}\text { NNT, NTX, } \\
\text { NP, XBN }\end{array}$ & KML, PKK & $\begin{array}{l}\text { Mekong at Vientiane, Sayphou } \\
\text { Loyang, Ban Lak (20) }\end{array}$ \\
\hline $\begin{array}{l}\text { Duckworth } \\
\text { et al. (1998a) }\end{array}$ & $\begin{array}{l}\text { October } 1994 \\
\text { to August } \\
1995\end{array}$ & $\begin{array}{l}\text { PKK, NK, } \\
\text { NP, KML, } \\
\text { XNN, PDD }\end{array}$ & $\begin{array}{l}\text { XP, BSW, } \\
\text { NNT }\end{array}$ & $\begin{array}{l}\text { Sayphou Loyang, Xe Khampho } \\
\text { PPA, Pakxan Wetlands }\end{array}$ \\
\hline $\begin{array}{l}\text { Evans et al. } \\
\text { (in prep.) }\end{array}$ & $\begin{array}{l}\text { November } \\
1995 \text { to } \\
\text { September } \\
1996\end{array}$ & $\begin{array}{l}\text { DHS, PXT, } \\
\text { DKT, SMK }\end{array}$ & $\mathrm{XP}$ & lower Xe Xou \\
\hline $\begin{array}{l}\text { Tizard et al. } \\
\text { (in prep.) }\end{array}$ & $\begin{array}{l}\text { November } \\
1995 \text { to } \\
\text { September } \\
1996\end{array}$ & $\begin{array}{l}\text { NNT, HNN, } \\
\text { NTX, XS, } \\
\text { PDD, NP, } \\
\text { KML }\end{array}$ & & $\begin{array}{l}\text { Mekong at Louangphabang, Ban } \\
\text { Phonsavan, Nam Ou from } \\
\text { Louangphabang to Phongsali, } \\
\text { Sayphou Loyang }\end{array}$ \\
\hline $\begin{array}{l}\text { Duckworth } \\
\text { (1996) }\end{array}$ & $\begin{array}{l}\text { February/ } \\
\text { March and } \\
\text { June/July } \\
1996\end{array}$ & $\mathrm{TMF}$ & & \\
\hline
\end{tabular}

31 December 1996 are incorporated in this review. Most of these surveys were associated with the Centre for Protected Areas and Watershed Management (CPAWM) of the Lao Department of Forestry, and focused on areas of suspected conservation importance or areas likely to be developed for hydropower projects. Ornithological data collection formed the basis of all the surveys, although data were also collected on mammals (e.g. Duckworth et al. 1994, 1995, Duckworth 1996, 1997a, in press, Ruggeri and Timmins 1996, Timmins et al. 1998), large reptiles (including testudines) and vegetation. Surveys exceeding one personweek of fieldwork investigated 20 areas (Figures 1 and 2, Table 2). Shorter visits to various other sites, together with roadside and aerial observations, allowed a broad picture of the extent of various habitats and their condition outside the study sites, and provided some records of key species. There is very limited information on the current status of birds in Laos north of $18^{\circ} 4 \mathrm{O}^{\prime} \mathrm{N}$ but coverage has been fairly representative for all habitats in the South and Centre (sensu King et al. 1975) of the country.

Although summary data about key species found during recent surveys have been or will be published elsewhere, much of the detailed information in the current paper has not been presented before, or has only appeared in unpublished survey reports. None of these latter data is referenced to a source or observer in the text; Table I summarises main sites and the papers which give details of them. The authors were involved in almost all surveys; others who contributed records from the same surveys are listed in the acknowledgements as it was not practicable to attribute individual records to observers in the text. 


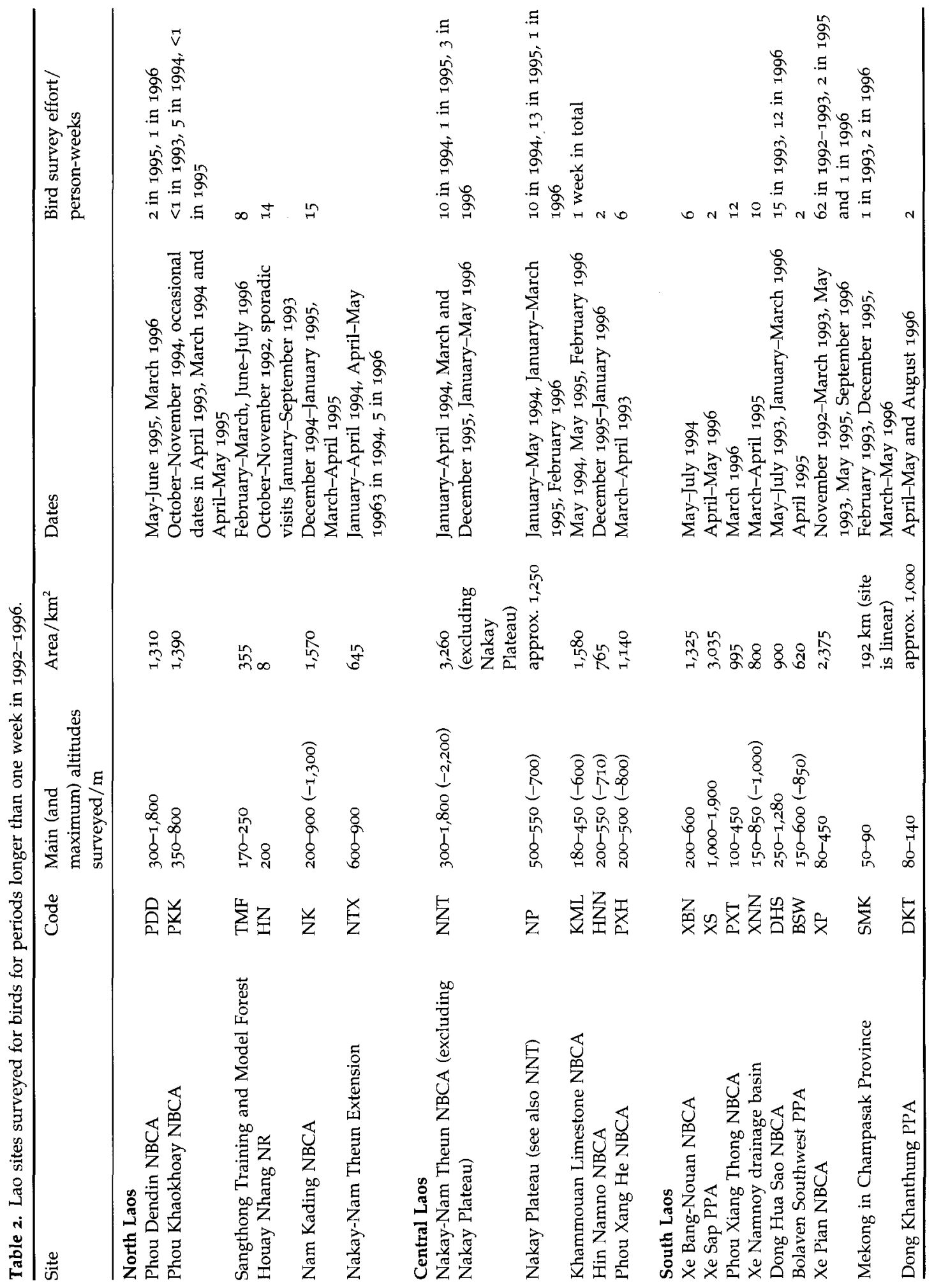


Recent information on certain species is also presented in Salter (1993). Unpublished observations from other projects are also used and referenced in the text. Further information was available from the files of the FRCP (explained below), which conducted reconnaissance surveys of many proposed reserves in 1988-1994. They interviewed villagers about animals, including three birds (Crested Argus, Green Peafowl and Sarus Crane). A few further sources, for example Robichaud (1992), gave recent ornithological data, but covered no key species. Many of our records were incorporated by Claridge (1996) but that source contains no other significant information on key species.

Several factors combined to reduce the value of recording precise numbers in assessing species status. These include: variation between observers, the presence of observers concentrating on fieldwork other than searches for threatened birds (for numbers to be meaningful, they would have to be scaled against effort) and seasonal variations (particularly important for calls). Recent records are therefore placed into broader status categories when this seems more helpful than quoting numbers. The following categories are employed to give an index of abundance:

common: species found daily and usually in some numbers;

frequent: species found on most days;

occasional: species found on fewer than half of all days.

\section{Abbreviations and conventions}

Abbreviations used in the text are as follows: BPKP, Bolisat Phattana Khet Phoudoi (Mountain Areas Development Corporation); BSW, Bolaven Southwest PPA; CPAWM, Centre for Protected Areas and Watershed Management, Department of Forestry, Vientiane; DHS, Dong Hua Sao NBCA; DKT, Dong Khanthung PPA; FRCP, Forest Resources Conservation Sub-programme of the LSFCP; HN, Houay Nhang Nature Reserve; HNN, Hin Namno NBCA; KML, Khammouan Limestone NBCA; LSFCP, Lao-Swedish Forestry Co-operation Programme; NBCA, National Biodiversity Conservation Area; NHM, Natural History Museum, Tring, U.K.; NK, Nam Kading NBCA; NNT, Nakay-Nam Theun NBCA; NP, Nakay Plateau; NTX, Nakay-Nam Theun Extension PPA; PDD, Phou Dendin NBCA; PKK, Phou Khaokhoay NBCA; PPA, Proposed Protected Area; PXH, Phou Xang He NBCA; PXT, Phou Xiang Thong NBCA; SMK, Mekong in Champasak Province; TMF, Sangthong Training and Model Forest; XBN, Xe Bang-Nouan NBCA; XNN, Xe Namnoy drainage basin; XP, Xe Pian NBCA; XS, Xe Sap PPA.

There are two rivers on the Nakay Plateau called Nam Mon, one a tributary of the Nam Xot, the other a tributary of the Nam Yang: the former is here called Nam Mon $(X)$, the latter Nam Mon (Y).

The taxonomy, nomenclature and sequence of Sibley and Monroe (1990, 1993) are followed throughout, as is the division of Laos into North (Northern), Central and South (Southern) employed by King et al. (1975). Records in square brackets indicate that the observers wish them to be treated as provisional. If a whole species account is in square brackets, the species is not confirmed to occur in Laos. Populations are assessed mainly at the species level; mention is occasionally made of threatened subspecies although these have not been 
considered in a systematic fashion. Scientific names of key species are given in the species account headings. All the localities listed in this paper and the conventions covering their use are given in Appendix 1, and the more frequently cited ones are plotted on Figures 1-17.

The word "evergreen" refers to trees which retain their leaves throughout the year. The term "broadleaved" refers to broadleaved rather than coniferous species; it encompasses dry dipterocarp, mixed deciduous, semi-evergreen and dry and wet evergreen forest types. Habitat types are discussed in detail under Results below.

\section{Results}

Forests

The preliminary national forest inventory (LSFCP 1992) was mainly intended for silvicultural purposes and the results do not indicate clearly the extent of remaining forest important for bird conservation. Mature forest was believed to cover over $45 \%$ of the country as a whole as late as 1993 (Salter 1993), and this proportion, although ever dwindling, is nonetheless much higher than in the neighbouring countries of Vietnam, China and Thailand (Collins et al. 1991). Cambodia and Burma may retain forests of the same magnitude of importance, but the political instability of these countries has left a paucity of recent information and suggests that the establishment of a functional network of protected areas under current conditions may be difficult. Laos thus has a special opportunity to lead in the protection of the region's forest wildlife.

Forest clearance for agriculture (principally shifting cultivation) has been recognised as a major problem by the government, which has proposed that shifting cultivation practices must be stopped by the year 2000: forest loss has been estimated at 100,000 ha of primary forest and 300,000 ha of secondary forest per year (Fujisaka 1991). However, given its widespread nature and the lack of available alternatives, such an immediate cessation is unlikely.

Forest cover differs greatly between the North of the country and the South and Centre (Collins et al. 1991). In the mountainous North, the shifting cultivation practised by ethnic hill-tribe groups has produced a patchwork of cultivation and successional habitats at various stages, with some districts now reduced to grassland by excessive burning and cultivation. Only about $35 \%$ of North Laos was considered to be forest by LSFCP (1992), and little of this is likely to be in the form of extensive blocks of primary forest; flights over parts of North Laos suggest that most is now secondary and all but the highest and steepest peaks have been affected. In Xiangkhouang, a province covering a considerable area above $1,000 \mathrm{~m}$, forest has been degraded in most areas, with clearance often extending to over $1,500 \mathrm{~m}$.

South and Central Laos are dominated by several ethnic groups who use permanent wet-rice cultivation, usually supplemented by low levels of shifting cultivation of hill-rice and vegetables at forest-edge sites. This more site-restricted agriculture has left large forest areas almost intact. Such areas of forest remain even in the flatter lowlands (especially south of the Bolaven Plateau), although most of the flat lowlands are deforested or dominated by dry dipterocarp forest. 
Many mountain and hill areas in the South and Centre retain extensive areas of barely encroached forest.

Most lowland areas, including those within protected areas, have been logged at least once, often relatively recently. In those cases where only a small proportion of trees was extracted, the logged areas retain important forests in moderate condition (e.g. in Dong Hua Sao NBCA and Bolaven Southwest PPA). Most remaining areas outside protected areas seem likely to be logged over the next 20 years. Moreover, the case of Nakay-Nam Theun NBCA (where pine-logging and Fokienia logging continued after reserve designation) suggests that some protected areas will also continue to be logged.

In lowland areas the preferred timber species are mainly dipterocarps. At higher altitudes various broadleaved species are taken and, in addition, pines (probably mostly Pinus, principally on the Nakay Plateau and parts of the South) and the conifer Fokienia hodginsii. The sizes and range of timber types harvested are being increased by the recent introduction of chipboard and plywood factories in several areas of Central and South Laos. Fokienia is so valuable that it has been profitable to build roads into the heart of some of the most extensive and least disturbed tracts of dry evergreen forest in the Annamite mountains of Nakay-Nam Theun NBCA and the Nakay-Nam Theun Extension and Nam Chouan PPAs, in order to extract it; these access roads affect some of the most important forests in Laos for wildlife. There has been very extensive logging of this species in North Laos (various sources). Furthermore, Fokienia logging is so lucrative that removal of logs by helicopter is economically viable, although latterly logging roads have replaced this need. Fokienia timber reportedly fetches more than $\$ 2,500 / \mathrm{m}^{3}$ uncut for "grade $\mathrm{A}^{\prime \prime}$ wood (BPKP representative verbally 1994).

Although official logging controls exist, there have been instances of extending salvage-logging of hydroproject inundation areas well beyond the inundation zone, of logging proposed inundation areas before confirmation that inundation will occur, and of over-exploitation in areas where a permit to take only dead standing trees has been granted. In Central Laos much logging is conducted by a quasi-autonomous organisation (BPKP) with a remit to develop the economy and infrastructure of the area, making regulation by central government difficult. Abuse of power by senior figures is illustrated by the fact that a provincial governor in the South was removed from office by the central government in 1995 because of his involvement in illegal logging operations.

In most forest areas of Laos there are heavy and perhaps unsustainable harvests of many non-timber forest products, of which rattan, Aquilaria resin, oleoresins (from Dipterocarpaceae) and palm products (leaves, hearts and fruits) are probably the most widespread and economically motivated. Although no direct effects of these harvests on particular bird species are known, the combined effect of excessive harvesting of many products (including the death of canopy trees from resin and fruit collection) is likely to alter forest ecology in many areas. A much more immediate threat is an indirect one: harvesters generally live off the land when working in remote areas, and collection of forest products is then a major cause of high local hunting pressure. Such activities are particularly concentrated in the late dry season when there are few farming activities and surface-water sources are at their fewest. 
A wide range of forest habitats is present in Laos, with the predominant type in any area dependent on altitude, rainfall patterns and edaphic factors. They include upper montane forest $(1,800 \mathrm{~m}$ and above), semi-evergreen forest, mixed deciduous forest, dry dipterocarp forest and pine forests dominated by the genus Pinus; these vegetation types are similar to those described by Round (1988). Habitat types recognised on recent bird surveys in Laos differ from Round (1988) in the following ways.

(1) In eastern Laos, some forests as low as $300 \mathrm{~m}$ are predominantly evergreen and support an avifauna different from that of semi-evergreen forest, whereas in Thailand only semi-evergreen formations are found today at low altitudes (Round 1988). Such habitats in Laos are referred to in this paper as "dry evergreen forest" rather than "hill evergreen forest" described by Round (1988), as the latter phrase (avoided entirely in this review) refers to evergreen forest above $900 \mathrm{~m}$. Dry evergreen forest occurs as a continuum from $300 \mathrm{~m}$ to about $1,400-1,500 \mathrm{~m}$ and the avifauna and forest physiognomy changes with altitude; above about $1,000 \mathrm{~m}$ dry evergreen forest does have many similarities to the "hill evergreen forest" of Round (1988), so lowaltitude and high-altitude dry evergreen forests are distinguished, where necessary, by citing exact altitudes.

(2) At approximately 1,400-1,700 $\mathrm{m}$, in a transition zone between dry evergreen forest and upper montane forest, many areas are dominated by the conifer Fokienia hodginsii, and are referred to in this paper as Fokienia forest.

(3) Wet evergreen forest is not described by Round (1988) but occurs locally in the Annamite range in eastern Laos from $600 \mathrm{~m}$ upwards wherever there is a low point in the mountain range which allows increased precipitation from clouds rolling in from the South China Sea. These areas are wet for most of the year owing to the orographic effect of the Annamite Mountains and the continual presence of humid air flowing up from the east.

(4) In the flat lowlands of South Laos a distinctive habitat occurs which is composed of a mosaic of semi-evergreen forest, mixed deciduous forest, dry dipterocarp forest and grassland: of these components the latter two predominate. It is referred to in this paper specifically as "lowland mosaic forest". However, where we describe a habitat as, for example, a mosaic of semievergreen and pine forest, this is not the same as lowland mosaic forest; the word mosaic merely implies a patchwork of forest types and not specifically the four components of "lowland mosaic forest".

(5) Rocky savanna habitat comprises extensive open areas of bare rock, grassland and scattered trees, always on sandstone outcrops. The avifauna is largely a depauperate version of that of dry dipterocarp forest, but rocky savanna is also an important habitat for Green Peafowl.

The conservation status of each habitat type depends on its extent and the relative rate of clearance and degradation. Four localised habitats are being damaged or destroyed at a relatively high rate: lowland mosaic forest (by clearance for cultivation, logging and burning), semi-evergreen forest of the flat lowlands (by logging and clearance), wet evergreen forest (by clearance for shifting 
cultivation) and Fokienia forest (by logging). The highly threatened forests in wetland areas are discussed under Wetlands below.

Loss of other habitats is occurring at a lower rate and is of long-term rather than immediate concern. Semi-evergreen forest on low, hilly areas is still extensive in the South and Centre of Laos, but is widely targeted for logging and is being gradually cleared for agriculture. Very few unlogged areas of this habitat are likely to remain within 20 years, either inside or outside reserves. Mixed deciduous forest experiences similar pressures but, being less extensive and more readily burnt, is probably more threatened than semi-evergreen forest. Dry evergreen forests are still extensive in South and Central Laos, with smaller (but still extensive) and less pristine areas in the North. Clearance rates in the North are thought to be high and rising, while those in the South and Centre are generally lower, but are high in the following areas: the Bolaven Plateau, the Dakchung Plateau plus hill areas to the south-east, and parts of the headwaters of the Xe Kong and Xe Banghiang. These areas have already lost a large proportion of their forest cover. Furthermore, hill-tribe groups are currently migrating south from overcrowded areas of North Laos into Central Laos: the extensively forested northern part of the Nam Theun-Nam Kading drainage basin is now being heavily impacted by this migration. Dry dipterocarp forests are extensive and relatively unattractive for agriculture, but are experiencing progressive degradation from fire and logging. Rocky savanna habitats are useless for agriculture or logging, but are extensively burnt each year. The effects of fire on the avifauna of these habitats are not known. Upper montane forest is the least threatened forest type, being unattractive for agriculture and logging (other than for Fokienia timber) and therefore unlikely to experience high human pressure until the surrounding lower-altitude forests have all been cleared.

Some of the more important forest areas within the protected area system are as follows. Flat lowland semi-evergreen forest and lowland mosaic forest are best developed in the Dong Khanthung PPA and only otherwise represented in Xe Pian NBCA. Xe Pian is also important for by far the largest area of lowland semi-evergreen forest on gently hilly terrain. Wet evergreen forest is perhaps restricted to the proposed Nakay-Nam Theun Extension, and small areas of Nakay-Nam Theun and Hin Namno NBCAs. Fokienia forest may be found in only Phou Loeuy NBCA, Nam Chouan PPA, the proposed Nakay-Nam Theun Extension, Nakay-Nam Theun NBCA and Xe Sap PPA; in at least four of these, some logging has already occurred.

\section{Karst limestone}

Karst limestone occurs extensively in North and Central Laos. The steep topography of karst discourages large-scale human use of the area. However, in some areas farmers walk substantial distances across the outcrops to cultivate pockets of deeper soil. Such sites would otherwise support stands of tall forest, which may be important refuges for species ranging into poorer forest nearby.

Karst limestone occurs in Khammouan Limestone NBCA, Hin Namno NBCA, part of the Nam Kading NBCA, and Nam Xam NBCA, although only the first two incorporate extensive areas. These two reserves are likely to be of high importance for species restricted to the karst belt running from Central Laos into 
central Vietnam. Hin Namno may also be important for species endemic to the Annamite mountain range, and its value is further enhanced because it includes areas of wet evergreen forest.

\section{Wetlands}

A national wetlands inventory exists (Claridge 1996) but its ability to highlight areas of priority concern for bird conservation was hampered by the lack of available data. Wetland areas throughout Laos are foci of human activity. They are often settled and are also used and modified for fishing activities (for many aquatic organisms other than fish), rice-farming, livestock-grazing and harvesting of grass.

Much of the country is mountainous and supports no wetlands other than rivers. However, the land bordering the Mekong and its major tributaries from Vientiane southwards supports extensive seasonal floodplains. Almost all of these have now been converted to seasonally flooded paddies. Although the wettest areas remain as marshes they are very heavily used by people, since this is probably the most densely inhabited region of Laos. Two areas, Xe Pian NBCA and Dong Khanthung PPA, support the most significant remaining floodplain wetlands, but they are of limited extent. Extensive natural river floodplain habitat may also remain in the Nong Louang wetlands of Savannakhet Province, but this area has not been adequately surveyed, and the large number of settlements in the vicinity suggest it will have limited bird populations.

In South Laos there is an abundance of small pools and a few larger marshes which are not part of the floodplains of the Mekong and its tributaries. Often these are in open areas of forest, with relatively low human densities. However, all but the most remote of these pools and marshes experience high levels of human use; those unaffected are among the most scarce and vulnerable wildlife habitats in Laos. The most important concentrations are in Dong Khanthung PPA, Xe Pian NBCA, Xe Khampho PPA and, to a lesser degree, Bolaven Southwest PPA and Dong Hua Sao NBCA.

Riverine habitats in Laos are diverse and abundant: they range from small seasonal mountain streams to huge sluggish rivers. However, an inventory of the riverine habitats of Laos is lacking and although they are among the nation's greatest natural assets there is no national strategy for managing them. As with other wetlands, rivers are a focus of human activity, particularly the slowflowing rivers in the lowlands, the banks of which have been extensively settled and altered. Fast mountain rivers which lie in steep-sided valleys have been the least affected. There is a growing threat to many Lao rivers from proposed hydropower projects.

Some large lowland rivers retain reasonably intact bankside habitat and relatively low human densities. The most notable are the Nam Theun and its major tributaries on the Nakay Plateau, the Xe Kong and Xe Pian in Xe Pian NBCA, stretches of the Xe Kong north of Attapu (perhaps together with some of its tributaries), and parts of the Seephandon section of the Mekong. All other rivers are known or suspected to be of lower conservation value. The stretch of the Nam Kading within Nam Kading NBCA is perhaps one of the least disturbed of all large rivers, but is relatively fast-flowing and rocky, making it unsuitable for 
many threatened bird species. Despite the importance of rivers to the general ecological health of an area, few protected areas encompass rivers of any prominence. In many cases major rivers form only the boundaries, reducing the likelihood of adequate protection.

Surviving concentrations of smaller slow-flowing rivers (which are of particular value for wildlife and are especially threatened) include those on the Nakay Plateau and those in the complex of reserves covering Dong Hua Sao NBCA, Xe Pian NBCA, Xe Khampo PPA and Bolaven Southwest PPA.

\section{Other habitats}

Other habitats are almost all of recent artificial origin, and therefore have few bird species restricted to them. The species inhabiting them are likely to have benefited from a major recent expansion in man-made habitats. However, a few key species use such habitats, especially where patches of taller forest survive. These species might be vulnerable if further degradation occurs. Several migrant raptors appear to favour open habitats, with little preference between man-made and natural areas. For several (perhaps many) other species (vultures and large waterbirds are the most notable, in view of their current precarious status), such habitats might be used if hunting pressure were lower. This assertion is made on the basis of habitat use by the same species in India; the ubiquity of hunting in Laos makes it difficult to assess the ability of most medium-large birds in Laos to use degraded areas. A few key species use secondary bamboo scrub, but their requirements are not fully understood.

\section{The protected area system}

Until recently, Laos had no official national conservation areas; earlier initiatives had resulted in implementation of few protective measures (Collins et al. 1991). The ongoing Lao-Swedish Forestry Co-operation Programme (LSFCP) includes a conservation component, the Forest Resources Conservation Sub-programme (FRCP), executed by IUCN. An integrated system of protected areas has been developed which aims to include representative areas of all forest habitats and all altitudes in each biogeographic sub-unit. By mid-1995, 18 had been legally gazetted as National Biodiversity Conservation Areas (NBCAs) and a further 11 had been proposed for NBCA status (Berkmüller et al. 1993, 1995a,b). At least one further area (Dong Khanthung) has been proposed subsequently (Berkmüller and Vilawong 1996, Timmins 1996b). All of these NBCAs and PPAs are shown on Figure 1. Management activities have started in about ten NBCAs, mostly on a small scale. When the programme is complete, Laos could have one of the most impressive protected area systems in Asia. However, unresolved and growing conflicts exist with more lucrative land uses, for example hydroelectric power and logging. NBCA status is a provisional one under which more precise area designations and regulations are intended to be given, and does not rule out sustainable logging and other commercial harvests within an area, as well as designation of zones under local community control. It is likely that only small sections of most NBCAs will be given a no-use designation (Chanthaviphone Inthavong verbally 1996). 
One of the objectives of the LSFCP (and more recently a World Bank Global Environment Facility project) is to develop a sustainable forestry programme in Laos. However, sustainable forest management practice has been carried out only in very few areas in which commercial logging has recently occurred. Several other foreign-funded projects throughout Laos, some of which are centred around NBCAs and PPAs, are seeking to establish sustainable practices in natural resource use.

\section{Hydroelectric power projects}

The government of Laos is embarking on a ambitious programme of hydroelectric dam construction (Berkmüller 1995, Usher 1996), with funding from a large number of competing foreign consortia. It plans to build 29 dams by the year 2010 and a further 31 are under consideration. Thailand, China and Vietnam will buy the power generated, providing Laos with a high proportion of its projected foreign income. Not one major river basin will remain intact (Berkmüller 1995), and up to 17 dams have been proposed for the Lao part of the Xe Kong catchment alone (Japan International Co-operation Agency 1993). It is doubtful that all 60 of these projected dams will be built; it appears that some proposals have already been rejected for a variety of reasons. Hydropower projects have a number of consequences on bird populations, the most obvious of which is the direct inundation of habitat; reservoir habitats are often poor substitutes for the rivers they replace. Moreover, to minimise the number of human residents affected, many projects are sited in areas of low human population density - the very factor that tends to make the areas good for wildlife. Reservoir outflows do not match those of the original river, which reduces their suitability for aquatic life, particularly in river-diversion and large-storage reservoir projects. A further consequence is impoundment of suspended sediments in reservoirs, leading to loss of sedimentary river features downstream. Indirectly, reservoirs provide hunters easy access to the new shoreline and remaining forest at its fringe, which prior to inundation was usually less accessible. The construction and other associated activities to implement each project bring many non-local people to the area, leading to increased levels of disturbance of habitat and direct harvesting of birds for consumption.

Projects at an advanced stage of planning or under construction, and which affect protected areas, include the following: (A) the Nam Leuk-Nam Mang hydropower project, which will inundate areas of Phou Khaokhoay NBCA (see WCS 1995a); (B) the Theun-Hinboun hydropower project, which will reduce waterflow in the Nam Kading within Nam Kading NBCA (see WCS 1995C); (C) the Nam Theun 2 hydropower project, which will inundate approximately $450 \mathrm{~km}^{2}$ of the Nakay Plateau and contribute to decreased flow in the Nam Kading within Nam Kading NBCA (see WCS 1995d, Nam Theun 2 Electricity Consortium 1997); (D) the Xe Namnoy-Xe Pian hydropower project, which will result in reduced waterflow in the Xe Pian within Xe Pian NBCA, Xe Khampho and Bolaven Southwest PPAs (see WCS 1995b); (E) the Xe Kaman 1 hydropower project, which will inundate areas of the Xe Kaman in Dong Ampham NBCA.

Effects on several species of riverine birds are likely to be significant (see Murray 1995) although there are no documented studies from the region from 
which to form clear predictions of which species will be affected and to what extent (see Duckworth et al. 1998b). In total, 14 NBCAs and PPAs could be affected (Berkmüller 1995).

\section{Hunting pressure}

Hunting is an almost ubiquitous activity in Laos and the majority of households possess a gun of some type. Locally made muzzle-loaders are perhaps the commonest, but breech-loading rifles and semi-automatic weapons are also common. These latter are often supplied by the government to village militia units. Hunting takes a variety of other forms of which snares and other triggered capture methods are perhaps commonest. Such traps are often associated with long fences made from forest undergrowth. In the late dry season men have little work to do and most hunt opportunistically on a regular basis. Longer excursions to hunt are occasional, and generally associated with other activities such as fishing and the collection of resins or other forest products. The effects of hunting are most pronounced around areas of settlement and in areas of regular collection of forest products. Rural army posts are present in most provinces and rely heavily for meat on locally caught wildlife. Some minorities, the Hmong in particular, are even more adept and frequent hunters than are the lowland Lao.

Hunting is widespread because wild-caught meat is free, because it is preferred to farmed meat for reasons of taste and lack of need for prior husbandry, and because hunting is a recreational activity. Furthermore bushmeat is a monetary commodity and regarded as a delicacy by urban Lao people. However, hunting specifically of key species seems rarely, if ever, to be essential for subsistence.

Unlike in some neighbouring countries such as Vietnam, the use of guns in Laos was until recently little regulated. This means that hunting pressure is often higher in Laos than a simple comparison of human population density between these two countries might suggest.

International trade in natural products occurs at high levels with all neighbours; Srikosamatara et al. (1992) and Srikosamatara and Suteethorn (1994) document aspects of the trade with Thailand. Observed levels of collection for the pet trade (including large domestic markets) are high for parakeets and Hill Myna and high relative to its small population size for Crested Argus. Significant trade in other bird species may have been overlooked on recent surveys.

\section{Descriptions of major study areas}

Study site accounts are presented in north-to-south order. Detailed information on the allocation of survey effort to different parts of each site can be found in the relevant papers listed in Table 1 .

\section{Phou Dendin National Biodiversity Conservation Area} $21^{\circ} 40^{\prime}-22^{\circ} 18^{\prime} \mathrm{N} 102^{\circ} \mathrm{OO}^{\prime}-4 \mathrm{O}^{\prime} \mathrm{E}$, Phongsali Province, North Laos

This reserve of $1,310 \mathrm{~km}^{2}$, near the northern tip of Laos, is mountainous ( $60 \%$ of the area is above $1,000 \mathrm{~m}$ and all exceeds $500 \mathrm{~m}$ ) and lacks roads or large human settlements (see Figure 3). Small villages are scattered within, the inhabitants of 


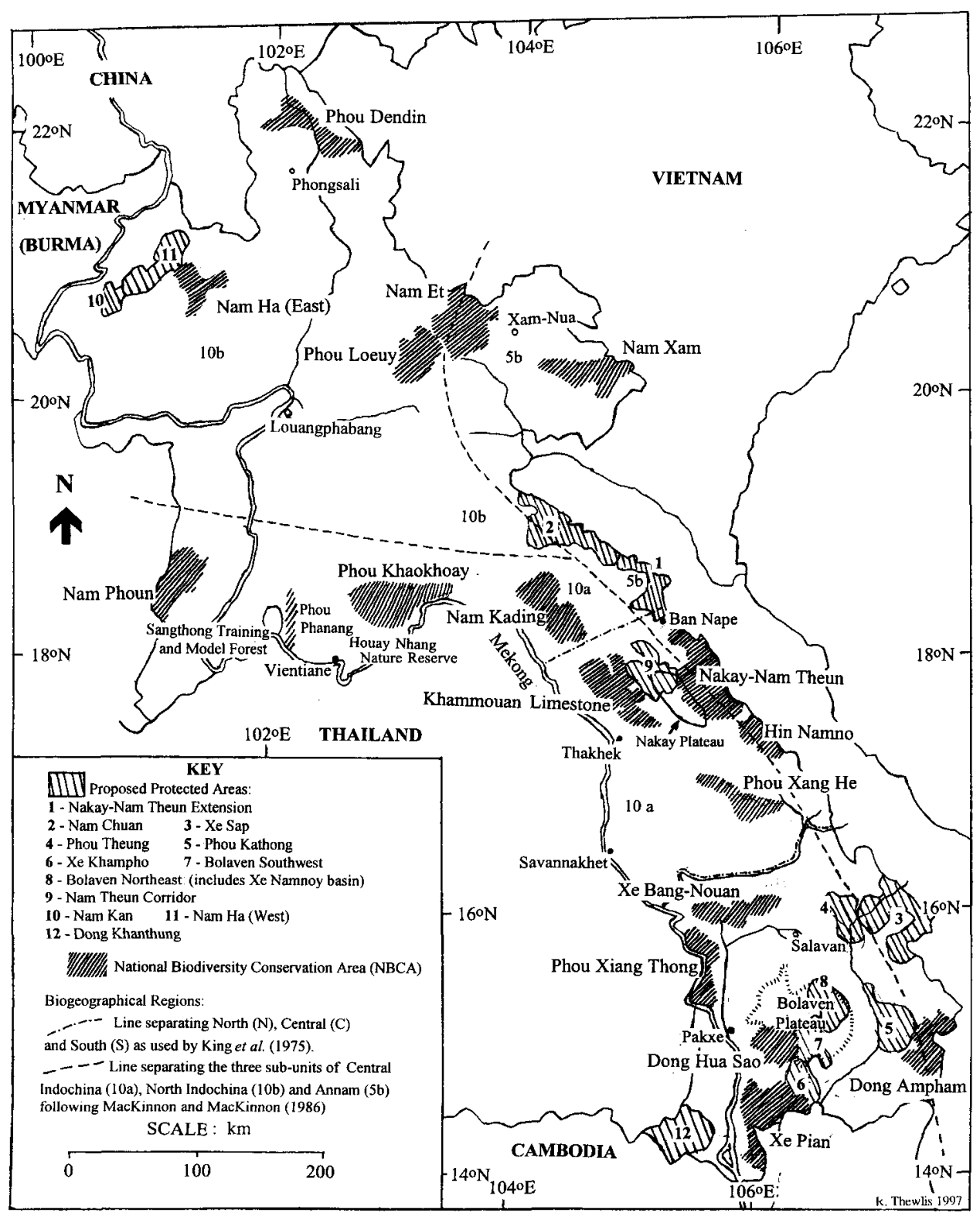

Figure 1. Location of National Biodiversity Conservation Areas (NBCAs) and Biogeographical Regions in Laos.

which practise hillside slash-and-burn cultivation. Large portions of the reserve, particularly along the Nam Ou above the inflow of the Nam Khang, are uninhabited and covered by unbroken dry evergreen and semi-evergreen forest.

The reconnaissance survey involved insufficient field effort to characterise the reserve's bird communities, but the information is of high importance as this is 


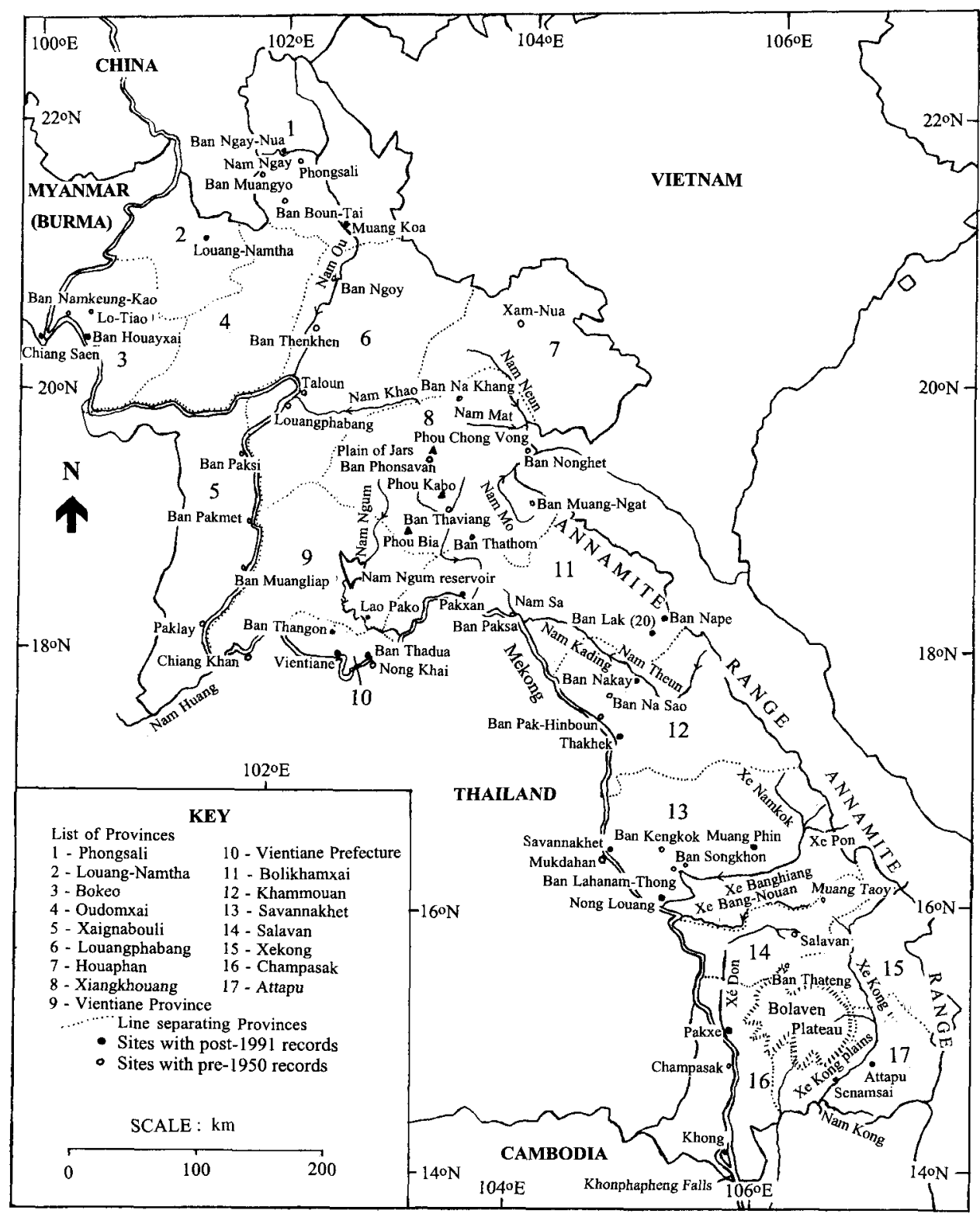

Figure 2. Laos, showing localities mentioned in the text and Provinces.

the only recent survey of an area much north of the Nam Kading. Significant records were also made adjacent to the NBCA along the lower Nam Ou.

Phou Dendin (which means "border area mountain": Venevongphet verbally 1995) today refers to the mountain range forming the watershed between the Mekong and Black River catchments; much of the region is thus in Vietnam, although the NBCA is entirely within Laos. Even in the 1920s the area was 


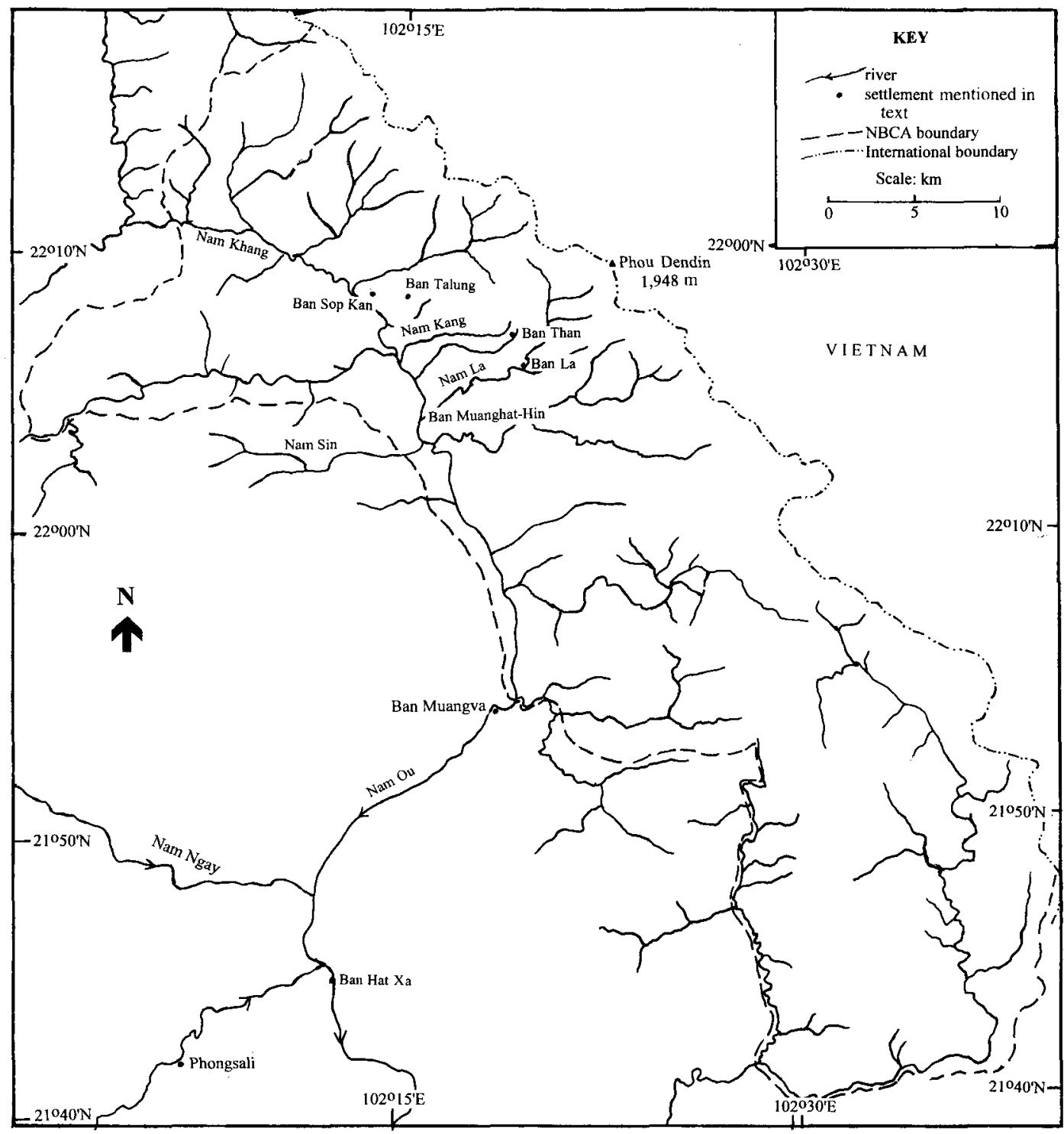

Figure 3. Phou Dendin National Biodiversity Conservation Area.

extensively deforested, and specimen collection (Bangs and van Tyne 1931) appears to have been concentrated in such habitat.

2. Phou Khaokhoay National Biodiversity Conservation Area $18^{\circ} 14^{\prime}-34^{\prime} \mathrm{N} 102^{\circ} 44^{\prime}-103^{\circ} 29^{\prime} \mathrm{E}$, Vientiane Prefecture, Vientiane and Bolikhamxai Provinces, North Laos

Phou Khaokhoay NBCA (Figure 4) covers $1,390 \mathrm{~km}^{2}$ at $200-1,700 \mathrm{~m}$. Originally most of this reserve supported broadleaved evergreen forest mixed with signi- 
ficant stands of pine. Where the underlying rock is covered by only $2.5-5 \mathrm{~cm}$ of soil, many areas of several hundred metres across support rocky savanna habitat. Extensive logging by State Forest Enterprise 3 during the 1980 s resulted in almost wholesale habitat destruction in some areas, many of which now support extensive bamboo. Important areas of primary forest persist mostly on steep slopes. The NBCA is within two hours' drive of Vientiane and accessible areas are heavily hunted; even the remoter parts show evidence of frequent incursion.

The 1994 survey visited two main areas: the Muang Hom road around the turn-off to the Nam Leuk dam and the dam site itself (where logging had been heavy); and the middle Nam Mang valley, where habitat was less degraded. Brief observations were made in a variety of degraded areas, including the headquarters complex and the lower Nam Mang. All observations were below $650 \mathrm{~m}$. A brief spring visit was made to Ban Nakhay, an area of rocky savanna at $400-$ $500 \mathrm{~m}$ adjacent to cultivation with pools at $200 \mathrm{~m}$.

The survey was a brief reconnaissance with substantial time devoted to activities other than bird surveying, and the results must be viewed in this light.

\section{Sangthong Training and Model Forest}

$18^{\circ} 12^{\prime}-18^{\circ} 26^{\prime} \mathrm{N} 102^{\circ} \mathrm{O2}^{\prime}-102^{\circ} 15^{\prime} \mathrm{E}$, Vientiane Municipality, North Laos

The Vientiane Forestry College Training and Model Forest (Figure 5) covers about $355 \mathrm{~km}^{2}$. Within the south-east quarter of the area a sector of 4,300 ha has been selected for intensive forestry management and training activities. Most of the forest lies between 180 and $500 \mathrm{~m}$, with the highest peak at $609 \mathrm{~m}$. The terrain is relatively gentle, but small steep-sided hillocks are numerous in the central part of the area. A major stream, the Nam Sang, runs through the TMF, and another, the Nam Thon, forms its eastern boundary, while the Mekong forms the southern boundary. Both are navigable throughout the dry season. Both have several villages along their length and there are further human settlements along the Mekong. Evergreen or semi-evergreen forest occurs in the centre and mixed deciduous forest in the east. Few areas west of the Nam Sang were investigated. Almost all remaining timber was removed by State Forest Enterprise 9 during the 1980s (Foppes 1995); thus no extensive primary forest remains in the sites visited, and indeed none is believed to exist in the entire area (W. Ehrhardt verbally 1996).

To the east of the forest area and of the densely settled Nam Thon valley rises the Phou Phanang National Biodiversity Conservation Area, a hilly protected area whose value for wildlife remains unknown. To the south lies the Mekong River. To the north and west lie areas which are probably similar in habitat to much of Sangthong forest, although reputedly much less degraded.

\section{Houay Nhang Nature Reserve}

\section{$18^{\circ}{ }^{\prime}{ }^{\prime} \mathrm{N} 102^{\circ} 41^{\prime} \mathrm{E}$, Vientiane Prefecture, North Laos}

Houay Nhang Nature Reserve (see Figure 1 ) covers 808 ha at $200 \mathrm{~m}$ altitude and is situated $14 \mathrm{~km}$ north of Vientiane. The reserve comprises logged degraded lowland semi-evergreen forest, regenerating scrub, rice paddies and areas of secondary dry dipterocarp forest. Several streams, ponds and other features including seasonal habitations are present. 


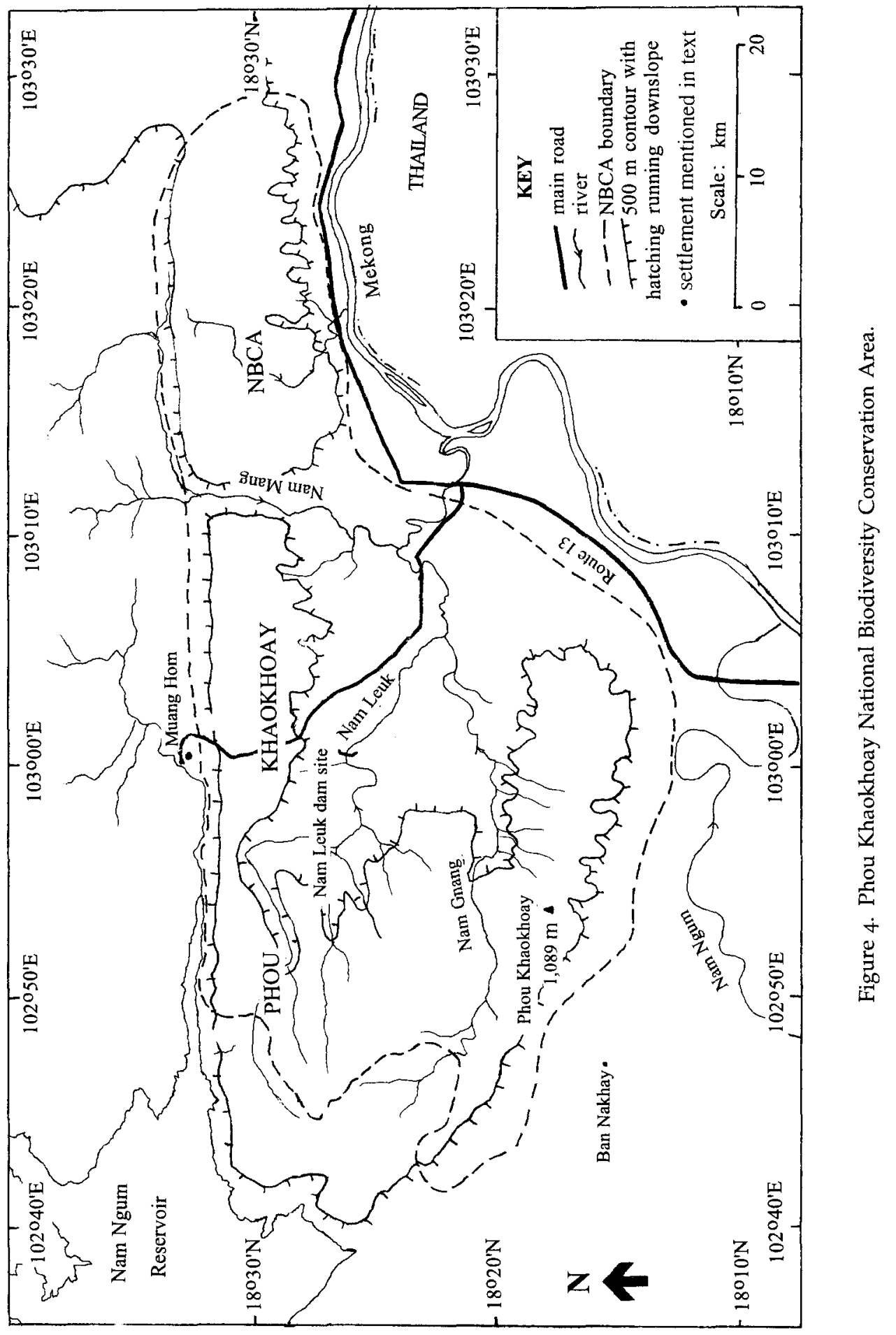




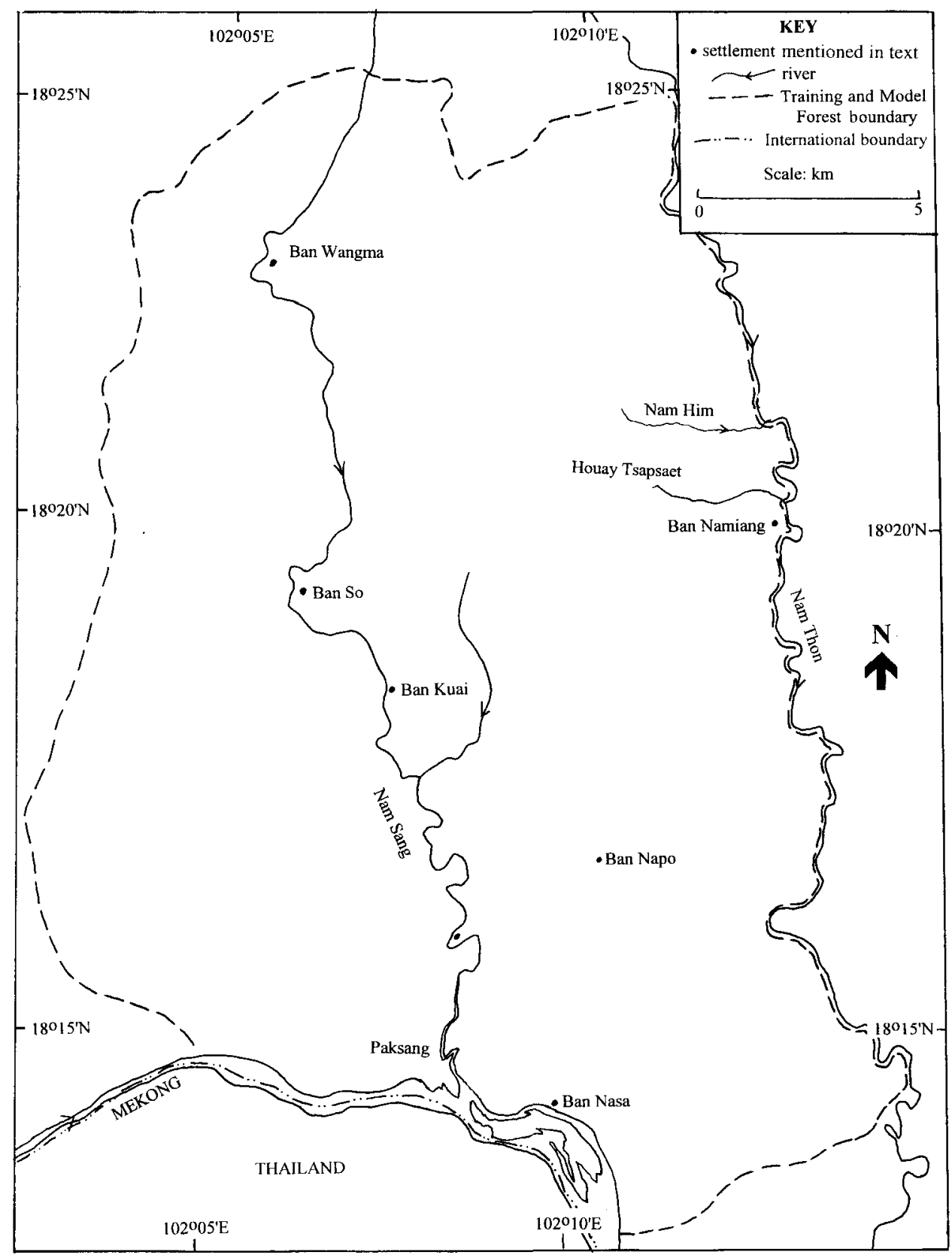

Figure 5. Training and Model Forest of Vientiane Forestry College, Sangthong District, Vientiane. 
5. Nam Kading National Biodiversity Conservation Area and surroundings $18^{\circ} 11^{\prime}-18^{\circ} 39^{\prime} \mathrm{N} 103^{\circ} 54^{\prime}-104^{\circ} 34^{\prime} \mathrm{E}$, Bolikhamxai Province, North Laos

The Nam Kading NBCA covers $1,570 \mathrm{~km}^{2}$ of dry evergreen forest on steep terrain at $160-1,600 \mathrm{~m}$ (see Figure 6). The reserve is bisected for $59 \mathrm{~km}$ by the Nam Kading (known as the Nam Theun in its upper reaches), whose altitude drops from 380 to $160 \mathrm{~m}$. A major tributary of the Nam Kading, the Nam Mouan, also crosses the NBCA. Many rapids make this stretch of the Nam Kading unnavigable. The reserve is not penetrated by any roads; access other than by foot is made difficult by the steep slopes which define most of the protected area boundary. Much of the area is entered by people only infrequently, usually for specific purposes (e.g. hunting, or to search for "mai dam", an extremely valuable and readily portable resinous wood product from Aquilaria sp.). Except around the abandoned village of Ban Donme, and at the upstream and downstream extremities of the protected area, little recent habitat destruction has occurred, although it appears that in the past large areas of the NBCA were modified. Much of the area is surrounded by cultivation, but largely natural habitat still links Nam Kading NBCA with Khammouan Limestone and Nakay-Nam Theun NBCAs.

Surveys in and around the NBCA were to investigate the effects of two dams on the Nam Kading, the Theun-Hinboun dam (abutting the upstream end of the NBCA) and proposed Nam Theun 1 dam (at the downstream extremity of the NBCA). The NBCA also includes two proposed extensions which include significant areas of dry evergreen forest on flatter terrain around the Nam Ao and dry evergreen forest on several limestone outcrops in the Nadi area. Degraded areas and stretches of the Nam Kading, Nam Theun, Nam Mouan and Nam Gnouang were surveyed well outside the NBCA boundaries, as well as limestone areas of the Nam Mouan valley and Sayphou Loyang formation.

6. Nakay-Nam Theun Extension Proposed Protected Area $18^{\circ} 21^{\prime}-18^{\circ} 48^{\prime} \mathrm{N}, 104^{\circ} 45^{\prime}-105^{\circ} 12^{\prime} \mathrm{E}$, Bolikhamxai Province, North Laos

Nakay-Nam Theun Extension Proposed Protected Area $\left(645 \mathrm{~km}^{2}\right)$ occupies a long stretch of the Annamites along the border with Vietnam, mostly at $600-900 \mathrm{~m}$ (see Figure 7). Forest is continuous with Nakay-Nam. Theun National Biodiversity Conservation Area to the south.

Nakay-Nam Theun Extension supports probably the largest area of wet evergreen forest within the protected area system, and is also one of few which support Fokienia forest. The mountains along the Vietnamese border are still well forested, although the valleys and hills to the west are heavily settled and forest cover is restricted to the highest peaks. Habitat clearance is encroaching very rapidly in some areas. There are extensive networks of trails in the mountainous areas within NTX, leading from both Vietnam and the populated areas within Laos. They appear to be used mainly by Vietnamese hunters and loggers. In 1996 a road was made into the wet evergreen forest of the southern border of NTX for logging of Fokienia; this road is referred to as the Ban Nahoua logging road.

\section{Nakay-Nam Theun National Biodiversity Conservation Area \\ $17^{\circ} 36^{\prime}-18^{\circ} 23^{\prime} \mathrm{N} 105^{\circ} 02^{\prime}-105^{\circ} 46^{\prime} \mathrm{E}$, Khammouan and Bolikhamxai Provinces, Cent- ral Laos}




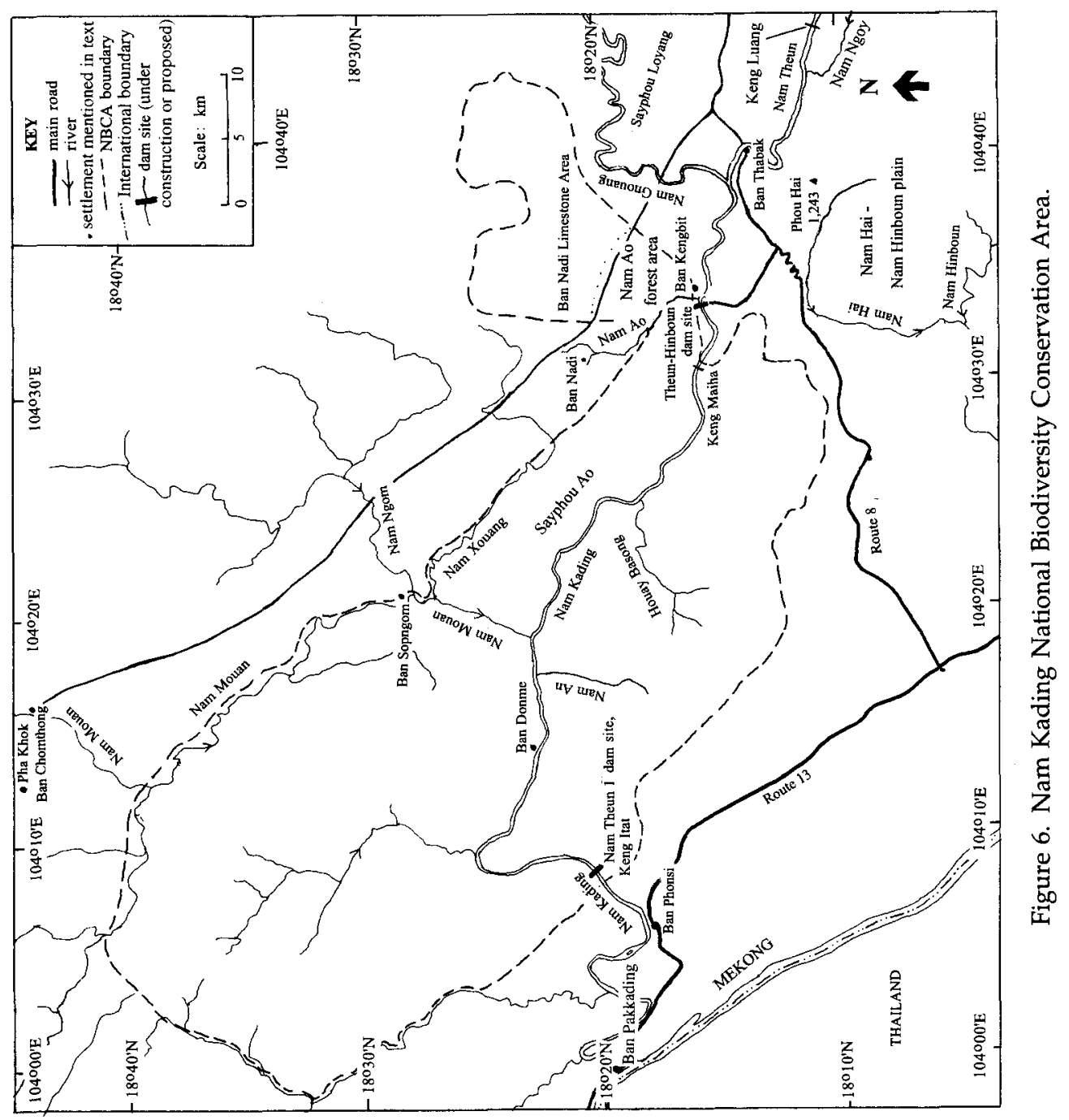


Nakay-Nam Theun NBCA (Figure 8) covers about $3,710 \mathrm{~km}^{2}$ of the Annamite Mountains and adjacent Nakay Plateau (which is treated as a separate study area, below). The topography is very rugged and the reserve is dominated by dry evergreen forest from 500 to $1,800 \mathrm{~m}$, much of it in excellent condition. It is one of the largest and most pristine areas of this habitat in the Annamites. For bird-recording purposes the reserve has been divided into five main areas: the Northern, Central and Southern Mountains, the Nam On Catchment and the Southern Escarpment. The Southern Escarpment extends down to $300 \mathrm{~m}$ and supports semi-evergreen forest. At 1,400-1,700 $\mathrm{m}$ in the Central Mountains and perhaps other sectors, Fokienia forest occurs. Some peaks along the Vietnamese border exceed 1,800 $\mathrm{m}$, and the highest, Phou Laoko, exceeds 2,200 $\mathrm{m}$. These peaks support upper montane forest. Small areas of wet evergreen forest occur along the Vietnamese border. The area also has many stretches of forested river, mostly above $550 \mathrm{~m}$.

There are extensive networks of trails in many areas of the reserve, including mountainous areas, leading both from Vietnam and the populated areas within Laos. Those in border areas appear to be used mainly by Vietnamese hunters and loggers. In 1994 logging of Fokienia trees by the Lao authorities was under way in the Central Mountains. Helicopters were being used, but a road was under construction from Ban Navang to increase access to the logging area, which lay in the remotest part of the reserve. Road construction and Fokienia logging had ceased, perhaps only temporarily, at the time of writing (1996).

The reserve is bordered by agricultural areas to the south and north-east. From these directions, and from the inhabited enclaves within the reserve, shifting cultivation is progressively expanding, most rapidly in the north-east where there has been a recent influx of migrant hill-tribe families from North Laos. Roads are planned to provide access to all enclave villages; these are likely to increase access for logging and other extractive industries.

Almost the entire catchment for the Nam Theun 2 hydropower project is within Nakay-Nam Theun NBCA. The north bank of the planned reservoir will define the south-western boundary of the protected area.

The protected area borders the smaller $\mathrm{Vu}$ Quang Nature Reserve on the Vietnamese side of the Annamites. The reserve is linked by an unprotected corridor of habitat to the karst habitats of Hin Namno NBCA to the south. This corridor has been recommended for improved protection (Berkmüller et al. 1995a).

\section{Nakay Plateau}

\section{$17^{\circ} 37^{\prime}-59^{\prime} \mathrm{N} 104^{\circ} 57^{\prime}-105^{\circ} 35^{\prime} \mathrm{E}$, Khammouan Province, Central Laos}

The $1,250 \mathrm{~km}^{2}$ Nakay Plateau (see Figure 8) is largely flat and supports a mosaic of pine and broadleaved evergreen forest at 500-600 $\mathrm{m}$. Hillocks dominated by broadleaf forest occur, particularly in the east. The Nam Theun and its many tributaries have extensive riverine dry evergreen forest, which is particularly outstanding along the Nam Mon (X). Pools and marshes are numerous only in the central plateau, most of which is heavily settled and degraded.

Human pressure is rapidly increasing in intensity and area of influence, in association with extensive logging operations. The central portion of the plat- 


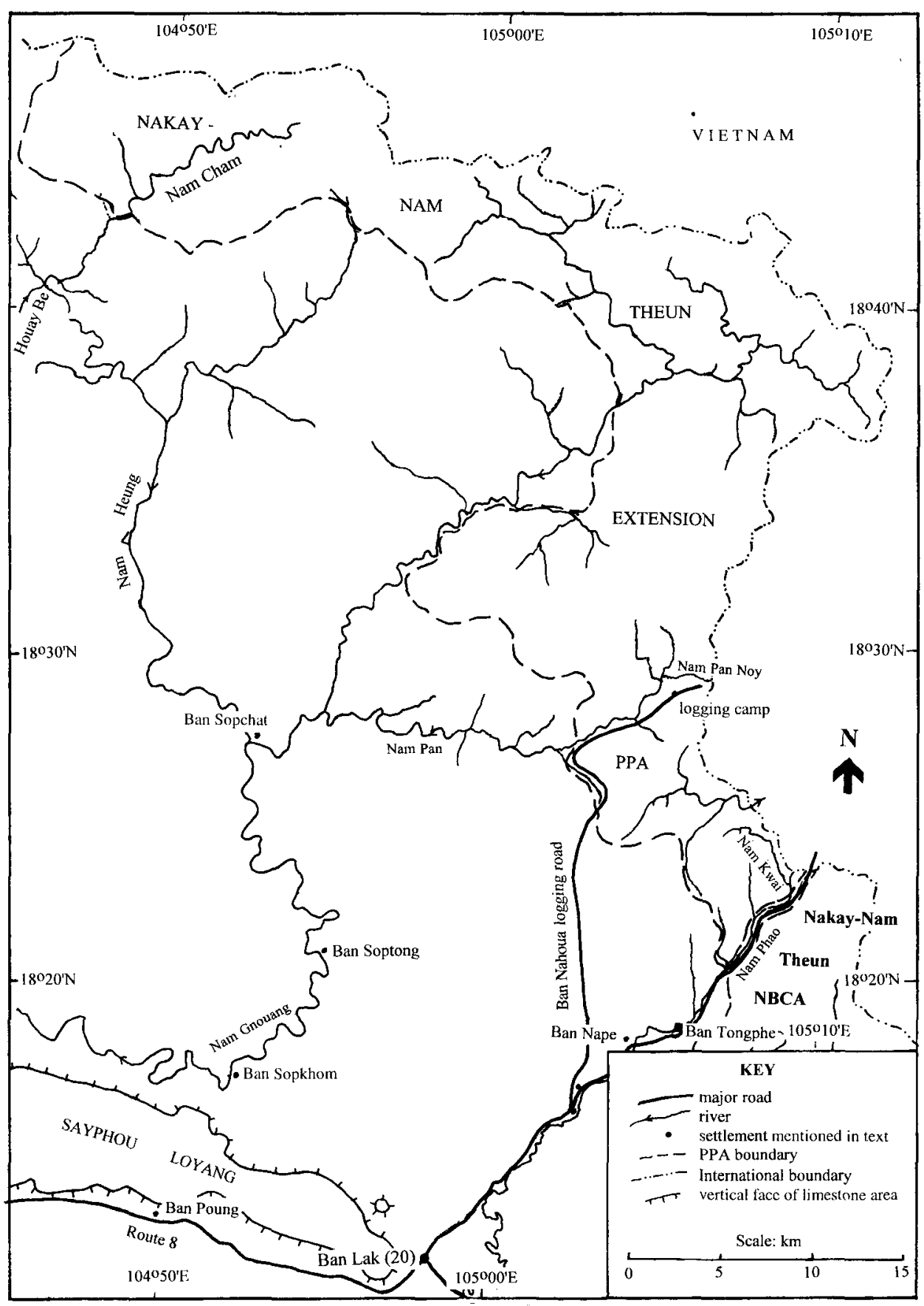

Figure 7. Nakay-Nam Theun Extension Proposed Protected Area. 


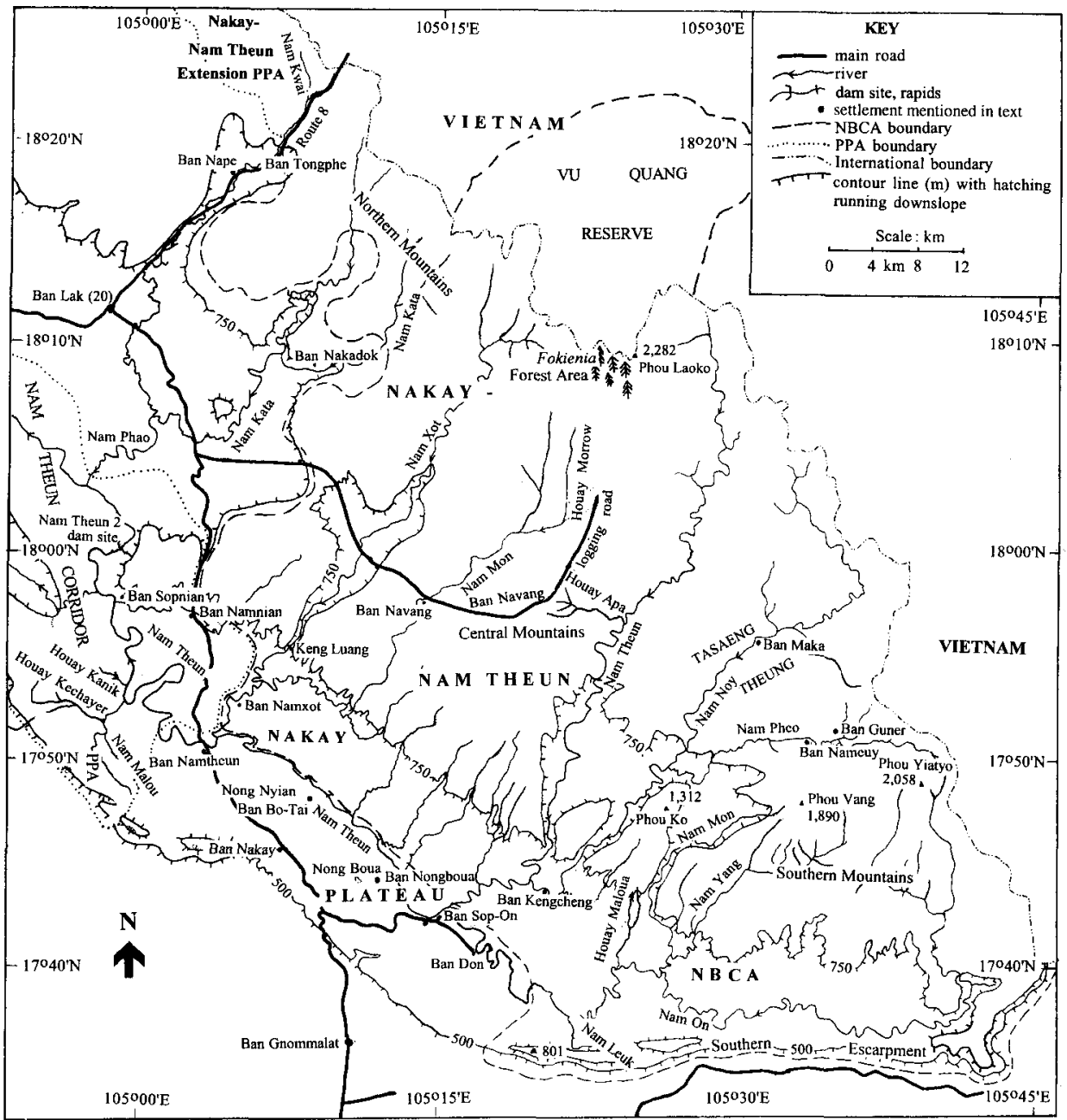

Figure 8. Nakay-Nam Theun National Biodiversity Conservation Area and the Nakay Plateau.

eau has been heavily degraded. Much of the broadleaf forest has been logged in past decades. About a third of the plateau is within the Nakay-Nam Theun NBCA; much of the remainder was until recently of equally high biological value, but the reserve boundary was delineated to avert conflict with the Nam Theun 2 hydropower project. This is scheduled to inundate a third or more of the plateau, including all larger and most smaller streams. The conservation value of the reservoir is still being debated, but it is likely to be incorporated at least in part into the NBCA. To the south, the plateau drops away sharply to the heavily settled Ban Gnommalat lowlands, while in other directions it is bounded by little-degraded forested hills of the Nakay-Nam Theun NBCA. A large portion of the north-western plateau and hills bordering the Nam Theun below (north of) the plateau have been proposed for protection, to link 
Nakay-Nam Theun NBCA with Khammouan Limestone NBCA. Parts of the plateau were surveyed in greatest depth in 1994 along with other areas of the Nakay-Nam Theun NBCA. The 1995 survey investigated the likely effects of the Nam Theun $2 \mathrm{dam}$, and most observations were made along rivers by boat or on foot. Thus, many forest-interior species found on the Nakay Plateau in 1994 were not observed in 1995.

\section{Khammouan Limestone National Biodiversity Conservation Area}

$17^{\circ} 26^{\prime}-18^{\circ} 05^{\prime} \mathrm{N} 104^{\circ} 25^{\prime}-105^{\circ} 10^{\prime} \mathrm{E}$, Khammouan Province, Central Laos

The Khammouan Limestone NBCA covers $1,620 \mathrm{~km}^{2}$, with mainly sparsely vegetated karst limestone at $180-850 \mathrm{~m}$ and some pockets of tall forest (see Figure 9). The boundary of the protected area is delineated by the foot of the limestone cliffs. In the north-east of the protected area the terrain is gentler and the hills and valleys support extensive tall forest, much of it secondary. The forests of the NBCA are contiguous with the Nakay Plateau at two points, and this link, named the Nam Theun Corridor, is a Proposed Protected Area. Forest is also still continuous with Nam Kading NBCA, across a forested ridge to the north of the Nam Hai-Nam Hinboun Plain. Most of the lowlands surrounding the area are heavily populated, and support only degraded habitat and cultivation. Large accessible valleys within the limestone have generally been severely degraded, but smaller isolated pockets still retain pristine forest.

Parts of the area up to $600 \mathrm{~m}$ were visited from three points in the north and once in the south during recent surveys.

\section{Hin Namno National Biodiversity Conservation Area}

$17^{\circ} 15^{\prime}-17^{\circ} 40^{\prime} \mathrm{N} 105^{\circ} 43^{\prime}-106^{\circ} 09^{\prime} \mathrm{E}$, Khammouan Province, Central Laos

Hin Namno $\left(865 \mathrm{~km}^{2}\right)$ comprises a sparsely vegetated largely karst limestone outcrop, with undulating forested limestone hills and valleys (see Figure 10). Phou Etva and the ridges abutting the Xe Bangfai to the south are non-calcareous sedimentary formations. Hin Namno NBCA traverses the Annamite mountain range, forming a low-altitude link across this chain of mountains, extending unbroken across the border into Vietnam. Forest in the east of Hin Namno NBCA may be the only example of wet evergreen forest on limestone in Laos.

The surrounding lowlands are heavily settled, with cultivation and secondary habitats predominating. Forest in the northern portion of the area is still in good condition whilst that in the south is mainly degraded with cultivation encroaching from Vietnam. Until recently it was inhabited by an ethnic group who cultivated small areas of the limestone with non-rice crops. All these people have now resettled in villages outside the protected area, although they still maintain some cultivation within the limestone. Villages to the north and west of Hin Namno are essentially dependent on paddy-rice cultivation, whilst those in the hills to the south and east have a greater dependence on hill-rice cultivation.

Forest linking Hin Namno NBCA with Nakay-Nam Theun NBCA has been proposed for protection. Phong Nha Cultural and Historical Site $\left(400 \mathrm{~km}^{2}\right)$ lies about $20 \mathrm{~km}$ to the east in Vietnam and covers limestone contiguous with that in Hin Namno. It is likely that there will be a proposal to extend the boundaries 


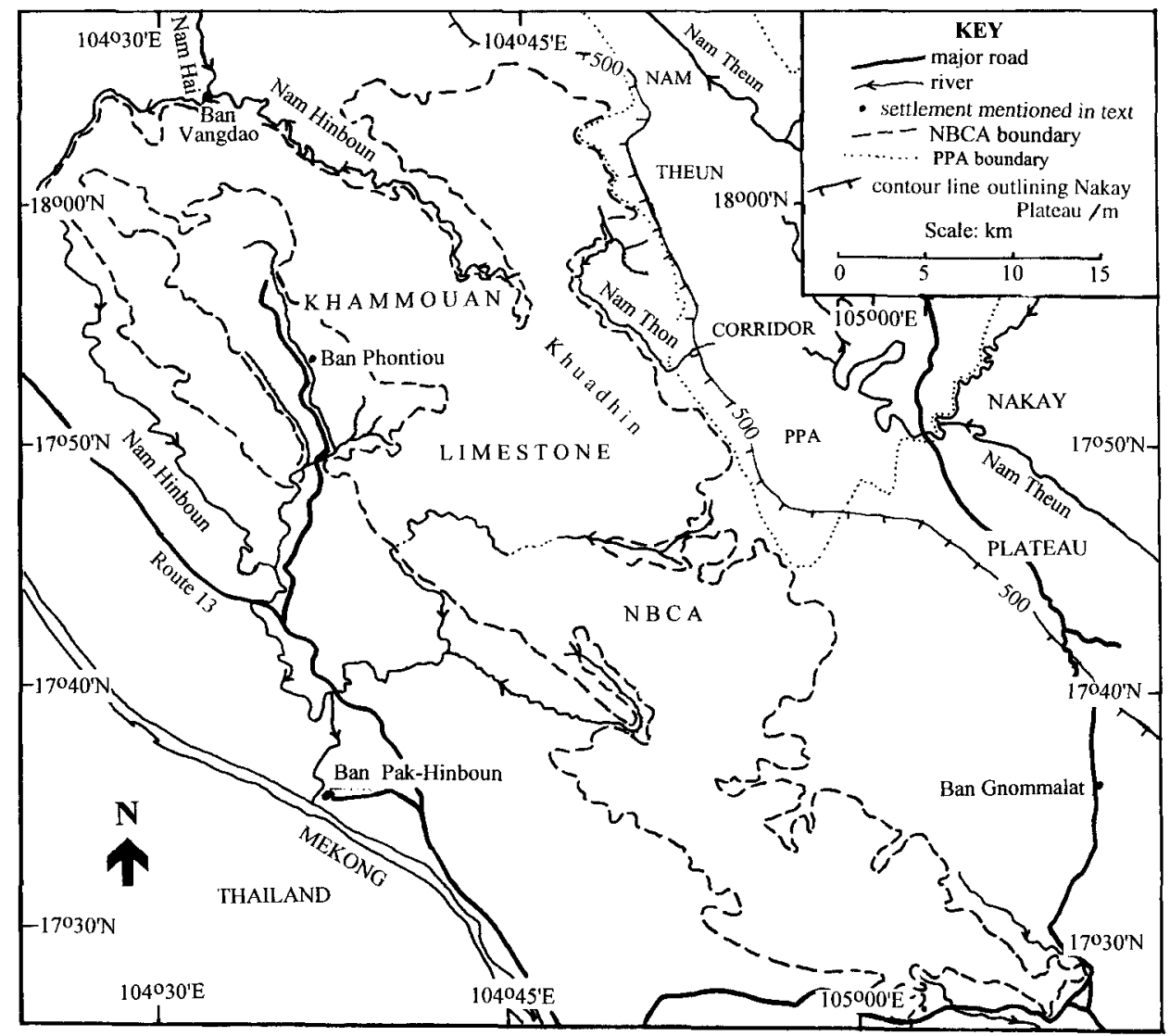

Figure 9. Khammouan Limestone National Biodiversity Conservation Area.

of Phong Nha up to the Lao border, making the two protected areas continuous (T. Dillon, WWF Indochina Programme, verbally 1996).

\section{Phou Xang He National Biodiversity Conservation Area} $16^{\circ} 42^{\prime}-17^{\circ} 04^{\prime} \mathrm{N} 105^{\circ} 19^{\prime}-106^{\circ} 06^{\prime} \mathrm{E}$, Savannakhet Province, Central Laos

Phou Xang He NBCA $\left(1,140 \mathrm{~km}^{2}\right)$ consists of two largely forested hill ranges, mostly at 200-700 $\mathrm{m}$ altitude, orientated north-west to south-east (Figure 11). The two ranges are divided by a flat corridor, 6-10 $\mathrm{km}$ wide, containing many villages and forest fragments. The protected area is surrounded by largely deforested plains. The eponymous massif Phou Xang He is a large sandstone formation dominated by semi-evergreen and mixed deciduous forest with extensive areas of rocky savanna. On the opposite side of the corridor, Phou Hinho is a steep igneous formation with narrow ridges and valleys, supporting dry evergreen forest. South of the protected area is a tract of flat, mainly lateritic land dominated by dry dipterocarp forest. The survey here concentrated most effort on the lowland corridor as this was under the greatest immediate threat.

The whole area, in particular the Phou Xang He massif, is heavily used. There are relatively few trails and access follows river beds in many areas. 


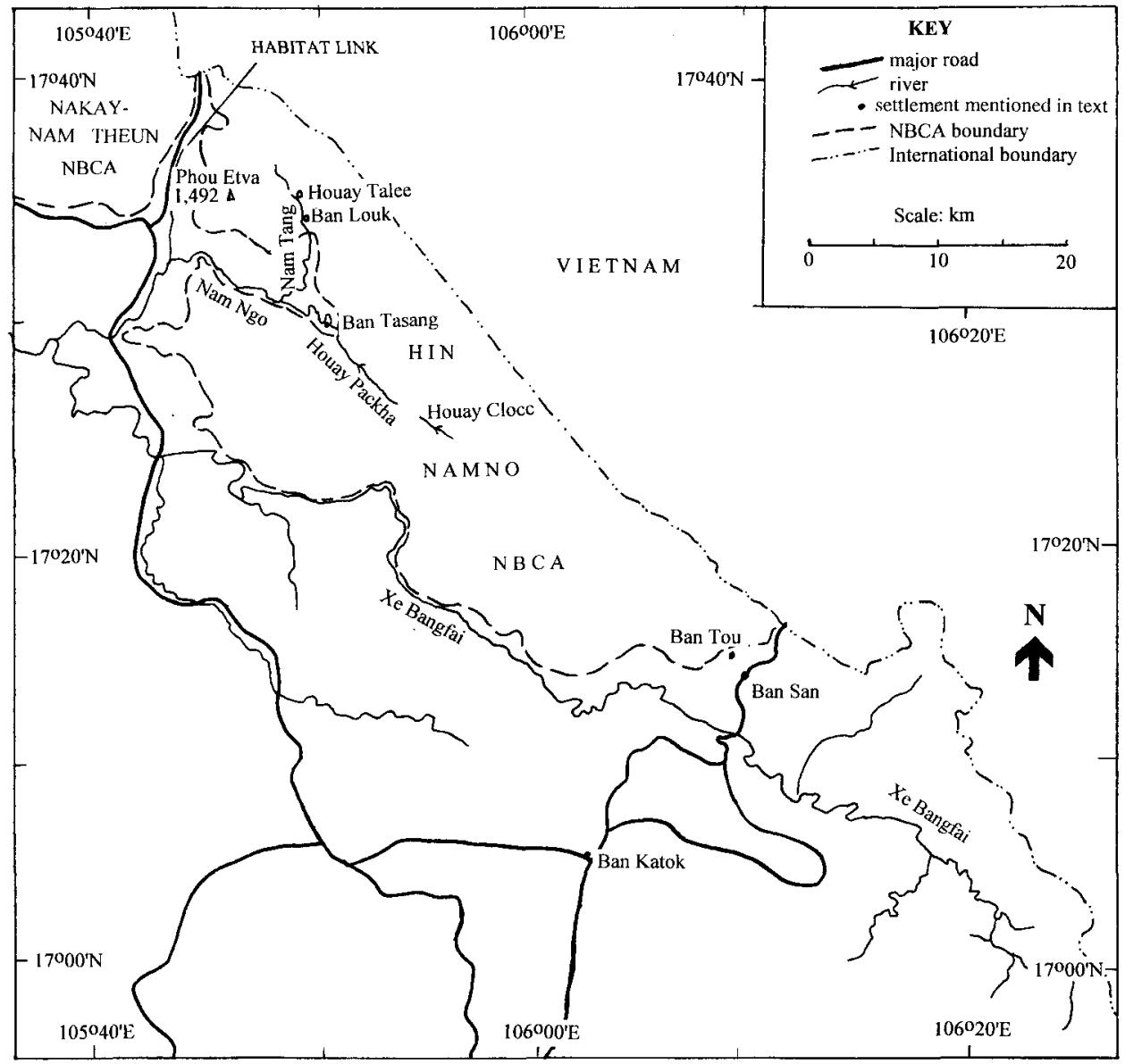

Figure 10. Hin Namno National Biodiversity Conservation Area.

\section{Xe Bang-Nouan National Biodiversity Conservation Area} $15^{\circ} 44^{\prime}-16^{\circ} \mathrm{Or}^{\prime} \mathrm{N} 105^{\circ} 36^{\prime}-106^{\circ} 17^{\prime} \mathrm{E}$, Savannakhet and Salavan Provinces, South Laos

Xe Bang-Nouan covers $1,300 \mathrm{~km}^{2}$ and encompasses almost all of the Xe BangNouan watershed, and is naturally delimited by a ring of low hills (Figure 12). The flat lowlands surrounding the NBCA are heavily populated and there is no longer any continuity with other major forested areas. The protected area can be conveniently split into three main physical sectors, which divide both wildlife communities and human usage. The terrain of the central sector of the reserve, termed the Central Hills, is hilly with the majority of peaks below $700 \mathrm{~m}$, and supports a mosaic of evergreen, semi-evergreen and mixed deciduous forest with extensive areas of rocky savanna in the west. This area is less disturbed than the lowlands and seems degraded only at its periphery; of the habitats in Xe Bang-Nouan, those of the Central Hills currently have the highest priority for wildlife conservation. East and west of the Central Hills the terrain is relatively flat, with some peripheral hills. Both these lowland areas are covered by habitat 


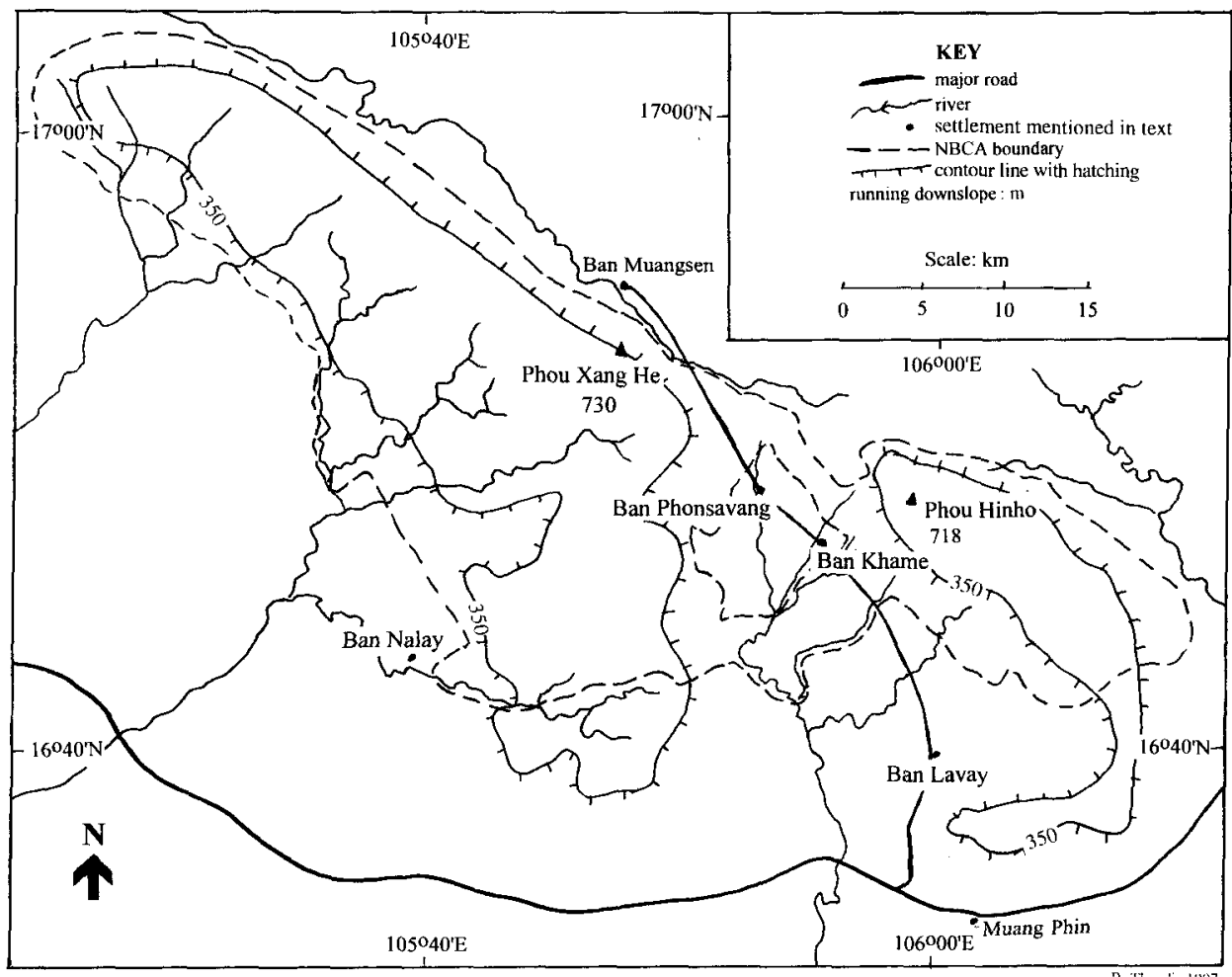

Figure 11. Phou Xang He National Biodiversity Conservation Area.

similar to the lowland mosaic forest south of the Bolaven Plateau; it has been heavily degraded by past commercial logging and includes numerous abandoned villages. Lowland forests generally have been very degraded by burning and are heavily used by local people for hunting and commercial collection of non-timber forest products. Many logging roads are no longer passable by vehicles, but even the remotest part of the area is easily reached within 3-4 hours' walk from villages around its perimeter (which number more than 10o).

\section{Xe Sap Proposed Protected Area}

\section{$15^{\circ} 57^{\prime}-16^{\circ} 19^{\prime} \mathrm{N} 106^{\circ} 42^{\prime}-107^{\circ} 28^{\prime} \mathrm{E}$, Salavan and Xekong Provinces, South Laos}

Xe Sap Proposed Protected Area covers $1,335 \mathrm{~km}^{2}$ of mountainous terrain along the border with Vietnam, of which $35 \%$ is above $1,000 \mathrm{~m}$ and twelve peaks exceed $1,900 \mathrm{~m}$ (see Figure 13). The proposed Phou Ajol extension covers an additional $1,700 \mathrm{~km}^{2}$. Phou Ajol $(2,193 \mathrm{~m})$ is the largest and highest massif in southern Laos. This region forms the catchments of the Xe Pon, the Xe Banghiang, the Xe Kong and the Xe Kaman. The forest cover remaining across most of Xe Sap and Phou Ajol extension is dry evergreen forest, and in both areas forest is continuous with that in Vietnam. Phou Ajol supports Fokienia forest above 1,500 $\mathrm{m}$ and upper montane forest above about $1,800 \mathrm{~m}$.

All major valleys and the lower slopes are apparently settled and have been 


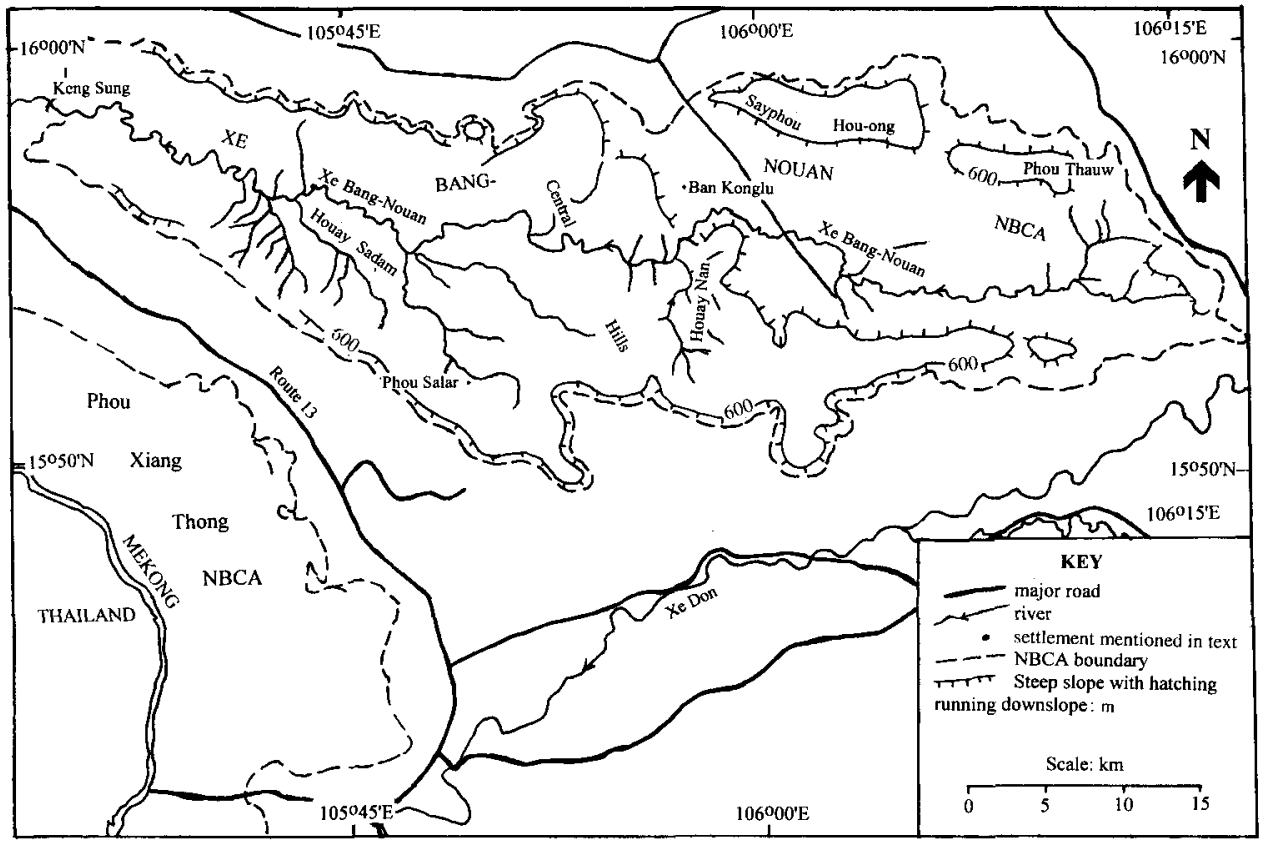

Figure 12. Xe Bang-Nouan National Biodiversity Conservation Area.

heavily degraded. Even slopes above 1,000 $\mathrm{m}$ have been cleared for cultivation in some areas. Extensive areas, mainly outside proposed boundaries, appear to be covered in secondary vegetation types, including low scrub, taller secondary growth, bamboo and secondary forest. South of the Phou Ajol extension the terrain changes to rolling hills of the dissected and degraded Dakchung Plateau $(800-1,400 \mathrm{~m})$, which supports large areas of pine formations and grassland.

Rates of forest clearance are probably relatively high in many areas, particularly on the northern edge of the proposed Phou Ajol extension. Along the northern edge of the Dakchung Plateau, however, recent forest clearance has been minimal; this appears to be a direct result of the reliance of local communities on paddy-rice cultivation. Encroachment is also apparently occurring from Vietnam. Hunting is probably heavy since levels of snaring on the lower slopes of Phou Ajol, and around Ban Ayun at the northern end of the Dakchung Plateau, were perhaps some of the highest found during any recent surveys.

Surveys in Xe Sap were brief and a large proportion of the area remains to be investigated. There was one other brief survey of part of the area in 1995 (Schaller 1995) but this gave little information on birds.

\section{Phou Xiang Thong National Biodiversity Conservation Area} $15^{\circ} 19^{\prime}-15^{\circ} 56^{\prime} \mathrm{N} 105^{\circ} 25^{\prime}-47^{\prime} \mathrm{E}$, Champasak and Salavan Provinces, South Laos

Phou Xiang Thong covers approximately $995 \mathrm{~km}^{2}$; much of the reserve lies at $100-300 \mathrm{~m}$ altitude, but extensive hilly areas in the south and central portions 


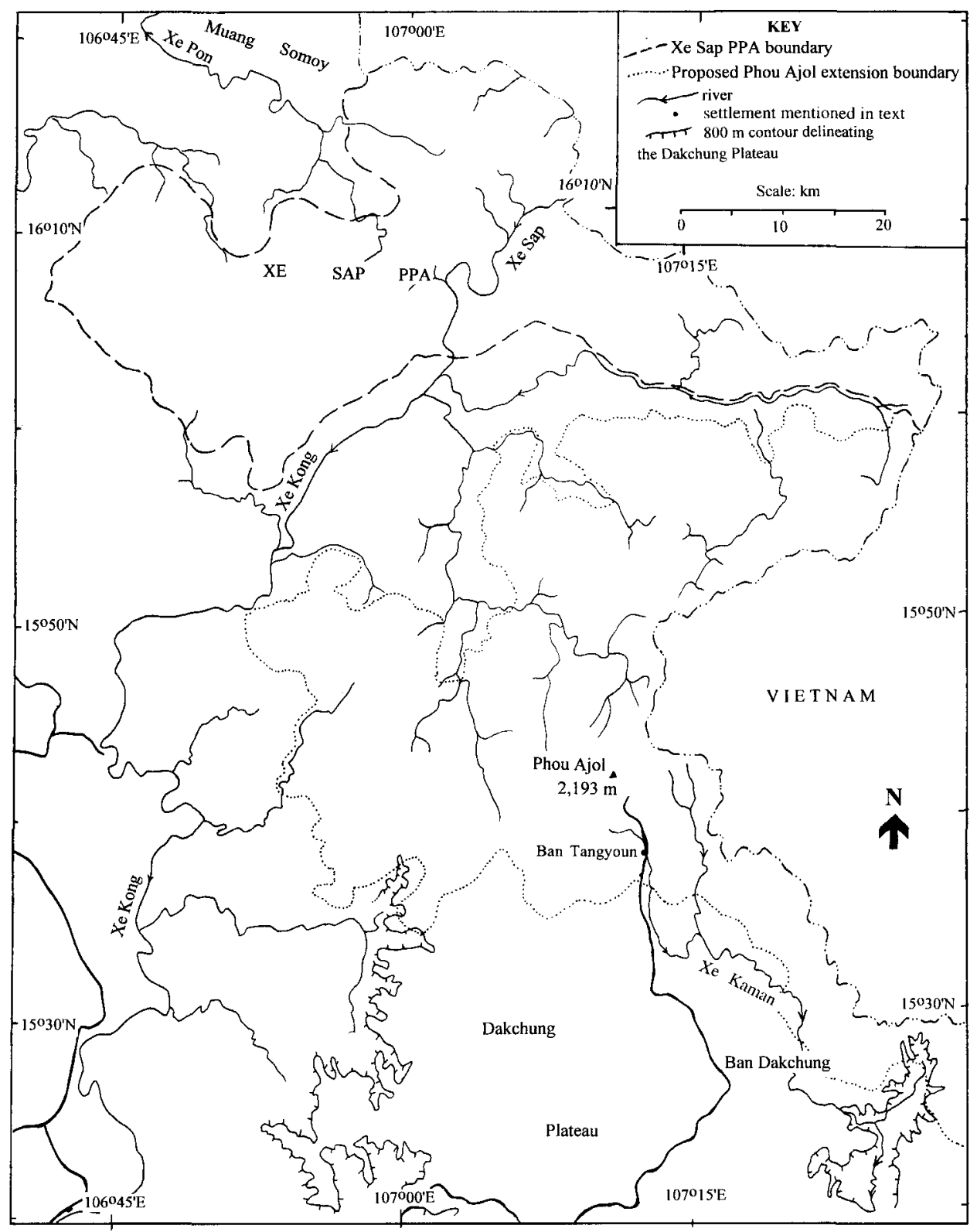

Figure 13. Xe Sap Proposed Protected Area.

lie at $300-650 \mathrm{~m}$ (see Figure 14). The highest point is Phou Nangam $(716 \mathrm{~m}$ ). The western edge of the reserve is formed by the Mekong River, the international boundary with Thailand. A steep escarpment defines the southern and eastern boundaries of the reserve, but further north the escarpment is lower and less clearly defined. Beyond the boundary, particularly to the south and east, lies a belt of heavily populated lowlands especially along the course of the Xe Don river and Route 13. Phou Xiang Thong is not linked to any other 
forest areas in Laos, despite being only $6 \mathrm{~km}$ from Xe Bang-Nouan NBCA. The predominant habitat is semi-evergreen forest, which covers most hillsides and occupies valley bottoms close to stream courses. Large areas in the north were logged in about 1990. Wide gentle valleys surrounding stream courses are dominated by extensive areas of rocky savanna habitat or a combination of this and mixed deciduous forest. No other NBCA includes a part of the Mekong River. The stretch in PXT includes parts over $500 \mathrm{~m}$ wide with steep earth or rock banks and parts where extensive rock outcrops and boulder piles constrict the stream to less than $100 \mathrm{~m}$ wide. There is a comprehensive network of trails within the reserve; the remotest part of the area is easily reached within five hours of the boundary. The Mekong is readily navigable along most of its length within the reserve. Large canoes with outboard motors are the main form of transport in the reserve, and are crucial links with the outside world for villages which lack road access.

On the Thai side of the Mekong lies Pha Taem National Park $\left(340 \mathrm{~km}^{2}\right)$, which has similar landforms and habitats to PXT, although little or no semi-evergreen forest (Srikosamatara and Sutheethorn 1994).

15. Xe Namnoy drainage basin

$14^{\circ} 55^{\prime}-15^{\circ} 15^{\prime} \mathrm{N} 106^{\circ} 32^{\prime}-50^{\prime} \mathrm{E}$, Champasak and Attapu Provinces, South Laos

The Xe Namnoy drains the south-east portion of the Bolaven Plateau. Most of the catchment is at 750-1,050 $\mathrm{m}$, but the river descends from the plateau in a steep gorge before joining the Xe Kong at about $100 \mathrm{~m}$. A dam is proposed for the Xe Namnoy $4 \mathrm{~km}$ upstream of Ban Latsasin at $770 \mathrm{~m}$ (Figure 15 ). A secondary dam across the upper reaches of the Xe Pian in Bolaven Southwest PPA, diverting water to the Xe Namnoy, is likely. Surveys concentrated on assessing the impacts of this project on bird populations.

Most of the plateau surveyed west of the Xe Namnoy is deforested and under a mosaic of cultivation, scrub and relict forest patches. Dry coarse grassland covers much of the south-east of the plateau, with forest patches remaining especially in valleys. Forest in the area is tall and luxuriant and its boundaries do not always correlate with obvious natural features, suggesting that the grassland is of artificial origin. The Nam Hiang area is a complex of streams and marshes surrounded by relict forest patches and extensive scrub. Pine forests are best developed in the Xe Namnoy catchment towards the edge of the escarpment at $950-1,050 \mathrm{~m}$, and seem not to have been logged, although this is apparently likely in the future. The middle reaches of the $\mathrm{Xe}$ Namnoy, along the gorge, support extensive semi-evergreen and mixed deciduous forest, as do the escarpment slopes ringing the plateau. The lowest reaches of the Xe Namnoy pass through degraded dry dipterocarp forest with some riverine mixed deciduous forest.

The Xe Namnoy catchment and escarpment are not proposed for national-level protection, although some of the area surveyed falls within the Bolaven Northeast PPA.

16. Dong Hua Sao National Biodiversity Conservation Area

$14^{\circ} 50^{\prime}-15^{\circ} 11^{\prime} \mathrm{N} 105^{\circ} 55^{\prime}-106^{\circ} 17^{\prime} \mathrm{E}$, Champasak and Attapu Provinces, South Laos

Dong Hua Sao NBCA (Figure 16) covers about $900 \mathrm{~km}^{2}$ of the southern Bolaven 


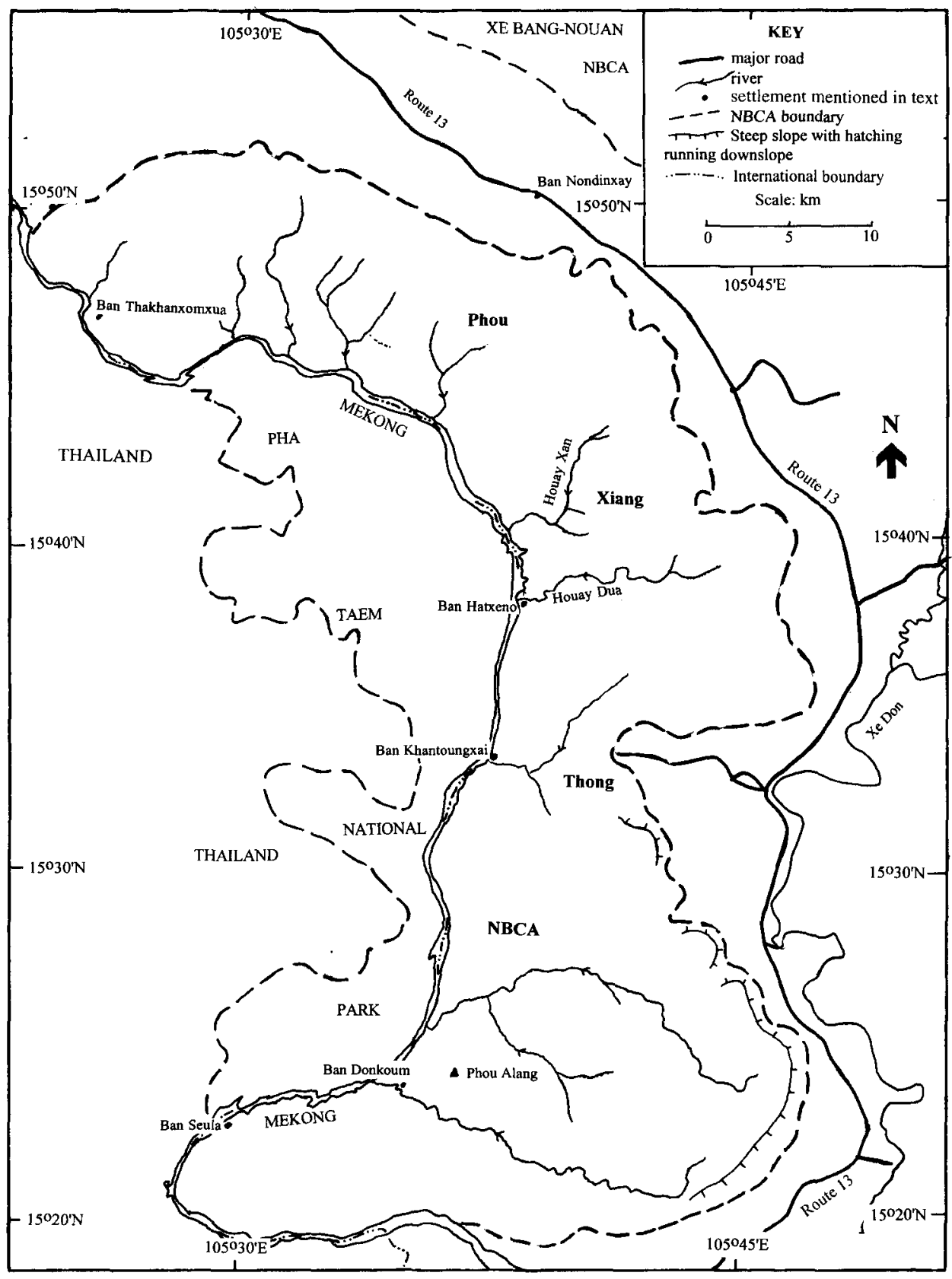

Figure 14. Phou Xiang Thong National Biodiversity Conservation Area.

Plateau, the intervening slope and adjacent lowlands. Most $(70 \%)$ of the area lies below $250 \mathrm{~m}$, but the sheer escarpment and plateau rise to over $1,200 \mathrm{~m}$. The slope forest is largely undisturbed primary, but the plateau is rapidly being cleared for coffee plantations and most lowland forests have been heavily affected 


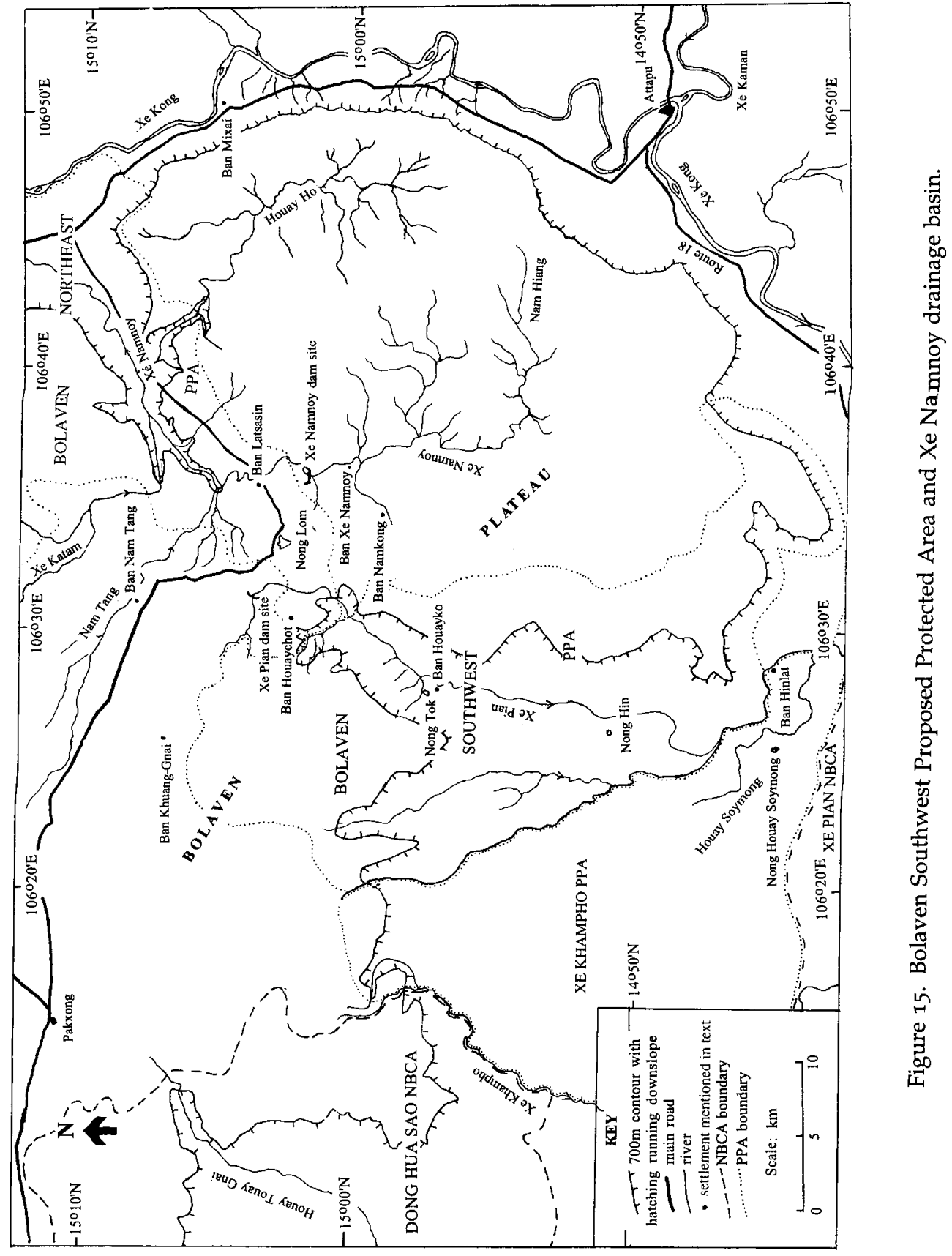




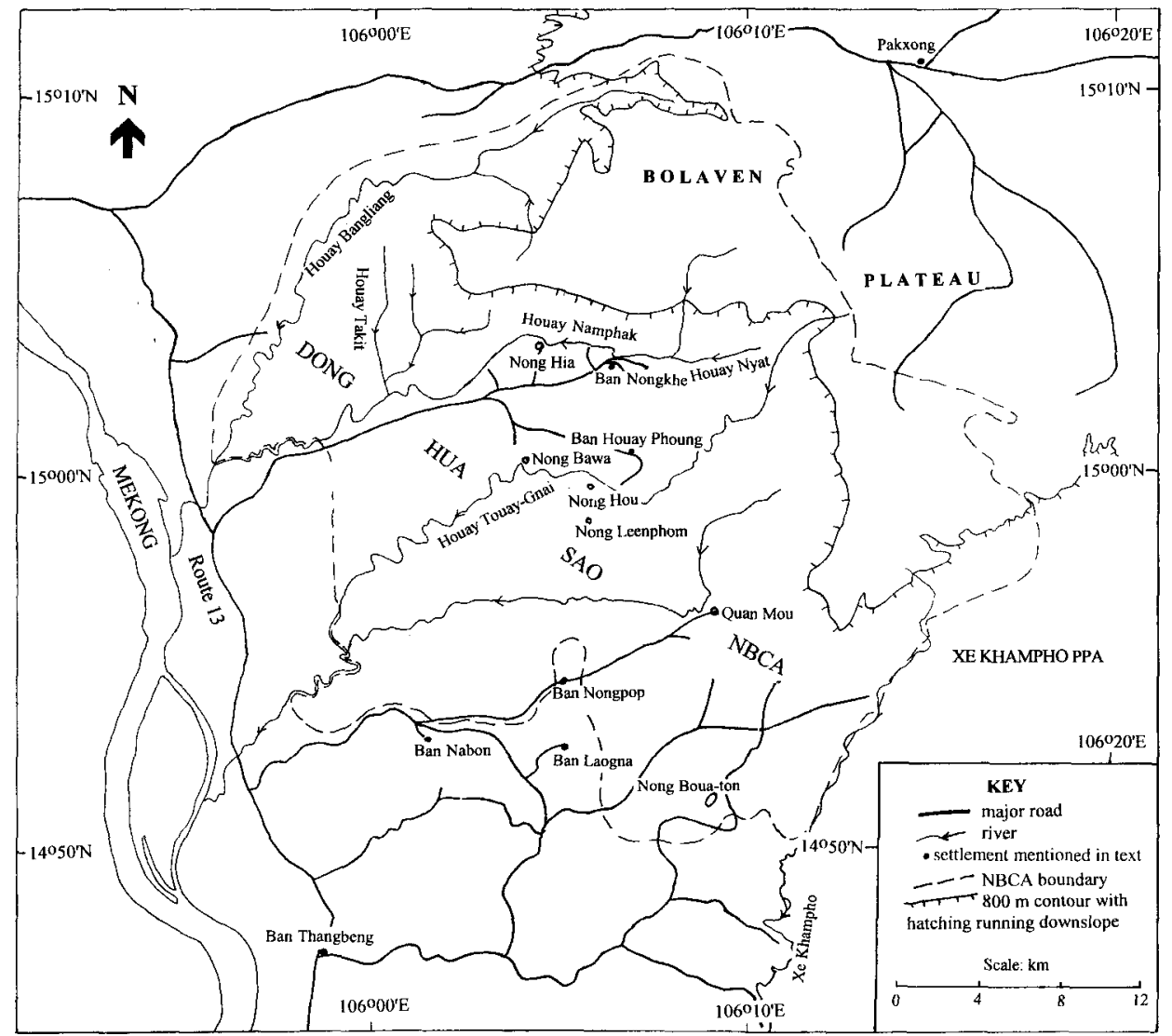

Figure 16. Dong Hua Sao National Biodiversity Conservation Area.

by logging, agriculture, hunting and collection of non-timber forest products. The area is surrounded by cultivation except to the east, where a large tract of forest (Xe Khampho PPA) links Dong Hua Sao NBCA with Xe Pian NBCA. Lowland and slope semi-evergreen forest covers over half the protected area, although there is also extensive mixed deciduous forest in the lowlands. The majority of forest on the plateau is dry evergreen forest. There have been significant changes in the surveyed areas since 1993 resulting from rapidly intensifying human use: increased hunting, disturbance, forest clearance, unsustainable use of pools and expansion of villages.

\section{Bolaven Southwest Proposed Protected Area}

$14^{\circ} 42^{\prime}-15^{\circ} 06^{\prime} \mathrm{N} 106^{\circ} 21^{\prime}-39^{\prime} \mathrm{E}$, Champasak and Attapu Provinces, South Laos

Bolaven Southwest Proposed Protected Area $\left(620 \mathrm{~km}^{2}\right)$ was surveyed as part of a study of the Xe Namnoy-Xe Pian hydropower project. The area covers the headwaters and middle reaches of the Xe Pian and parts of the escarpment of the Bolaven Plateau (Figure 15). The headwaters lie in extensive, probably unlogged, escarpment and plateau forest at 400-1,000 $\mathrm{m}$, little of which was visited. The 
middle reaches of the Xe Pian flow through extensive lowland semi-evergreen forest, much of which has been logged and parts of which appear to be secondary growth around the sites of abandoned villages. There is a moderate density of static wetlands, some permanent, in the lowlands of the reserve. Human population density is high along the northern and southern edges of the area but low within it, and there is a stretch of over $20 \mathrm{~km}$ of the river with no settlements. The area is bordered to the west by the extensive forests of Xe Khampho PPA.

\section{Xe Pian National Biodiversity Conservation Area} $14^{\circ} 00^{\prime}-14^{\circ} 50^{\prime} \mathrm{N} 105^{\circ} 53^{\prime}-106^{\circ} 30^{\prime} \mathrm{E}$, Champasak and Attapu Provinces, South Laos

Xe Pian NBCA (Figure 17) includes a core (termed the Main Block) of mostly little-degraded semi-evergreen forest covering about $1,500 \mathrm{~km}^{2}$. The Main Block is on gently rolling hills at $150-350 \mathrm{~m}$, rising at the western perimeter to form a ridge whose highest point is $844 \mathrm{~m}$. This area is supplemented by two regions of different habitat: Dong Kalo to the south and the Xe Kong plains to the east. Both areas are largely flat expanses covered by dry dipterocarp forest with some lowland mosaic forest. Two lowland rivers, the Xe Pian and the Xe Kong, flow across the plains. The Xe Kong plains and Dong Kalo total an additional $900 \mathrm{~km}^{2}$ and support many pools, most of which are seasonal. Much of the southern boundary runs along the international frontier with Cambodia where similar forest is apparently found (satellite imagery held at the National Office of Forest Inventory and Planning, Vientiane). The Northern Zone, mostly outside the protected area consists of an exploited mosaic of mixed deciduous forest and wetlands, some seasonal and some permanent, and agricultural land.

There are a limited number of trails providing access to the Main Block. Dong Kalo and the Xe Kong plains are more heavily used and there are several seasonal roads.

\section{Mekong in Champasak Province}

$13^{\circ} 55^{\prime}-15^{\circ} 18^{\prime} \mathrm{N} 105^{\circ} 38^{\prime}-58^{\prime} \mathrm{E}$, Champasak Province, South Laos

The Mekong in Champasak Province covers a $192 \mathrm{~km}$ stretch from Phou Xiang Thong NBCA to the Cambodian border (see Figure 17). Gently flowing through flat lowlands for most of this length, this is one of the widest sections of the Mekong in Laos, with stretches over $2 \mathrm{~km}$ wide. The southernmost stretch has a particularly high density of islands; the local name Seephandon ("Four Thousand Islands") reflects this. In Seephandon the Mekong drops over $15 \mathrm{~m}$ in a series of rapids and waterfalls, the largest of which is known as the Khonphapheng Falls. The banks of the Mekong are heavily settled throughout the province and there is considerable human activity on the river, predominantly for transport and fishing. The Mekong is an important communication line for people and trade, being navigable almost throughout this length with the exception of the rapids and falls in the south; thus very few places are free from disturbance or hunting. Probably no natural riverine forest is left except in the south of Seephandon. Many seasonally flooded sandbars, low vegetated islands and rocky islets occur; along parts of the river, sandbars extend for over $10 \mathrm{~km}$. 


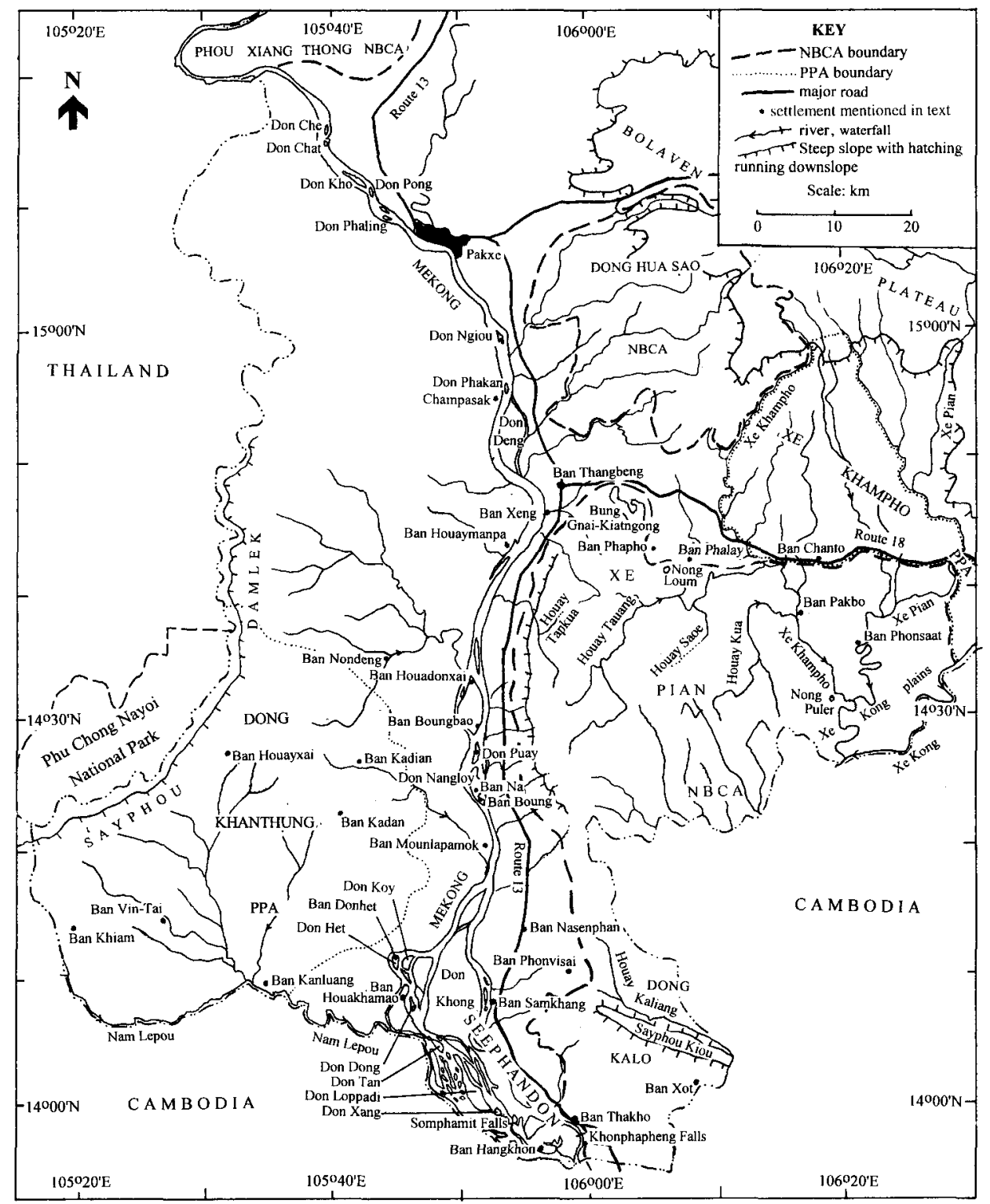

Figure 17. The Mekong River in Champasak Province, Xe Pian National Biodiversity Conservation Area, and Dong Khanthung Proposed Protected Area.

\section{Dong Khanthung Proposed Protected Area}

$14^{\circ} 07^{\prime}-32^{\prime} \mathrm{N} 105^{\circ} 12^{\prime}-45^{\prime} \mathrm{E}$, Champasak Province, South Laos

Dong Khanthung Proposed Protected Area $\left(1,000 \mathrm{~km}^{2}\right)$ comprises flat lowlands $(80-140 \mathrm{~m})$ stretching from the Mekong west to a steep escarpment along the border with Thailand (Figure 17). It supports nationally outstanding areas of 
largely pristine dense lowland semi-evergreen forest at its centre and along the Thai border, the latter continuous with forest in Thailand's Phu Chong Nayoi National Park $\left(687 \mathrm{~km}^{2}\right)$. In the south-east, the lowland mosaic forest supports a high density of pools and is continuous with similar habitat in Cambodia. The region outside of the PPA, adjacent to the Mekong, is heavily settled. Much of Dong Khanthung has had few permanent settlements during the last 25 years owing to armed conflicts. With recent stabilisation, people are moving back into the region; the south-westernmost village of Ban Khiam was only reoccupied in 1992. District authorities have put together a social and economic development plan, including road improvements, new settlements, livestock-rearing areas, silviculture and agricultural land developments, which will conflict with the conservation importance of the area. Also included within the new plan is the designation of about $200 \mathrm{~km}^{2}$ as provincial conservation forest (Berkmüller and Vilawong 1996).

\section{Key species accounts}

The species accounts serve to provide the evidence for a national risk assessment, and form a baseline for a reassessment in the future. For each species, the threat category by which it was selected as a key species (e.g. Globally Threatened) is given. Each account is arranged by presenting the data from major study sites in a north-to-south order, followed by an account of the historical status and where detectable any change in status between historical and recent records. For each species, the threat category, the significance of the Lao population and the urgency of conservation action deduced from the species account are summarised in Table 3.

\section{Rufous-throated Partridge Arborophila rufogularis At Risk in Thailand}

PDD: Three birds heard calling, then shot by hunters, at $1,740 \mathrm{~m}$ in an isolated fragment of dry evergreen forest $1 \mathrm{~km}$ north-west of Phou Dendin mountain in March 1996. NTX: Two were seen snared in wet evergreen forest at 1,100-1,200 m in January 1995 (G. B. Schaller verbally 1995). Heard frequently in Fokienia forest above $900 \mathrm{~m}$ from the Ban Nahoua logging road in April 1996. NNT: Commonly heard (usually 3-4 per day) in the Fokienia forest area (April 1994), but not in dry evergreen forests nearby. Other: One in a market in Phongsali, 15 March 1996.

There is no evidence to suggest a decline in numbers. In both NNT and NTX it was found in Fokienia forest but appeared to be absent from dry and wet evergreen forest in the vicinity, so it may have narrow habitat requirements. Calling appears to be seasonal: it was heard in NTX commonly in April but not in January. Delacour (1929) called it a numerous high-altitude bird near Ban Nape in January and February 1928. He gave no indication as to the habitat type, or whether the species was absent from adjacent forest areas. It was very common in montane areas of Tranninh (Delacour 1926, Delacour and Jabouille 1927, David-Beaulieu 1944); this may still be so but there has been no recent comprehensive survey there. 


\section{Bar-backed Partridge Arborophila brunneopectus At Risk in Thailand}

PDD: At least three heard between 1,125 and 1,225 $\mathrm{m}$ in dry evergreen forest, c. $5 \mathrm{~km}$ due east of Ban La on 28 May 1995. Three, not heard calling, shot by hunters on 22 March 1996 at the same place as the three Rufous-throated Partridges (see above). Another heard at $635 \mathrm{~m}$ in forest near the Nam Ou, west of PDD at co-ordinates $22^{\circ} 06^{\prime} \mathrm{N} 102^{\circ} 06^{\prime} \mathrm{E}$ in May 1995. NK: Recorded in bamboo near Ban Donme and in forest near the Nam An mouth, heard daily in the upper Nam An Valley, and seen and heard once on the slopes of Sayphou Ao. There were single records on the ridge across the Nam Theun from Ban Kengbit and at 1,100 $\mathrm{m}$ in the Nadi limestone area (all records April-May 1995). NTX: The species was heard commonly in the Nam Kwai area in January and February 1994. In 1996, a pair was heard on a ridge in dry evergreen forest near the Vietnamese border in the Nam Cham headwaters at $885 \mathrm{~m}$; another pair was heard just south of the logging camp on the Ban Nahoua logging road. NNT: Heard, usually daily, almost throughout dry evergreen forest and semi-evergreen forest (up to at least $1,500 \mathrm{~m}$ in the Fokienia forest area) in January-April 1994, December 1995 and February and April 1996. NP: Birds were widespread and heard daily in some areas with a predominance of semi-evergreen or dry evergreen forest in 1994, 1995 and 1996. Birds were also heard on both days spent in dry evergreen forest at around $500 \mathrm{~m}$ on hills bordering the Nam Theun downstream of the NP. HNN: In January 1996 the species was probably common at the Houay Clocc site, with two groups seen on 1 January and one heard on 4 January. One to two groups were recorded daily at the Houay Talee site. Two groups were heard from the degraded secondary forest west of Ban Tou. PXH: Commonly seen on Phou Hinho (April 1993; call not then known). XBN: One heard on Phou Thauw at approximately $700 \mathrm{~m}$ (July 1994). XS: One group (the same) heard daily in a valley area at $1,450 \mathrm{~m}$ on the slopes of Phou Ajol; species heard on one other occasion in a valley area at 1,650 m (May 1996). XNN: Several sightings and calls heard almost daily in the larger patches of degraded forest above $750 \mathrm{~m}$ (March-April 1995). DHS: Only found in the remaining plateau areas of primary dry evergreen forest; one sighting of two birds and heard on three occasions (June 1993). Other: One heard in Phongsali province, along the Nam Ngay, between Ban Ngay-Nua and Ban Ngay-Tai, on 27 March 1996. Recorded in the forest around Pha Khok to the west of the Nam Mouan, March 1996. Present beside the Nam Theun near the Nam Ngoy between 22 February and 22 March 1995.

The bird is still widespread, locally common and in no immediate danger. However, hunting has reduced numbers in Thailand (Round 1988) and eventually may threaten Lao populations too. Historically, the bird was common at $\mathrm{Xe}$ Pon (David-Beaulieu 1949-1950), throughout Tranninh (Delacour and Jabouille 1927, David-Beaulieu 1944), around Ban Namkeung-Kao and Lo-Tiao (Delacour and Greenway 1940) and at 800-1,300 $\mathrm{m}$ around Ban Nape (Delacour 1929). It was especially common on the Bolaven Plateau (Engelbach 1932). It was twice recorded near Muang Taoy at 500-800 $\mathrm{m}$ (Engelbach 1932) and three were taken at Ban Nakay (Nua) (Dickinson 1970a).

Two captives were seen in Ban Nameuy (NNT, April 1994), another at Ban Thabak (December 1994) and several were seen in markets. 


\section{Silver Pheasant Lophura nycthemera At Risk in Thailand}

PDD: A feather found at $780 \mathrm{~m}$ in the Ban Than area, May 1995. Four females in dry evergreen forest fragments near Ban Talung on 24 March 1996 around $1,000 \mathrm{~m}$; a pair in secondary forest on a ridge above Ban Sop Kan at $700 \mathrm{~m}$ the following day. Feathers of at least three males on the banks of the Nam Ou at Ban Hat Xa in March 1996. PKK: Recorded by Salter (1993). NK: A party of three in the east of the reserve, six along the Nam Ao valley in the Nam Ao forest, two singles on the northern slope of Sayphou Ao and one in the upper Nam An valley. Feathers found near Ban Donme and along the Houay Basong. Local people reported that the bird was widely distributed. Lophura pheasants not identified to species were encountered on three occasions in the Nadi limestone area, where the remains of a Silver Pheasant were also found. All records from 1995 . NTX: Remains were found in forest in the Nam Kwai area in 1994, and near the logging camp along the Ban Nahoua logging road in April 1996. NNT: Probably present in all forest habitats of the NBCA (except possibly the southern escarpment); probably commoner in the surveyed areas of dry evergreen forest above 1,000 m, possibly because hunting pressure was lowest there. Records are from 1994-1996. NP: Probably common in both broadleaf and pine-dominated elements of the habitat mosaic, with several records in 1994 and 1995. Remains seen commonly in villages and in the field. HNN: In 1996 feathers from a female were found in the forested upper valley of the Houay Packha. XBN: Two at c. $500 \mathrm{~m}$ on Sayphou Hou-ong in June 1994. XS: Remains were found on several occasions in forest on Phou Ajol, and in local villages in 1996. XNN: Encountered frequently above $750 \mathrm{~m}$ and reported by all local hunters in February-April 1995 . DHS: Seen once each in both remaining areas of primary dry evergreen forest on the Bolaven Plateau in May 1993 and once at $450 \mathrm{~m}$ in unlogged slope forest in the upper Houay Bangliang valley in February 1996. BSW: One seen at $500 \mathrm{~m}$ in the Xe Pian valley in April 1995.

There is no evidence of a decline other than one associated with forest clearance. The species was recorded, often as common, from Muang Taoy and the Bolaven Plateau (Engelbach 1932), Ban Ngoy (Dickinson 1970a), Salavan (Delacour and Jabouille 1940), Phongsali (Bangs and van Tyne 1931), Ban Namkeung-Kao (Delacour and Greenway 1940), Ban Houayxai, Xiangkhouang, and Ban Nonghet (Delacour 1948), Ban Nape (Delacour 1929) and throughout Tranninh (Delacour and Jabouille 1927, David-Beaulieu 1944), and was reported by villagers in Xe Pon (David-Beaulieu 1949-1950). Engelbach (1927a) heard calls which he provisionally attributed to this species from the $\mathrm{Xe}$ Don plains at the foot of the Bolaven Plateau, but never saw the bird. This suggests an altitude of 200-300 $\mathrm{m}$, which might seem unlikely for this species, but birds were seen as low as $450 \mathrm{~m}$ in DHS; he may, however, have heard Siamese Fireback, which is sometimes judged to have similar calls, and his later work does not clarify this point (Engelbach 1932).

Three races occur in Laos (Delacour 1977): L. n. engelbachi (believed to be endemic to the Bolaven Plateau, and recorded by the surveys in DHS, XNN and BSW), L. n. beaulieu (the North, south to $17^{\circ} \mathrm{N}$ ) and $L$. $n$. berliozi (west slopes of the Annamites and the Nakay Plateau). L. n. engelbachi is recognised as a Threatened subspecies by McGowan and Garson (1995). Birds in XBN and XS were much darker in coloration than those from NNT, suggesting they could feasibly be of 
the race $L . n$. engelbachi, or $L . n$. beli which occurs in Central and the northern part of South Annam, immediately adjacent to Central and South Laos (Delacour 1977). All these races are maintained in the review by McGowan and Panchen (1994).

It was commonly snared in NNT, XS and DHS, where many piles of feathers plucked by hunters were found. Remains were frequently found in villages around NK. It is frequently seen in urban food markets (Salter 1993). The race L. $n$. engelbachi may be targeted for capture if trade between the Bolaven and Thailand increases; pheasant-keepers pay high prices for something rare and high demand caused a severe decrease in populations of $L$. n. lewisi (another dark race) in Thailand (Round 1988).

Most records come from large blocks of dry evergreen forest. However, on the NP it was seen at several sites along riverbanks and in both broadleaved and pine-dominated parts of the habitat mosaic. Several birds were seen both in small primary forest patches and in tall secondary growth in areas dominated by shifting cultivation on the Bolaven Plateau in XNN. The observations from all sites across the country confirm that, in Laos, Silver is the prevailing Lophura pheasant above about $500 \mathrm{~m}$, with Siamese Fireback filling an equivalent role in the lowlands.

\section{[Imperial Pheasant Lophura imperialis Globally Threatened}

This species was provisionally reported from Laos by David-Beaulieu (19491950) on the basis of hunters' reports from Central Laos. The record was discounted by Collar et al. (1994). In 1994, villagers reported that an all-dark pheasant lived in the NNT area, but no other evidence could be traced. The description appears to be a composite that includes Coral-billed Ground-cuckoo features. In HNN, perhaps a more likely locality for dark pheasants since several lowaltitude valleys cross the Vietnamese border relatively close to where Vietnamese Pheasant $L$. hatinhensis has been found (Eames et al. 1994a), extensive inquiries have yielded no local reports.]

\section{Siamese Fireback Lophura diardi Globally Threatened}

PKK: One probable record from the Nam Leuk dam site in October 1994. TMF: One record in very degraded forest in July 1996; widely reported by villagers. NK: No trace of this species was found in 1995 but hunters stated that it occurs locally in low forests in the west of the NBCA. NP: One in bamboo near the mouth of the Houay Kanik in 1995. In 1994, two females were seen in bamboo forest continuous with semi-evergreen forest about $2 \mathrm{~km}$ north-east of Ban Sop-On, and the species was reported from several other areas, including Ban Nam Theun and Ban Don, where remains were also found in villages. Since few villagers seemed to be familiar with it, it may be uncommon on the plateau. HNN: In 1996 feathers of a recently caught male were seen in Ban Tasang (reportedly snared in degraded forest close to the village). Feathers of a female were found along a trail in the same area. Two males were flushed from the dry streambed of the Houay Packha, and feathers from a female were found in the same area of secondary habitat. PXH: 
Probably frequent in April 1993 in semi-evergreen forest and dry evergreen forest, although seen on fewer than five occasions. XBN: Common in MayJune 1994 (found daily when searched for) in the Central Hills and adjacent lowlands (especially along the Xe Bang-Nouan between the hills), including degraded bamboo-dominated mixed deciduous forest. Found only once in degraded semi-evergreen forest/mixed deciduous forest around the Houay Sadam in seven days. PXT: Four sightings were made during March 1996 in semi-evergreen forest, and shed or plucked feathers were found in three other areas. DHS: Remains of at least five individuals plucked by hunters were found in February 1996, four in areas of logged flatland forest, one on the unlogged slopes at $500 \mathrm{~m}$ in the Houay Bangliang valley close to where Silver Pheasant was recorded. The provisional report mentioned by Salter (1993) has since been retracted by the observer. XNN: Reported, as scarce, on the Bolaven Plateau, and as the commonest Lophura species in the lowlands of the $\mathrm{Xe}$ Namnoy. There were two sightings of pairs in the lower Xe Namnoy valley and one of a single on the plateau at $800 \mathrm{~m}$ during March-April 1995. XP: In 1992-1993, common (2-3 groups seen per day when searched for) over large areas of primary semi-evergreen forest up to $400 \mathrm{~m}$, with lower densities in degraded semi-evergreen forest and in the largest semi-evergreen forest patches amongst mixed deciduous forest and dry dipterocarp forest. DKT: One seen along the road between Ban Kanluang and Ban Kadan in April 1996 (Berkmüller and Vilawong 1996). Other: Recorded from Dong Ampham NBCA, March 1992 (Salter 1993) and reported by hunters in 1995 from Xe Khampho PPA. One seen on Route 18 near Ban Chanto. A wing feather was found in forest fringing the Nam Hai-Nam Hinboun plain in 1995. Several were seen on separate occasions on sale in Ban Lak (20) market, also freshly caught birds seen on several occasions being offered for sale along the main north-south Route 13.

There is no suggestion of a decline in density in the remaining habitat. However, habitat loss has been considerable, especially around Vientiane and in the Mekong lowlands. Previously, David-Beaulieu (1949-1950) found it to be frequent in Savannakhet Province, Delacour and Greenway (1940) recorded a flock of seven $30 \mathrm{~km}$ east of Louangphabang at $500 \mathrm{~m}$, Engelbach (1927a) described it as common in the Salavan region and later (Engelbach 1932) as the common pheasant of the plains of South Laos.

The species is snared in large numbers in PKK (from where birds are sold in Vientiane), XP, PXH and probably elsewhere. It is frequently sold as food in markets. Captive individuals were found in Vientiane and Savannakhet zoos, at a restaurant in Vientiane, at two menageries in Ban Lak (20) and at one in Pakxe. The scarcity in logged parts of $\mathrm{XBN}$ and the logged lowlands of DHS suggests that logged forest may be unsuitable for this bird, perhaps indirectly through raised hunting levels. However, the species was widely reported in the TMF (an area completely logged), and furthermore Robson et al. (1989) described it as adapting well to secondary forest and even scrub woodland in close proximity to human habitation. Although birds were frequently found in degraded parts of XP, they could have been emigrants from the healthy population in the undegraded Main Block. This set of results makes it difficult to understand the species's tolerance of degradation: further information is needed on this subject. 
Laos probably has the largest national population of this bird, with the Xe Pian population being of special importance. Most suitable lowland forest probably lies outside protected areas in small degraded forest blocks. Most of this habitat is vulnerable to logging and subsistence use by rural villages, which may lead to major population declines.

Most records came from below $650 \mathrm{~m}$; there was one record from XNN at $800 \mathrm{~m}$. Round (1988) gave an upper limit in Thailand of $750 \mathrm{~m}$. Field observations and village reports suggest that the species frequently associates with large ungulates.

\section{[Germain's Peacock-pheasant Polyplectron germaini Globally Threatened}

Collar and Andrew (1988) mentioned unconfirmed reports from hunters on the Bolaven Plateau of this species. These were not reiterated in Collar et al. (1994) and there is no evidence that the species has ever occurred in Laos. During discussions with villagers in XP in 1992, an effort was made to establish which species of Polyplectron was present. Villagers' descriptions clearly indicated Germain's, yet the large number of feathers found and the few sightings were of Grey. It is likely that a similar confusion generated the earlier reports.]

\section{Grey Peacock-pheasant Polyplectron bicalcaratum At Risk in Thailand}

PDD: Common (up to five heard per day) in May 1995. In March 1996, several heard from the Nam Kang valley; from riverine forest south of Ban Muangva; also heard from degraded and burnt secondary forest and relict forest patches near Ban Muanghat-Hin and around Phou Dendin. PKK: One sighting and two heard counter-calling briefly by the Nam Mang (November 1994). TMF: Heard almost daily in February-March 1996 from degraded semi-evergreen forest in the northern part of the area, usually 1-2 birds per day (once five). Not recorded in June-July 1996, when, however, most time was spent in the south. NK: Heard daily in forest throughout most of the reserve including a karst limestone outcrop to the north of the Nam Xouang (January-March 1995). Peak daily count of 14 individuals heard along the Houay Basong on 20 March, with 4-8 separate birds heard most days. In the Nam Ao forest they were recorded only occasionally in 1995, while they were not heard from the Nadi limestone area in May 1995. NTX: Commonly heard (2-4 from one place in the course of a morning) in surveys around the Nam Kwai site during fieldwork, January-March 1994. In April and May 1996, heard daily (up to five birds per day) in both the Nam Cham and the Ban Nahoua logging road areas. NNT: Common (at least four per day) in most of the main forest types, with birds calling frequently (January-April 1994, February-March 1995, January-February and April-May 1996). Only 1-2 heard per day in the southern escarpment, and not recorded in the Fokienia forest area or higher. NP: Widespread, heard daily in most forest areas, although usually in small numbers. The highest numbers, of up to nine daily, were heard in extensive dry evergreen forest rather than pine-dominated areas on peripheral hills in the Houay Kechayer headwaters (for all surveys in 1994, 1995 and 1996). Birds were also heard $(2-4)$ on both days spent in dry evergreen forest at about $500 \mathrm{~m}$ on hills bordering the Nam Theun downstream of the NP. KML: Heard locally 
within extensive stands of tall forest inside the protected area in May 1995. Up to nine birds heard daily in surveys between the Nam Thon and Khuadhin in February 1996. HNN: In late 1995 and early 1996 one to two were heard daily at the Houay Clocc and Houay Talee sites; single birds were also heard in the degraded secondary forest of the Nam Ngo (30 December and 5 January) and Nam Tang (6 January) valleys. A single was heard from the degraded secondary forest west of Ban Tou. PXH: Heard commonly on Phou Hinho (up to four per day in March 1993). XS: Heard only once: on 20 May 1996 from 1,400 m on Phou Ajol. Schaller (1995) reported finding feathers close to Ban Dakchung. DHS: Heard from all areas of the unlogged slope evergreen forest at $400-600 \mathrm{~m}$ during February 1996; no more than two were heard in any area visited. There were no records during 12 observer-days in the upper Houay Bangliang valley in apparently ideal habitat. Feathers were found at a campsite west of Houay Takit, in flat logged forest several $\mathrm{km}$ from the slopes, but a local guide stated that they would have been from birds snared on the slopes and that the species does not occur in the lowlands. There were no records during the 1993 survey, which was conducted at a time of lower calling and lower snaring activity. XP: Heard commonly (up to six per day) around Houay Tapkua (February 1993); feathers were frequently found in hunters' plucking piles by Houay Saoe and Houay Kua, although birds were not heard (December 1992). Other: The species was heard from forest around Pha Khok to the west of the Nam Mouan, and in forest around the confluence of the Nam Mouan and Nam Chouan. One and three birds were heard on the two mornings spent in the northern forest fringe of the Nam Hai-Nam Hinboun plain. Up to seven per day in forest along the Nam Ngay between Ban Ngay-Nua and Ban Ngay-Tai, during 25-27 March 1996, and several heard from scrub on 20 March 1996 at the mouth of the Nam Ngay.

Populations of this species appear healthy in Laos. It was quite common in Tranninh (David-Beaulieu 1944); scarce in the Upper Mekong and Louangphabang Provinces (two pairs taken at Lo-Tiao: Delacour and Greenway 1940); and collected at Ban Muangliap (Robinson and Kloss 1931). A total of 15 specimens from Tranninh (where very common) were referable to $P$. b. bicalcaratum (which ranges from Chittagong and Tenasserim through Thailand to North Laos and southern Yunnan) rather than P. b. ghigii of Annam (Delacour and Jabouille 1927, 1931). Delacour (1929) found it common at Ban Nape with specimens intermediate between these two subspecies. Birds in XP in 1992-1993 fitted P. b. ghigii.

The species is subjected to heavy snaring in XP and plucked feathers were also found widely in NNT, NK and many other areas. Captive individuals were seen near Nam Ha (East) NBCA (Salter 1993) and in Ban Lak 20.

The species frequently utters a characteristic loud call and so is more easily surveyed than are Lophura pheasants. Calling levels seem much lower in late May-December than from late January to early May, but this has not been confirmed by repeated visits to the same site. The absence of records from XBN is thus of unknown significance, as it was surveyed in the wet season (May-July). At some sites, identification was based solely on call; the known calls of Germain's Peacock-pheasant (see Robson et al. 1993a) are very different. King et al. (1975) quote the transcription by Delacour of the call of Germain's Peacockpheasant but this fits the call of Grey Peacock-pheasant; such a call has not been heard from Germain's at all by J. C. Eames (verbally 1997). 
Robson et al. (1991) considered that in Vietnam the species preferred areas of dense palm growth and bamboo. There was no evidence for this in Laos, where the bird occurred in dry and wet evergreen forest and semi-evergreen forest, even in quite small fragments and right up to clearings in some areas (e.g. NK, PDD). On the NP, it seemed commoner in broadleaf than in pine-dominated areas, and scarcer in disturbed forest than in unencroached areas. The highest records came from 1,500 and $1,400 \mathrm{~m}$ (NNT and XS respectively, in dry evergreen forest).

\section{Crested Argus Rheinardia ocellata Globally Threatened}

NTX: Common around the Nam Kwai area in wet evergreen forest, where at least ten birds giving the whoohyow call (see below) could be heard in a radius of about $1 \mathrm{~km}, 24$ January-2 February 1994. Display grounds were found at 1,100-1,200 $\mathrm{m}$ in January 1995 (G. B. Schaller verbally 1995). Commonly heard calling, although at lower density, along the Ban Nahoua logging road in April 1996. NNT: Scarce east of and around the Ban Navang logging road (1,000$1,200 \mathrm{~m}$ ), where only three calling birds were heard along at least $7 \mathrm{~km}$ of trail between 15 and 30 April 1994 and only two calling males were thought to be present during April-May 1996. Present, probably quite common, around the headwaters of the Nam Pheo in wet evergreen forest, where five were heard giving the whoohyow call in an area of less than $4 \mathrm{~km}^{2}$ on a brief visit to hills around Ban Guner (650-750 m, 26 April 1994). Also reported on the high slopes of the Phou Vang-Phou Yiatyo massif (but not Phou Ko to the west) and from the Ban Maka area at the head of the Nam Noy valley. Heard once on 27 December 1996 from the Nam On valley at around $650 \mathrm{~m}$. HNN: The only confirmed record of this species was of feathers found on 30 December 1.995 in the forested higher Houay Packha valley. However, locals from Ban Tasang, Ban Louk, Ban Katok, Ban San and Ban Tou all described this species and reported it as occurring in the forests close to the Vietnamese border. XS: 1-2 called regularly at c. 1,450 $\mathrm{m}$ on Phou Ajol during the May 1996 survey period. Feathers were seen in houses in Ban Dakchung. Other: There are reports from a total of six areas during village interviews, but descriptions have been inconsistent (Salter 1993) and there seems to be some confusion with other pheasant species, including Green Peafowl and Grey Peacock-pheasant. Thus none of these reports should be treated as a confirmed record.

There is insufficient evidence to suggest that this species has undergone a major decline in Laos. Historically, it was often heard in deep forests near the top of the Annamite range in the Ban Nape region (Delacour 1929). DavidBeaulieu (1949-1950) found it in the eastern parts of Savannakhet Province (adjacent to Xe Pon) where local people trapped it with ease. David-Beaulieu (1944) had convincing reports from villagers in eastern Tranninh.

Although the habitat in NTX and NNT is under threat, the bird may be more acutely threatened by selective snaring. Display grounds at Nam Kwai were being heavily snared when the area was visited in 1994. One group of Vietnamese hunters caught at least three birds, which they took alive to Ban Nape, during this time. There was a pile of plucked feathers at another display ground when visited in March. In the Nam Noy-Nam Pheo catchment the birds were also 
snared, judging by the number of feathers kept as house decorations. One live bird was captive in Ban Nameuy, presumably for sale to outsiders. In April 1994, three more live captives (one male, two females) were for sale near Ban Tongphe. A hunter in Ban Soptong reportedly had around 20 captives in 1994, all of them taken in forest above Ban Nape. Snaring pressure is apparently very high on the southern slopes of Phou Ajol in XS, which probably explains the lack of records of Crested Argus and other gamebirds from this area.

In Vietnam Crested Argus is still widespread in the Annamites but has become localised owing to habitat loss and hunting pressure (Robson et al. 1993a).

The species occurs up to $1,500 \mathrm{~m}$, with a strong preference for wet evergreen forest. The low densities in dry evergreen forest at NNT may be natural because it supports an extremely varied mammal community and diurnal primates are noticeably tame, indicating low hunting pressure (Duckworth in press). Furthermore, people in Ban Navang did not recognise the species.

\section{Green Peafowl Pavo muticus Globally Threatened}

PKK: At least six heard at a communal roosting area north of Ban Nakhay (22 March 1994); two heard there on 1 and 2 May 1995. NP: Convincing reports of former presence were received from several areas in 1994. In most cases it was suspected that the birds had since disappeared. A few may remain. PXT: Thirteen calling males were recorded during March 1996 in rocky savannas with strips of mixed deciduous or semi-evergreen forest, with one concentration of seven, and four other records of 1-2. Reports were received from four other locations which could not be visited. DHS: Single birds seen on two occasions in June-July 1993 at Quan Mou, a site at which local people reported large numbers. None was recorded in 1996 at Quan Mou despite two days' searching during the main calling season. A new farming settlement of nine families was found at the site in 1996, inhabitants stating that peafowl had been heard in 1995 but not in 1996 and that at least one bird had been shot in 1995. The Quan Mou colony is presumed extinct. Another bird was reportedly shot at Ban Laogna, $10 \mathrm{~km}$ to the south-west, in 1995. Reports were received of continuing presence at another site, Nong Boua-ton, some $10 \mathrm{~km}$ to the south. BSW: Unconfirmed reports from Ban Houaychot (small numbers in the southern headwaters of the Xe Pian at 750$800 \mathrm{~m}$ ) and Ban Hinlat (a large population reported around the banks of the Xe Pian and the nearby Houay Soymong), 180-200 m. Locally caught chicks were seen nearby (I. Baird verbally 1995). XP: At least two singles heard on the Xe Kong plains (March 1993) and feathers were found $20 \mathrm{~km}$ away, upstream of Ban Phonsaat, in May 1995. DKT: One seen at a pool $10 \mathrm{~km}$ south-east of Ban Khiam on 2 May 1996 and feathers found several km distant. Reports were received of presence in many parts of the area in May and August 1996. Other: Reports, as yet unsubstantiated, from Nam Ha (East) and Nam Phoun NBCAs in the North, the Nam Kong catchment, Dong Ampham NBCA, and three proposed protected areas in the South: Phou Kathong, Phou Theung and Xe Khampho.

Five were captive at a menagerie in Savannakhet in March 1993; their place of capture is unknown.

A recent review of the status of this species in Laos (Evans and Timmins 1996) found that it was formerly very common throughout much of the country, but 
has undergone a dramatic decline in the past 50 years. This decline is continuing and the species may become extinct in Laos quite soon. Reports were gathered of colonies becoming effectively extinct in NK, NP, XBN, XNN and KML during 1985-1995, and reports or evidence of hunting and in most cases also population declines were collected from the few extant colonies. Overall, the most important sites are now believed to be XP, DKT, PXT and BSW.

\section{White-winged Duck Cairina scutulata Globally Threatened}

NP: Several sightings and reports from villages show that the species is widespread, although localised, on rivers at 500-520 m. Most records were of birds on or by the bank of major rivers. Prints along river margins or other wetlands provided further localities. The sites of records in 1995 closely matched those from 1994 and the Nakay Plateau probably supports 6-12 groups, each perhaps representing a single or pair occupying a potential breeding territory. Some suitable habitat seems to be unused, suggesting that numbers have been reduced by hunting. DHS: Several convincing reports were received in February 1996, suggesting the species is occasional within the area. BSW: Three groups (of two, three and four) on the Xe Pian mainstream and adjacent pools at $300-320 \mathrm{~m}$ in April 1995. In conjunction with reports from hunters, a total population of 10-20 adult birds is estimated, including some birds occurring as high as $800 \mathrm{~m}$. XP: One on 27 December 1993 over the Houay Kua $(250 \mathrm{~m})$; a group of three at a pool in dense forest in the northern Xe Kong plains in May 1995; a pair with three young was photographed on the Houay Tauang, probably in December 1994 (Padith Vanalatsmy verbally 1995; photographs examined by the authors). DKT: Widely reported in May and August 1996. One was seen flying over open dipterocarp forest between Ban Khiam and Ban Vin-tai (110 m) in mid-August 1996.

The species has evidently declined greatly, having been recorded widely from Central and South Laos (Delacour 1929, 1932, Engelbach 1927a,b, 1932, DavidBeaulieu 1949-1950, Dickinson 1970a). Populations remain in three parts of the country: NP; the XP, BSW, DHS and Xe Khampho PPA complex; and the DKT area. Although well separated from the XP, BSW, DHS and Xe Khampho PPA complex, the DKT area adjoins the Sayphou Damlek mountains of Thailand, where a large White-winged Duck population occurs (Parr et al. 1994), and these two areas presumably form parts of a single population. The remaining populations are threatened by opportunistic hunting, and the NNT population may be wholly lost if the proposed Nam Theun 2 hydroelectric project goes ahead.

The status, natural history and conservation of this bird in Laos are detailed by Evans et al. (1997).

\section{Comb Duck Sarkidiornis melanotos At Risk in Thailand}

The sole Lao record is of one which stayed for several days at P.K. 20 on Route Coloniale no.9 in Savannakhet Province, but no details of year or season were given (David-Beaulieu 1949-1950). 


\section{Yellow-crowned Woodpecker Picoides mahrattensis At Risk in Thailand}

The sole Lao record is of one collected in 1876 in the area of the "Kouys" ethnic group (Oustalet 1899-1903), which is probably in South Laos according to Delacour and Jabouille (1931). However this name seems not to be used today in Laos and the locality has not been traced. The site involved may even be in eastern Cambodia, as there is an ethnic group of Cambodian people called the Kouy (spelt today Quoi) living in this area (Lic Vuthy verbally 1997).

\section{Crimson-breasted Woodpecker Picoides cathpharius At Risk in Thailand}

A few were collected on Phou Kabo (February 1940) and at Ban Nonghet in February 1939 (David-Beaulieu 1944).

\section{White-bellied Woodpecker Dryocopus javensis At Risk in Thailand}

XBN: Two records around Ban Konglu in June 1994. XNN: One over the Xe Kong near the mouth of the Xe Namnoy in April 1995. DHS: A pair on tall trees in freshly cleared plantations at the interface between semi-evergreen and mixed deciduous forest near Quan Mou in March 1996. XP: Locally common in the Xe Kong plains and Dong Kalo in 1993, with one record in degraded forest of the Northern zone. Several on the Xe Kong plains in 1995. DKT: One in dry dipterocarp forest $10 \mathrm{~km}$ south-east of Ban Khiam in May 1996 and another between Ban Khiam and Ban Vin-tai in mid-August 1996.

Historically it was recorded widely from the South (Engelbach 1932) and fairly frequently in Savannakhet Province (David-Beaulieu 1949-1950); during 1993, little time was spent in suitable habitat at $\mathrm{PXH}$ so the lack of records there may not be significant.

The species seemed to be commonest in lowland mosaic forest in Laos; all records came from below $300 \mathrm{~m}$. It often joined mixed species flocks.

Streak-throated Woodpecker Picus xanthopygaeus (formerly At Risk in Thailand)

XBN: During May-July 1994, a single at Keng Sung and at least three together near Ban Konglu. XP: A few singles on the Xe Kong plains in March 1993.

The species has always been local in Laos; previously it was only recorded (twice) from the Bolaven Plateau (Engelbach 1932). Although listed as At Risk in Thailand by Round (1988), it was dropped without explanation from the list presented in Treesucon and Round (1990).

All recent records came from dry dipterocarp forest and it may be commoner than records suggest, as effort in this habitat has been relatively low. It associated loosely with mixed-species flocks.

\section{Red-collared Woodpecker Picus rabieri Globally Threatened}

PKK: $1-2$ in dry evergreen forest beside the Nam Mang in November 1994. TMF: Several records in degraded semi-evergreen forest or bamboo-dominated areas 
during February-July 1996. Recently fledged juveniles were seen on 30 June 1996; two other presumed families at around the same time from widely separated localities indicated breeding in this extensive, heavily logged area. NK: One at $600 \mathrm{~m}$ just east of the Nam Theun 1 dam site and occasionally seen downstream of Keng Maiha. More frequent (but still not daily) in the Nam Ao forest, which is flatter than the Nam Kading valley. One in degraded forest north of the Nam Xouang in April. All records from 1995. NP: Occasional throughout broadleaved forest in 1994, 1995 and 1996. KML: One in secondary forest in the NBCA, and one in bamboo-dominated secondary growth in the Nam Thon area, both in February 1996. PXH, XP: Common (usually found daily) in primary evergreen and semi-evergreen forest below $500 \mathrm{~m}$, frequent or occasional in degraded semievergreen forest, but generally absent from deciduous woodlands. $\mathbf{X B N}$ : Common; seen daily (up to four groups) in degraded semi-evergreen forest around the Houay Sadam site, and along the Xe Bang-Nouan south-west of Ban Konglu. Less common in the Central Hills at $400-600 \mathrm{~m}$. PXT: One in March 1996 in tall semi-evergreen forest at $450 \mathrm{~m}$ on Phou Alang. DHS: Common in semi-evergreen forest below $500 \mathrm{~m}$; frequent or occasional in degraded semievergreen forest, but generally absent from deciduous woodlands. Other: One at about $600 \mathrm{~m}$ in degraded dry evergreen forest on the ridge of mountains bordering the Nam Theun south of Ban Lak 20 in April 1994. One in Ban Lak 20 market in April 1996.

There is no evidence to suggest a decline in numbers. It was recorded previously in Laos from Ban Muangliap and Ban Hoi Mak (Baker 1920), low altitudes in the Ban Thathom region of Tranninh (David-Beaulieu 1948) and Boungkham and Pakxe (Engelbach 1932). However, it is known only from Laos and Vietnam, with one old record from Yunnan, China (Cheng 1987).

There were relatively few records above $400 \mathrm{~m}$ or in steep, hilly terrain. Birds were not common in heavily degraded forest at most sites, but around the Houay Sadam (XBN) up to four groups were seen daily in such habitat, and breeding seemed widespread in very degraded forest at TMF. It often associated with mixed-species flocks, most often including White-crested Laughingthrush Garrulax leucolophus, Large Scimitar-babbler Pomatorhinus hypoleucos, and other woodpeckers, particularly Greater Yellownape Picus flavinucha, Lesser Yellownape P. chlorolophus, Laced Woodpecker P. vittatus, Greater Flameback Chrysocolaptes lucidus and Common Flameback Dinopium javanense. Birds were commonly flushed from the floor and understorey, as found by Delacour (1929) and Robson et al. (1989).

\section{Black-headed Woodpecker Picus erythropygius At Risk in Thailand}

PXH: Common in areas of dry dipterocarp forest (up to six groups seen daily) in April 1993. XBN: Common during May-June 1994 in areas of dry dipterocarp forest, with 1-3 groups recorded daily around Keng Sung, 1-2 at Phou Salar and up to nine groups per day around Ban Konglu. PXT: Small numbers, mostly singles, were seen in most areas of dry dipterocarp forest visited in March-April 1996, often with an encounter every few hours of fieldwork. Not recorded from rocky savanna with scattered trees (unlike most other species using dry dipterocarp forest in PXT). XNN: Several records both in the pine forest on the Bolaven 
Plateau and in dry dipterocarp forest by the lower Xe Namnoy during FebruaryApril 1995. XP: Common in dry dipterocarp forest, and frequent in areas of predominantly mixed deciduous forest on the Xe Kong plains and Dong Kalo (many seen daily) in 1993; several records on the Xe Kong plains in 1995 and recorded there in September 1996. DKT: Common in dry dipterocarp forest in May 1996, with a maximum of three parties per day. Other: Two on 10 December 1994 at $100 \mathrm{~m}$ near Ban Paam and present south of Ban Xekaman on I March 1996.

It was the commonest woodpecker in Savannakhet Province (David-Beaulieu 1949-1950) and South Laos (Engelbach 1932). Oustalet (1899-1903) documented birds in the "Kouys" area and near Attapu.

Recent records were overwhelmingly from dry dipterocarp forest (as found by Engelbach and David-Beaulieu), where it remains the commonest woodpecker, and sometimes adjacent mixed deciduous forest; birds were often in groups of 4-6 and loosely associated with mixed-species flocks.

\section{Pale-headed Woodpecker Gecinulus grantia At Risk in Thailand}

PKK: One in dry evergreen forest beside the Nam Mang in November 1994. NK, NP, PXH, XP: Very local; occasional to common in stands of large bamboo in primary and degraded semi-evergreen and dry evergreen forest. DHS: One on the plateau in primary dry evergreen forest away from any large bamboos in June 1993. BSW: One in riverside semi-evergreen forest along the Xe Pian downstream of Ban Houayko in April 1995.

There is no evidence of a change in status: although it was described as rare at Lo-Tiao (Delacour and Greenway 1940), Delacour and Jabouille (1940) recorded it throughout Laos. It was collected from Attapu Province (Oustalet 1899-1903), Phongsali (Bangs and van Tyne 1931) and the Bolaven Plateau (Engelbach 1932).

The highest record was at about $1,000 \mathrm{~m}$ in DHS. It did not habitually join mixed-species flocks. It had a preference for a tall bamboo which only grew under the forest canopy. Birds could be found daily in at least three areas where this bamboo was abundant (Houay Tapkua; XP; Nam Ao, NK; Phou Hinho, PXH), but were found markedly less frequently in other areas, where bamboo was less abundant. The species was not recorded from extensive bamboo at TMF where the closely related Bamboo Woodpecker G. viridis was common; these two species have not been found to overlap in range in Laos.

The commonest call of the species resembles closely one of those of Bay Woodpecker Blythipicus pyrrhotis, so only sight records were used to assess the species's status.

\section{Red-vented Barbet Megalaima lagrandieri (formerly Globally Near-Threatened)}

NK: Common in 1995 throughout most of the surveyed forest areas in and around the NBCA, including the Nam Ao forest. Present although not common in May 1995 in the Nadi limestone area where Great Barbet $M$. virens was common. NTX: Common in the Nam Kwai area in January and February 1994 and in evergreen forest and scrub along the Ban Nahoua logging road including the logging camp area in April 1996. NNT: The commonest barbet in many forested habitats during 1994-1996, and occurred up to at least 1,500 m (although it 
was scarce above 1,00o m where Great Barbet was common). NP: Common in the pine/semi-evergreen mosaic in all survey years. One occupied nest-hole found in a small patch of dry dipterocarp forest amongst pines near Nam Leuk on 1 May 1994. KML: Present in February 1996 in the north-eastern area adjoining NP. HNN: Present at both the Houay Clocc and Houay Talee sites in January 1996. PXH: Common in April 1993 in forested habitats at all altitudes (200-500 m). XBN: Heard once on Phou Thauw (700 m) in July 1994. XS: Frequent to common on the slopes of Phou Ajol below 1,400 m, occasional above this altitude; Great Barbet was not recorded. PXT: Present in March 1996 on a few of the higher hills (300-600 m) supporting semi-evergreen forest. XNN: Frequent in forest on the Bolaven Plateau in February-April 1995. DHS: Common in primary and degraded forest above 1,000 $\mathrm{m}$ on the Bolaven Plateau in June 1993; unrecorded in the lowlands in May 1993, but possibly overlooked, since it was common at some localities there in February 1996. XP: One along the Xe Khampho river (100 m) on 5 March 1993. SMK: Heard from the Cambodian side of the Mekong in the Ban Hangkhon area on 1 and 3 May 1996.

The species was known from a wide area of Central and South Laos; it was common in forested areas of the Bolaven Plateau (Engelbach 1932) and recorded from Ban Nape (Delacour 1929) but only once from Tranninh (David-Beaulieu 1944). The discovery of its continuing widespread distribution in Laos, even in degraded forests, fully supports its recent removal from the list of NearThreatened birds. It appears to be similarly widespread in Vietnam, where it has been recorded between 50 and $1,900 \mathrm{~m}$ from primary, logged and secondary evergreen forest (Robson et al. 1989, 1993a).

\section{Great Hornbill Buceros bicornis At Risk in Thailand}

PDD: One over the Nam Ou, c. $5 \mathrm{~km}$ west of its confluence with the Nam Khang (just outside PDD) in May 1995. NK: Along the Nam An, 1-7 birds were regularly seen at its mouth and up to $4 \mathrm{~km}$ upstream; a primary feather was found along the Nam Kading about $9 \mathrm{~km}$ (straight line) upstream from the Nam An mouth. All records March-April 1995. NTX: Four over Nam Kwai in late January 1994. NNT: A party of up to 19 on several days in January 1994 around the middle Nam Xot, a party of two near the end of the Ban Navang logging road in April 1994 and a single at 1,300 $\mathrm{m}$ in the Houay Morrow valley in April 1994. Remains were seen along the upper Nam Xot and near the Houay Apa. In 1996, along the Ban Navang logging road, singles were recorded on fewer than a third of days during April-May, with one record of two; the species was markedly less frequent than was Rufous-necked Hornbill. NP: Trophy feathers, heads or casques were seen in several villages, but no live birds were seen in any of the survey years. HNN: Two, probably the same birds in each case, were seen on 30 December and 3-4 January at the Houay Clocc site. Also recorded on the 7 and 8 January at the Houay Talee site, all records probably from a single group of four or more birds. XBN: Two in the Central Hills at the Houay Nan site, July 1994. DHS: A party of at least three at $500 \mathrm{~m}$ on the slopes above Ban Nongkhe on 14 February 1996, with six there next day. Scapular feathers were found at a site where hunters had plucked birds at the foot of the slopes near Houay Takit. BSW: Two old skulls in Ban Khuang-Gnai, on the Bolaven Plateau, in April 1995. 
XP: Local and rare in 1992-1993 (fewer than ten records in total, with the largest flock being four) in primary semi-evergreen forest.

No site has been found to support large numbers. This suggests that the species has declined greatly. Engelbach (1932) described it as common in wellwooded areas of South Laos, particularly in hills and mountains. It was also considered common in the Upper Mekong and Louangphabang Provinces (Delacour and Greenway 1940), in Tranninh, where it was less montane than were the other large hornbills (David-Beaulieu 1944) and, by implication, around Ban Nape and Nam Theun (Delacour 1929). It was, however, considered rare in Savannakhet Province (David-Beaulieu 1949-1950), occurring in tall forest or even in fruiting trees among cleared forest at Xe Banghiang. Although DavidBeaulieu does not state this explicitly, it seems from his account that most of his observations in forest in Savannakhet Province were in deciduous areas rather than in the dense evergreen forest favoured by hornbills; this may explain his categorisation of them as rare.

Several heads and casques were seen as trophies in villages around NK, NTX, NNT, NP, XBN and BSW, and for sale in Vientiane market.

\section{Brown Hornbill Anorrhinus tickellii Globally Near-Threatened}

PDD: One heard $2 \mathrm{~km}$ south-east of Ban Muanghat-Hin on 26 March 1996. A flock of at least five, over the Nam Ou, some $5 \mathrm{~km}$ west of its confluence with the Nam Khang (just outside PDD) in May 1995. NK: Three groups at widely scattered locations within the main NBCA forests. One flock in the Nam Ao forest. Heard once in a stream valley within the Nadi limestone area. Records from February to May 1995. NTX: Groups encountered commonly in the Nam Kwai area in January and February 1994. Heard daily from the logging camp. A group of five seen in riverine dry evergreen forest along the upper Nam Cham on 13 May 1996. NNT: Seen throughout in the 1994-1996 surveys in dry evergreen forest, up to at least $1,200 \mathrm{~m}$. Flocks of $20-30$ were frequent and several large parties were even seen on the heavily hunted slopes around Ban Nakadok. On the Ban Navang logging road several flocks of up to ten birds were seen daily along an $8 \mathrm{~km}$ stretch of road. NP: In 1994 and 1995 the species was locally common in the least disturbed areas of pine/semi-evergreen forest mosaic, with 1-3 flocks seen daily in such areas. They were not found in the heavily degraded central portion of the plateau. Flocks were generally smaller than those encountered in NNT. In February 1996 only one group was encountered, in the headwaters of the Nam Malou. HNN: Recorded daily at the Houay Clocc site in January 1996. Records all probably came from one mobile and sometimes fragmented group of at least 13 birds. PXH: Two encounters in April 1993 on Phou Xang He. XBN: A flock of at least 10 in the Central Hills and a group of over 30 at c. $700 \mathrm{~m}$ on Phou Thauw in June and July 1994. Other: One along the Nam Ngay, Phongsali Province, c. 5 km west of Ban Ngay-Tai, 26 March 1996. A group around Pha Khok to the west of the Nam Mouan in March 1995.

Recent records are widespread from dry evergreen forest, with the highest encounter rates in NNT, although the species has declined on the Bolaven Plateau (where there are no recent records) and possibly elsewhere. Formerly it was common but shy on the Bolaven Plateau (Engelbach 1932), scarce throughout 
Tranninh at low and middle altitudes (David-Beaulieu 1944), numerous near Ban Nape (Delacour 1929), fairly numerous at Lo-Tiao (Delacour and Greenway 1940) and recorded from Nam Mo (Oustalet 1899-1903), Ban Muangyo (Bangs and van Tyne 1931) and Nakay (Dickinson 1970a).

Birds mixed freely with Oriental Pied Hornbills Anthracoceros albirostris and douc langurs Pygathrix nemaeus at two sites. Feathers from hunted birds were found frequently across the Nakay Plateau, and dead birds themselves were seen for sale in several settlements on the Nakay Plateau and in Ban Lak 20.

\section{Rufous-necked Hornbill Aceros nipalensis Globally Threatened}

PDD: Two flew across the Nam La over scrub and grassland from one forested ridge (at $900 \mathrm{~m}$ ) south to another (at $1,100 \mathrm{~m}$ ) on the 20 March 1996. NTX: Remains found in forest (G. B. Schaller verbally 1995). NNT: Common in April 1994 (1-4 groups daily) above about 1,00o $\mathrm{m}$ in dry evergreen forest and Fokienia forest. One flying across the Nam Pheo valley probably emerged from forest at around $700 \mathrm{~m}$. A pair and a lone female along the Ban Navang logging road, 1617 March 1995. Regularly recorded every 2-3 days during January-February and April-May 1996 in the same area, with up to five birds audible from a single point during the former period.

The species was previously collected much less often than other hornbills and may always have been local, presumably because of its altitudinal distribution. David-Beaulieu (1944) considered it to be rather rare throughout Indochina. He found groups commonly throughout Tranninh, echoing Delacour and Jabouille's (1927) reports. They were found especially in mountainous regions.

Birds were mostly in groups of up to five in fruiting trees. Males (and perhaps females) called often. They were easily approachable and many hunted remains were found along paths and at campsites in the Central Mountains of NNT.

\section{Wreathed Hornbill Aceros undulatus At Risk in Thailand}

PDD: One over a gorge in forest along the Nam Ou, north of Ban Hat Xa, just outside PDD, on 19 March 1996. NK: At least 60 around the mouth of the Nam An, and small numbers (up to three parties per day, regularly of 1-3 birds) in and over forest elsewhere in the NBCA, including the Nam Ao forest area where birds were seen flying from and towards the Nadi limestone area. Records from January to April 1995. NTX: A flock of 30-40 birds in January 1995 (G.B. Schaller verbally 1995). NNT: Three sightings in 1994 of 1-2 at 650-700 m. In January 1996, a party of $4-7$ seen along the Ban Navang logging road. NP: Two singles on the Nakay Plateau in 1995. In February 1996, large hornbills (all those identified were Wreathed) were seen on all days at sites on the southern edge of the plateau and from the Nam Thon area west of the Plateau; most of those seen were flying (in both directions) between NP and the KML area. Most groups were of 1-3 although one of 10-11 was seen. KML: At least one pair and probably several other birds were found in an extensive area of tall forest in May 1995. In February 1996, large hornbills (all those identified were Wreathed) were seen on every day of the survey of the Khuadhin area. See also the account for NP. HNN: A pair in a fruiting strangler fig at the Houay Clocc site and a male seen flying 
over the southern tip of the reserve in January 1996. PXH: One pair on Phou Hinho; calls and wingbeats of large hornbills were heard once on Phou Xang He and twice on Phou Hinho (April 1993). XBN: 2-4 seen daily in the Central Hills (probably only two groups involved); one associated with a large flock of Oriental Pied Hornbills in a fruiting tree in degraded riverside habitat close to Ban Konglu; two at c. $700 \mathrm{~m}$ on Phou Thauw. All records in May-June 1994. DHS: Flocks of up to 24 on several days around Ban Nongkhe $(200-400 \mathrm{~m}$ ) in May 1993; less common (found only once every few days) in other parts in May 1993, and occasional on the plateau in June 1993. In February 1996 large hornbills (including those identified to species), were recorded almost daily in the upper Houay Bangliang valley (with a maximum group size of 13) and markedly less often (0.3-0.6 encounters per observer-day) in the Houay Takit, Ban Houay Phoung, middle Houay Namphak and Ban Nongpop sectors. Judging from the ratio (2:14) of Great to Wreathed Hornbills amongst the birds identified, it is likely that most of those unidentified were also Wreathed. BSW: Frequent sightings of 1-2 in semi-evergreen forest at $300-400 \mathrm{~m}$ in the vicinity of the Xe Pian river in April 1995. XP: Frequent in semi-evergreen forest especially on higher ground around Houay Tapkua, where flocks of up to 21 were seen in March 1993. Small parties frequently flew over the paddies north of the area, heading to or from the lowlands of DHS, during November 1992-March 1993. Other: One seen around Pha Khok and large hornbills were heard in forest around karst to the east of Ban Chomthong in March 1995.

This species has apparently declined. Although it was quite frequent in Upper Mekong Province (Delacour and Greenway 1940) and it was generally the commonest large hornbill throughout Tranninh (David-Beaulieu 1944), it was the rarest hornbill in Savannakhet Province, with only one record in several years (David-Beaulieu 1949-1950; see discussion above under Great Hornbill). It was very common on the Bolaven Plateau and its slopes (Engelbach 1932).

Recently at DHS, the highest encounter rates were in slope forest, which probably experiences least hunting and has been least heavily logged. There were no records of large hornbills from the sector north of Ban Nabon, apparently the most heavily hunted and heavily logged sector visited and also the most remote from the slope forests. At XBN none was seen in apparently suitable lowland forest at the Houay Sadam site in 1994, and local people said that, although many years ago large hornbills were common in the lowlands, they were now found in XBN only in the mountains.

Bills of this species were occasionally seen as trophies but markedly less frequently than were those of Great, perhaps because of the lack of a casque.

\section{Blyth's Kingfisher Alcedo hercules Globally Threatened}

PDD: Four records (1-2 birds) on the Nam Sin, probably representing 2-3 pairs; two of the records were from areas predominantly of scrub, 21-22 March 1996. NK: Frequent sightings along the Nam Ao (January 1995) were clustered into two areas, suggesting two breeding territories. A provisional sighting of one bird on the Houay Basong. NTX: In 1994 one bird was seen on several occasions on the Nam Kwai. In April and May 1996 we had the following records: Nam Pan Noy, one bird caught in a net; Nam Cham, three records of singles, probably 
representing one pair, one in an area of predominantly scrub; Nam Heung, three records of two singles and a two, probably representing two pairs, one in an area predominantly of scrub; Houay Be, three records of two singles and a two, probably representing two pairs. NNT: In 1994, birds were seen on the Nam Pheo (two singles and a group of two along a $10 \mathrm{~km}$ stretch and another two at a locality further upstream). NP: In 1994, birds were seen on the Nam Mon (X). In 1995 a pair occupied the Nam Xot well above Ban Namxot and one pair and a single (perhaps a transient) lived on its tributary the Nam Mon. Of seven smaller streams surveyed, Blyth's Kingfisher was confirmed on three, Nam Yang, Houay Maloua and Nam Malou, with an unconfirmed sighting on the Nam Mon (Y). Extrapolating to cover the unsurveyed small streams, the Nakay Plateau probably supports at least 12 pairs. XNN: One near Ban Nam Tang $(880 \mathrm{~m})$ and one other unconfirmed sighting at about $800 \mathrm{~m}$ in March 1995. DHS: Up to two in February 1996 at $280 \mathrm{~m}$ around the Houay Namphak-Houay Nyat confluence ( $5 \mathrm{~km}$ east of Ban Nongkhe) and along the Houay Namphak up to $1 \mathrm{~km}$ upstream and the Houay Nyat up to $2 \mathrm{~km}$ upstream. Believed to be a single pair. Not found along the next $12 \mathrm{~km}$ of the Houay Namphak downstream. Only a few other stretches of river within the reserve may be suitable. Other: One on a forested stream of unknown name, about $25 \mathrm{~km}$ west-north-west of Phongsali town, Phongsali Province, 24 March 1996.

Recent Lao records come from a much wider area than do historical ones. Singles were collected at Nam Mo (Oustalet 1899-1903) and Ban Muangyo (Bangs and van Tyne 1931). David-Beaulieu (1944) stated that on certain rivers in Tranninh, notably the Nam Neun, it was intermittently common; he also recorded it on smaller rivers.

Recent records were mostly along shallow stony or rocky streams 2-20 m wide on gentle gradients with well-wooded banks, which in most cases shaded the water. None was recorded during many days' fieldwork on wide rivers (over 15-20 m) within NNT, XP, BSW, DHS or on the Nam Kading, nor were they found on streams of appropriate size at 1,000-1,400 $\mathrm{m}$ in NNT or DHS. They may be restricted to perennial shaded streams and small rivers on gentle gradients below $1,000 \mathrm{~m}$. The degree of tolerance to bankside forest degradation is not yet known although areas of scrub appear to be tolerated in the North. Some were paired and engaging in sexual chases in NNT and NP in February-April in 1994 and 1995, where they presumably breed.

\section{Ruddy Kingfisher Halcyon coromanda At Risk in Thailand}

PXH: Singles at Ban Lavay on 10 April 1993 and on Phou Hinho on 17 April 1993.

The species was previously known from Laos only from one in Tranninh on 17 April (David-Beaulieu 1944). The dates of all Lao records fit with passage migrants. The record of the species from southern Champasak in Thewlis et al. (1996: 85) is a typographical error.

\section{Crested Kingfisher Megaceryle lugubris At Risk in Thailand}

PDD: Two on the Nam Ou, Phou Dendin NBCA, March 1992 (Salter 1993). Seven contacts ( 11 birds), all within the reserve, on a $240 \mathrm{~km}$ survey of the Nam Ou 
(500-600 $\mathrm{m}$ ) and one on the only one of its tributaries surveyed, the Nam La, in May 1995. In 1996, three singles on the Nam Ou south of PDD, and seven encounters in PDD of $2-4$ birds, probably representing a total of four pairs. Also two encounters of singles on the Nam Sin probably of 2-3 pairs. Records were from river stretches in scrub and forest areas. PKK: Two daily (November 1994) along the forested Nam Mang valley and one on its lower course, where bankside land was dominated by agriculture and very degraded forest. NK: One pair on the Nam Kading around the mouth of the Nam An in March-April 1995. A pair was resident round the Theun-Hinboun dam site in December 1994-January 1995 but was not recorded in March-April 1995, by which time destruction of the rapids was underway with explosives. NTX: In 1994 there was a resident pair on the Nam Phao around the mouth of the Nam Kwai. From 13 April to 25 May 1996 there were the following records: Nam Pan in scrub, one single; Nam Gnouang in scrub, four singles, probably representing 2-3 pairs; Nam Heung, mainly in stretches of secondary forest and scrub, seventeen encounters of 1-2 birds, probably representing 3-5 pairs; tributary of the Nam Cham in forest, one single; Nam Cham, mainly through scrub, seven singles, probably representing 2-3 pairs. NNT: In 1994 one pair was recorded on the middle Nam Xot, one on the Nam Noy at the edge of NP and five in $10 \mathrm{~km}$ on the shady lower section of the Nam Pheo. In 1995 two singles were seen on the upper Nam Noy. NP: In 1995 several records on the Nam Xot (including two close to Ban Namxot in atypical slow-flowing river habitat) probably all stemmed from a pair centred around Keng Luang (on the Nam Xot). A pair on the Nam Mon (X) was seen once. A single was seen on the Nam Yang upstream of the Nam Mon (Y). In 1994 a pair was also recorded centred around Keng Luang (on the Nam Xot). Other: A single on the Nam Mouan at its confluence with the Nam Chouan in March 1995. In late March 1996, 1-2 on the Nam Ngay and four more between Ban Ngay-Tai and Ban Ngay-Nua.

The species was previously noted widely. Engelbach (1932) met it in South Laos only on the Xe Kong in its mountainous course where it seemed to replace Pied Kingfisher, which predominated in the lowlands. David-Beaulieu (1944) found it commonly throughout the lower rivers of Tranninh but only exceptionally noted it at the altitude of Xiangkhouang $(1,150 \mathrm{~m})$, where it had been recorded by Delacour and Jabouille (1927). Oustalet (1899-1903) and Bourret (1943) both recorded groups of two along the Nam Mo, separated by 50 years. David-Beaulieu (1949-1950) saw it only once in Savannakhet Province, on a tributary of the Xe Pon. Delacour (1929) found it east of Ban Nape, along streams in damp montane forest. Delacour and Greenway (1940) recorded several near Ban Namkeung-Kao.

Individuals seem to roam widely up- and downstream of their main home range (e.g. the Theun-Hinboun dam site birds used over $6 \mathrm{~km}$ of river), meaning that they are sometimes seen in atypical habitat. Most stretches of river regularly used by this species were larger than those supporting Blyth's Kingfisher: the course usually exceeded $10 \mathrm{~m}$ wide, there were many boulders and the fringing forest when present was not tall enough to shade most of the river. Although absent from the slow-flowing rivers on NP, they occurred at the edge where rivers were rockier. If, as seems likely, they need permanently flowing turbulent rivers, they will be restricted to the North and the Annamites. 


\section{Pied Kingfisher Ceryle rudis National Historical Decline}

XP: A total of seven birds within a $5 \mathrm{~km}$ stretch of the $60 \mathrm{~km}$ surveyed of the Xe Kong river (13 March 1993), but not recorded on the other rivers of the reserve despite intensive fieldwork. Along the same stretch, three singles on 4 May 1995 and one on 12 May 1995. The river is over $100 \mathrm{~m}$ wide at this point and flows in many channels around shingle and rocky islands. SMK: On the Mekong south of Pakxe there were the following records: two at Ban Hangkhon during 2-5 December 1995 (J. N. Dymond in litt. 1996), two there on 3 May 1996 and five on 4 May 1996. On 5 May 1996 recorded from north of Don Puay (one), and possibly the same bird seen twice to the north of Ban Houadonxai. Also seen in May 1996 at Don Ngiou (two). Other: Regularly present at Chiang Saen, northern Thailand on the Mekong along the Lao-Thai border (Heath 1996).

The recent records cluster in only five localities, all but one in the southern part of the South. This species appears to have declined. Previously, it was described as: quite frequent on the Mekong around Savannakhet but rarer on the Xe Banghiang river (David-Beaulieu 1949-1950); common on the Mekong in Upper Mekong and Louangphabang Provinces (Delacour and Greenway 1940); present along the Xe Kong river and along the Mekong between Khon and Pakxe but much less common than in Cambodia (Engelbach 1927a, 1932). Delacour (1929) described it as "common throughout"; this may or may not have included the three Lao localities visited, Ban Nape, Nam Theun and Nakay.

\section{Coral-billed Ground-cuckoo Carpococcyx renauldii Globally Near-Threatened}

PKK: Heard once in the Nam Mang valley (November 1994). TMF: Singles heard in February and March 1996 in bamboo-dominated regrowth almost lacking mature trees. None heard during June-July 1996. NK: Recorded in March-April 1995 along the upper Nam An (one), along the Nam An c. $2 \mathrm{~km}$ from the Nam Kading (one), near the Nam Kading between the Nam An mouth and Ban Donme (two), and in the area around Ban Donme (possibly an additional three). Locals reported that it was widespread. Birds heard twice in the Nam Ao area in January were provisionally identified as this species. NTX: At least one seen in wet evergreen forest near Nam Kwai at 600-700 m in late January 1994. Three or possibly more heard almost daily from 13 to 27 April 1996 in dense bamboo and banana areas along the Ban Nahoua logging road. NNT: Singles heard around 1,000 m on 15 April 1994, March 1995 and April-May 1996 in dry evergreen forest of the Central Mountains. Most other areas of the reserve in 1994 were surveyed before the main period of calling. NP: Widespread records in 1994; particularly common around the lower Nam Xot/Nam Mon $(X)$ where at least 12 individuals were calling from several $\mathrm{km}^{2}$ in mid-March. Primary feathers were also found beside a trap-line near Ban Kengcheng (Ban Hang) in 1994. Only four were heard along $28 \mathrm{~km}$ of the Nam On (1-3 April 1994). In 1995, birds were locally common in less degraded forest along the Nam On, Nam Xot, Nam Mon (X) and Nam Theun. In February 1996 calls were heard once in the headwaters of the Houay Kechayer and three birds heard close to the lower Nam Theun. PXH: One heard at 250-300 m in semi-evergreen forest in April 1993 near 
Ban Nalay. This was identified retrospectively, too late for inclusion in Thewlis et al. (1996). XBN: Two seen together in the Central Hills, but none heard during the survey (June-July 1994), which fell outside the main calling period. PXT: One calling on 27 March 1996 from a mosaic of mixed deciduous/semi-evergreen forest. Another was heard in semi-evergreen forest nearby on the same day. DKT: One heard east of Ban Vin-tai on 4 May 1996.

As the species is so skulking it is difficult to assess its status or population trend. It is most easily surveyed by call, the frequency of which varies with season: occasional calls are heard in December-February with high calling rates in March-May. Calling is probably over by June, but this has only been confirmed by revisits at one site, TMF. There are a few historical records: villagers said it was common $20 \mathrm{~km}$ north of Salavan (in the foothills of Muang Taoy area) where a specimen was procured (Engelbach $1927 \mathrm{~b}$ ), and it was found near Ban Ngoun north-east of the plain of Savannakhet (David-Beaulieu 1949-1950) and near Ban Nonghet in Tranninh (Delacour and Jabouille 1927). The species is vulnerable to snaring in the same way as are pheasants. A captive in the Ban Lak 20 hotel was later eaten. One was seen (alive) being transported by air from Salavan to either Vientiane or Savannakhet (Salter 1993).

Almost all records are from wet or dry evergreen forest and occasionally semievergreen forest. Most records come from below $800 \mathrm{~m}$.

\section{Alexandrine Parakeet Psittacula eupatria At Risk in Thailand}

XP: Groups of 1-3 were found occasionally throughout the Northern Zone and frequently on the Xe Kong plains; also present in the Ban Nasenphan area; all are open areas surveyed in 1992-1993 and May 1995. SMK: Two near Khonphapheng Falls (February 1993). Other: One at $800 \mathrm{~m}$ between Ban Paam and Muang Sansai (Attapu Province) on 9 December 1994.

This parakeet has probably declined considerably. The lack of records from PXH, XBN, DHS and PXT is particularly significant as these areas all contain suitable habitat. It was formerly described as "not rare" in Savannakhet Province (David-Beaulieu 1949-1950), very common on the Xe Don plains and present around Pakxe (Engelbach 1932). One was collected near Nong Khai (Robinson and Kloss 1931), on the Thai bank of the Mekong opposite Ban Thadua. This area was visited frequently during 1992-1995, and no wild parakeets of any species were found. Lekagul and Round (1991) also record Alexandrine Parakeet as formerly present on the Thai bank of the Mekong opposite PXT; none was found in PXT during prolonged fieldwork in suitable habitat in 1996.

Most records of this species came from areas of open degraded mixed deciduous forest, although David-Beaulieu (1949-1950) appears to have considered it typical of dry dipterocarp forest.

Parrots are collected from the nest by villagers at XP (e.g. over 4o Red-breasted Parakeet $P$. alexandri nestlings were seen for sale near Senamsai, May 1995) and this may be the main threat to Alexandrine Parakeet. Parakeets, including Alexandrine, are popular pets throughout South and Central Laos and they were often observed being traded along bus routes. All the Lao parakeets are typical of forest edge or open forest, which are the areas most used by people. They may thus be particularly susceptible to hunting and nest-robbery. 


\section{Spot-bellied Eagle-owl Bubo nipalensis Globally Near-Threatened}

PKK: [One bird heard calling at $350 \mathrm{~m}$ on the evening of 11 November 1994.] XNN: [Calls matching the description of this species in Lekagul and Round (1991) and similar to Barred Eagle-owl B. sumatranus were heard at Ban Nam Tang (880 m) on 9 April 1995.]

Historically, David-Beaulieu (1944) heard it once in Tranninh and Delacour and Jabouille (1927) recorded one from Xiangkhouang. Captives have been seen in a Vientiane zoo but their provenance is unknown.

\section{Tawny Fish-owl Ketupa flavipes Globally Near-Threatened}

NP: [One in riverside trees at $550 \mathrm{~m}$ along the Nam Xot above Ban Namxot, in March 1994.] BSW: [One at $300 \mathrm{~m}$ in a stand of tall trees beside the Xe Pian near Ban Houayko.] XP: [One visiting a waterhole in dry dipterocarp forest at $100 \mathrm{~m}$ (Xe Kong plains) on 3 and 6 March 1993. This bird sat for long periods on the bare mud around a pool intermittently through the night.l Other: Feathers found in January 1995 at $500 \mathrm{~m}$ along the Nam Theun $38 \mathrm{~km}$ downstream of the Nam Theun 2 dam site were identified as this species by comparison with material in the NHM on the basis of size and markings.

All but the Nam Theun record are unconfirmed because although birds were clearly Tawny or Buffy Fish Owl K. ketupu by colour, all observers were cautious in judging size when unfamiliar with both species. The only previous records from Laos come from Nam Mat and Nam Neun where the species was very rare (David-Beaulieu 1944).

\section{[Blyth's Frogmouth Batrachostomus affinis At Risk in Thailand}

TMF, HN, NK, NP, PXT, DHS, XP: Commonly or frequently recorded in relation to the amount of nocturnal fieldwork. Also occasionally heard by day. Mainly in semi-evergreen or dry evergreen forest below $600 \mathrm{~m}$, but also recorded from mixed deciduous forest close to semi-evergreen forest at PXT. Other: Heard at Lao Pako (April).

The lack of records from some areas is thought to be due to a lack of familiarity with the calls by some observers. All identifications of this species are provisional; they are based on calls, heard January-June. To our ears, they precisely match Blyth's Frogmouth calls recorded in Marshall (1978); P. D. Round (verbally, after listening to our recordings from South Laos) agrees with our identification. The species has subsequently been recorded from east of the Mekong, in southern Vietnam (Robson 1997).

The wide distribution and use of degraded areas (Lao Pako, TMF and HN) suggest that the species's population in Laos is healthy. Batrachostomus affinis is included in Javan Frogmouth B. javensis by Treesucon and Round (1990), but Sibley and Monroe (1990) restrict javensis to Java (although there seems little justification for this: Wells and Medway 1976, Marshall 1978). Using Sibley and Monroe's classification, $B$. javensis is Globally Near-Threatened and B. affinis is At Risk in Thailand.] 


\section{Pale-capped Pigeon Columba punicea Globally Threatened}

NK: Two on 7 January 1995 on the slopes north of the Nam Kading near Keng Maiha (470 m). XNN: A group of 4-5 individuals on 13-17 April 1995 at Nam Hiang $(850 \mathrm{~m})$.

Historical records in Laos came only from the Xe Kong river, $60 \mathrm{~km}$ south-east of Salavan, where it was rare and localised (Engelbach 1932), although in a previous assessment he described it as common there (Engelbach 1927a).

The XNN birds were in an area of open dry dipterocarp forest around a complex of streams and swamps. There were many fruiting bushes in this area in which the birds were probably feeding, but this was never observed directly. The birds in NK were at a small steep stream in dry evergreen forest and moved slowly up the valley, making brief visits to each pool, perhaps to look for washed-up food items such as seeds. Although the species is suspected to be nomadic (Round 1988), it is notable that the XNN record is from close to Engelbach's. Both groups were confiding, the NK birds being observed within $10 \mathrm{~m}$.

One of the XNN birds was a late-stage juvenile which had largely acquired the pale head-patch. Both the birds in NK were young birds which were only starting to grow some pale feathers on the crown.

\section{Pompadour Green-pigeon Treron pompadora At Risk in Thailand}

TMF: Probably fairly common in habitats derived from semi-evergreen forests. Four or five records (in addition to many other unidentified green-pigeons) during February-June 1996, with largest group size three or four. Other: Two live birds (male and female) seen in Ban Lak 52 market on 4 March 1996 and two shot in 1996 in Vientiane Province came from unknown locations.

These are the only recent records, which strongly suggests that the species has declined, especially as green-pigeons were checked carefully at all sites. Delacour and Jabouille (1940) listed it as occurring throughout Laos. Specific records, of 1-2, come from: Ban Boun-Tai (Bangs and van Tyne 1931); Salavan and Pakxe (Engelbach 1932); Ban T’Woi and Ban Hoi Mak (Robinson and Kloss 1931). In Thailand lowland forest destruction is the principal threat faced by this species (Round 1988). Lowland forest remains plentiful in Laos, although little remains in flat lowland areas, and most of that has been selectively logged; these may be important factors in the decline of this species in Laos.

\section{Yellow-footed Green-pigeon Treron phoenicoptera At Risk in Thailand}

XNN: Two flocks (totalling 15 birds) by the lower Xe Namnoy and adjacent Xe Kong on 19 April 1995. XP: Up to five daily on the Xe Kong plains in March 1993; present in Dong Kalo in February 1993 and eight south of Sayphou Kiou on 5 February 1993. Seen several times in the lower Xe Pian in May 1995, with the largest single flock being over 50 in one tree. A single and a flock of six on the Xe Kong plains on 18-20 September 1996.

The species seems to have contracted in range. It was the commonest greenpigeon in open forest habitats in South Laos (Engelbach 1932) and Savannakhet Province (David-Beaulieu 1949-1950), but unrecorded elsewhere in the country 
(Delacour and Jabouille 1940). This description remains true today in the least disturbed open wooded areas of the South; however, there are no recent records from Central Laos or many lowland areas of the South (including XBN, PXT and DKT). It seems most unlikely that birds still visit large gardens in the centre of Savannakhet town as observed by David-Beaulieu (1949-1950).

Recent records were mainly in denser forest areas within lowland mosaic forest; the species may be restricted to the flat lowlands in Laos.

\section{Yellow-vented Green-pigeon Treron seimundi Globally Near-Threatened}

NK: Seven near Keng Maiha on 28 December 1994. One bird in Ban Kengbit on 4 January 1995 had been shot at a fruiting tree $3 \mathrm{~km}$ to the south. Remains of another were found on the slopes at the northern border of the Nam Hai-Nam Hinboun plain on 28 January 1995. NTX: One on 13 April 1996 at the edge of dry evergreen forest next to the logging camp, with two present the next day and three on 21 April. Two further birds on 21 April frequented forest at the transition of wet and dry evergreen. NNT: Seven or more with at least three Thick-billed Green-pigeons T. curvirostra and one White-bellied Green-pigeon on 10-11 March 1994 in heavily degraded forest along the southern escarpment of the reserve $(400 \mathrm{~m})$, and one $1 \mathrm{~km}$ or so away on the same day. NP: Feathers found on 15 February 1996 close to the lower Nam Theun. HNN: One with two or more green-pigeons in a small tree at $500 \mathrm{~m}$ on 6 January 1996 at the Houay Talee site. Other: Several singles were seen in the Ban Lak 20 market during March 1995 and 1996. At least four were in a fruiting tree in fairly closed forest on the karst area of Sayphou Loyang $(820 \mathrm{~m})$ on 12 May 1995.

There were no previous Lao records (Mlikovsky and Inskipp in prep.), but the species seems to occur regularly in at least the Nam Theun catchment.

\section{White-bellied Green-pigeon Treron sieboldii Globally Near-Threatened}

NNT: Two singles on 10 March 1994 from heavily degraded forest (400 m) on the escarpment slopes along the southern boundary. One was briefly joined by a Yellow-vented Green-Pigeon and the other was with seven Yellow-vented and three Thick-billed Green-Pigeons in a fruiting tree. NP: A provisional record of 1-3 near the lower Nam Xot on 13 March 1994. One along the Nam Mon (X) near the Nam Xot on 6 February 1995. Other: Several singles were seen in the Ban Lak 20 market in early 1995 and in 1996.

There were no previous Lao records (Mlikovsky and Inskipp in prep.).

\section{Green Imperial-pigeon Ducula aenea At Risk in Thailand}

NP: Found widely in small numbers. Flocks of up to five were seen only on the Nam Theun downstream of Nong Nyian in 1994. In 1995 the only records were of a group of three and a single by the Nam Xot. XBN: Heard on a few occasions along the Xe Bang-Nouan at the Houay Sadam site and from Ban Konglu in June 1994. PXT: One flying across the Houay Xan valley, and calls on four occasions from Phou Alang and the Houay Dua valley in March 1996. All records associated with semi-evergreen forest. XNN: Two pairs along the Xe Kong near the mouth of the 
Xe Namnoy in April 1995. DHS: A single and a flock of three flying over Quan Mou in June 1993. No calls heard. Two seen and heard on 9-10 February 1996 at Nong Hou. One heard very close to Ban Houay Phoung on 11 February 1996 and two heard at Nong Bawa, a few kilometres to the west, on a brief visit on the same day. Calls, provisionally identified, heard in logged semi-evergreen forest north of Ban Nongpop on 1 March 1996. BSW: Two near the Xe Pian downstream of Ban Houayko in April 1995. XP: In November 1992-March 1993 several small groups seen daily on the Xe Kong plains, present in Dong Kalo, seen twice in primary semievergreen forest of the Main Block and frequently at its fringe in degraded semievergreen forest (possibly due to easier detection of flying birds). Two flying over secondary regrowth north of Ban Phapho in May 1993. Daily sightings during 712 May 1995 along the Xe Pian of 10-30 birds including flocks of up to 15. DKT: Recorded widely and seen daily in small numbers in May 1996. Near Ban Vin-tai, three confirmed Green and over 23 unidentified imperial-pigeons (presumed to be Green on the basis of altitude and habitat) were recorded on 4 May. Other: Five heard calling on 21 April 1995 along about $5 \mathrm{~km}$ of stream north of Ban Chanto in the Xe Khampho PPA.

This species has probably undergone a major decline. Historically, it was widespread and recorded from Tranninh, although not particularly commonly (David-Beaulieu 1944), frequently in Savannakhet Province (David-Beaulieu 1949-1950), very commonly on the gentle northern slopes of the Bolaven Plateau (no altitude given), the Muang Taoy region and the upper Xe Kong (Engelbach 1932), commonly in all parts visited by Delacour (1929: (i.e. the Ban Nape, Ban Nakay (Nua) and Nam Theun areas), Ban Muangyo (Bangs and van Tyne 1931), Ban Ngoy (Dickinson 1970a) and Ban Manau (Robinson and Kloss 1931).

Recent records are conservative assessments as many unidentifiable overflying Ducula pigeons were seen. The high proportion of Mountain Imperial-pigeon $D$. badia among those identified at sites north of the Bolaven Plateau suggests that the majority of unidentified birds were also Mountain, which was common above $400 \mathrm{~m}$ in most surveyed areas.

Groups exceeded five only along the Xe Pian in XP and in DKT and the total seen per day rarely reached double figures at any site. This suggests that populations were not healthy at any of the sites except DKT, XP and perhaps Xe Khampho PPA.

Records in several areas came mainly from semi-evergreen forest and riverside forest habitat, or relate to birds flying over scrub or forest edge. All recent records came from below $550 \mathrm{~m}$; the altitudes of historical records from Ban Nape may have exceeded this. This bird is a lowland riverine forest specialist in Thailand, where it is now restricted to just three sites on the mainland, owing to clearance, hunting and inundation of lowland river valleys (CCB 1992).

The seasonality of calling is not clear, since few occupied sites have been searched during the rainy season, but it may peak in March-May.

\section{Sarus Crane Grus antigone Globally Near-Threatened}

DHS: A report by villagers of birds seen flying over, October 1992 (Salter 1993) XP: Two adults with a well-grown juvenile on the Xe Kong plains, 5 March 1993. Two at a pool there in March 1989 from where eggs were reportedly taken (Salter 
1993); Cox et al. (1991) saw two in this region in April-May 1992. Breeding reported in Dong Kalo in 1992 (Salter 1993). Two adults shot and two chicks seen in 1995 reportedly came from the Ban Xot area (Padith Vanalatsmy verbally 1995). Another chick was reportedly taken near Ban Xot in July 1996 and a party of four reported near Ban Xot by villagers in July 1996. DKT: Breeding reported in 1995 by villagers in wetlands west of the Mekong, presumably in DKT (E. Briggs verbally 1995). Presence reported at several localities by villagers in DKT in May and August 1996, including one site where attempted breeding had occurred that year. Two were seen in mid-August 1996, $4 \mathrm{~km}$ to the north of Ban Khiam (J. Barzen verbally 1996). Two chicks 4-5 weeks old were seen in Pakse in mid-August 1996 and were said to have come from DKT. The owner also stated that he took two eggs from DKT in 1995. Other: Reports from Savannakhet Province (Salter 1993) in 1987 (egg taken, Nong Louang, bird alive in captivity in Savannakhet town, 1992) and June 1992 (one shot near Ban Kalon-Dong). Two birds in the Vientiane Inter Zoo at Ban Keun were apparently taken as chicks from Champasak.

Sarus Crane numbers have declined greatly and many villagers in South and Central Laos are aware of the bird's recent local extinction (Salter 1993, Barzen 1997). Hunting and collecting of eggs and chicks is presumably the cause. DavidBeaulieu (1949-1950) saw three pairs on drying rivers in the Kong Kok area of Savannakhet, a province where it was reportedly not rare but very localised. Delacour and Jabouille (1931) recorded it on the rivers of the Xe Don, where it was timid; Engelbach (1932) saw groups of 4-5 at pools in open dry dipterocarp forest around Salavan and on the Xe Don plains; they were occasionally kept in the grounds of temples.

\section{Masked Finfoot Heliopais personata Globally Threatened}

BSW: Three singles along the Xe Pian around Ban Houayko, 10-17 April 1995. XP: Two singles on several days on the Xe Pian in early March 1993. Repeated records involving at least five birds during 5-12 May 1995 from two stretches of the Xe Pian downstream of Ban Phonsaat.

There are no previous records from Laos (Mlikovsky and Inskipp in prep.). Occupied stretches of river were wide ( $20 \mathrm{~m}$ or more) and slow-flowing with no emergent vegetation, although the banks had good cover. One bird, in the middle of a river, swam ahead of the boat for some way and only flushed at $20 \mathrm{~m}$, when it flew up onto the bank and hid in the vegetation. Others just walked onto river banks and hid in vegetation rather than flying away; this behaviour has also been observed in peninsular Thailand and may make them more vulnerable to hunting during the dry season. Two of the May 1995 birds seemed to be paired.

There are just three confirmed records from Cambodia, the last being in 1952; there were no confirmed records during recent surveys (Mundkur et al. 1995). There are only two recent records from Vietnam (Robson et al. 1989, Le Xuan Canh et al. 1997).

\section{Wood Snipe Gallinago nemoricola Globally Threatened}

NP: Three singles flushed from dense riverside cover along the Nam Xot on 8 February 1995 and a single individual by the Nam On on 23 February were all seen from boats. All sightings were during the early morning. 
This snipe was only recorded historically in Laos from Tranninh where it was described as an uncommon passage visitor in pairs or singles between October and April (David-Beaulieu 1944). It is presumably a winter visitor to Laos, its confirmed breeding grounds lying in the Himalayas and in central Sichuan, China (Collar et al. 1994).

\section{Great Thick-knee Esacus recurvirostris At Risk in Thailand}

SMK: The species was seen repeatedly, 1993-1996 (I. Baird and Boonhong Mounsouphon verbally 1996), from a small area of the Mekong at Ban Hangkhon in Champasak Province, an area with numerous sandbars and rocky islets. In April-May 1996 a maximum of three was seen there by the authors. One with a nest nearby (contents unrecorded) was captured by a village dog at Ban Hangkhon on 5 June 1996 (I. Baird in litt. 1996).

This species has declined greatly. There are very few records despite extensive searches of suitable habitat on the Mekong. David-Beaulieu (1949-1950) found it a common resident along the Mekong in Savannakhet Province, principally on sandbars including those by Savannakhet town. Engelbach (1932) noted that it visited the Xe Don plains in small numbers between April and June. Robinson and Kloss (1931) found a pair at Ban Huang and a single female at Ban Muangliap both in January, by which time it was already known from the upper Mekong (Oustalet 1898).

Eggs of the species are collected by local people in the Ban Hangkhon area (Boonhong Mounsouphon and I. Baird verbally 1995).

\section{Long-billed Plover Charadrius placidus Globally Near-Threatened}

NK: Two birds present over several days in December 1994-January 1995 on a large island of coarse sand and gravel $2.5 \mathrm{~km}$ downstream of the Theun-Hinboun dam site. Other: One on a gravel bank along the Mekong, $12 \mathrm{~km}$ west of Vientiane, 21 December 1996.

Delacour and Jabouille (1940) listed the species for all Laos, but the few specific records relate to one at Ban Namkeung-Kao (Delacour and Greenway 1940) and to occasional birds in Savannakhet Province (David-Beaulieu 1949-1950). Passage in Savannakhet seemed irregular, with birds appearing mainly in the early dry season as sandbanks were exposed and migration of other species was in progress.

\section{River Lapwing Vanellus duvaucelii National Historical Decline}

PDD: March 1992, six (Salter 1993). A pair and a single on the Nam Ou, within the protected area, May 1995; the river had little suitable habitat and no others were seen in the $150 \mathrm{~km}$ to its mouth. In 1996 on the $\mathrm{Nam} \mathrm{Ou}$, singles south and north of Ban Hat Xa (28 March 1996). TMF: Two showing territorial behaviour on a Mekong sandbank at Paksang on 13 March. One there and two on another sandbank opposite Ban Nasa (1.5 km downstream) on 22 June. Three around Ban Nasa, but none at Paksang itself, on 15 July. Breeding probably unsuccessful. NTX: Eight along a $40 \mathrm{~km}$ stretch of the Nam Gnouang between Ban Sopkhom and Ban Sopchat in May 1996. NK: Nineteen in a $17 \mathrm{~km}$ stretch of river around 
Ban Donme. Twelve birds in the stretch from Keng Maiha to Ban Kengbit in December 1994 were probably the source of records throughout the area in January and February 1995, including: two pairs attempting to breed on the same stretch; four apparently non-breeding birds up the Nam Gnouang, and up to four non-breeding birds along the river upstream of Ban Kengbit. Around 16 birds were in $35 \mathrm{~km}$ of the lower Nam Kading between Keng Itat and the Mekong. One on the Nam Mouan at Ban Sopngom on 23 March. NNT: Two found along the Nam Xot in 1995. Probably no more than four breeding pairs present given the extent of suitable habitat. NP: Found on all wide rivers (Nam Theun, Nam Xot and Nam On). Counts in 1994 totalled 80 birds, and in 1995, 94 birds, perhaps representing 40 breeding pairs. Also 33 on the Nam Theun river, February 1990 (Salter 1993). PXT: Small numbers were recorded along the Mekong in March 1996. The largest group size was four. Summing maximum counts for each section of river gives a total of 21 individuals. The Ban Thakhanxomxua stretch was not surveyed and is likely to support a few more individuals. XNN: Eight groups of two on the Xe Kong between Ban Mixai and the mouth of the Xe Namnoy. XP: In 1993 and 1995, 3-4 groups of two on the lowest $28 \mathrm{~km}$ of the Xe Pian (which lacked many sand- or shingle banks). Along the Xe Kong from the mouth of the Xe Pian to Senamsai (about $60 \mathrm{~km}$ ) nine groups of two and two singles were seen in 1993, with five groups of two and three singles there in May 1995. About ten individuals, including two groups of four, along the Xe Kong during 18-21 September 1996. SMK: On 4 May 1996 at least eight were found in the $2 \mathrm{~km}$ upstream of Ban Hangkhon, possibly representing 3-4 breeding pairs. Territorial aggression was shown by some. One pair was seen at a different location nearby during 2-5 December 1995. Also recorded from Don Xang (one), Ban Houakhamao (two), Ban Boung (one), Don Deng (three) and Don Kho (six on 28 April, eight on 6 May). Other: The Mekong River between Vientiane and Savannakhet Provinces, June 1990, a total of about 100 in flocks of up to 30; seven along $50 \mathrm{~km}$ of the Mekong in Xaignabouli Province, March 1991 (Salter 1993).

The status and conservation needs of this species in Laos south and east of Vientiane is reviewed by Duckworth et al. (1998b). In summary, it remains widespread but both range and numbers have shrunk since the first half of the century. Historically it was described as abundant and ubiquitous in suitable habitat throughout Laos. It was: encountered the length of the Mekong (Oustalet 1898); one of the most commonly collected birds (from seven sites) along the Mekong around Paklai and between Vientiane and Ban Pak-Hinboun (Robinson and Kloss 1931); the commonest riverine bird along the Upper Mekong and in the Louangphabang region (Delacour and Greenway 1940); a ubiquitous breeder on low-altitude rivers in the province of Tranninh, with records up to 1,100 $\mathrm{m}$ (David-Beaulieu 1944); and very common on rivers in the southern four provinces of Laos, and on the Xe Banghiang and the Mekong in Savannakhet Province (Engelbach 1932, David Beaulieu 19491950). Current numbers in the region studied are estimated at 366-713, which may represent $1.5-5 \%$ of the world population. The most significant concentrations in South and Central Laos appear to be in the Nam Theun basin (especially NP, where there may be over 40 pairs), the Xe Kong basin and the Seephandon region. There are scattered recent records from several areas of the North. Only rivers wider than $30 \mathrm{~m}$ appear to be used in Laos. 
Duckworth et al. (1998b) demonstrated that, in the Nam Theun basin, River Lapwing numbers were inversely related to the number of villages along otherwise suitable stretches of river. Human disturbance, probably mainly incidental to activities such as fishing, is thought to reduce River Lapwings in moderately or heavily populated areas. Furthermore, it is possible that many occupied areas are in fact too disturbed for successful breeding and act as demographic sinks, with successfully breeding source populations restricted to more remote areas. Many proposed hydroelectric dams, sited in areas away from heavy human settlement, threaten to make these remote areas unsuitable for River Lapwings, both within the flooded area and where the flow regime is modified downstream. The species may thus be highly threatened in Laos.

A pair on the Nakay Plateau had at least three chicks on 1 March 1995. A pair on the Xe Pian was incubating on 6 March 1993 and one on the Nakay Plateau had four eggs on 3 April 1994. The latest date when intense territorial defence, including dive-bombing of the human intruder, was seen was 28 April; in view of the timing of wet season water-level rises, it is unlikely that breeding occurs much after this.

\section{Grey-headed Lapwing Vanellus cinereus Globally Near-Threatened}

PKK: Six near Ban Nakhay on 1 May 1995. HN: Five flew over on 31 October 1992. NP: A total of 48 on the Nakay Plateau in January 1995 (largest aggregation 14 birds); many suitable areas remained unvisited in the centre of the plateau. The wintering population may well exceed 100. In 1994 we recorded: five on the lower Nam On (2 April); several groups of 1-5 on the degraded central wetlands (January); over 20 near Nong Boua on 9 February; five over the Nam Theun south of Ban Nam Theun (late February); and five along the Nam Theun past the mouth of the Nam Xot (13 March). Thirty-five or more on 5 February 1996 around Nong Boua. Also eight along the Nam Theun river and 30 south of Nong Boua, February 1990 (Salter 1993). DHS: A party of five on 25 February 1996 just south of Ban Nabon. BSW: Two at Nong Houay Soymong, 26 March 1992 (Salter 1993). XP: At least 31 in the agricultural regions of the Northern Zone and eight in the naturally open areas of the Xe Kong plains and Dong Kalo; also recorded March 1989 (Salter 1993). The wintering population in the Northern Zone probably exceeds 50 birds. Other: A single flew downstream at Ban Thadua (20 March 1993); up to four at Ban Thangon reservoir (October-December 1992). Parties of four and three along the Mekong north of Louangphabang on 1o March 1996. Two groups of two on 14 March 1996 on the Nam Ou north of Muang Koa, one on $28 \mathrm{March}$ on the Nam Ou near Ban Hat Xa, a group of 12 along the $\mathrm{Nam} \mathrm{Ou}$ on 27 March 1996. Small numbers (under 30) were recorded at various sites in the Vientiane area in 1989-1991 (Scott and Rose 1989, Perennou et al. 1990, Perennou and Mundkur 1991). Salter (1993) recorded birds at: Nam Sa, Bolikhamxai Province (six, November 1990) and the Mekong River in Xaignabouli Province (two in $50 \mathrm{~km}, 29$ March 1991).

The bird was a regular migrant to Tranninh and between Xiangkhouang and Vientiane, often as isolated individuals in flocks of Red-wattled Lapwings $V$. indicus; a group of 15 was considered exceptional (David-Beaulieu 1944). One was collected at Ban Muangliap (Robinson and Kloss 1931). The species was 
stated to be found throughout Laos (Delacour and Jabouille 1940) although there do not seem to be any primary references to its occurrence in the South.

These are lower numbers than recorded in Vietnam, where Robson et al. (1993a) found it in flocks of up to 130 together in North Annam.

Birds were most often encountered in open areas of dry short grazed turf surrounding shallow muddy pools. Other records include one foraging on riverine gravel upstream of Ban Namxot (7 February 1995, but not present on numerous other days) and three resting on a sandbank on the Nam Theun close to Ban Sopnian. The association with dry paddies and short grassland around villages is likely to put this species at increased hunting risk.

\section{Small Pratincole Glareola lactea At Risk in Thailand}

TMF: Eight on 22 June and a fully fledged juvenile on 15 July on a large Mekong sandbank $1 \mathrm{~km}$ downstream of Ban Nasa. NK: A flock along the Nam Kading $4 \mathrm{~km}$ upstream of Ban Phonsi on a complex of sandbars and bare, seasonal islands numbered 26 in late January 1995 and at least 53 in April 1995. NP: One on the Nam Theun at the confluence with the Nam On on 19 February 1995 was probably only a transient visitor. PXT: Repeated records of a group of up to five along the Mekong between Ban Donkoum and Ban Seula during March 1996. A few may have been overlooked elsewhere in the reserve. XNN: A group of ten on the Xe Kong near the mouth of the Xe Namnoy (19 April 1995). SMK: there were 8o-150 around the Khonphapheng Falls (4-7 February 1993). Two around Ban Hangkhon during 2-5 December 1995 (J. N. Dymond in litt. 1996) and a minimum of 53 in late April/early May 1996. Elsewhere, working from south to north, recorded in April-May 1996 as follows: small islands west of Don Loppadi (at least three); north end of Don Tan (four); 41 on small islands north of Don Dong; islands near Ban Houakhamao (six); small islands between Don Het and Don Koy (at least 23); Ban Na on Don Nangloy (77); islands north of Don Puay (91); Ban Boungbao (three); north of Ban Houadonxai (25); Ban Houaymanpa (40); Ban Xeng (four); south end of Don Deng (50); north end of Don Deng (120); Don Ngiou (at least 25); Don Pong (five); Don Kho (at least 100 on 28 April); Don Che/Don Chat (two). XP: 145 (at least) along the Xe Kong river between the Xe Pian and Senamsai (13 March 1993); two counts of 50-100 along this stretch of the Xe Kong in May 1995. Other: Found widely on the Mekong, eight at Savannakhet town (24 March 1993), up to 60 in Vientiane (November 1992, April 1993, February and December 1994, February 1995, April 1996). On 10 April 1996 1213 were seen on a sandbar by Ban Thadua, after similar numbers there on 17 March 1996. A single on the Mekong upriver of Louangphabang on 10 March 1996. Six along $50 \mathrm{~km}$ of the Mekong in Xaignabouli Province in March 1991 (Salter 1993).

Previous records, like recent ones, come from wide rivers: the bird bred abundantly in the Mekong in Savannakhet Province and in the lower reaches of the Xe Banghiang (David-Beaulieu 1949-1950); although very common on the Xe Kong, birds disappeared in the rainy season (Engelbach 1932); a large group was seen on the Mekong, $30 \mathrm{~km}$ west of Louangphabang (Delacour and Greenway 1940); it was widely recorded around rapids on the upper Mekong (Oustalet 1898); birds were collected at Nong Khai (opposite Ban Thadua on the Thai bank), Ban 
Pak Tung and Ban Hua Chang (Robinson and Kloss 1931) and one was found in Tranninh, at $\mathbf{1 , 1 5 0} \mathrm{m}$ at a lake north-west of Xiangkhouang (David-Beaulieu 1944).

The species is still common in many areas, although there were relatively few on the Mekong around Louangphabang and along the Xe Kong. Recent records in Laos are mainly from the Mekong and the lower, wider stretches of the Nam Kading and Xe Kong. The species seems restricted in Laos to sparsely vegetated or bare sandbars, shingle banks and rocky islands along the courses of major rivers. Birds in Vientiane were suspected to be breeding in such habitat (distraction display was given) in April 1993, and copulation was observed in December 1994. Much of the Mekong north of PXT has yet to be searched. Flocks of 50 or more are still quite widely recorded, especially in the South where there is no evidence for a decline in numbers or high vulnerability to disturbance; large numbers occur close some towns and villages. Records from March to early May 1996 totalled 695 individuals along the Mekong from the north end of PXT to the Cambodian border $(192 \mathrm{~km})$, assuming no movement between localities over this period. The total population along this stretch must be considerably higher, since many suitable sites, especially in the Seephandon area, were not searched. Even in areas searched, the species can be hard to detect, being small and well camouflaged.

\section{Indian Skimmer Rynchops albicollis Globally Threatened}

There are no recent records, yet historically the species was sometimes seen in small groups along the Mekong from Pakxe, south into Cambodia, with records between January and March (Engelbach 1929, 1932). It was previously considered common in this stretch, but rarer on the Mekong north of Pakxe (Oustalet 1898).

\section{River Tern Sterna aurantia At Risk in Thailand}

XP: Three presumed pairs and a single on a $60 \mathrm{~km}$ stretch of the Xe Kong river, 13 March 1993; 2-4 along the Xe Kong in May 1995 included one which ventured occasionally up the lowest reaches of the Xe Pian. SMK: Salter (1993) listed one record from Khonphapheng Falls: this in fact was an accidental reference to the 1993 provisional record of the next species. However, there are subsequent confirmed records from the same general area. Two were seen near Ban Hangkhon during 2-5 December 1995 (J. N. Dymond in litt. 1996) and up to to (including at least two juveniles) during 29 April-5 May 1996; there are reportedly 6-8 pairs which nest close to this village and leave when the water levels rise in mid-May (I. Baird in litt. 1996). One was seen from Ban Samkhang on 4 March 1996. Elsewhere along the Mekong in Champasak Province during April-May 1996, three singles and a pair from Don Tan to Ban Donhet (probably two pairs involved), from Ban Mounlapamok to Don Puay (two singles and one adult with an immature), at Don Ngiou (one bird) and Don Kho (two adults feeding two fully fledged juveniles). Other: Recorded from the Mekong at Xaignabouli Province, North Laos, March 1991 (two in $50 \mathrm{~km}$ ) by Salter (1993). One along the Mekong $9 \mathrm{~km}$ upstream of Vientiane airport, North Laos, on 21 December 1996 (P. Davidson in litt.). 
Records from the Mekong in Champasak in 1996 suggest an estimated 10-30 breeding pairs, with others known to occur on the lower Xe Kong. Few searches have been conducted along the Mekong north of PXT.

Previously the species was much more numerous, being quite common on the Mekong downstream from Pakxe and occasional on the Xe Don river, its tributaries and even on the Bolaven Plateau (Engelbach 1927a, 1932). It was an extremely common breeder on the Mekong in Savannakhet Province, although rarely was seen away from this river, even up the Xe Banghiang, making the record of one at a lake in Tranninh all the more odd (David-Beaulieu 1944, 1949-1950). It was also common at Paklay and on the Mekong between Ban Paksi and Savannakhet (Bangs and van Tyne 1931) and also on that river throughout Upper Mekong and Louangphabang Provinces (Delacour and Greenway 1940). Birds were collected from Paklay, Ban Pakmet, Hoi King and Ban Pak-Hinboun (Robinson and Kloss 1931). Kerr (1933) reported two species of tern breeding commonly on sandbanks in large rivers between Phou Bia and the Mekong in March 1932; it seems likely that River Tern was one of these species.

Birds often seemed almost oblivious of human presence (David-Beaulieu 19491950), but it seems likely that the major decline in Laos is due to excessive human disturbance on sandbars. People in Ban Hangkhon reportedly do not kill the bird, because they are associated with spirits of people who have died in the river (Baird and Mounsouphom 1994).

\section{Black-bellied Tern Sterna acuticauda Globally Threatened}

SMK: [One at Khonphapheng Falls, 6 February 1993]. Other: One recent undated record from Chiang Saen, northern Thailand, was on the Mekong along the LaoThai border. The species was considered a vagrant at this site (Treesucon and Chance in Round 1995).

This tern has declined drastically, having been commonest in the South and Centre: in Savannakhet Province, it bred in large colonies (which outnumbered River Tern) and was more regular there than in Tranninh, although even there it was a common rainy-season visitor to pools on the Plain of Jars and one was taken at Xiangkhouang (David-Beaulieu 1944, 1949-1950). It was common on the Mekong in South Laos (Delacour and Jabouille 1931, Engelbach 1932). Robinson and Kloss (1931) collected birds between Ban Muangliap and Xieng Khan, at Ban Yoi Hai, Ban Hua Chang and, in February, four at Nong Khai. We have not confirmed the species despite many visits to several of the historical localities over four years. Kerr (1933) reported two species of tern breeding commonly on sandbanks in large rivers between Phou Bia and the Mekong in March 1932; it seems likely that Black-bellied Tern was one of these species.

It was even more confiding to human activity than was River Tern (David-Beaulieu 1949-1950).

\section{Little Tern Sterna albifrons National Historical Decline}

SMK: A pair, probably breeding, near the north tip of Don Kho, on 28 April and 6 May 1996.

This tern was once as common as Black-bellied Tern along the Mekong in 
South Laos (Engelbach 1932) and has clearly declined greatly. It is notoriously sensitive to disturbance of its breeding areas in at least some other parts of its range (e.g. Lloyd et al. 1991).

\section{Jerdon's Baza Aviceda jerdoni Globally Near-Threatened}

PKK: One on 28 October 1994 at $500 \mathrm{~m}$ in an open area with pine trees near Nam Leuk. HN: One on I November 1992. NP: Three singles in February-March 1995 along the Nam On and one there on 5 January 1994. SMK: Singles, possibly different, on 3 and 5 December 1995 near Ban Hangkhon, Champasak Province (J. N. Dymond in litt. 1996).

The only previous record is of one in Ban Thateng in December 1931 (Engelbach 1932). The eight recent records were from cleared areas or degraded forest near clearings. Judging from its status in Thailand (Lekagul and Round 1991), birds in Laos could be either non-breeding migrants or residents; there is as yet no evidence for breeding in Laos.

\section{Black-eared Kite Milvus lineatus National Historical Decline}

HN: [Singles flew south on 18 and 19 October 1992.] NNT: [One on 18 March 1994 over degraded forest along Route 8 close to Ban Nape.] NP: [Two on 3 April 1994 close to dusk perched in trees on the edge of a large open area close to Ban Sop-On.] Other: One confirmed as M. lineatus was captive at Wat Simuang temple in Vientiane in December 1995; it appeared to have been captured recently.

These few records, most of which were not certainly differentiated from Black Kite $M$. migrans, suggest that birds are much rarer than formerly. Black-eared Kite was regular in winter on the plains of Tranninh (but not abundant), in Savannakhet Province (David-Beaulieu 1944, 1949-1950) and in South Laos (Engelbach 1932). It even occurred around towns (Delacour and Jabouille 1931). The lack of a single recent record from $\mathrm{XP}$, where many days were spent in suitable habitat in winter 1992-1993, is a stark contrast to the historical records, and a surprise as it remains a common winter visitor to Thailand (Lekagul and Round 1991).

Black Kite seems never to have been recorded from Laos, which seems surprising as it was found (as M. govinda) in northern Cambodia (Oustalet 1899-1903) and still breeds in Thailand (Lekagul and Round 1991); David-Beaulieu (19491950), however, expressed doubt that he could separate the two species in the field, implying that Black might have been overlooked.

The October, March and April records probably involved passage birds; unusually high numbers of Grey-faced Buzzards Butastur indicus were also present.

Brahminy Kite Haliastur indus National Historical Decline

DKT: At least six along the Nam Lepou downstream of Ban Kanluang on 14 August 1996. SMK: Three singles in 1993, from Ban Samkhang (3 February), Don Khong (29 January) and Khonphapeng Falls (6 February). One adult recorded 
regularly during late April-early May 1996 around Ban Hangkhon, an immature there on 3 May and an adult near Somphamit waterfall on 1 May. Up to five were seen at Ban Hangkhon during 2-5 December 1995 (J. N. Dymond in litt. 1996). Elsewhere, birds were recorded in April-May 1996 at Don Tan (one adult), near the mouth of Nam Lepou (one immature), around islands near Ban Houakhamao (one adult), near Ban Donhet (two or more adults, one immature), near Don Koy (one adult).

In view of this bird's association with rivers and the time we spent in the riverside towns of Vientiane, Savannakhet and Pakxe for the above records, the species must now be very scarce in Laos, and apparently regular only in the Seephandon region. By contrast, it once bred very commonly along the Mekong and $\mathrm{Xe}$ Banghiang rivers in Savannakhet Province, venturing into villages in the interior of this province (David-Beaulieu 1949-1950), and was common along the rivers of South Laos (Engelbach 1932). Delacour (1929) described it as "common throughout", although this may or may not include the three Lao study sites, Ban Nape, Nam Theun and Ban Nakay (Nua). However, in five years in Tranninh, David-Beaulieu (1944) only saw it three times, always on the plains. The species has declined greatly in some other South-East Asian countries (Lekagul and Round 1991, van Balen et al. 1993), although healthy populations remain in parts of Cambodia (Scott 1992).

\section{White-bellied Fish-eagle Haliaeetus leucogaster National Historical Decline}

There are no recent records. It has evidently declined as it was formerly not rare by the Mekong near Khonphapheng Falls and from there to the border with Cambodia (Engelbach 1932). Delacour and Jabouille (1940) listed it for the whole of Laos, although there seem to be no other primary published records.

\section{Lesser Fish-eagle Ichthyophaga humilis Globally Near-Threatened}

PDD: Four, at three sites (and three single unidentified fish-eagles) on forested stretches of the Nam Ou, within the protected area in May 1995. Salter's (1993) record of one on the Nam Ou, March 1992, gave no precise locality. In 1996 along forested stretches of the $\mathrm{Nam} \mathrm{Ou}$, one on 28 March north of Ban Hat Xa, and one on 27 March north of Ban Muanghat-Hin. PKK: [Two single unidentified fish-eagles beside the Nam Mang (November 1994).] NNT: There were records in 1994 probably involving a single pair from the middle reaches of the Nam Xot upstream of the Nakay Plateau; in 1995 one was along the middle reaches of the Nam Noy on 28 February. NP: Records from both 1994 and 1995, each involving 1-2 adults and $0-1$ juvenile birds, suggest four occupied territories. These were (i) around the Nam Theun 2 dam site on the Nam Theun, (ii) around the Nam Malou on the Nam Theun, (iii) above Ban Namxot on the Nam Xot, (iv) the upper Nam On. The total number of territories on NP and in adjoining areas of NNT is unlikely to have exceeded 10. One on 17 February 1996 was on the Nam Theun $1 \mathrm{~km}$ from the Nam Theun 2 dam site. HNN: One was over a heavily degraded stretch of the Xe Bangfai on 12 January 1996 at the point where the road from Ban Katok to the Vietnamese border crosses the river. XNN: A single 
over the Xe Namnoy $4 \mathrm{~km}$ downstream of the confluence with the Xe Katam on 12 April 1995. DHS: One immature along the Houay Touay-Gnai on 10 February 1996 about 2 km west of Nong Hou. BSW: In April 1995 one on two days along the Xe Pian near Ban Houayko, and an occupied nest $17 \mathrm{~km}$ downstream. These probably refer to two separate territories. XP: $1-3$ almost daily on the Xe Kong plains around the mouth of the Xe Khampho in March 1993, with one other on the upper reaches of the Houay Tauang in the Main Block during February 1993. During 7-12 May 1995, one was encountered regularly along the Xe Pian $3 \mathrm{~km}$ south of Ban Phonsaat and another seen $5 \mathrm{~km}$ north of that village, but none was seen around the mouth of the Xe Khampho in four observer-days. Other: Birds probably of a pair seen on several occasions near Keng Luang on the Nam Theun in January 1995.

This bird has apparently declined: it was common on almost all low- and middle-altitude rivers in Tranninh (David-Beaulieu 1944) and rather less so on the Xe Banghiang and its tributaries in Central Laos (David-Beaulieu 1949-1950). It is now reduced to a few isolated populations in the least-disturbed drainage basins (Xe Kong, Nam Theun, Nam Ou and perhaps others) between which dispersal may be limited. Each is vulnerable by nature of its small size.

All recent records came from larger forested perennial rivers with at least some slow-flowing reaches. Birds on the Xe Kong and NP rivers appear to use 15$25 \mathrm{~km}$ of river per pair.

\section{Grey-headed Fish-eagle Ichthyophaga ichthyaetus Globally Near-Threatened}

PDD: [Three reported in March 1992 (Salter 1993).] NNT, NP: [Singles (provisionally identified) over the middle Nam Theun (19 March 1995) and around the confluence of the Nam On and Nam Yang (2 April 1994). Also one provisionally on the Nam Theun river, February 1990 (Salter 1993).] XP: A pair displaying around the inflow of the Xe Khampho during March 1993. Two perched on the ground and on a log in the bed of a large, almost dry pool in the north of the Xe Kong plains on 21 April 1995.

This raptor was perhaps less common than Lesser Fish-eagle and has also evidently declined. Historically it was quite rare throughout Indochina (Delacour and Jabouille 1931). One was seen at a lake on the Bolaven Plateau and it was common at certain large pools in the South and in the mountainous reaches of the Xe Kong (Engelbach 1932). Oustalet (1899-1903) recorded singles near Vientiane and on the Xe Don. The historical records of the two fish-eagles need cautious interpretation, as, of the two French residents who published bird observations, one (Engelbach, in the South) never recorded Lesser, while the other (David-Beaulieu, in the Centre and North) never found Grey-headed. It is difficult to see how this could arise considering the relative distribution of the two species today. It is possible that each observer was encountering both species, but naming birds seen in the field by extrapolating from a few shot specimens.

Recent records come from locations and habitats similar to those where Lesser Fish-eagle was recorded. Lao numbers are tiny: at Tonle Sap lake in Cambodia over 100 pairs were estimated in 1996 (Parr et al. 1996); Lesser Fish-eagle has yet to be recorded from Cambodia. 


\section{White-rumped Vulture Gyps bengalensis Globally Near-Threatened}

BSW: [Vultures not identified to species were reported from the (largely cultivated) areas around Ban Hinlat, but not from further north.] XP: Vultures were found mainly over the more open habitats and agricultural areas of the Northern Zone (sporadic records) and daily on the Xe Kong plains. Surprisingly, none was seen over Dong Kalo, in similar habitat to the Xe Kong plains lowland mosaic forest. Flocks of $40-60$ vultures were seen at water buffalo carcasses on the Xe Kong plains in March 1993, with over 40 in the Northern Zone in January 1993. These flocks included all three species, and many White-rumped/Longbilled Vultures were not identified to species. At most 11 White-rumped were positively identified at a single carcass. There were daily sightings of 2-8 on the Xe Kong plains in May 1995. Single birds were over the Main Block of semievergreen forest in December 1992 and January 1993. Two on the Xe Kong plains on 21 September 1996. SMK: At least one in a mixed party of ten vultures at an unidentified carcass on the banks of the Mekong near Ban Hangkhon on 29 April 1996. DKT: One unidentified vulture (possibly this species) was soaring over Nam Lepou on 28 April 1996, and another was seen near Ban Khiam in midAugust 1996. Other: One over the lower Xe Xou on 28 February 1996.

This species has declined greatly, having once occurred throughout Laos but now being restricted to the southern parts of Champasak and Attapu Provinces. It was abundant (and the commonest vulture) in Savannakhet Province and Tranninh (David-Beaulieu 1944, 1949-1950); Delacour and Jabouille (1927) also found it commonly in the areas of Tranninh that they visited. In Champasak and Attapu Provinces, it was common but outnumbered by Red-headed (Engelbach 1932). The species is almost extinct in Thailand (Lekagul and Round 1991) and Vietnam (only one recent record: Le Xuan Canh et al. 1997); it may soon be extinct in Laos.

\section{Long-billed Vulture Gyps indicus Globally Near-Threatened}

BSW: [Possibly present, based on unspecific local reports, as described under White-rumped Vulture.] XP: See comments under White-rumped Vulture. The highest count at a single carcass was ten on the Xe Kong plains in March 1993, and Long-billed was generally less numerous than the other two vultures. Two and a single were seen over the Main Block in January 1993. None was positively identified in 1995. SMK: At least one in a mixed party of ten vultures at an unidentified carcass on the banks of the Mekong near Ban Hangkhon on 29 April 1996. Other: Four over the town of Attapu on 25 January 1993.

The species has declined greatly, having occurred throughout Laos 50 years ago but now being restricted to the southern parts of Champasak and Attapu Provinces. It was abundant in Savannakhet Province and Tranninh, although it was the least frequent of the vultures (David-Beaulieu 1944, 1949-1950). In Champasak and Attapu Provinces it was again the least frequent although still common (Engelbach 1932). It is possibly extinct in Thailand (Lekagul and Round 1991), in Vietnam (no recent records: J. C. Eames verbally 1997) and it may soon be extinct in Laos.

David-Beaulieu (1949-1950) complained of the senseless shooting of vultures by Europeans, but it is unlikely that this alone caused the collapse in populations of all three species. In March 1993 one Long-billed Vulture was shot in our pres- 
ence in XP by a passing wealthy Laotian in an outboard-driven boat, who did not bother to collect the corpse; it seems he shot it for fun.

Red-headed Vulture Sarcogyps calvus Globally Near-Threatened

BSW: [Possibly present, based on unspecific local reports, as described under White-rumped Vulture.] XP: See comments under White-rumped Vulture. The maximum count at a single carcass was ten on the Xe Kong plains in March 1993. Two singles were seen over the Main Block in January 1993. There were daily records of 2-8 over the Xe Kong plains in May 1995. SMK: At least two in a mixed party of ten vultures at an unidentified carcass on the banks of the Mekong near Ban Hangkhon on 29 April 1996. Other: One over the town of Attapu on 25 January 1993; one north of Attapu near the eastern base of the Bolaven Plateau, 23 March 1992 (Salter 1993).

The species has declined greatly, having occurred throughout Laos 50 years ago but now being restricted to the southern parts of Champasak and Attapu Provinces. It was abundant in Savannakhet Province and Tranninh (Delacour and Jabouille 1927, David-Beaulieu 1944, 1949-1950) and in Champasak and Attapu Provinces it was the commonest vulture, even occurring occasionally on the Bolaven Plateau (Engelbach 1932). In Thailand it is now confined to the remotest parts (Lekagul and Round 1991), as it is in Vietnam (Le Xuan Canh et al. 1997; J. C. Eames verbally 1997) and Laos.

\section{Rufous-winged Buzzard Butastur liventer Globally Near-Threatened}

NK: Two by Ban Phonsi (1 April 1995) behaved as if breeding or at least holding territory. PXH: Common in April 1993 ( $1-2$ records of $1-2$ per day) in and to the south of the reserve. XBN: 1-2 near Ban Konglu in June 1994. PXT: One over farmland with many remnant tall trees near Ban Nondinxay on 9 May 1996, some distance outside the reserve boundary. None was seen in several areas of apparently suitable habitat within the reserve. XNN: One at the confluence of the Xe Namnoy with the Xe Kong on 6 May 1995. One near the Xe Namnoy, $4 \mathrm{~km}$ downstream of the Xe Katam confluence on 12 April 1995. XP: Frequent in the Northern Zone and common (with up to three per day) on the Xe Kong plains in 1993. Up to two seen on most days on the Xe Kong plains, May 1995. DKT: One in dry dipterocarp forest south-west of Ban Khiam on 3 May 1996, and 10 singles and one group of two during aerial surveys on 17 August 1996. Other: One in dry dipterocarp forest $20 \mathrm{~km}$ north of Attapu on 7 April 1995. Ones and groups of two seen rarely from roads through suitable habitat in Central and South Laos, during 1992-1996, but never more than two contacts in a day's driving.

There is no evidence for a decline in numbers. Historically, it was relatively common in the open forests of Central Laos (David-Beaulieu 1949-1950) and occurred by the Mekong in Champasak (Engelbach 1932).

Recent records were mainly in dry dipterocarp forest with denser forest patches or in agricultural land with many remaining trees and forest patches.

\section{Greater Spotted Eagle Aquila clanga Globally Threatened}

NP: [Singles in February 1990 (Salter 1993) and March 1994.]

The only confirmed record is of a specimen from the $\mathrm{Xe}$ Banghiang 
(David-Beaulieu 1949-1950); a few other unidentified Aquila eagles in this period might also have been this species.

The 1994 individual, presumably on passage, seemed to roost in trees beside abandoned paddyfields.

\section{Imperial Eagle Aquila heliaca Globally Threatened}

There are no recent records. One was shot in Ban Souy in January 1926 (Delacour and Jabouille 1927). One was taken at Xiangkhouang in December 1941 and many others were observed in Tranninh over five years (David-Beaulieu 1944). An unidentified Aquila eagle on the Nakay Plateau on 9 March 1995 showed features of this species.

White-rumped Falcon Polihierax insignis Globally Near-Threatened

XBN: 1-2 most days at Keng Sung and singles on both days spent around Ban Konglu (May to June 1994). XP: 1-2 most days in Dong Kalo in February 1993 and one on the Xe Kong plains in March 1993. SMK: A shot bird in the possession of a hunter at Don Khong in August 1996 presumably originated from plains nearby.

This species has possibly declined; historically it was a very common breeder in Savannakhet Province and locally widespread around Salavan, but not known from North Laos (Engelbach 1932, Delacour and Jabouille 1940, David-Beaulieu 1949-1950). One was collected in the Kouys area (Oustalet 1899-1903). The lack of records from $\mathrm{PXH}$ is of no significance because little time was spent in suitable habitat.

Almost all records, past and recent, came from dry dipterocarp forest or adjacent narrow strips of riverine forest.

\section{Pied Falconet Microhierax melanoleucos Globally Near-Threatened}

NP: The few records in 1994 were of two singles near Ban Sop-On and three pairs, one each upstream of Ban Kengcheng (Ban Hang) and both up- and downstream of Ban Namxot. In 1995, records came from six sites, which were patchily distributed along the Nam Mon (X), Nam Xot and the Nam Theun either side of the inflow of the Nam Xot. HNN: One in heavily degraded secondary habitat along the Vietnamese border to the south of the reserve in February 1996.

It was "numerous" at Ban Nape (Delacour 1929), but relatively rare in Tranninh, occurring mainly in open forest (David-Beaulieu 1944). There is no firm evidence that the species has declined, although the vague description by Delacour, quoted above, could hardly be applied to the Ban Nape area today.

Most records came from riversides, where birds perched in emergent leafless crowns, with a few from forest-edge clearings close to broadleaved forest types. Repeated trips along favoured stretches of river revealed that birds (as groups of two or three) were very faithful to selected tree clumps, usually emergents. 


\section{Lesser Kestrel Falco naumanni Globally Threatened}

There are no recent records in Laos. It was previously an abundant and regular winter visitor to Tranninh, especially around the Plain of Jars (David-Beaulieu 1944). Although these records seem surprising in view of the status of the species in southern China today (M. Leven verbally 1995), there is no doubt about them as David-Beaulieu collected specimens of both sexes (the identification of which was confirmed by Bourret 1943) and described their natural history.

\section{Oriental Darter Anhinga melanogaster Globally Near-Threatened}

NK: Singles (probably the same bird) were seen over the Nam Kading near Ban Donme on 5 and 8 April 1995. DHS: A single on several dates at Nong Hia in May 1993; seen once over forest $3 \mathrm{~km}$ to the south. No records in February 1996. BSW: [Reported by villagers to visit the Ban Hinlat area during the rainy season; one unconfirmed sighting in May 1995 (T. Roberts verbally 1995).] XP: Three seen repeatedly along the Xe Pian and one on the Xe Kong within the NBCA in May 1995; none was seen during four months of survey in suitable habitat in November 1992-March 1993. Bung Gnai-Kiatngong is listed by Scott (1989) as supporting darters, but this seemingly stemmed from local reports (R. E. Salter verbally 1993).

This species has declined markedly. It was formerly a widely distributed and numerous resident, mostly on low-altitude rivers but occasionally to $1,200 \mathrm{~m}$. It was recorded from Tranninh (David-Beaulieu 1944), Upper Mekong and Louangphabang Provinces (Delacour and Greenway 1940), quite commonly on the Mekong and its tributaries, especially the Xe Banghiang, in Central Laos (David-Beaulieu 1949-1950), and commonly on large rivers in Champasak, Salavan and Attapu Provinces (Engelbach 1932). Bangs and van Tyne (1931) reported it as regular on a journey down the Mekong between Paklay and Savannakhet, and one was collected at Ban Sa Ngao on the Mekong (Robinson and Kloss 1931).

Resident birds have possibly been extirpated from Laos as the dates of most recent records in Laos are suggestive of wet-season visitors (mid-May onwards).

\section{Little Cormorant Phalacrocorax niger National Historical Decline}

SMK: Small cormorants were recorded moving south along the Mekong each evening at Ban Hangkhon during 30 April-4 May 1996. At least 28 Little Cormorants were identified on 1 May, but larger flocks of up to 85 on 3 and 4 May could not be distinguished with certainty from Indian Shag $P$. fuscicollis. DKT: One on the Nam Lepou on 28 and 29 April 1996, 4 km downstream of Ban Kanluang.

The species has probably been declining since the first historical records were made: last century it was common in Xiangkhouang, but scarcer further south in the country (Oustalet 1898). It was not recorded from Xiangkhouang Province by David-Beaulieu (1944), suggesting that a decline was already under way in Laos. Other historical records are: one on the Bolaven Plateau ( $1,000 \mathrm{~m}$; Engelbach 1932); occasional on the Xe Don and its tributaries (Engelbach 1932) and 
exceptionally on lakes bordering the Mekong around Savannakhet (DavidBeaulieu 1949-1950).

The species appears also to have declined in Cambodia to the extent that it is believed to be of special conservation concern there (Scott 1992).

\section{Great Cormorant Phalacrocorax carbo At Risk in Thailand}

There are no recent records. One was recorded from Tranninh (David-Beaulieu 1944). Oustalet (1898) believed that it lived in groups on the Mekong whilst Delacour and Greenway (1940) recorded it the length of the Mekong in the Provinces of Upper Mekong and Louangphabang in at least the period NovemberMarch. Delacour and Jabouille (1940) recorded it throughout Laos. In Thailand it has declined from a common species to an occasional wanderer (Round et al. 1988) whilst in Vietnam there are no recent records (J. C. Eames verbally 1997). A long-term decline may have occurred in Laos as neither Engelbach (1932) nor David-Beaulieu (1949-1950) recorded it on the Mekong in South and Central Laos. Whether it ever bred in Laos will probably never be known.

\section{Grey Heron Ardea cinerea At Risk in Thailand}

NP: Up to five around several pools near Ban Nongboua in February 1994; one at Nong Boua in February 1990 (Salter 1993). PXH: Two at a reservoir near the NBCA on 20 March 1993. PXT: Six together roosting in a tree south of Ban Khantoungxai on 30 March 1996. An unidentified Ardea, probably this species, flew west over the Houay Xan on 28 March 1996. XNN: Small numbers at several sites along the main rivers on the plateau at $800 \mathrm{~m}$ in February-April 1995. BSW: A party of three in trees by the Xe Pian $(300 \mathrm{~m})$ in April 1995. XP: Frequent on wetlands in the Northern Zone, and occasional on the Xe Kong plains during 1992-1993; one near Ban Phonsaat along the Xe Pian on 4 May 1995; two on the Xe Kong on 6 May 1995; also recorded in the NBCA in March 1989 (Salter 1993). Other: Scattered records of under five in the Vientiane area, all in winter (Salter 1993). Two at Pakxan wetlands on 20 December 1994 and five at Ban Thangon reservoir on 30 October 1992. One over Ban Thadua on $17 \mathrm{March} 1996$. Three on the Mekong at Chiang Saen, 11-12 December 1995.

The species still occurs widely in Laos in winter in small numbers, but appears to have declined. Historically it was quite common in South and Central Laos in lowlands and on the Bolaven Plateau (Engelbach 1932, David-Beaulieu 19491950). In the North (Tranninh), occasional passage movements were noted in September and October, but the species was not recorded at other seasons (David-Beaulieu 1944). It was common the length of the Mekong in Upper Mekong and Louangphabang Provinces from November to March (Delacour and Greenway 1940). There was no evidence of breeding during recent surveys in Laos, and historically it is not clear whether it bred in South and Central Laos.

Recent records came predominantly from marshes and pools with fewer birds in riverside areas. Most of the latter were towards the end of the dry season, when many pools and marshes are dry. The two at the Pakxan wetlands flew in at dusk to an area which had been used by many people during the daytime. 


\section{Purple Heron Ardea purpurea At Risk in Thailand}

NP: Up to three on pools near Ban Namtheun, Ban Don and Ban Bo-Tai, in January-March 1994 and February-March 1995. Two at Nong Boua in February 1990 (Salter 1993). PXH: One flew over high, heading north, on the evening of 8 April 1993. XNN: Two regularly at Nong Lom in March-April 1995. DHS: 1-2 on lowland wetlands in May 1993 and singles at pools on 31 January and 15 February 1996. BSW: Three at Nong Houay Soymong on 26 March 1992 (Salter 1993). XP: Frequent on wetlands in the Northern Zone and occasional on the Xe Kong plains in 1992-1993; one along the Xe Pian in May 1995; also recorded there in March 1989 (Salter 1993). SMK: A party of eleven flew over Ban Hangkhon in Champasak Province at dusk on 2 May 1996, moving north. DKT: One northwest of Ban Kadian on 5 May 1996 and one during aerial surveys on 17 August 1996. Other: One at Don Chuan sandbank, Vientiane, on 24 April 1993; Salter (1993) recorded scattered small numbers from the Vientiane area, all in winter.

The species still occurs widely in Laos in winter in small numbers, but appears to have declined. Historically it was quite common in South and Central Laos in lowlands and on the Bolaven Plateau (Engelbach 1932, David-Beaulieu 19491950). In the North (Tranninh), David-Beaulieu (1944) recorded one in October. There was no evidence of breeding during recent surveys in Laos, although there were more records in late April and May than there were of Grey, and historically it is not clear whether or not the species bred in Laos.

Recent records come predominantly from marshes and pools, particularly those retaining dense emergent growth in their centres, with very few birds in riverside areas.

Malayan Night-heron Gorsachius melanolophus (formerly Globally NearThreatened) At Risk in Thailand

PKK: Three singles around the Nam Leuk: one overhead at dusk and two flushed in degraded forest from the floor by day (November 1994). DHS: At least eight (most calling; May 1993) in the middle Houay Namphak, an area of mostly logged semi-evergreen forest, including strips among coffee plantations. BSW: Six individuals calling from degraded semi-evergreen forest along the Xe Pian around Ban Houayko in April 1995. XP: [A single (provisionally identified) flying down the Houay Saoe at dusk, November 1993; two seen and at least six calling birds along the Xe Pian in April-May 1995. SMK: In late April-early May 1996 one calling daily at 17hoo-19hoo or later, and again around dawn, from a small patch of degraded semi-evergreen forest at the edge of Ban Hangkhon, Champasak Province.

Historically there are no records in the primary sources, although it was said to inhabit wooded regions throughout Laos by Delacour and Jabouille (1931, 1940).

Almost all records of this elusive species are of birds calling in the period mid-April-mid-May, presumably the main calling season for the species. At two sites (Ban Nongkhe, DHS; and Xe Kong plains, XP) birds were found calling during May but none was encountered during visits in February-March.

The species's apparent tolerance of degradation at BSW, DHS, PKK and Ban 
Hangkhon is encouraging. However, habitat requirements are too poorly known to suggest that it is not at risk. All records came from below $300 \mathrm{~m}$.

\section{Schrenck's Bittern Ixobrychus eurythmus Globally Near-Threatened}

HN: One at a secluded pool in dry paddy within degraded secondary forest on 25 October 1992. XP: One on a well-vegetated pool in the mixed deciduous forest of the Northern Zone on 11 January 1993.

The species was previously recorded in Laos only by David-Beaulieu (1944), who saw a male in April 1940 at Xiangkhouang. Habitats such as those of the two recent records are abundant in Laos and the species is probably too skulking to be heavily hunted.

\section{Black-headed Ibis Threskiornis melanocephalus Globally Near-Threatened}

There are no recent records and only one (undated) historical record, of a single bird on the Xe Banghiang (David-Beaulieu 1949-1950). King et al. (1975) listed the species for South and Central Laos since it occurred on the boundary between the regions (B. F. King in litt. 1995). Given Engelbach's lack of records, it seems unlikely that it was abundant in South Laos during the 1920s. The lack of recent records is perhaps surprising as birds still occur in Thailand, although the species no longer breeds (Lekagul and Round 1991). In Cambodia it was described as fairly common, and the most frequently seen ibis (Thomas 1964); surveys in 1996 recorded over 260 birds at Tonle Sap lake where it still breeds in very high numbers (Parr et al. 1996).

There are two populations: a resident one in India, Burma and Cambodia, and a migrant population in eastern China which winters in extreme south-eastern China. It is not known to which population the bird recorded in Laos belonged.

\section{White-shouldered Ibis Pseudibis davisoni Globally Threatened}

XP: Singles (probably the same bird) on three days in March 1993 on the Xe Kong plains. Repeated sightings of a party of three along the Xe Pian in the same area, 5-12 May 1995.

This species has undergone a major decline in Laos. It once occurred quite commonly (with many breeding records), including north along the Mekong at least as far Ban Houayxai (Burmese border, $20^{\circ} \mathrm{N}$ ) where several flocks were seen (Oustalet 1898, Delacour and Greenway 1940). It was seen frequently from the Mekong between Louangphabang and Savannakhet (Bangs and van Tyne 1931) and three were collected between Ban Pakmet and Chiang Khan (Robinson and Kloss 1931). It was very common in Central Laos, especially in the lower reaches of the Xe Banghiang (David-Beaulieu 1949-1950) and frequent around the Mekong, Xe Don and (especially) Xe Kong in the South (Engelbach 1932), often in small flocks.

The 1993 bird fed at two pools in open forest on the Xe Kong plains, while the three in 1995 were seen repeatedly along the river shore; almost all pools outside the river channel were probably dry at this time. Large areas of apparently suitable habitat remain on the Nakay Plateau and in the South. However, the paucity 
of sightings suggests that, even if the species does still breed, extinction in Laos may be imminent. The only other recent records from its formerly wide Asian range are from central and east Kalimantan in Indonesia and from Cat Tien National Park in Vietnam (Holmes 1991, Robson et al. 1993b, Sözer and van der Heijden 1997).

\section{Giant Ibis Pseudibis gigantea Globally Threatened}

XP: Singles on 3 February 1993 (Dong Kalo), 13 March 1993, 7 and 9 May 1995 (Xe Kong plains). DKT: Two were flushed from a pool to $\mathrm{km}$ south-east of Ban Khiam on 1 May 1996, and probably the same two from a pool further east later the same day. Not found during aerial surveys in August 1996.

Thewlis and Timmins (1996) reviewed all known records of this species prior to 1996: there were only two isolated historical records from Laos, in contrast to the abundance of White-shouldered Ibis, and it seems likely that Giant Ibis was never common here; the XP records in 1993 followed a gap of thirty years during which the bird was feared extinct throughout its historical range around the lower Mekong and Gulf coast of Thailand. There are only two other recent records, both from north-eastern Cambodia (J. Barzen in Mundkur et al. 1995, Desai and Lic Vuthy 1996).

Both recent and historical records indicate a preference for pools in areas of open deciduous forest (Thewlis and Timmins 1996). Breeding areas are not known.

\section{Spot-billed Pelican Pelecanus philippensis Globally Threatened}

DKT: One moribund bird found in an area of pools near Ban Nondeng, north of Dong Khanthung, was captured and taken to Pakxe in early December 1996. Another was reportedly found south-west of Ban Nondeng in the same period.

Historical reports suggest it was a seasonal visitor to the Mekong in southern Laos where it occurred in small groups in June and returned to the main tributaries of the Mekong in August (pairs or singles were seen on the Xe Don and neighbouring lakes at this time: Engelbach 1932). This may still be true, as few surveys were conducted in the area during this period. Elsewhere populations have declined (Collar et al. 1994), to extinction in Thailand (Round et al. 1988). Large numbers and several breeding colonies remain in Cambodia, where a flock of 1,800-2,000 was recently reported (Mundkur et al. 1995). A single seen by David-Beaulieu (1949-1950) on the Mekong in Savannakhet Province was believed to have been this species although, since it was rather distant, the possibility of Great White Pelican P. onocrotalus could not be ruled out. Great White Pelican was listed as very common in Cambodia and Cochinchina by Delacour and Jabouille (1931).

\section{Painted Stork Mycteria leucocephalus Globally Near-Threatened}

Other: One immature bird was found being kept captive in Ban Lak 52 on 2 July 1996, having been shot from a flock of 13 which briefly visited paddies a few $\mathrm{km}$ 
north of there around 30 June. The possibility of these birds being from the semi-wild population in Bangkok cannot be entirely ruled out.

The species has declined in Laos, having once occurred in small groups throughout the country. Two were taken by the Mekong north of Vientiane in June 1929 (Bangs and van Tyne 1931); small flocks were sometimes observed on river plains or large lakes of the South (Engelbach 1932); birds occurred yearround with highest numbers between October and March the length of the Mekong in Savannakhet Province and especially in the great marshy triangle between Ban Kengkok, Ban Songkhon and Ban Lahanam-Thong (David-Beaulieu 1949-1950), close to what is today called Nong Louang. Populations in Thailand have collapsed (Round et al. 1988). In Cambodia this stork remains common in the Tonle Sap area, although it is believed to be threatened by the harvesting of eggs and young (Mundkur et al. 1995).

\section{Asian Openbill Anastomus oscitans Globally Near-Threatened}

DKT: Eight soaring over the Nam Lepou on 9 August 1996.

The species had not previously been reported from Laos. It is the commonest stork in Thailand, occurring in large numbers during the dry season (Lekagul and Round 1991). In Cambodia, there have been erratic recent records of flocks of 300-1,000 from several parts of the country during April-June, with a small number of breeding colonies being occupied from November to March (Mundkur et al. 1995).

\section{Woolly-necked Stork Ciconia episcopus At Risk in Thailand}

DHS: Searches in both May 1993 and February 1996 revealed what may be a single pair, roaming between various small wetlands around the middle Houay Namphak. Stork footprints, perhaps of this species, were also found at a few pools north of Ban Nabon in February 1996. BSW: One from the Nong Houay Soymong wetlands on 26 March 1992 (Salter 1993). Two were seen on three successive days at Nong Tok and one on the only visit to Nong Hin in April 1995. XP: Up to three recorded almost daily over and within open areas in the Xe Kong plains and Dong Kalo area; locally frequent over the southern edge of the Northern Zone; sporadic elsewhere in this area. Occasionally above and within canopy breaks in denser forest in 1992-1993. A group of five south of Sayphou Kiou, 5 February 1993. One seen perched in a dry dipterocarp from a bus on Route 13, and another soaring overhead between Ban Thangbeng and Ban Nasenphan, close to XP (28 January 1993). Several were seen soaring over the Xe Pian and the Xe Kong and one was seen feeding on the riverbank in May 1995. A flock of six at a pool in the north of the Xe Kong plains, April 1995. Two to three singles on the Xe Kong plains during 18-20 September 1996. SMK: Recorded from Khonphapheng Falls (Salter 1993). DKT: Three parties of two singles and one of two $10 \mathrm{~km}$ south-east of Ban Khiam on 1-2 May 1996. Two birds together close to the track between Ban Houayxai and Ban Kadian at the end of April 1996 (Berkmüller and Vilawong 1996). Twenty-nine during aerial surveys on 17 August 1996 at five locations (singles and two groups of 12); none was recorded 
from the ground. A party of ten storks thought to be this species was also seen in Mounlapamok district in February 1996 (J. Foppes verbally 1996).

Populations of this species have collapsed in Laos. David-Beaulieu (1949-1950) found it common in pairs and small groups on rivers, lakes, pools and even flooded paddies in Savannakhet Province (in which PXH lies). Engelbach (1927a) found it frequently along the Mekong, by lakes on the Xe Don plains (close to XBN and PXT) and on the Bolaven Plateau (close to DHS and XNN) and later (Engelbach 1932) accounted for its status in Southern Laos in one word: "common". In North Laos, by contrast, David-Beaulieu (1944) recorded only one individual in Tranninh in five years, and Delacour and Greenway (1940) recorded a few in Upper Mekong and Louangphabang Provinces in north-west Laos. It has been extirpated from most of Thailand (Lekagul and Round 1991) although in Cambodia it is still common in some parts, even being seen in numbers from main roads (J. C. Eames verbally 1997).

Feeding birds (in groups of up to six) in XP in the dry season were closely associated with water in drying riverbeds and numerous seasonal pools, which presumably concentrated prey as they shrank from November onwards. Only a few were seen on larger rivers, associated with backwater pools. Birds were probably commonest on the Xe Kong plains, and were distinctly rarer in the heavily used wetlands of the Northern Zone of XP. All recent records came from below $300 \mathrm{~m}$. There are local reports of breeding at Ban Pakbo in the Xe Kong plains area of XP (Salter 1993).

\section{Black-necked Stork Ephippiorhynchus asiaticus At Risk in Thailand}

DKT: Two singles were seen on 17 August 1996 during an aerial survey; one was c. $5 \mathrm{~km}$ north of Ban Khiam, the other $2.6 \mathrm{~km}$ north of Ban Paling.

This species has become much rarer in Laos. The historical records imply that birds were mostly non-breeding visitors. Several were seen along the Mekong in north-west Laos, November 1938-March 1939 (Delacour and Greenway 1940). It was not very common in Central Laos, but David-Beaulieu (1949-1950) saw singles sometimes along the Mekong, and once a flock of 12. Engelbach (1932) thought that it was not rare along the Mekong south of Pakxe and by large pools on the Xe Don plain and the Bolaven Plateau. Populations elsewhere in the region have also shrunk: it no longer breeds in Thailand (Lekagul and Round 1991) and the breeding population in Cambodia has declined markedly (Mundkur et al. 1995).

\section{Lesser Adjutant Leptoptilos javanicus Globally Threatened}

DHS: One at Nong Leenphom ( $4 \mathrm{~km}$ south of Nong Hou) on 8 February 1996 and one at Nong Hou three hours later. Two at Nong Hou early on the morning of to February were thought to have roosted very nearby. See Woolly-necked Stork (above) for records of stork footprints. XP: Recorded throughout the more open areas in January-March 1993, with almost daily sightings on the Xe Kong plains in March 1993 of up to five individuals together. One was seen soaring over the Xe Kong plains in May 1995. DKT: Singles were seen 6 and $10 \mathrm{~km}$ south-east of Ban Khiam on 1 and 2 May 1996. During aerial surveys on 17 
August 1996, 42 birds were noted at ten locations, in groups of 1-8. Groups of four and one were noted $3-4 \mathrm{~km}$ north of Ban Khiam, during ground-based surveys in the previous week. Occupied nests of one or both species of adjutant (seven nests in 1996) were reported by local people from the foot of the escarpment along the Thai border; see the account for Greater Adjutant. Berkmüller and Vilawong (1996) also received reports of nesting adjutants from the Thai border area, apparently in different locations, and from one area at the northern end of the dense Central Forest area.

The species was formerly found in small numbers throughout Indochina, being abundant only in the southern half of the region (Delacour and Jabouille 1931). It has declined in Laos: it was quite frequent in forests of the plains of the South (Engelbach 1932), but very scarce in Savannakhet Province (David-Beaulieu 1949-1950) and there are no primary records for the North. The species has seriously declined elsewhere, especially in Thailand (Round et al. 1988). In Cambodia it has declined too, although it is still fairly common in some areas and small numbers still breed; but these birds are believed to be threatened by the harvesting of eggs and young (Mundkur et al. 1995). In Vietnam the only known breeding locality is Cat Tien National Park (Robson et al. 1993a,b).

Two adults seen in semi-captivity at a fish farm on the outskirts of Pakxe in 1992 had reportedly been taken as chicks from the nest, somewhere in Attapu Province. Another was seen in a menagerie in Savannakhet town in July 1995 (E. Briggs verbally 1995).

In XP birds fed in habitats similar to those of Woolly-necked Storks, although none was seen within the Main Block of semi-evergreen forest. In the more intensively used wetlands of the Northern Zone birds were seen less frequently than in Dong Kalo or the Xe Kong plains, with only two overflying and two feeding individuals seen in several weeks of fieldwork.

\section{Greater Adjutant Leptoptilos dubius Globally Threatened}

BSW: [One at Nong Houay Soymong wetlands on 26 March 1992 (Salter 1993).] DKT*: [Provisional records of one bird during ground-based surveys on 17 August 1996, at a pool 1o km south-south-east of Ban Vin-Tai, and of at least 33 during aerial surveys on the same day. They differed from Lesser Adjutant, with which they were seen, in being noticeably larger and having grey upperwing and mantle coloration, in contrast to the black upperwing and mantle colour of Lesser Adjutant. Some showed large gular pouches. However, they did not show contrastingly pale greater coverts and inner secondaries indicated as diagnostic by Lekagul and Round (1991). During the flight, birds were seen at seven locations in groups of $1-18$, predominantly in the south-west, along the Cambodian border. At three of the locations two, four and three active nests were seen: at the former location both adjutant species were present; at the latter two locations only Greater was present. Adjutant nests were also reported from several sites along the base of the Sayphou Damlek mountains in the south-east (with up to seven at one locality) and from one area at the northern end of the dense Central Forest area. All overflight records: J. Barzen verbally 1996.]

* See note added in proof 1, p. 131. 
Engelbach (1932) found this species commonly on the Mekong "below Khon" at the far southern tip of Laos, and recorded one on the Xe Don plains.

The species has declined very severely throughout its range, but a breeding population also remains in Cambodia, and larger numbers do so in Assam (Scott 1992, Mundkur et al. 1995).

\section{Blue-naped Pitta Pitta nipalensis Globally Near-Threatened}

NK: A pair and two females in the upper Nam An valley and the southern escarpment (700-900 m) during April 1995. Other: Outside NTX, a male with nest material in bamboo and banana scrub along the Houay Be at $500 \mathrm{~m}$ on 22 May 1996. Single dead birds in Ban Lak (20) market in March 1994 and 1995.

Previous records were only from the North: it was abundant around Ban Namkeung-Kao (Delacour and Greenway 1940) and one was collected at Ban Boun-Tai (Bangs and van Tyne 1931).

The status of this species in Laos remains unclear. The relative distributions and habitat use of this species and Blue-rumped Pitta $P$. soror in NK were not clearly established, as conditions for finding pittas in most of the reserve were poor. At no locality in the reserve were both seen.

\section{Blue-rumped Pitta Pitta soror Globally Near-Threatened}

NK: Several records in the eastern part of the NBCA (up to $550 \mathrm{~m}$ ) during December 1994 and January 1995, including some snared by hunters. NTX: One on a ridge $(850 \mathrm{~m})$ above the Nam Kwai in 1994. NP: In 1995, two corpses were seen for sale in Ban Namnian. A single of this or Blue-naped Pitta seen in evergreen forest/semi-evergreen forest south of Ban Namnian. HNN: One on 1 January 1996 and a probable record the previous day, both at the Houay Clocc site. PXT: [One in semi-evergreen forest in March 1996 could not be told from Blue-naped Pitta but was probably Blue-rumped on range.] DHS: One in degraded semi-evergreen forest, Ban Nongkhe (300 m), in May 1993. XP: Common in primary and moderately degraded semi-evergreen forest, but scarcer in very degraded semi-evergreen forest in 1992 and 1993.

It was quite common below $800 \mathrm{~m}$ on the north-east slopes of the Bolaven Plateau (Engelbach 1932) and one was taken at Ban Nape (Delacour 1929).

This species is much more difficult to survey than is Bar-bellied Pitta, as its calls are quieter, less distinctive and less frequent. It was not recorded from deciduous habitats. Blue-rumped Pitta is frequently stated to be a hill or montane species (e.g. King et al. 1975, Round 1988, Lekagul and Round 1991). This is clearly not so in Laos: at Xe Pian, where it was possible so see six or more individuals in a day, it was observed between 100 and $500 \mathrm{~m}$, whilst Robson et al. (1989) found it at $50 \mathrm{~m}$ in Vietnam.

\section{Bar-bellied Pitta Pitta ellioti Globally Near-Threatened (formerly Globally Threatened)}

TMF: A freshly shot, recently fledged juvenile on 30 June 1996. PXH: Common in April 1993 in semi-evergreen forest and a mosaic of semi-evergreen $/ \mathrm{mixed}$ 
deciduous forest. PXT: Fairly common during March 1996 in some semievergreen forest areas, especially on lower, flatter terrain. Calls were heard almost daily in this habitat. Possibly also present in some taller mixed deciduous forest stand.s. None was located during four days on Phou Alang at about $450 \mathrm{~m}$. DHS: In 1993, common in the lowlands, in semi-evergreen forest (including logged areas), and hill slopes to at least $400 \mathrm{~m}$. Common during February 1996 in the Houay Takit sector in logged semi-evergreen forest, with up to ten heard daily. Occasional single calling birds or feathers plucked by hunters were recorded in most other sectors, up to at least $400 \mathrm{~m}$. The scarcity of records in apparently suitable habitat after February may have been due to a change in calling frequency. BSW: Frequent in April 1995, even in heavily degraded areas, in forest below $300 \mathrm{~m}$ along and around the Xe Pian. XP: Recorded in 1992-1993. Status in semi-evergreen forest as that of Blue-rumped Pitta; also present at Dong Kalo and on the Xe Kong plains in patches of riverine lowland mosaic forest. Other: One at Lao Pako on 17-19 April 1993.

This pitta is clearly much commoner and more widespread than previous Lao records suggested. Engelbach (1932) took one from Attapu and three from the gentler north-east slopes of the Bolaven. Oustalet (1899-1903) recorded one from an untraced locality, the Kouys area, believed to be in Champasak or Attapu Provinces.

It is widespread and common in Vietnam, where it has been found in secondary and logged forest, and even scrub, and up to higher altitudes than previously known (Rozendaal and Nguyen Cu 1989, Robson et al 1989, 1993a,b). The results from Laos fully support the recent downgrading of status from Threatened to Near-Threatened.

It was unrecorded from deciduous forests. Populations are probably large in the evergreen and semi-evergreen forests of BSW, XP, DHS and PXH. Birds seemed commonest in flat or slightly sloping areas rather than on steeply sloping land, and all records were from below $500 \mathrm{~m}$. There were many records of plucked feathers from snared birds at localities listed.

\section{Black-and-red Broadbill Cymbirhynchus macrorhynchos At Risk in Thailand}

DHS, BSW, XP: Scattered records and locally common (several groups per day in some places) in lowland areas (up to $300 \mathrm{~m}$ ). DKT: Present in dry dipterocarp forest south-east of Ban Vin-Tai on 4 May 1996.

These records are the only ones for Laos (Mlikovsky and Inskipp in prep.); the absence of previous records is surprising, as it is a conspicuous species and the Pakxe region was among the most collected in Laos.

Sites holding these birds were usually degraded semi-evergreen forest or mixed deciduous forest or a riverine mosaic of the two, and frequently close to water. The highest densities were found in a mosaic of very degraded semievergreen forest and secondary growth on the southern edge of the Northern Zone of $\mathrm{XP}$, and only one group was found deep in the pristine semi-evergreen forest of the Main Block. Birds were generally in small groups. Active nests were found in May in DHS and DKT.

These records recall the species's status in Thailand, where it is limited to areas below $300 \mathrm{~m}$ in the immediate vicinity of waterways and, although threatened 
by deforestation, can maintain populations in logged areas provided relict tall trees and moist secondary growth remain (Round 1988). However, whereas Round considered that the species was limited to evergreen and semi-evergreen forest formations, some Lao records were in mixed deciduous forest some distance from semi-evergreen forest.

\section{White-winged Magpie Urocissa whiteheadi Globally Near-Threatened}

NTX: Recorded frequently around the Nam Kwai in 1994. A group of four $1 \mathrm{~km}$ south of the logging camp in dry evergreen forest on 17 April 1996. Along the upper Nam Cham, three at $690 \mathrm{~m}$ on 15 May and a single seen later the same day in the same area. None recorded from Fokienia forest. NNT: Common in Tasaeng Theung in 1994, where several groups were seen daily. Also recorded around the middle Nam Xot in 1994, once from forest close to Ban Nakadok and once in low secondary forest between the Nam Xot and Nam Mon (X). Records ranged from 500-800 m. NP: Particularly common and widely distributed in both 1994 and 1995 in mosaic areas of pine/semi-evergreen forest where several (14) groups were seen daily. A similar pattern was found in February 1996 although there was only one provisional record from hills on the south-western edge of the plateau. HNN: A party of at least five on successive days in January 1996 at the Houay Talee site.

These records reflect historical accounts: Delacour (1929) found large flocks east of Ban Nape, and David-Beaulieu (1944) found it in Tranninh only in the Nam Mat basin, particularly along riverbanks.

This species seemed to prefer a mosaic of open forest, secondary growth and dense forest patches; with the exception of the Nam Kwai site (NTX) there were few records in extensive dense forest. Birds were seen commonly along wooded rivers and in heavily logged areas, usually in flocks of 8-12 and often encountered late in the day drinking from rivers. There were a few records of the species being hunted. In Vietnam it has similarly been recorded from logged and secondary forest habitat (Robson et al. 1993a).

\section{Yellow-breasted Magpie Cissa hypoleuca Globally Near-Threatened}

DHS: Singles in the lowlands in May 1993 and February 1996. BSW: Heard several times in semi-evergreen forest around the lower Xe Pian in April 1995. XP: Recorded November 1992-February 1993 when common in pristine semievergreen forest around Houay Saoe and Houay Kua but scarcer in more degraded forest; not common in the hillier area around Houay Tapkua.

The only previous Lao record came from Engelbach (1932), who took one at the northern foot of the Bolaven Plateau, on the Xe Don plains.

Birds in XP, the stronghold of this species in Laos, had narrow habitat requirements, being almost restricted to dry semi-evergreen forest below $400 \mathrm{~m}$ with an abundance of a small-stemmed bamboo (different from that in which Paleheaded Woodpecker was found). The scarcity in DHS may be because of heavy logging there, or perhaps habitat differences related to higher rainfall. In Thailand birds inhabit a wide altitudinal range (Round 1988). Birds often followed flocks of White-crested Laughingthrushes Garrulax leucolophus, as did Green 
Magpies C. chinensis at other sites. The two Cissa species were not found sympatrically at any site.

Ratchet-tailed Treepie Temnurus temnurus (formerly Globally Near-Threatened)

NK: Probably common in the Nam Ao forest; present elsewhere in the reserve and in the lower valleys of the Nadi limestone area. NTX: Common in 1994 in the wet evergreen forest at the Nam Kwai site. Common along the Ban Nahoua logging road and frequent in Fokienia forest in 1996. Not recorded from areas further north in NTX. NNT: Common in 1994: several pairs found daily in some areas of dry evergreen forest in the Northern Mountains, but particularly scarce at the higher altitudes surveyed in the Central Mountains, where singles were seen at $950 \mathrm{~m}$ and $1,050 \mathrm{~m}$. Present in Tasaeng Theung. Two along the Ban Navang logging road $(1,000 \mathrm{~m})$ in March 1995. NP: Scarce in 1994 and 1995, although probably frequent in areas of extensive broadleaf forest types. KML: Two singles in degraded forest in the southern habitat link (Nam Theun Corridor PPA) west of NP in February 1996 (200 m). HNN: Probably common in forest at the two northern sites in January 1996; also seen in degraded mixed deciduous forest in the Nam Ngo valley. PXH: 1-2 observed twice in dry evergreen forest ( $300 \mathrm{~m}$ ). Other: Present on the Nam Theun near the Nam Ngoy and Keng Luang (January-March 1995).

It was recorded previously from north of Xe Pon at $450 \mathrm{~m}$ (David-Beaulieu 1949-1950) and, as numerous, in forests near Ban Nape (Delacour 1929). The Ban Nape record was omitted from Delacour and Jabouille (1940), presumably inadvertently.

Although recorded from old $12 \mathrm{~m}$ tall secondary growth around $550 \mathrm{~m}$ in the Nam Noy valley (NNT), it occurred mainly in tall forest. It has been recorded from a wider range of habitats in Vietnam, comprising primary, logged and secondary evergreen forest and even scrub (Robson et al. 1993a). It generally associated with mixed-species flocks including White-crested Laughingthrushes, Green Magpies and larger woodpeckers. Some of the calls were similar to those of Green Magpie.

\section{Brown-rumped Minivet Pericrocotus cantonensis Globally Near-Threatened}

TMF: A flock of at least seven near Ban Namiang on 29 February and 1 March in heavily degraded Lagerstroemia-dominated deciduous forest. NP: A group of under ten in semi-evergreen forest near Ban Namxot on 7 March 1995 and a single in a broadleaved forest strip within open pine mosaic north of the Nam On on the same day. Both were in mixed-species flocks. PXH: One in degraded secondary growth between the two hill ranges on 1 April and another on Phou Xang He on 28 March 1993 in semi-evergreen-dominated forest mosaic. PXT: 12 in dry dipterocarp forest near Ban Hatxeno on 21 March 1996. DHS: Two in a mixed flock by the Houay Nyat on 18 February 1996 and one well downstream next day $(260-280 \mathrm{~m})$. One seen at $500 \mathrm{~m}$ in the upper Houay Bangliang valley on 23 February and two $1 \mathrm{~km}$ away at the same altitude on 24 February. These records were all in semi-evergreen or dry evergreen forest. Another one was confidently identified from a party of four Ashy $P$. divaricatus/Brown-rumped 
Minivets in logged semi-evergreen forest north of Ban Nongpop (18o m). XP: A group of about 10 and a single in the Northern Zone (January 1993), a single at Houay Tapkua (February 1993) and a party of at least 10 and two singles on the Xe Kong plains (March 1993).

Historically, the species was known from the Muang Taoy region (the upper Xe Kong), near Pakxe and the north-east slopes of the Bolaven (Engelbach 1932).

Ten of the 18 recent records were from more open forest-types, including degraded areas. The few recent records reflect in part the difficulties of separation from Ashy Minivet (see Thewlis et al. 1996), which seems to share the same habitat. Nonetheless, Brown-rumped Minivet does appear to be a genuinely scarce bird in Laos, although it has been seen recently more frequently than Rosy Minivet $P$. roseus.

\section{Yellow-bellied Fantail Rhipidura hypoxantha Rare in Thailand}

This montane species was only ever recorded in Laos from high altitudes in the North, at Phou Kabo and Ban Phu Soung (David-Beaulieu 1944). There is no recent information.

Japanese Paradise-flycatcher Terpsiphone atrocaudata Globally Near-Threatened

NNT: One on 13 April 1994 in Fokienia-dominated forest along the Nam Xot at $1,600 \mathrm{~m}$.

Engelbach (1932) collected one on the Bolaven Plateau in April 1930.

Brown Dipper Cinclus pallasii At Risk in Thailand

PDD: In 1995, one on the Nam Khang; one pair and a single on a mountain stream $5 \mathrm{~km}$ east of Ban La. On the Nam Ou, singles north of Ban Hat Xa on 19 and 28 March 1996 just outside the reserve. NK: One on several occasions along the middle Nam An in April 1995 (300 m). NTX: Present in January-April 1994 on the upper Nam Phao. A pair held territory on the Nam Pan Noy adjacent to the logging camp (1996). NNT: Present in 1994 along the Nam Xot both in the middle reaches $(600 \mathrm{~m})$ and in the Fokienia forest area $(1,500 \mathrm{~m})$.

Historically, David-Beaulieu (1944) described the species as rare and localised in Laos, but less so in Tranninh where he saw it on the Nam Mo, Nam Thie, Nam Ngum and Nam Khao. It was also found along streams east of Ban Nape (Delacour 1929).

In NNT and NTX, this species favoured rapids on large rivers of at least $7 \mathrm{~m}$ in width, within forest. In Phou Dendin NBCA, it was found mainly on streams in forest, but once on a stream flowing through grass and scrub. Further work is required to determine whether it is dependent on forested rivers and thus of conservation concern in Laos. Round (1988) declared its status in Thailand unclear as there were very few recent records; it is presumed to be resident although breeding has never been confirmed.

\section{Black-breasted Thrush Turdus dissimilis Globally Near-Threatened}

NP: A female on 23 and 28 February 1995 in a small flock of thrushes, foraging in bamboo scrub along the bank of the Nam On. Other: Around 10 in a fruiting 
tree in evergreen forest $17 \mathrm{~km}$ north-west of Louang-Namtha in mid-December 1995 (J. N. Dymond in litt. 1995).

The only previous Lao record of this winter visitor is of three at Ban Namkeung-Kao (Delacour and Greenway 1940). A female collected at Xiangkhouang on 22 November 1941 and published by David-Beaulieu (1944) as this species was reidentified by Dickinson (1970b) as a Japanese Thrush $T$. cardis.

\section{Grey-sided Thrush Turdus feae Globally Threatened}

NP: A first-winter and an adult along the Nam Mon $(X)$ on 3 and 6 February 1995 respectively. Birds were seen singly on sections of bank with much bare earth and overhanging vegetation.

These are the first Indochinese records of this poorly known thrush (Mlikovsky and Inskipp in prep.). The river banks on NP also supported small numbers of Eyebrowed Thrushes T. obscurus, and many Eurasian Blackbirds T. merula and Scaly Thrushes Zoothera dauma; both Grey-sided Thrushes were foraging alone.

\section{White-browed Shortwing Brachypteryx montana Rare in Thailand}

The only Lao records are of a pair at Lo-Tiao and one at Taloun, all in January 1939 (Delacour and Greenway 1940).

\section{Fujian Niltava Niltava davidi Globally Near-Threatened}

NK: [Locally common in the eastern part of the NBCA and the neighbouring Nam Ao forest between 400 and $550 \mathrm{~m}$ in December 1994 and January 1995.] Two were mist-netted. NTX: [Common at the Nam Kwai site in January-February 1994.] NNT: [Locally common at 500-800 $\mathrm{m}$ in forest around Ban Nakadok in January 1994.] NP: [Occasional records in January-February 1994. Single individuals were seen in February-March 1995 along the Nam On, the upper Nam Xot and the Nam Mon (Y).] HNN: [In January 1996, one in the Houay Packha valley $(200 \mathrm{~m})$, and one at the Houay Talee site could have been either Fujian or Rufous-bellied Niltava $N$. sundara.] Other: Single dead birds for sale in the Ban Lak (20) market in [February 1994 and] January 1995.

Past records are from Ban Nape and Nam Theun (Delacour 1929), the Bolaven Plateau (Engelbach 1932, Dickinson 1970a) and Phongsali (Bangs and van Tyne 1931). Dickinson (1973) examined the specimens from Ban Nape and Nam Theun and reassigned them to Rufous-bellied Niltava. He also examined the specimen from Phongsali and reassigned it to Vivid Niltava N. vivida, leaving the Bolaven birds as the only Lao records. This reassessment was apparently not adopted by King et al. (1975), who appear to have treated all the records mentioned above as referring to Fujian.

The species is difficult to distinguish from Rufous-bellied Niltava, which has been recorded several times in Laos from the North (Delacour and Jabouille 1940, David-Beaulieu 1944) in addition to the disputed records above. The identification and taxonomy of this closely related and possibly conspecific pair of taxa is not fully understood (Inskipp et al. 1996) and in view of this we prefer to treat most recent records as provisional. Of the recent records, only the January Ban 
Lak 20 bird and some of the Nam Kading birds were confirmed (by measurements taken in the hand) as Fujian (following King et al. 1975); the others showed plumage characters of Fujian as described by Lekagul and Round (1991) and Dickinson (1973). There has been no recent evidence to support the presence of Rufous-bellied Niltava from the same area.

All recent records come from the Nam Theun catchment, or adjacent areas. Field records came predominantly from damp shaded stream valleys and gullies at $400-800 \mathrm{~m}$.

\section{Blue-fronted Robin Cinclidium frontale Globally Near-Threatened}

A single female was collected at Xiangkhouang in January 1926 (Delacour and Jabouille 1927).

\section{[Purple Cochoa Cochoa purpurea Globally Near-Threatened}

NTX: The record of two on 29 January 1994 near the Nam Kwai in wet evergreen forest at $750 \mathrm{~m}$ (Evans and Timmins 1994) is here retracted because of the possibility of confusion with atypically dark Green Cochoas.

There are no records from Laos (Mlikovsky and Inskipp in prep.). This record was inadvertently published without a caveat by Evans and Timmins (1994).]

\section{Green Cochoa Cochoa viridis Globally Near-Threatened}

PDD: Three at $1,740 \mathrm{~m}$ in an isolated fragment of dry evergreen forest, amid large burnt areas and grassland $1 \mathrm{~km}$ north-west of Phou Dendin, on 23 March 1996. NK: Commonly heard in tall forest in valleys and depressions within the Nadi limestone area, mostly about $650 \mathrm{~m}$ altitude (with one at 1,150 m) in May 1995. NNT: Two singles seen in April 1994 in the Fokienia forest area, one in stunted ridge-forest and the other in denser valley-bottom dry evergreen forest, rather than in Fokienia-dominated stands. Two singles in April-May 1996, in dry evergreen forest around the Ban Navang logging road. XS: Heard on 11 May on the slopes of Phou Ajol. XNN: One near Ban Nam Tang (900 m) on 15 April 1995. DHS: Heard and seen frequently, even in quite fragmented forest, on the Bolaven Plateau at 1,000-1,200 $\mathrm{m}$ in June 1993. Other: Two adults and six juveniles (all dead) were on sale as food in Ban Phonsavan market in July 1995.

Historically, small numbers were recorded from the Bolaven (Engelbach 1932), Tranninh (David-Beaulieu 1944), Phongsali and Ban Muangyo (Bangs and van Tyne 1931).

Calls proved the easiest method of surveying this elusive species; they were given commonly in the Nadi limestone area in May and frequently in DHS in June, but no calling was recorded from NNT in January-April or XNN in MarchApril. With the exception of the Nadi limestone area, records came mainly from $1,000-1,800 \mathrm{~m}$ altitude. The three birds seen at Nadi all showed a very dark plumage unlike that of birds seen elsewhere in Laos.

\section{Jerdon's Bushchat Saxicola jerdoni Globally Near-Threatened}

TMF: A dense population was found on sedimentary deposits where the Nam Sang enters the Mekong. An estimated 15 territories were found in a sample of 
25 ha in mid-March, when the singing males were conspicuous. The sample area included large areas of unsuitable bare rock and sand. The site as a whole probably supported 100-200 pairs. Much smaller numbers were present in July. There were no records outside the river channel. Other: A male, perhaps accompanied by a female, on 1 April 1996 in low bushes on a Mekong island $2 \mathrm{~km}$ downstream of the mouth of the Nam Ou.

The TMF records were described in more detail, and all historical records from throughout the species's range were reviewed, by Duckworth (1997b). In North Laos, it was a common resident above $1,400 \mathrm{~m}$ in Tranninh, particularly at Nonghet, a high valley $(1,500 \mathrm{~m})$ dominated by rocks and tall herbs in place of the original forest and subject to frequent fires, frosts and fog (Delacour and Jabouille 1927, David-Beaulieu 1944). A breeding female was taken on 12 May 1929 at Ban Muangyo $(750 \mathrm{~m})$ in the far north of Laos, an area of ricefields surrounded by good forest (Bangs and van Tyne 1931). The TMF records are the first for Laos in riverine habitat, which disappears during the rainy season; it is not known where the bushchats move to. There are records from both mountain and rivervalley habitats in other range states (e.g. Burma: Smythies 1986).

Duckworth (1997b) also discussed the possibility that changes in river dynamics connected with extraction of gravel for construction work or with proposed dams on the Mekong mainstream might endanger the TMF population in the future.

\section{Golden-crested Myna Ampeliceps coronatus At Risk in Thailand}

NNT: One in a day-and-a-half's survey, 10-11 March 1994, below $300 \mathrm{~m}$ on the southern escarpment. PXH: Four on 22 March to the east of Ban Khame; two on 2 and 3 April east of Ban Phongsavang; two south of Ban Muangsen on 6 April; and one north of Ban Nalay on 19 April. XBN: Flocks of up to eight recorded daily flying over the Xe Bang-Nouan in May and June 1994, but not recorded in areas away from the river. DHS: In June-July 1993, several groups of two were seen occasionally in logged and unlogged semi-evergreen forest. In 1996, in the Ban Houay Phoung area, a group of four on 8 February and ten on 10 February. BSW: One near a large clearing on 8 April, six over the Xe Pian river on 12 April and two in a fruiting tree $17 \mathrm{~km}$ downstream on 19 April (all in 1995). XNN: Present along the lower Xe Namnoy in March and April 1995. XP: In the vicinity of Nong Loum, groups of 11 and six on 9 January 1993, and two on 11 January 1993. Recorded west of Ban Phalay on 11 January 1993. It was frequent in degraded semi-evergreen forest along the Houay Tauang in January 1993. Parties of six and two along the Xe Pian on the Xe Kong Plains on 8 May 1995, and also recorded along the Xe Kong.

There is no evidence to suggest it has declined. Previously it was found, always locally or occasionally, in Tranninh (only one site: David-Beaulieu 1944), Savannakhet Province (David-Beaulieu 1949-1950), and the Muang Taoy region and the Xe Kong plains (Engelbach 1932). Birds sometimes entered towns at fruit seasons.

This quiet, canopy-haunting species is localised and is easily overlooked. It frequently associated with Hill Mynas. Records were all below $400 \mathrm{~m}$ and usually below $300 \mathrm{~m}$ mostly from riverine habitat, cultivated or degraded areas associ- 
ated with fragmented semi-evergreen or mixed deciduous/semi-evergreen forest or at the periphery of extensive evergreen or semi-evergreen forest. At XBN, birds seemed most active in the mornings when flocks of up to eight (sometimes in company with Hill Mynas) flew in a strange manner up and down the river, possibly flycatching. Round (1988) considered this species At Risk in Thailand owing to the pet trade, although in Laos no captive birds have been recorded during recent surveys.

\section{Hill Myna Gracula religiosa At Risk in Thailand}

PDD: Two along the Nam Ou in degraded forest in May 1995. TMF: Observed daily in open areas adjacent to forest around Ban Wangma, with a peak count of 42. Small numbers (2-4) were seen along the Nam Sang between Ban So and Ban Wangma on four dates. Four flew over the Houay Tsapsaet on 4 March. This area was barely visited during the rainy season, and the only records of the species were of seven near Ban Wangma and four over Ban So. Over-harvesting has apparently pushed the birds into the least-inhabited parts of the area. NK: Present in the Nam Ao forest and common in most other areas visited below $750 \mathrm{~m}$, particularly in forest along the Nam Kading. None in the Nadi limestone area (which was mainly surveyed above $750 \mathrm{~m}$ ), upper Nam An area, the scrub and secondary growth upstream of the NBCA, or along the Nam Kading downstream of the NBCA. NTX: [No records in 1994 or 1996.] NNT: In 1994, probably common on the Southern Escarpment $(250-400 \mathrm{~m})$, present in secondary forest and clearings in the inhabited enclaves $(500-600 \mathrm{~m})$ and one record from deep forest at $950 \mathrm{~m}$ on the Ban Navang logging road. Not recorded around Ban Nakadok ( $500-900 \mathrm{~m}$ ), the middle Nam Xot site, or other high-altitude sites (over $1,000 \mathrm{~m}$ ). Not recorded in December 1995 from the upper Nam On catchment (650 $\mathrm{m}$ and over) or in 1996 from the Ban Navang logging road. NP: Common throughout areas retaining forest but scarcer on the heavily degraded central plateau, in both 1994 and 1995 (500-600 m). KML: Very common in degraded forest in the southern habitat link (Nam Theun Corridor PPA) west of the Nakay Plateau in February 1996 ( $200 \mathrm{~m}$ ), but not recorded in forest in the Khuadhin area $(200-250 \mathrm{~m})$. XBN: Common in dense lowland forest, including close to habitation; scarcer in hill forests and dry dipterocarp areas. DHS: Common in forest areas of the lowlands $(100-400 \mathrm{~m}$ ) in 1993 and 1996 , but not recorded from the plateau (over 1,000 m). XNN: Locally frequent in most habitats with tall trees, including pine forest, up to about $1,000 \mathrm{~m}$. BSW: Common below $350 \mathrm{~m}$ in extensive logged semi-evergreen forest. XP: Common (flocks of up to 20 ) in areas retaining large trees, including close to large villages such as Ban Phapho, around the Main Block, but scarcer within it. SMK: Present at Khonphapheng Falls (February 1993) and Ban Hangkhon (May 1996). DKT: Several records from lowland mosaic forest south-east of Ban Vin-Tai; two birds flying over the dense Central Forest area. Other: Present on the ridge bordering the Nam Theun to the south of Ban Lak 20 in April 1994. Several groups were seen in the Nam Mouan valley in March 1995 where it is probably common. Present in Xe Khampho PPA (April 1995). There were few sightings from roads (it was seen twice along Route 8), which, for such a conspicuous bird, suggests that it was scarce or absent over large areas. 
Historically, Hill Myna occurred throughout the Bolaven, Xe Don and Salavan regions; it was described as particularly common at Ban Thateng (Engelbach 1932). It did not seem very common in Savannakhet Province where it only inhabited dense forest (David-Beaulieu 1949-1950). It was fairly common in Tranninh (David-Beaulieu 1944) and very common in Ban Nape, Nam Theun and Nakay (Delacour 1929). Birds were collected at Ban Yoi Hai (Robinson and Kloss 1931), Ban Muangyo and Ban Thangon (Bangs and van Tyne 1931).

Hill Mynas seemed to occur patchily in most areas. In XBN, they were less common in hill forests although on two occasions flocks of up to 30 were seen in this habitat associated with fruiting trees. In XP they were least frequent in dry dipterocarp forest areas. In $\mathrm{XNN}$ they were found mainly in fruiting streamside trees. The largest flock was of over 100 in one fruiting tree on NP. As a relatively mobile bird, both seasonally and on a daily basis (flocks may fly substantial distances to roost), it is difficult to generalise its habitat choice in Laos. Preliminary assessment suggests that birds are commonest in predominantly forested areas with some open patches, such as the interface of dense semievergreen forest with cleared areas. They seemed to be scarce within extensive dry dipterocarp forest and at higher altitudes (decreasing above $500 \mathrm{~m}$ and very scarce above $800 \mathrm{~m}$ ).

It is a common cagebird in Vientiane and other towns, and a group of villagers in PXH proudly displayed a week-old brood just taken from the nest; Salter (1993) observed nestlings for sale in Attapu town market in March 1992. Birds from Laos are traded with Thailand and Vietnam (Salter 1993). It has been reduced by capture for the cage-bird trade in Thailand (Lekagul and Round 1991).

\section{Yellow-billed Nuthatch Sitta solangiae Globally Threatened}

XS: Birds were recorded commonly, generally associated with mixed-species flocks, throughout the forests of Phou Ajol (900-1,200 m). They were also present in degraded evergreen forest close to Ban Tangyoun $(1,200-1,400 \mathrm{~m})$ and in pine forest $(1,000 \mathrm{~m})$ to the south-west of Ban Dakchung.

These are the first records for Laos. Former records came only from highaltitude areas of Vietnam (Tonkin and South Annam) and the island of Hainan, China, where the principal threat is deforestation (Collar et al. 1994).

\section{Beautiful Nuthatch Sitta formosa Globally Threatened}

NNT: Seen four times: one in quite degraded dry evergreen forest above Ban Navang at about $950 \mathrm{~m}$ on 16 April 1994 and $1-3$ in three large mixed-species flocks in Fokienia forest between 1,500 and 1,700 m in April 1994.

Both former records (of a single and a flock of about ten) were from Phou Kabo, in February and October 1939, where David-Beaulieu (1944) believed it to be a rare migrant.

NNT has the most south-easterly population ever found and the lowest published altitudinal record. It is rare throughout its world range, and most of its habitat is severely threatened by shifting cultivators. Despite David-Beaulieu's (1944) assessment, it seems unlikely that it is migratory, although it may under- 
take altitudinal movements with season. It is possibly associated in Laos with the particularly threatened Fokienia-dominated forest, but further data are required.

\section{Brown-throated Treecreeper Certhia discolor At Risk in Thailand}

There are no recent records. Past records come only from Tranninh where it was exceedingly common, but restricted to mountains (David-Beaulieu 1944).

\section{Yellow-browed Tit Sylviparus modestus At Risk in Thailand}

XS: Common above $1,600 \mathrm{~m}$ in Fokienia forest and upper montane forest, and present below this altitude, commonly associated with mixed-species flocks.

The only historical record is of a specimen from Phou Bia in 1946 (David-Beaulieu 1948).

\section{Black-throated Tit Aegithalos concinnus At Risk in Thailand}

NTX: Common (groups of 3-5 daily) above $900 \mathrm{~m}$ in Fokienia forest adjacent to the Ban Nahoua logging road. NNT: Several sightings in and around Fokienia forest in 1994; occasional above 1,000 m elsewhere in the Central Mountains in 1994 and 1996. XS: Common on Phou Ajol up to 1,600 m, although less common above this altitude. $\mathrm{XNN}$ : Common in mature and degraded forest and coffee plantations above $750 \mathrm{~m}$ on the Bolaven Plateau. DHS: Common on the Bolaven Plateau, particularly in disturbed areas and forest edge.

The species was known in Laos from Tranninh, where it seemed to be fairly rare (David-Beaulieu 1944) and from the Bolaven Plateau (Engelbach 1932).

Birds were commonly in groups of 10 or more, in monospecific or mixedspecies flocks.

\section{Plain Martin Riparia paludicola At Risk in Thailand}

TMF: At Paksang, two on 14 February 1996 and four, probably six, on 13 March. Birds were moving in groups of two and singing; some sexual chasing was observed. At least ten in the Paksang-Ban Nasa area on 24 June, and 81 and 103 there on 14 and 15 July respectively. The February-June counts represent minima; it is likely that eight pairs were in the surveyed area during this period. Substantial numbers had evidently arrived from elsewhere by July. XP: 1-2 near Ban Phapho on 31 December 1992 during a period of hirundine movement through the area. Other: One near Don Chuan, Vientiane, on 31 March 1996. On the Nam Ou: four south of Muang Koa (30 March 1996), and up to eight from a motorboat south of Muang Koa (31 March 1996). There are recent records from the Mekong on the Lao-Thai border near the Thai town of Chiang Saen (Heath 1996).

Plain Martin has declined in Laos for unknown reasons. It was a common resident around the lower reaches of the Xe Banghiang river and its confluence with the Mekong (David-Beaulieu 1949-1950), and Engelbach (1932) observed it between Pakxe and Champasak in November and March (months that we were in the area). It was abundant on the Mekong in the Upper Mekong and Louang- 
phabang region, and over paddies in Ban Namkeung-Kao (Delacour and Greenway 1940) and occurred in north-east Laos (Delacour and Jabouille 1940) and Ban Muangyo (Bangs and van Tyne 1931).

\section{Wire-tailed Swallow Hirundo smithii At Risk in Thailand}

TMF: At Paksang, 6-12 on 14 February, 13 March and 22 June 1996 are minimum figures; the birds showed much territorial behaviour around the exposed rocks in the channel. In the Paksang-Ban Nasa area, 163 and 327 were seen on 14 and 15 July respectively. Both July counts probably under-represented the situation, by as much as $50 \%$, as many swallows seen were too distant to identify to species. Many juveniles were present and, as with Plain Martin, many additional birds had clearly moved into the area between June and July. NK: Five pairs in the $8 \mathrm{~km}$ between Keng Itat and Ban Phonsi on 28 January. Twenty-two, including four juveniles, between Ban Donme and the Nam An mouth in April. Three pairs were resident in the $6 \mathrm{~km}$ of the Nam Kading between Keng Maiha and the Theun-Hinboun dam site in December. During January the species became markedly commoner. Upstream of the dam site, 11 were seen moving upriver on 26 January, mainly as pairs. PXT: Common along the Mekong, especially where extensive rocky shelves constricted the flow of the river and produced numerous low cliffs. Much scarcer where earth or rocky banks lined wider reaches of the river. Summing maximum counts from each section of the Mekong suggested a minimum of 80 birds observed, of which at least 11 and perhaps 20 or more were juveniles. A preliminary estimate of 29-37 breeding pairs was made, based on counts of separate groups and individuals presumed to represent breeding pairs. The lower figure is derived from the number of apparent pairs during the earlier part of the survey, the higher number during the last week. No explanation for the discrepancy between these two periods can be offered. The area around Ban Thakhanxomxua was not visited but is likely to support several more pairs. XNN: Up to six along the cliff at the proposed Xe Namnoy dam site presumably included the foraging birds encountered up and down the river and around Nong Lom. A family of five on the lower Xe Namnoy. Odd pairs were seen sporadically near flowing water throughout the area. BSW: Two at a waterfall $5 \mathrm{~km}$ downstream of Ban Houayko in April 1995. SMK: Two at Khonphapheng Falls (February 1993); a single near Ban Thakho by the Mekong (4 February 1993). Up to three were seen at Ban Hangkhon, Champasak Province, on several days, with one $2 \mathrm{~km}$ upstream in May 1996. Elsewhere, recorded from Don Phakan (seven), Don Ngiou (two), Don Phaling (two), Don Kho (two), Don Pong (two) and Don Che/Don Cha (at least 15). Some of these totals may include juveniles. XP: About 20 on 13 March 1993 along $45 \mathrm{~km}$ of the Xe Kong river between the Xe Pian-Xe Kong confluence and Senamsai; 3-5 there in May 1995 and two in September 1996.

Historical data are too imprecise to be confident that a change in status has occurred. Engelbach (1932) found the species on the Mekong and Xe Kong rivers but gave no assessment of status. Numbers were stated as very small on the Mekong, although birds abounded on the middle and lower Xe Banghiang in Savannakhet Province, with several thousands once seen together (David-Beaulieu 1949-1950). Bangs and van Tyne (1931) noted small numbers in 
the North on the Nam Ou river downstream of Ban Thenkhen and on the Mekong south of Ban Paksi. Although numbers of the same magnitude as DavidBeaulieu's have not been seen in recent years, the seasonal pattern of abundance at the TMF, and the fact that the specific location of David-Beaulieu's single very large count has not been revisited, indicate that caution must temper any assumption that a major decline has occurred.

Recent records came from the larger rivers wherever there were rocky outcrops in the river channel which stood more than about $2 \mathrm{~m}$ above seasonal low water levels. Isolated rocky features were often occupied along long stretches of otherwise unsuitable river course. The bulk of the population is along the Mekong. The Xe Namnoy was the narrowest occupied river found so far: at the breeding site, where constricted by rapids, it was only about $6 \mathrm{~m}$ wide, but elsewhere was 15-20 $\mathrm{m}$ wide.

Birds nest in river rocks (and occasionally on bridges across rivers) and feed along rivers in the vicinity of the nest-site. Breeding activity commences around midwinter: in NK, birds were seen investigating suitable riverside rocks for crevices in mid-December, and mating on 25 December; a pair had just started nestbuilding at Keng Itat on 28 January. In early February, birds were seen prospecting for nest-sites at the Khonphapheng Falls. Many young birds fledged in PXT in the last week of March, and juveniles were observed at TMF in June.

During the dry season, birds were mostly in pairs or parties of up to ten, but larger parties were noted in PXT in late March and very much larger numbers in TMF during the early part of the wet season. It is likely that some shortdistance seasonal movement occurs between breeding and non-breeding areas, and that large flocks occur only outside the breeding season.

Hydroelectric dams are expected to affect several populations of this species, for example in XNN and NK, but their adaptability to reservoirs is not known. They nested on the Ban Pakkading bridge in 1995.

\section{Grey-bellied Tesia Tesia cyaniventer At Risk in Thailand}

XS: Common in forest and thick secondary growth, throughout surveyed areas of Phou Ajol and the Dakchung Plateau.

Previously, singles were recorded from east of Ban Nape (Delacour 1929) and at $400 \mathrm{~m}$ at Ban Namkeung-Kao (Delacour and Greenway 1940). David-Beaulieu (1939) recorded the species from Tranninh, but later (David-Beaulieu 1944) failed to refer to it, presumably attributing his earlier records to Slaty-bellied Tesia $T$. olivea. At the time of these historical records, the taxonomy of these two tesias was uncertain. Ludlow and Kinnear (1937) summarised the differences between the two forms, which had previously been confounded under $T$. cyaniventer, but fell short of expressing an unambiguous view that the two were separate species. It is therefore possible that some confusion surrounds the naming of these tesias in historical accounts and a careful review of all existing specimens is needed. Delacour and Jabouille (1940) accepted that two species were involved and considered that $T$. cyaniventer (sensu stricto) occurred throughout Laos. Primary evidence for the species's occurrence in the South was not given and has not been traced. Delacour and Jabouille (1940) recorded Slaty-bellied in Laos only in the North. Slaty-bellied Tesia has been recorded recently in areas of NNT and NTX, 
including the Ban Nape area where Delacour (1929) recorded birds that he referred to Grey-bellied.

Ashy-throated Warbler Phylloscopus maculipennis At Risk in Thailand

XS: Recorded once in upper montane forest on 13 May at 1,950 m on Phou Ajol. The sole historical Lao record is of one at Phou Bia (North Laos) in December 1946 (David-Beaulieu 1948).

\section{Yellow-vented Warbler Phylloscopus cantator Globally Near-Threatened}

PKK: One at $350 \mathrm{~m}$ along the Nam Mang on 9 November 1994. NTX: Occasional around the Nam Kwai site in 1994. One at $800 \mathrm{~m}$ in April 1996 along the Ban Nahoua logging road. NNT: Common in 1994 in the dry evergreen forest of the Northern Mountains, around the Middle Nam Xot and around Ban Nakadok (500-800 m). NP: Frequent around Ban Namxot in 1994. There were no records in 1995. Other: A single seen north-west of Louang-Namtha in December 1995 (J. N. Dymond in litt. 1995).

Historically, this species was recorded from Ban Muangyo (Bangs and van Tyne 1930, 1931) and described as rare in the high plains of Tranninh and the lower altitudes of Ban Thaviang (David-Beaulieu 1944).

The lack of records from NP in 1995 may indicate sporadic occurrence, although the species may have been overlooked as observations away from the river were less extensive than in 1994 and boat-based observers paid little attention to small arboreal birds. Surveys of NNT, NTX and NP in 1996 were perhaps too high or brief to detect the species.

\section{Broad-billed Warbler Tickellia hodgsoni Globally Near-Threatened}

The sole Lao record is of one near Ban Na Khang (North Laos) at 1,500 m on 29 February 1940 (David-Beaulieu 1944).

\section{Rufous-faced Warbler Abroscopus albogularis At Risk in Thailand}

PDD: Two singles in Phou Dendin NBCA (800 $\mathrm{m}$ and 1,100 m), 28 and 29 May 1995. One or more in scrub on 24 March 1996 near Ban Talung around 1,000 m; in scrub on a ridge above Ban Sop Kan at $700 \mathrm{~m}$ on 25 March 1996. NK: Up to two groups seen daily in the higher Nam An valley (above $700 \mathrm{~m}$ ). Common in the Nadi limestone area down to 600 m. NTX: Common in 1994 around the Nam Kwai site and in 1996 along the Ban Nahoua logging road and in the Nam Cham area (2-5 small parties daily). NNT: Common in 1994 in mixed-species flocks in the dry evergreen forest of the Northern and Central Mountains (600-1,800 m). Up to three birds seen in almost every mixed-species flock found along the Ban Navang logging road in 1994, 1995 and 1996. In December 1995, probably common in transitional dry/wet evergreen forest $\left(645^{-800} \mathrm{~m}\right)$ in the upper Nam On catchment.

Historical records came only from Tranninh, where it was quite common in forest understorey above 1,200 m (David-Beaulieu 1944). 


\section{Black-hooded Laughingthrush Garrulax milleti Globally Threatened}

XS: Observed on at least three occasions at different locations: on 17 May at $1,450 \mathrm{~m}$ a single bird was observed but several others were heard in the vicinity; on 22 May three birds out of a larger flock were seen at 1,250 m; and on the same day another flock was briefly glimpsed at $1,350 \mathrm{~m}$. The species was also probably encountered at 1,550 m on 19 May. It may be common; relatively little time was spent in the altitude range from which most of the records came.

This species has not previously been recorded from Laos. All former records have come from Vietnam (Collar et al. 1994). The extent of habitat within the altitudinal range recorded is quite limited in South Laos, and the species may be vulnerable to habitat loss.

\section{Grey Laughingthrush Garrulax maesi Globally Near-Threatened}

NK: Common above $700 \mathrm{~m}$ (1-2 fairly large parties daily) in the higher Nam An valley, and one near the upper reaches of the Houay Basong. NTX: The commonest laughingthrush, usually with 3-5 parties encountered daily around the Nam Kwai site $(600-900 \mathrm{~m})$ in 1994, and the Ban Nahoua logging road (in Fokienia forest and at 500-1,000 $\mathrm{m}$ in dry evergreen forest) in 1996. In the Nam Cham headwaters only $1^{-2}$ groups seen daily. NNT: The commonest laughingthrush in the forests at $600-800 \mathrm{~m}$ at the head of the Nam Pheo valley in Tasaeng Theung and in dry evergreen forest above 1,000 $\mathrm{m}$, including the Fokienia forest area, in the Central Mountains. Several parties (up to six along the Ban Navang logging road, and 1-3 elsewhere) were encountered each day in these areas. The species was absent or much less common in the dry evergreen forest below $900 \mathrm{~m}$ elsewhere in the reserve, where White-crested G. leucolophus was the commonest flocking Garrulax. At least some flocks contained over 20 birds.

Delacour (1929) found that it was numerous in damp forest east of Ban Nape. It was local in Tranninh although abundant around Xiangkhouang (Delacour 1926, Delacour and Jabouille 1927) and rather rare on Phou Kabo at 1,800-2,000 m (David-Beaulieu 1944).

\section{White-cheeked Laughingthrush Garrulax vassali (formerly Globally} Near-Threatened)

XS: Two records: a large flock in scrub close to degraded forest and a flock in secondary forest $(1,200 \mathrm{~m})$ in the Ban Tangyoun area on 21-22 May 1996. These habitats and altitude were surveyed only briefly. XNN: Common above $800 \mathrm{~m}$ in evergreen forest and in extensive areas of scrub provided that they contained some old secondary growth. Several flocks could be seen per day. DHS: Frequent in dry evergreen forest above $1,000 \mathrm{~m}$ around the upper Houay Namphak.

Formerly, this bird had been found commonly in the Muang Somoy region (David-Beaulieu 1949-1950) and the Bolaven Plateau above $800 \mathrm{~m}$ (Engelbach 1932). Elsewhere it occurs only in southern and central Annam, Vietnam (King et al. 1975, Robson et al. 1989, 1993a,b) and Cambodia (Duckworth and Hedges 1998). In Vietnam it is not considered to be at risk, owing to its wide habitat choice, including grass, scrub and forest edge (Robson et al. 1993b). 
In DHS and XNN it occurred in large flocks (often 10-30 birds), often in association with other passerine species and woodpeckers.

\section{Spot-breasted Laughingthrush Garrulax merulinus Globally Near-Threatened}

One was recorded from Xiangkhouang on 6 January 1926 (Delacour and Jabouille 1927) and there were three records from Phou Kabo in understorey shrubbery at 1,800-2,000 m (David-Beaulieu 1944). All records were of the form obscurus rather than the highly distinctive (and possibly specifically distinct: N. J. Collar verbally 1997) annamensis. Delacour and Jabouille (1931) reassigned the 1926 bird from the nominate to obscurus.

\section{Red-tailed Laughingthrush Garrulax milnei Globally Near-Threatened}

NNT: Common above 1,000 $\mathrm{m}$ in the Central Mountains in 1994 and 1996. XS: Probably common, encountered four times on the slopes of Phou Ajol, in dry evergreen and Fokienia forest (up to 1,750 m) in May 1996. The species was also recorded in degraded dry evergreen forest $(1,200 \mathrm{~m})$ close to Ban Tangyoun on 21 May 1996. DHS: Frequent above 1,000 $\mathrm{m}$ around the upper Houay Namphak but not in forest isolates or in scrub. Other: One corpse in a market in Xam-Nua (Salter 1993).

The species was historically common on the Bolaven Plateau above $800 \mathrm{~m}$ (Engelbach 1932) but very rare in Tranninh, being found only at three highaltitude sites (Delacour and Jabouille 1927, David-Beaulieu 1944).

Round (1988) referred to its occurrence in scrub in Thailand and suggested that it is not under serious threat there; but it has not been found in such habitat in Laos. Recently observed birds seemed more secretive than White-cheeked Laughingthrush and less likely to associate with mixed-species flocks. They usually moved in groups of 2-4. The species was not recorded from the Bolaven within XNN, perhaps as a consequence of its lower altitude than DHS (mostly below $800 \mathrm{~m}$ ).

\section{Short-tailed Scimitar-babbler Jabouillea danjoui Globally Threatened}

NTX: A presumed pair on 28 January 1994 at $750 \mathrm{~m}$ close to the Nam Kwai. NNT: Two in a mixed-species flock including Bar-backed Partridge on 27 December 1995 in the Nam On catchment $(800 \mathrm{~m})$, and other groups possibly heard on two occasions.

These are the first records for Laos (Mlikovsky and Inskipp in prep.) of a species previously believed to be endemic to Vietnam. Both encounters were of birds foraging on the ground. Those in NTX seemed to be probing the soil with their bills; on approach they made scolding calls at the observer for a short time before resuming such foraging.

\section{Spotted Wren-babbler Spelaeornis formosus Globally Near-Threatened}

NTX: Several were heard and one seen in wet evergreen forest at $600-900 \mathrm{~m}$ around Nam Kwai during 26 January-2 February 1994. 
There were no previous records from Laos (Mlikovsky and Inskipp in prep.). The only other record for Indochina was in West Tonkin, Vietnam, in May 1995 (Robson 1995).

\section{Sooty Babbler Stachyris herberti Globally Threatened}

KML: Three groups (of up to three birds) on fairly open vegetated karst at $280-$ $480 \mathrm{~m}$ on 16 and 17 May 1995. The groups were $200 \mathrm{~m}$ apart along a $1.5 \mathrm{~km}$ stretch of limestone close to Ban Vangdao. HNN: Common ( $\mathrm{I}-4$ flocks daily) in January 1996 at the Houay Clocc and Houay Talee sites, making it one of the commonest bird species recorded at these sites. All but one flock were associated with areas with visible limestone rocks, be it scattered boulders beneath tall closed-canopy forest or more sparsely vegetated karst. The exception was a group perhaps a hundred metres from rock or karst. Other: Two to three flocks of up to 12 seen on Sayphou Loyang, near Ban Poung, on 17 and 18 January 1996. The species was not recorded on five other visits to this area of limestone between 1994 and 1996 .

Until 1994, this babbler was known to science only from five collected in the centre of the area now forming KML on 24 February 1920 (Baker 1920, 1921, Williamson 1945). The localities given for the collection site in these sources are incorrect (D. Brandon-Jones in litt. 1994). We believe the true site is Ban Na Sao (coordinates $17^{\circ} 53^{\prime} \mathrm{N} 104^{\circ} 37^{\prime} \mathrm{E}$ ) which is very close to Ban Phontiou. This accords with the expedition diary which is held at the Zoological Reference Collection in Singapore (D. Brandon-Jones in litt. 1994). This area has not been visited recently, and it is not clear if there is still a village at the location. Kloss (1921) suggested Ban Na Sao was near the present-day location of Ban Lak (20) but did not name it as such or give geographical coordinates for it. The locality was believed to be Ban Lak 20 (= Ban Lak Sao), by Eames et al. (1995), although this name is not used in the primary references. The only other record of this species anywhere is from Vietnam in 1994 from limestone within Phong Nha Cultural and Historical Reserve; this reserve lies $20 \mathrm{~km}$ to the east of HNN (Eames et al. 1995).

Birds were building a nest on a ledge in a hollow in tree-enclosed karst on 16 and 17 May 1995. Two birds brought fibrous and leafy material to the site regularly and a third bird was seen occasionally. The nest-site was on a $2.5 \mathrm{~m}$ high rock-face. Most flocks in HNN seemed large, in some cases over 20 birds. They were not usually with mixed-species flocks, although Lesser Dicrurus remifer or Greater Racket-tailed Drongos $D$. paradiseus were the species most frequently in association. On one occasion a flock responded to alarm calls of a racket-tailed drongo by rapidly flying to the ground. Flocks were mainly seen moving over the surface of karst limestone, or the understorey of associated vegetation, but flocks were also seen in the canopy layer. Birds investigated crevices in the karst and picked through leaf-litter. One bird in KML was seen to take a stick-insect (Phasmida) from a low tree branch; in HNN birds were seen on several occasions hammering small snail shells against rocks.

The abundance of this species in its restricted (and largely invulnerable) habitat, and its presence in several separate areas of karst limestone, suggest that it is not immediately threatened. One possible threat is the clearance of patches of tall forest at the foot of the karst, which may prove to be an important habitat 
component. Until this possibility has been studied, it may be appropriate to consider this species Globally Near-Threatened.

\section{Grey-faced Tit-babbler Macronous kelleyi Globally Near-Threatened}

PXH: Heard daily in small numbers in semi-evergreen forest, but probably rather local. PXT: One on 7 March 1996 in a belt of semi-evergreen forest along a stream in dry dipterocarp forest near Ban Donkoum. XNN: Scarcer than in BSW, but still frequent, in the evergreen forest on the Bolaven Plateau at $750-850 \mathrm{~m}$, including tall secondary growth. DHS, XP: Very common (sometimes dozens daily) in semi-evergreen forest, but much scarcer in heavily degraded areas, much scarcer in areas of XP above $350 \mathrm{~m}$ and not found on the plateau in DHS. BSW: One of the most abundant birds in both logged and unlogged semi-evergreen forest around the Xe Pian $(200-300 \mathrm{~m})$. Several heard at $300-600 \mathrm{~m}$ along the valley of the Xe Pian.

DHS, XP and BSW support very large numbers of this species, but this abundance is not mirrored elsewhere in Laos. The lack of records from XBN and the great scarcity in PXT were particularly surprising. Engelbach (1932) had previously found it in dense lowland forest near Pakxe, coexisting with Striped Titbabbler $M$. gularis. In contrast to the latter, it was not found to venture into secondary scrub, nor was it found at Salavan (Delacour 1932).

Recent records, except around XNN, came from below $400 \mathrm{~m}$, although Robson et al. $(1993 \mathrm{a}, \mathrm{b})$ recorded birds at 1,080 $\mathrm{m}$ in Vietnam and Duckworth and Hedges (1998) found it at $900 \mathrm{~m}$ in eastern Cambodia. Robson et al. (1991) found the species commonly in logged and secondary forest.

The behaviour and ecology was similar to Striped Tit-Babbler, although Greyfaced seemed to occur less often in the understorey. Groups of up to six freely associated with mixed-species flocks.

\section{Chestnut-tailed Minla Minla strigula At Risk in Thailand}

NNT: Common above $1,800 \mathrm{~m}$ on Phou Laoko in April 1994 and present on an exposed summit of about $1,750 \mathrm{~m}$ above the Houay Morrow valley, often in the understorey in mixed-species flocks.

It was abundant at $1,800-2,817 \mathrm{~m}$ on Phou Bia and probably rare on Phou Kabo (David-Beaulieu 1944).

\section{Yellow-throated Fulvetta Alcippe cinerea Globally Near-Threatened}

Recorded in Laos only from south-east Tranninh, where it was uncommon on Phou Kabo and abundant at Ban Muang-Ngat (David-Beaulieu 1944).

\section{Spectacled Fulvetta Alcippe ruficapilla Globally Near-Threatened}

NNT: A pair in the understorey of upper montane forest on the main summit ridge of Phou Laoko $(2,150 \mathrm{~m})$. The subspecies involved may be A. r. danisi (C. 
Robson in litt. 1994). XS: Very common, generally encountered in groups of two in low-stature upper montane forest on ridges above $1,800 \mathrm{~m}$.

A. r. danisi was previously found once on Phou Kabo (where believed to be rare) at 2,000 $\mathrm{m}$ and was very common at 2,500-2,800 $\mathrm{m}$ on Phou Bia (Delacour and Greenway 1941, David-Beaulieu 1944). These are the only confirmed records of this race, but there are unconfirmed records from Yunnan and Guizhou Provinces in China (Eames et al. 1994b).

All Lao records came from upper montane forest, as did the recent record of this species from Vietnam (Robson et al. 1993b).

\section{Rufous-throated Fulvetta Alcippe rufogularis Globally Near-Threatened}

PDD: One in bamboo scrub at $900 \mathrm{~m}$ on a ridge above the Nam Kang. PKK: Common in evergreen forest around the Nam Mang, with flocks of up to six on most days; one associating loosely with a mixed-species flock about $3 \mathrm{~km}$ east of the Nam Leuk dam site (310 m). TMF: In 1996, this species abounded throughout all relict forest, even in deciduous areas and those with a predominance of bamboo, and was occasional in scrub on old cultivation. Up to nine groups (usually of two, sometimes three, or, in June-July, four) were found daily. During the period of peak song (April, when no survey work was conducted) even higher numbers would probably have been recorded. A nest with young chicks was found on 6 July. NK: Up to four heard daily in the lower Nam An valley and on the lower parts of the south slope of Sayphou Ao, and fewer on the northern slope (where fieldwork was concentrated in the upper regions of the slope). Up to eight records daily in more level forest around the karst limestone outcrop north of the Nam Xouang, probably the most degraded forest in the NBCA survey area in which they were found. There were three records from a stream valley within the Nadi limestone. A very dense population of this species was found in the Nam Ao forest, frequently with up to 20 records per day. There was a single record on the slope to the north above the Nam Hai-Nam Hinboun Plain. NNT: Three groups (of five, two and two) and a single around the Nam Kata catchment near Ban Nakadok in January 1994. NP: One heard near Ban Sop-On in 1994. In 1995 the species was heard frequently (a few birds on most days) over a wide area mainly from strips of evergreen forest/semi-evergreen forest. The increase in records resulted from increased familiarity with its vocalisations. PXH: Common in relatively undisturbed dry evergreen forest on Phou Hinho. Other: Two records in roughly half-a-day's searching in the area around Keng Luang on the Nam Theun in January 1995.

It was previously known from Central Laos at Nam Theun (Delacour 1929); and from the North in Tranninh (Delacour and Jabouille 1927, David-Beaulieu 1944), Ban Pakmet (Baker 1920, Kloss 1921), Ban Muangyo and Ban Boun-Tai (Bangs and van Tyne 1931).

Those in NNT, NP, NK and PXH were predominantly associated with damp stream valleys on dry evergreen forest slopes at mid-altitudes $(200-800 \mathrm{~m})$. One of the densest populations so far found, in the Nam Ao forest, was in a complex of moist gullies in dry evergreen forest on relatively flat terrain. At PKK, birds seemed commonest in dense low vegetation within unlogged dry evergreen 
forest, especially where the floor was carpeted by monocotyledonous herbs. However, the bird near the Nam Leuk was in an area of extensive bamboo regrowth. The population at TMF was common in a variety of degraded forest types.

The forms A. r. major and A. r. blanchardi are recorded from Laos (Deignan 1964). David-Beaulieu (1944) found both (not overlapping) in Tranninh, but otherwise there is no historical information on areas of contact. The subspecies of the recently observed populations in Laos have not been determined. Different subspecies may inhabit different habitats. A. $r$. major in Thailand is limited to little-degraded forest on the lower hill slopes (Round 1988, Lekagul and Round 1991). This form may thus be threatened by forest loss. More recently, Robson $e t$ al. (1993a) recorded the species (presumably A. r. blanchardi on range) at two sites in North Annam in primary, logged and secondary evergreen forest. This form may therefore be less susceptible to habitat degradation.

Birds were often in monospecific small groups of up to six birds, especially at dusk when they were often found bathing in secluded streams. They also occurred in mixed-species flocks, most commonly associating with Buff-breasted Pellorneum tickelli, Grey-throated Stachyris nigriceps and Spot-necked Babblers S. striolata.

\section{Mountain Fulvetta Alcippe peracensis Rare in Thailand}

HNN: Commonly recorded at the southern end of the reserve, in a mosaic of secondary and degraded forest. Fulvettas were not recorded at the northern end of the reserve, but Grey-cheeked Fulvetta A. morrisonia was found a few $\mathrm{km}$ further north in the southern escarpment of NNT. PXH, XP, DHS: Common in semi-evergreen and dry evergreen forest, including extensive areas of logged forest at DHS, but markedly rarer in drier or more open forest. XS: Common in evergreen and Fokienia forest at 1,700 $\mathrm{m}$ and below on Phou Ajol, and common in extensive low secondary growth of the Dakchung Plateau. BSW, XNN: Common in semi-evergreen and evergreen forest, logged forest and drier or more open forest.

Two forms of Mountain Fulvetta were seen, as detailed in Thewlis et al. (1996). They were altitudinally allopatric, with the lowland form (found at all sites except $\mathrm{XS}$, ranging up to $850 \mathrm{~m}$ in XNN) believed to be A.p. grotei and the montane form (only above $1,000 \mathrm{~m}$ in DHS and XS, although provisionally recorded at $200 \mathrm{~m}$ in PXH) A. p. annamensis. The species is common and widespread in Laos, with no apparent threats; it was only considered of concern in Thailand because of its naturally small range there (Round 1988). Historical records suggest a similar range and status for the two forms, as summarised in Thewlis et al. (1996).

Robson et al. (1993b) suggested that A. p. grotei might be more appropriately treated as a full species. However, the status of neither A. p. grotei nor $A$. $p$. annamensis in Laos gives cause for concern: despite their fairly limited range within Laos both forms appear to be tolerant of habitat degradation.

Remarkably, no species of Alcippe was found in PXT or XBN.

Whiskered Yuhina Yuhina flavicollis At Risk in Thailand

PDD: Two near the Vietnamese border on 22 March 1996 at 1,600 $\mathrm{m}$ in an isolated fragment of dry evergreen forest $1 \mathrm{~km}$ north-west of Phou Dendin; the following 
day, $5-8$ birds were in a small forest patch surrounded by burnt-out areas and grassland, $1 \mathrm{~km}$ east-south-east at 1,790 m. NNT: Common in April 1994 above $1,800 \mathrm{~m}$ on Phou Laoko and present on an exposed summit at $1,750 \mathrm{~m}$ above the Houay Morrow valley.

The few past records were from near Phongsali (Bangs and van Tyne 1931), on Phou Kabo (where abundant) and generally elsewhere in Tranninh above 1,200 m (David-Beaulieu 1944).

Spot-breasted Parrotbill Paradoxornis guttaticollis At Risk in Thailand (formerly Globally Near-Threatened)

PDD: Two or more at 1,100 $\mathrm{m}$ on 24 March 1996 in tall grass on the edge of secondary forest between Ban Than and Ban Talung. Other: Singles seen on 18 and 21 May 1996 on a mountainside $4 \mathrm{~km}$ south-west of Ban Keoleuk, Xiangkhouang Province $(1,200 \mathrm{~m})$ in a mosaic of grass and burnt scrub, lacking extensive bamboo.

Historical records all came from the North: four at Phongsali (Bangs and van Tyne 1931), common over 1,200 $\mathrm{m}$ in Tranninh, particularly on Phou Chong Vong (David-Beaulieu 1944), and common in herbs and bushes at Taloun (Delacour and Greenway 1940).

\section{Short-tailed Parrotbill Paradoxornis davidianus Globally Threatened}

TMF: Common in February-March 1996 (one or two flocks seen daily when suitable habitat was surveyed), principally in mature bamboo. One record in June-July 1996, when little fieldwork was conducted in suitable habitat. Maximum flock size was at least eight, possibly 15. Other: One on a mountainside $4 \mathrm{~km}$ south-west of Ban Keoleuk, Xiangkhouang Province $(1,200 \mathrm{~m})$ on 18 May 1996 in a mosaic of grass and scrub, some of which was burnt, lacking extensive bamboo.

The species has been observed at very few other sites in the world in recent decades, and the TMF appears to be the only one where it was shown to be common (see Collar et al. 1994, Rank 1996, J. N. Dymond in Round 1996, J. C. Eames verbally 1997). The few other Lao records came from further north: LoTiao and Ban Houayxai (Delacour and Greenway 1940) and Ban Namkeung-Kao (Delacour and Jabouille 1940). The reasons for the species's highly localised distribution within its restricted range (northern Thailand, Laos, Burma and Vietnam and adjacent China: Collar et al. 1994) remain obscure.

\section{Lesser Rufous-headed Parrotbill Paradoxornis atrosuperciliaris Globally Near-} Threatened

The only Lao record is of a small flock at Ban $\mathrm{Na}$ Khang at $1,400 \mathrm{~m}$ (David-Beaulieu 1948).

Greater Rufous-headed Parrotbill Paradoxornis ruficeps Globally NearThreatened (formerly Globally Threatened)

The only two Lao records, of flocks at 1,800 $\mathrm{m}$ on Phou Kabo and at 1,400 $\mathrm{m}$ at Ban Na Khang, are both from Tranninh (David-Beaulieu 1944). 


\section{Yellow-bellied Flowerpecker Dicaeum melanoxanthum Rare in Thailand}

There are no recent records from Laos. Historically, one was collected on Phou Bia at 2,700 $\mathrm{m}$ (David-Beaulieu 1944) and birds were common in the urban centre of Xiangkhouang which, at 1,150 m, may be the lower altitudinal limit of the bird (David-Beaulieu 1948). The assessment as "common" should be viewed with caution, however, as David-Beaulieu had not observed the bird in Xiangkhouang by 1944 despite his residence in the town. This suggests that the bird was either local or irregular in occurrence in the town. Care would be needed in comparing its status there today with David-Beaulieu's assessment.

\section{Green-tailed Sunbird Aethopyga nipalensis At Risk in Thailand}

NNT: Common above $1,800 \mathrm{~m}$ on Phou Laoko in April 1994. XS: Common on Phou Ajol above $1,450 \mathrm{~m}$, but much less common below this altitude down to $1,400 \mathrm{~m}$, in May 1996.

Past Lao records come only from Tranninh at Phou Kabo, where not abundant, and Phou Bia, where common over 2,00o m (David-Beaulieu 1944). The birds at Phou Kabo were named as a new subspecies, A. n. blanci (Edmond-Blanc 1944); the subspecies of recent birds was not established. Although the species must have a very small area of occupancy in Laos, its mountaintop habitats are probably relatively safe.

\section{Asian Golden Weaver Ploceus hypoxanthus Globally Near-Threatened}

XP: [At least ten (identification provisional) in a mixed-species roost in thick vegetation at the edge of Nong Puler (Xe Kong plains, March 1993). The roost also included 40 unidentified weavers and 100 Scaly-breasted Munias Lonchura punctulata. Up to three were seen at another pool $2 \mathrm{~km}$ distant. This record was inadvertently published without a caveat by Anderson (1993).] DKT: Two males and possibly a female in sedge-like vegetation around a pool $10 \mathrm{~km}$ south-east of Ban Khiam on 3 May 1996. Seventeen birds and numerous nests were seen in a complex of pools $3-5 \mathrm{~km}$ north of Ban Khiam. Seven birds and further nests were also seen at a pool between Ban Khiam and Ban Vin-Tai. The very conspicuous nests of this species were seen at several more pools during aerial surveys on 17 August 1996.

These are the only Lao records. The species seems likely to be threatened by intensification of human use at the remote wetlands it occurs in. Cultivation, cutting for thatch, collection of nests and heavy grazing by domestic stock are all possible threats.

\section{Pin-tailed Parrotfinch Erythrura prasina At Risk in Thailand}

PKK: Two single males around the Nam Mang, one in one of the better areas of forest and the other in coarse streamside herbage. TMF: A male on 6 March 1996 in coarse herbs beside the Nam Him. A flock of under ten, including at least two dependent juveniles, near Ban Napo on 29 June-1 July. A flock of at least 30 (probably four or five times this number) in a large stand of bamboo (in seed) 
west of Ban Kuai during 3-6 July. NK: Three or four large flocks (some exceeding a hundred) and numerous small parties were seen daily in the Nam Ao forest in January 1995. In the forests of the rest of the NBCA, numbers rarely exceeded a dozen. All these records were in areas of seeding bamboo. A single was seen in the level lowland forest on the northern fringe of the Nam Hai-Nam Hinboun plain, where no bamboo was found. NNT: Two females in a mixed-species flock on 4 May 1996 along the Ban Navang logging road (1,000 m).

This is a notably nomadic and irruptive species (Smythies 1981), so accurate status assessment is difficult. Historically, it was recorded in the mountains of the north-west as well as the Mekong valley at 400-1,500 m; it was particularly numerous around Lo-Tiao and $5 \mathrm{~km}$ from Ban Namkeung-Kao (Delacour and Greenway 1940). David-Beaulieu (1949-1950) found a flock in the Xe Pon area, 1.5 days' walk from Muang Phin (not far from PXH); this was his only sighting in several years. They were along a small tributary of the Xe Nam-Kok.

Single birds showed long periods of inactivity, meaning that when not in flocks the species may be overlooked.

\section{Discussion}

This discussion has several aims: (1) to link together species that have declined in areas of remaining habitat in Laos since the first half of the twentieth century and/or are currently at risk in Laos and to identify the threats facing them; (2) to suggest species for which populations in Laos are particularly important on a global scale; (3) to outline the implications of these findings for conservation (where a Lao population is both internationally important and declining, urgent action is required, and it is particularly needed in sites with concentrations of higher priority species); $(4)$ to outline future survey needs. For each species, the risk category in Laos, the global importance of the Lao population and the action priority are summarised in Table 3 .

\section{Limitations of analysis}

The analysis has a number of limitations arising from an incomplete information base. For many species National Historical Declines could not be demonstrated, either because the historical evidence is too poor or because insufficient recent survey effort has been spent in suitable areas to determine the current status of populations; often, both factors are at work. The few species for which good historical information exists and insufficient recent fieldwork appears to be the hindrance to accurate assessment are highlighted in Table 3.

Similarly, the global importance of the populations of many species cannot be determined, and no quantitative thresholds for the categories could be set. In Laos, many of them were predominantly recorded from the north, outside the foci of recent surveys. The remainder include species for which even small populations (if present) might be globally significant (e.g. Indian Skimmer, Blackbellied Tern), members of difficult species groups (e.g. Wood Snipe and the green-pigeons), secretive or nocturnal species (e.g. Schrenck's Bittern and the owls) and five species with modest populations in Laos for which a clear picture of status in other range states was not available for comparison (Yellow-footed 
Table 3. Key bird species in Laos: international threat status, risk status in Laos, global importance of Lao population, and action priority

\begin{tabular}{|c|c|c|c|c|c|}
\hline Species & $\begin{array}{c}\text { International } \\
\text { threat } \\
\text { status }\end{array}$ & $\begin{array}{c}\text { National } \\
\text { Historical } \\
\text { Decline }\end{array}$ & $\begin{array}{c}\text { Risk } \\
\text { status } \\
\text { in Laos }\end{array}$ & $\begin{array}{c}\text { Global } \\
\text { importance }\end{array}$ & $\begin{array}{l}\text { Action } \\
\text { priority }\end{array}$ \\
\hline Rufous-throated Partridge & ART & 0 & 0 & ? & 0 \\
\hline Bar-backed Partridge & ART & o & 0 & ? & o \\
\hline Silver Pheasant & ART & 0 & 0 & $\mathrm{C}$ & 0 \\
\hline Siamese Fireback & GT & o & PARL & HW & High \\
\hline Grey Peacock-pheasant & ART & o & o & C & 0 \\
\hline Crested Argus & GT & o & ARL & $\mathrm{H}$ & High \\
\hline Green Peafowl & GT & + & ARL & $\mathrm{H}$ & Acute \\
\hline White-winged Duck & GT & + & ARL & $\mathrm{H}$ & Acute \\
\hline Comb Duck & ART & o & PARL & $?$ & Inf \\
\hline Yellow-crowned Woodpecker & ART & o & PARL & o & Inf/Mid \\
\hline Crimson-breasted Woodpecker & ART & o & LK & ? & 0 \\
\hline White-bellied Woodpecker & ART & o & PARL & $\mathrm{C}$ & Mid \\
\hline Streak-throated Woodpecker & (ART) & o & PARL & $?$ & Inf \\
\hline Red-collared Woodpecker & GT & o & o & HW & o \\
\hline Black-headed Woodpecker & ART & o & o & $\mathrm{C}$ & 0 \\
\hline Pale-headed Woodpecker & $\mathrm{ART}$ & o & o & $\mathrm{C}$ & o \\
\hline Red-vented Barbet & (GNT) & o & 0 & HW & 0 \\
\hline Great Hornbill & ART & + & ARL & $?$ & High \\
\hline Brown Hornbill & GNT & ? & PARL & HW & Mid \\
\hline Rufous-necked Hornbill & GT & ? & ARL & $\mathrm{H}$ & High \\
\hline Wreathed Hornbill & ART & + & ARL & $\mathrm{C}$ & High \\
\hline Blyth's Kingfisher & GT & $?$ & PARL & $\mathrm{H}$ & Inf/Mid \\
\hline Ruddy Kingfisher & ART & o & LK & $?$ & o \\
\hline Crested Kingfisher & ART & ? & $o$ & 0 & 0 \\
\hline Pied Kingfisher & & + & ARL & 0 & Inf \\
\hline Coral-billed Ground-cuckoo & GNT & o & 0 & HW & 0 \\
\hline Alexandrine Parakeet & ART & + & ARL & o & Mid \\
\hline Spot-bellied Eagle-owl & GNT & ? & LK & ? & o \\
\hline Tawny Fish-owl & GNT & o & LK & $?$ & Inf \\
\hline [Blyth's Frogmouth] & ART & o & $o$ & $?$ & o \\
\hline Pale-capped Pigeon & GT & o & LK & $?$ & $\operatorname{lnf} /$ High \\
\hline Pompadour Green-pigeon & ART & + & ARL & ? & Mid \\
\hline Yellow-footed Green-pigeon & ART & + & ARL & o & Mid \\
\hline Yellow-vented Green-pigeon & GNT & 0 & LK & $\mathrm{C}$ & Inf \\
\hline White-bellied Green-pigeon & GNT & 0 & LK & $?$ & Inf \\
\hline Green Imperial-pigeon & ART & + & ARL & ? & Mid \\
\hline Sarus Crane & GNT & + & ARL & 0 & Acute \\
\hline Masked Finfoot & GT & o & ARL & $\mathrm{H}$ & High \\
\hline Wood Snipe & GT & o & LK & $?$ & $\operatorname{lnf}$ \\
\hline Great Thick-knee & ART & + & ARL & $?$ & High \\
\hline Long-billed Plover & GNT & o & LK & ? & Inf \\
\hline River Lapwing & & + & ARL & $\mathrm{C}$ & High \\
\hline Grey-headed Lapwing & GNT & o & PARL & HW & o \\
\hline Small Pratincole & ART & o & PARL & $C$ & o \\
\hline Indian Skimmer & GT & + & ARL & ? & Inf/Acute \\
\hline River Tern & ART & + & ARL & $?$ & High \\
\hline Black-bellied Tern & GT & + & ARL & $?$ & Inf/Acute \\
\hline Little Tern & & + & ARL & o & Mid \\
\hline Jerdon’s Baza & GNT & o & 0 & ? & $o$ \\
\hline Black-eared Kite & & + & ARL & o & Mid \\
\hline Brahminy Kite & & + & ARL & o & High \\
\hline White-bellied Sea-eagle & & + & ARL & $o$ & Inf/High \\
\hline
\end{tabular}


Table 3. cont.

\begin{tabular}{|c|c|c|c|c|c|}
\hline Species & $\begin{array}{c}\text { International } \\
\text { threat } \\
\text { status }\end{array}$ & $\begin{array}{c}\text { National } \\
\text { Historical } \\
\text { Decline }\end{array}$ & $\begin{array}{c}\text { Risk } \\
\text { status } \\
\text { in Laos }\end{array}$ & $\begin{array}{c}\text { Global } \\
\text { importance }\end{array}$ & $\begin{array}{l}\text { Action } \\
\text { priority }\end{array}$ \\
\hline Lesser Fish-eagle & GNT & + & ARL & $\mathrm{H}$ & High \\
\hline Grey-headed Fish-eagle & GNT & + & ARL & $?$ & High \\
\hline White-rumped Vulture & GNT & + & ARL & $\mathrm{H}$ & High \\
\hline Long-billed Vulture & GNT & + & ARL & $\mathbf{H}$ & High \\
\hline Red-headed Vulture & GNT & + & ARL & $\mathrm{H}$ & High \\
\hline Rufous-winged Buzzard & GNT & o & PARL & HW & Mid \\
\hline Greater Spotted Eagle & GT & 0 & LK & $?$ & $\operatorname{lnf} /$ Mid \\
\hline Imperial Eagle & GT & o & LK & ? & Inf/Mid \\
\hline White-rumped Falcon & GNT & ? & PARL & $\mathrm{C}$ & Inf \\
\hline Pied Falconet & GNT & ? & LK & $?$ & Inf \\
\hline Lesser Kestrel & GT & $?$ & LK & ? & Inf \\
\hline Oriental Darter & GNT & + & ARL & 0 & High \\
\hline Little Cormorant & & + & ARL & 0 & Inf \\
\hline Great Cormorant & ART & + & ARL & 0 & Inf/Acute \\
\hline Grey Heron & ART & + & ARL & 0 & Mid \\
\hline Purple Heron & ART & + & ARL & $o$ & Mid \\
\hline Malayan Night-heron & ART (GNT) & o & LK & C & 0 \\
\hline Schrenck's Bittern & GNT & o & LK & $?$ & o \\
\hline Black-headed Tbis & GNT & o & ARL & o & Inf/High \\
\hline White-shouldered Ibis & GT & + & ARL & $\mathrm{H}$ & Acute \\
\hline Giant Ibis & GT & o & ARL & $\mathrm{H}$ & Acute \\
\hline Spot-billed Pelican & GT & $?$ & ARL & 0 & Inf/High \\
\hline Painted Stork & GNT & + & ARL & $o$ & High \\
\hline Asian Openbill & GNT & 0 & ARL & $o$ & Mid \\
\hline Woolly-necked Stork & ART & + & ARL & ? & High \\
\hline Black-necked Stork & ART & + & ARL & o & High \\
\hline Lesser Adjutant & GT & + & ARL & $\mathrm{C}$ & Acute \\
\hline Greater Adjutant & GT & 0 & ARL & $\mathrm{H}^{*}$ & Acute* \\
\hline Blue-naped Pitta & GNT & 0 & LK & $?$ & 0 \\
\hline Blue-rumped Pitta & GNT & 0 & PARL & HW & 0 \\
\hline Bar-bellied Pitta & GNT (GT) & 0 & PARL & HW & 0 \\
\hline Black-and-red Broadbill & ART & 0 & $o$ & $o$ & 0 \\
\hline White-winged Magpie & GNT & 0 & PARL & $\mathrm{H}$ & Mid \\
\hline Yellow-breasted Magpie & GNT & 0 & PARL & HW & Mid \\
\hline Ratchet-tailed Treepie & (GNT) & 0 & 0 & HW & 0 \\
\hline Brown-rumped Minivet & GNT & 0 & 0 & $?$ & 0 \\
\hline Yellow-bellied Fantail & RIT & 0 & LK & o & 0 \\
\hline Japanese Paradise-flycatcher & GNT & 0 & LK & ? & 0 \\
\hline Brown Dipper & ART & $?$ & PARL & o & $\operatorname{Inf}$ \\
\hline Black-breasted Thrush & GNT & 0 & LK & ? & 0 \\
\hline Grey-sided Thrush & GT & 0 & LK & ? & o \\
\hline White-browed Shortwing & RIT & 0 & LK & $o$ & 0 \\
\hline [Fujian Niltava] & GNT & o & PARL & ? & Inf \\
\hline Blue-fronted Robin & GNT & 0 & LK & $?$ & Inf \\
\hline Green Cochoa & GNT & 0 & o & HW & 0 \\
\hline Jerdon's Bushchat & GNT & $?$ & PARL & $\mathrm{H}$ & Inf \\
\hline Golden-crested Myna & ART & o & PARL & $\mathrm{C}$ & Mid \\
\hline Hill Myna & ART & 0 & 0 & $\mathrm{C}$ & 0 \\
\hline Yellow-billed Nuthatch & GT & 0 & LK & ? & Inf \\
\hline Beautiful Nuthatch & GT & 0 & PARL & $\mathrm{H}$ & Inf/Mid \\
\hline Brown-throated Treecreeper & ART & 0 & LK & 0 & Inf \\
\hline Yellow-browed Tit & ART & $o$ & 0 & o & 0 \\
\hline Black-throated Tit & ART & 0 & 0 & C & 0 \\
\hline
\end{tabular}


Table 3. cont.

\begin{tabular}{|c|c|c|c|c|c|}
\hline Species & $\begin{array}{c}\text { International } \\
\text { threat } \\
\text { status }\end{array}$ & $\begin{array}{c}\text { National } \\
\text { Historical } \\
\text { Decline }\end{array}$ & $\begin{array}{c}\text { Risk } \\
\text { status } \\
\text { in Laos }\end{array}$ & $\begin{array}{c}\text { Global } \\
\text { importance }\end{array}$ & $\begin{array}{l}\text { Action } \\
\text { priority }\end{array}$ \\
\hline Plain Martin & ART & + & ARL & $?$ & Inf/Mid \\
\hline Wire-tailed Swallow & ART & $?$ & PARL & $?$ & o \\
\hline Grey-bellied Tesia & ART & 0 & o & 0 & o \\
\hline Ashy-throated Warbler & ART & o & o & $?$ & $o$ \\
\hline Yellow-vented Warbler & GNT & 0 & o & $?$ & $\operatorname{Inf}$ \\
\hline Broad-billed Warbler & GNT & 0 & LK & ? & Inf \\
\hline Rufous-faced Warbler & ART & $?$ & o & $?$ & o \\
\hline Black-hooded Laughingthrush & GT & 0 & PARL & $\mathrm{H}$ & Inf / Mid \\
\hline Grey Laughingthrush & GNT & 0 & 0 & HW & o \\
\hline White-cheeked Laughingthrush & (GNT) & o & 0 & HW & $o$ \\
\hline Spot-breasted Laughingthrush & GNT & 0 & LK & $?$ & Inf \\
\hline Red-tailed Laughingthrush & GNT & 0 & o & HW & $o$ \\
\hline Short-tailed Scimitar-babbler & GT & o & PARL & C & Inf \\
\hline Spotted Wren-babbler & GNT & 0 & PARL & $?$ & Inf \\
\hline Sooty Babbler & GT & 0 & PARL & HW & Inf \\
\hline Grey-faced Tit-babbler & GNT & 0 & o & HW & o \\
\hline Chestnut-tailed Minla & ART & 0 & 0 & o & 0 \\
\hline Yellow-throated Fulvetta & GNT & $?$ & LK & $?$ & Inf \\
\hline Spectacled Fulvetta & GNT & o & o & $\mathrm{HW}$ & o \\
\hline Rufous-throated Fulvetta & GNT & 0 & 0 & HW & 0 \\
\hline Mountain Fulvetta & RIT & 0 & 0 & $\mathrm{HW}$ & 0 \\
\hline Whiskered Yuhina & ART & 0 & 0 & o & o \\
\hline Spot-breasted Parrotbill & ART (GNT) & o & LK & $?$ & Inf \\
\hline Short-tailed Parrotbill & $\mathrm{GT}$ & 0 & LK & $\mathrm{H}$ & Inf \\
\hline Lesser Rufous-headed Parrotbill & GNT & 0 & LK & $?$ & Inf \\
\hline Greater Rufous-headed Parrotbill & GNT (GT) & 0 & LK & $?$ & Inf \\
\hline Yellow-bellied Flowerpecker & RIT & $?$ & LK & o & Inf \\
\hline Green-tailed Sunbird & $\mathrm{ART}$ & $?$ & o & $?$ & o \\
\hline Asian Golden Weaver & GNT & 0 & ARL & $?$ & Mid \\
\hline Pin-tailed Parrotfinch & ART & 0 & 0 & $?$ & 0 \\
\hline
\end{tabular}

In assigning urgency for action, factors not included in the preceding four columns of the table are sometimes used to determine the priority level accorded; thus for two species of pitta (Blue-rumped and Bar-bellied) and two of magpie (White-winged and Yellow-breasted), assessments in the first four columns are very similar yet urgency for action is different. This apparent discrepancy arises because both pittas have a wide geographical range in Laos, whereas recent records of both magpies come from a smaller area.

Explanation of column codings:

Species: Those in square brackets have not been confirmed as occurring in Laos.

International threat status GT: Globally Threatened. GNT: Globally Near-Threatened. ART: At Risk in Thailand. RIT: Rare in Thailand. Parentheses enclose a former threat category superseded by a later analysis.

National Historical Decline (in Laos) +: demonstrable decline has occurred between historical surveys (up to 1949) and the present day. ?: decline uncertain; collection of further modern data will allow decision as to whether decline has occurred. o: no decline is demonstrable, either because present status is the same as historical status or historical data are insufficient to permit such designation.

Risk Status in Laos ARL: At Risk in Laos in the short or medium term. PARL: Potentially At Risk in Laos. o: Not At Risk in Laos. LK: Level of threat to the species is Little Known in Laos (this category can be assigned even in the absence of a specific knowledge of the species's population).

Global importance H: confirmed as high global importance. HW: as high global importance and widespread in Laos. C: confirmed moderate global importance. ?: Global importance not known. o: not likely to be of global importance.

Action priority Acute, High, Mid and o represent decreasing priority of urgency of conservation action for the species. Inf: priority or type of action uncertain: further information required as a high priority. 
Table 4. Numbers of species in five categories and divided by habitat: At Risk in Laos, Potentially At Risk in Laos, Not At Risk in Laos, those for which level of threat is Little Known; plus those which have undergone National Historical Decline in Laos

\begin{tabular}{|c|c|c|c|c|c|}
\hline & $\begin{array}{l}\text { At Risk } \\
\text { in Laos }\end{array}$ & $\begin{array}{c}\text { Potentially At } \\
\text { Risk in Laos }\end{array}$ & $\begin{array}{c}\text { Not At Risk } \\
\text { in Laos }\end{array}$ & $\begin{array}{l}\text { Level of threat } \\
\text { Little Known }\end{array}$ & $\begin{array}{c}\text { National } \\
\text { Historical } \\
\text { Decline }\end{array}$ \\
\hline Wetlands & 31 & 5 & 2 & 4 & 24 \\
\hline $\begin{array}{l}\text { Open forest } \\
\text { types and scrub }\end{array}$ & 8 & 5 & 5 & 8 & 8 \\
\hline Dense forest & 5 & 15 & 27 & 20 & 3 \\
\hline Total & 44 & 25 & 34 & 32 & 35 \\
\hline
\end{tabular}

For the purposes of this table, karst is included under dense forest.

Green-pigeon, River Tern, White-rumped Falcon, Brown-rumped Minivet and Asian Golden Weaver).

Birds new to Laos have recently been found at such a rate that further species listed in Collar et al. (1994) will certainly be found, both migrant and resident. Eleven key species were found for the first time in Laos only in or after 1992, and provisional records of one other would also be new for the country.

\section{Historical declines and species currently At Risk in Laos}

All of the 35 species showing a National Historical Decline (and thus At Risk in Laos) are conspicuous (with the exception of Pompadour Green-pigeon), so it is likely that both past and present status assessments are correct. Indeed, for less conspicuous species historical data are mostly too incomplete to detect any trend other than a steep decline, and decreases in some species seem likely to have been overlooked. For almost all National Historical Decline species, a strong case can be made for human activity causing the change, in the majority of cases through direct harvesting or disturbance of the birds. However, for some migrants (e.g Black-eared Kite, Black-necked Stork), although anthropogenic threats (harvesting, habitat loss and/or habitat degradation) are known or presumed to occur in Laos, it may be that there has been some other principal cause of the decline acting in countries where the species breeds. Anthropogenic threats are also the basis for identifying nine other species as At Risk in Laos even though no National Historical Decline can be shown (Giant Ibis, Black-headed Ibis, Spot-billed Pelican, Asian Openbill, Greater Adjutant, Crested Argus, Masked Finfoot, Rufous-necked Hornbill and Asian Golden Weaver) and 25 further species as Potentially At Risk in Laos because the threats to them are either less severe or are more difficult to demonstrate with present data. Some of the 32 species listed in Table 3 as Little Known in Laos may yet be found to be At Risk given further study. Table 4 illustrates the high proportion of wetland birds which are At Risk in Laos, contrasting with the large number of species occurring in dense forest which are currently Not At Risk in Laos in this analysis.

Although most are clearly threatened by direct human pressure, this does not act equally in all habitat types and so the reasons that particular species are At Risk in Laos are discussed below by habitat. 


\section{Wetland habitats}

Most of the large key species of lowland rivers, marshes and standing water (15 including storks, ibises, herons, cormorants, eagles, Sarus Crane and Whitewinged Duck) have demonstrably undergone a major decline. David-Beaulieu (1949-1950: 49) found the ricefields of Central Laos transformed at the start of the rainy season, when small flocks of storks and cranes fed in flooded paddies; to find large wading birds living in such proximity to people is unimaginable in Laos today. Today, despite the abundance of suitable habitat, these species are all but restricted to the parts of the lowlands of South Laos with low human population density, bordering similar habitat in Cambodia which presumably acts as a population reservoir. For some species, populations in Laos may only be viable as long as dispersal to and from Cambodia can occur. Six additional species (Masked Finfoot, Black-headed Ibis, Giant Ibis, Spot-billed Pelican, Asian Openbill and Greater Adjutant) for which no decline within Laos can be demonstrated (because of the paucity of historical records) experience the same threats as the 15 species above and all are considered to be At Risk in Laos.

Hunting of adults and nestlings is probably the major cause for the decline of larger birds. Wetlands are the foci of human activity and settlement (see Results) and experience particularly high levels of hunting. The easy accessibility of lowland rivers and wetlands as well as the unhindered observation they allow contribute to the high levels of hunting. The decline of waterbirds may be due in part to widespread changes in vegetation of wetlands and clearance of their fringing forests, which has proceeded faster than for most other forest in Laos, but since much unoccupied habitat remains this is surely of secondary importance. Loss of favoured nest-sites may have affected tree-nesting species, such as White-winged Duck and fish-eagles, which may therefore continue to decline even if persecution were brought under control.

The major rivers once supported large populations of nine species (three species of tern, Indian Skimmer, Great Thick-knee, River Lapwing, Pied Kingfisher, Brahminy Kite and Plain Martin) which have since declined, some apparently to the brink of extinction in Laos. As well as direct persecution, incidental disturbance is likely to be important, particularly for birds nesting on sandbars, such as terns and waders. Human presence results in lowered densities of River Lapwing (Duckworth et al. 1998b) and probably other species. However, no explanation can be offered for the declines of Pied Kingfisher and Plain Martin.

Asian Golden Weaver is not known to have declined in Laos but is at risk as its few breeding sites (pools with abundant emergent vegetation) are heavily used by people and are susceptible to trampling by livestock.

Grey-headed Lapwing is considered Potentially At Risk in Laos since it occurs close to habitation and may be at elevated risk from hunting. Jerdon's Bushchat occurs not only in riverine habitats but also on hills. Its precise habitat requirements are not understood; it is unclear why it frequents seasonal river islands and secondary hill scrub but not all other extensive areas of scrub. It is so poorly understood that it is considered Potentially At Risk. Wire-tailed Swallow may have declined in Laos: this and the future threat from hydroelectric projects suggest that it should be considered Potentially At Risk in Laos, pending further study. 
The collapse of large waterbird populations parallels but is somewhat less advanced than those in other South-East Asian countries, particularly Thailand. Round et al. (1988) firmly believed that the major cause of the decline in Thailand was hunting and direct persecution, because large numbers of even the biggest waterbird species remain in some densely populated agricultural countries, such as India, where people traditionally view wildlife from a different standpoint. The same is likely to be true of Laos.

The effects of pesticide use in Laos are unknown. Levels are low but increasing in open country and agricultural land; some farmers use DDT and other persistent organochlorines (Claridge 1996). Very large quantities of chemicals were dropped on parts of Laos during the international conflicts before 1975. These may have had substantial effects on bird populations both in and downstream of affected areas, and some persistent chemicals may have had further serious effects in the succeeding years. Persistent organochlorine pesticides may have contributed to the declines in large waterbirds, Black Kites and vultures in Thailand (Round 1988).

\section{Forest habitats (open formations)}

Forest birds declining or at risk fall into two habitat associations: open deciduous forest, sometimes extending into adjacent scrub and cultivation; and dense forest, including semi-evergreen, dry and wet evergreen, Fokienia-dominated and upper montane forest.

Eight species associated with deciduous forest, scrub and cultivation have demonstrably declined in the remaining areas of habitat (Green Peafowl, Blackeared Kite, White-rumped, Long-billed and Red-headed Vultures, Alexandrine Parakeet, Yellow-footed Green-pigeon and Green Imperial-pigeon). All are large enough to be favoured quarry, and Alexandrine Parakeet was probably taken in large numbers from nesting areas. Like wetland habitats, open forest allows easy human access and easy opportunities for hunting. Furthermore, natural deciduous forests are mostly in the lowlands, which have a relatively high human population density. The same reasons make Rufous-winged Buzzard Potentially At Risk in Laos.

On current evidence Yellow-footed Green-pigeon and Alexandrine Parakeet appear to be associated with lowland mosaic forest, as do three other species showing no demonstrable decline (White-bellied Woodpecker, Streak-throated Woodpecker and White-rumped Falcon). Since such habitats are rare and disproportionately threatened with clearance and degradation, these species are all considered Potentially At Risk in Laos.

\section{Forest habitats (dense formations)}

The majority of key species in Laos are associated with dense forest habitats. However, only three (Great Hornbill, Wreathed Hornbill and Pompadour Green-pigeon) have shown a National Historical Decline, and only two others (Crested Argus and Rufous-necked Hornbill) are currently thought to be At Risk in Laos. The National Historical Declines shown by Great and Wreathed Hornbill are probably a result of direct human persecution. Their conspicuousness and 
flocking behaviour at fruiting trees make them easily hunted, and their low reproductive output means that hunted birds are replaced but slowly. Their declines contrast with the apparent health of populations of evergreen forest pheasants and raptors. Hornbills also appeared to be the most vulnerable group on Doi Suthep-Pui, in northern Thailand (Round 1984) and are declining through hunting in northern Borneo (Bennett et al. 1997). Rufous-necked Hornbill, the third large hornbill species, is presumed to be At Risk in Laos for these same reasons, particularly as it has a more restricted distribution than do the other two. Crested Argus is threatened by hunting and clearance of wet evergreen forest. Pompadour Green-pigeon is probably associated with flat lowland semievergreen forest and subject to heavy hunting.

Fifteen other dense forest species are thought to be Potentially At Risk in Laos. Hunting and/or the destruction of localised habitats are the main threats in all these cases. It is suspected that some localised and threatened habitats have a small number of bird species mainly dependent on them. The candidates among the key species (excluding those mentioned above) are Spotted Wren-babbler and Short-tailed Scimitar-babbler in wet evergreen forest, Beautiful Nuthatch in Fokienia forest, Black-hooded Laughingthrush in high-altitude dry evergreen forest around Xe Sap NBCA, Fujian Niltava in valley bottoms in lower-altitude dry evergreen forest, Brown Dipper on large rocky forested rivers and Blyth's Kingfisher along small, permanent, slow-flowing forested rivers. Further study is needed to prove the connection (and thus the degree of threat) in all of these cases. Yellow-breasted Magpie occupies a limited area; whether it is at risk or not depends largely on the integrity of the recently established Xe Pian NBCA. Similarly the future of White-winged Magpie may depend on the extent of destructive human activities in the middle-altitude forest mosaics in eastern Central Laos. Finally, four species (Siamese Fireback, Bar-bellied Pitta, Bluerumped Pitta and Golden-crested Myna) are Potentially At Risk in Laos due to elevated levels of hunting or collecting and their restriction to lower altitudes.

For most other dense forest species, gradual habitat clearance appears to be the only significant threat and, since in the more widespread or less heavily used forest types in Laos this threat is a mid-term rather than immediate concern, they have not been considered to be At Risk in Laos.

\section{Karst limestone}

Few bird species found so far in Laos are restricted to limestone and, of those that are, none is of immediate concern owing to the rugged terrain which reduces human access. However, Sooty Babbler is treated as Potentially At Risk because of the absence of ecological information on its use of tall forest, the threatened component of this habitat.

\section{Populations of high global importance}

These are species either on the brink of global extinction; Globally Threatened or Near-Threatened but occurring commonly at many sites in Laos; those for which recent Lao records are more substantial than those from anywhere else in their range; or have limited geographical ranges of which Laos is a substantial part. 
The global importance of the population in Laos of each key species is indicated in Table 3. They are of high global importance for $38^{*}$ key species and of moderate global importance for 16 more. Another 50 could not be categorised and the remaining 31 seem unlikely to occur in globally important populations.

Populations of many waterbirds and open forest species are, despite severe declines, still of high global importance. Those of Giant Ibis and Whiteshouldered Ibis are of paramount importance, although they may be too small to survive without the protection of adjoining remnant populations in Cambodia. Laos also holds populations of high global importance of Green Peafowl, Whitewinged Duck, Masked Finfoot, Lesser Fish-eagle, Grey-headed Lapwing, three species of vulture, Rufous-winged Buzzard, Greater Adjutant ${ }^{*}$ and Jerdon's Bushchat.

A high proportion of populations of high global importance inhabit dense forest; few of these species are currently thought to be At Risk in Laos. Of particular significance are the forests of the lowlands. Semi-evergreen forests of the flat lowlands are still relatively widespread (although mostly fragmented and degraded) whilst semi-evergreen forests on low hills are in better condition and even more extensive. Together, these forests support populations of high global importance for Siamese Fireback, Red-collared Woodpecker, Brown Hornbill, Bar-bellied Pitta, Blue-rumped Pitta, Grey-faced Tit-babbler, Mountain Fulvetta and Yellow-breasted Magpie.

Mid- and high-altitude forests support many highly important populations. In particular, several endemic and near-endemic species appear to be centred on the dry, wet and Fokienia-dominated evergreen forests of the Annamite Mountains. They include Crested Argus, White-winged Magpie, Ratchet-tailed Treepie and Grey, White-cheeked and Black-hooded Laughingthrushes. More widespread (although not necessarily more numerous) species include Blyth's Kingfisher, Rufous-necked Hornbill, Coral-billed Ground-cuckoo, Green Cochoa, Beautiful Nuthatch, Red-tailed Laughingthrush and Rufous-throated Fulvetta, present in both the Annamites and parts of North Laos.

Four species which do not fall into the above categories have populations of high global importance in Laos: Spectacled Fulvetta, Short-tailed Parrotbill, Sooty Babbler and Red-vented Barbet.

\section{Priorities for species and area protection in Laos}

Bird species conservation measures in Laos need to fulfil two aims: ( 1 ) long-term preservation of large tracts of natural habitats with healthy species communities; (2) immediate action for individual species At Risk in Laos and thus in urgent need of protection (many of which require more than the simple protection of habitat). With regard to the first objective, the species At Risk in Laos and those with populations of high global importance are found through a wide range of habitats. Thus the needs of bird conservation are in line with the target that the protected area system should cover representative portions of all habitats. No formal review has yet been made of the completeness of the protected areas system in relation to bird communities.

* See note added in proof 1, p. 131. 
Table 3 indicates the action priority for each key species. Seven are of Acute Priority, 19 of High Priority, 16 of Moderate Priority and the remainder of lower or unknown priority. Several of unknown priority may prove to be of High or even Acute Priority given more information.

The following discussion uses species priorities to identify priority sites for conservation action. It focuses on areas which have already been surveyed. Some as yet unsurveyed areas are likely also be of high priority, especially in the North.

Two regions of the South, (i) Dong Khanthung PPA and (ii) the complex covering Xe Pian NBCA, Dong Hua Sao NBCA, Bolaven Southwest and Xe Khampho PPAs, are considered here to be the two highest priorities for bird conservation in Laos, both for acute action and for long-term protection of significant populations. Within these regions, Dong Khanthung and Xe Pian are the most significant areas. The reasons are as follows. (1) Between them, they support all seven Acute Priority species (White-winged Duck, Green Peafowl, Sarus Crane, Giant Ibis, White-shouldered Ibis, Lesser Adjutant and Greater Adjutant* ). (2) They support 14 of the 19 High Priority species and have the most important known Lao populations for at least eight of these (Siamese Fireback, Masked Finfoot, three species of vulture, Grey-headed Fish-eagle, Oriental Darter and Woolly-necked Stork). (3) They are key sites for eight of the 16 Moderate Priority species (White-bellied Woodpecker, Alexandrine Parakeet, Yellow-footed Greenpigeon, Green Imperial-pigeon, Rufous-winged Buzzard, Asian Openbill, Asian Golden Weaver and Yellow-breasted Magpie). (4) They support globally significant populations of lower priority species such as Red-collared Woodpecker, Bar-bellied Pitta, Blue-rumped Pitta and Grey-faced Tit-babbler. (5) They are the most important parts of the reserve system in Laos for several habitats, including lowland rivers, streams and wetlands, flat and hilly semi-evergreen forest and flat lowland forest mosaic. The principal threat to birds in these areas is thought to be hunting pressure, with habitat loss and degradation a less urgent concern at present. Small-scale logging is widespread and might become a major threat to bird populations if it expands.

The next most significant area is Nakay-Nam Theun NBCA, for the following reasons. (1) It supports five High Priority species (Crested Argus, Rufous-necked, Great and Wreathed Hornbills and Lesser Fish-eagle). (2) It supports four Moderate Priority species (Brown Hornbill, Blyth's Kingfisher, White-winged Magpie and Beautiful Nuthatch). (3) There are nationally significant populations of many species of lower or unknown priority, for example Ratchet-tailed Treepie, Grey Laughingthrush, White-bellied and Yellow-vented Green-pigeons, Short-tailed Scimitar-babbler, Green Cochoa, Red-tailed Laughingthrush and Coral-billed Ground-cuckoo. (4) It contains one of the largest and most intact areas of dry evergreen forest in the Annamite Mountains, together with important areas of Fokienia-forest and upper montane forest.

The adjoining Nam Theun Extension PPA is smaller and does not cover such a diversity of habitats as Nakay-Nam Theun NBCA, but it extends the area of protected habitat for many of the species just listed. It also supports further large areas of wet evergreen forest, which is particularly important for the High Priority Crested Argus. Threats to these two areas are numerous and changing rapidly

* See note added in proof 1, p. 131. 
as they are opened up for exploitation. Clearance of wet evergreen forest and logging of the Fokienia forests are the most acute threats to non quarry birds.

The Nakay Plateau (part of which falls within Nakay-Nam Theun NBCA) is also a priority area, for the following reasons. (I) It supports a population of one Acute Priority species (White-winged Duck). (2) It supports four High Priority species (Siamese Fireback, Wreathed Hornbill, Lesser Fish-eagle and perhaps the largest Lao population of River Lapwing). (3) It supports significant populations of three Moderate Priority species (Brown Hornbill, Blyth's Kingfisher and White-winged Magpie). (4) It supports a remarkably large number of other key species including concentrations of Grey-headed Lapwing and Pied Falconet. (5) It contains a large extent of lowland riverine habitat in good condition. All riverine habitat, and large areas of other habitat are due to be inundated by the Nam Theun 2 Hydropower project reservoir and if this takes place the value of the area for many of these species will be greatly reduced.

Other areas in Laos are of lower priority than these for species in the Acute, High and Moderate Priority classes. These sites alone do not support all the Acute and High Priority species or all the species occurring in globally significant numbers in Laos. Further sites worthy of mention are as follows. (1) Additional areas supporting populations of the Acute Priority Green Peafowl (these include areas within Phou Xiang Thong and Phou Khaokhoay NBCAs). (2) Xe Sap PPA, which probably has the most extensive high-altitude forest within the Lao range of the Moderate Priority Black-hooded Laughingthrush, and is also important for Crested Argus, Spectacled Fulvetta and other species. Shifting cultivation is occurring relatively rapidly in this area. (3) Khammouan Limestone and Hin Namno NBCAs, which both cover large areas of karst limestone known to support Sooty Babbler, endemic to central Laos and central Vietnam. Ongoing research suggests that other endemic bird and mammal species may also be present. Although the karst habitats are unlikely to be heavily threatened, tall fringing forests may be. The use of such forests by endemic species is unknown and, until its importance is understood, karst areas deserve special attention. They also support populations of High Priority species such as large hornbills and, in Hin Namno, Crested Argus. (4) Sites supporting large-river specialists. Lao populations of these, other than River Lapwing, are probably not of great global significance, but this is the most threatened bird community at national level and several species (River Tern, Little Tern, Brahminy Kite and Great Thick-knee) have been accorded a High Priority. Several others (e.g. Black-bellied Tern, White-bellied Sea-eagle, Indian Skimmer) have been accorded unknown priority but if still occurring then they would be of Acute or High Priority. The Seephandon area of the Mekong, particularly in the Ban Hangkhon area, is the most important known site for birds of this habitat, but there are also significant, widely dispersed, populations elsewhere.

\section{Conservation policy issues}

This section draws attention to some broad conservation policy issues related to birds for which further debate or development is desirable.

Berkmüller et al. (1995a) outlined the management approach required in National Biodiversity Conservation Areas. Further research is needed to enhance 
management efforts, but the principal need is to train reserve staff and to establish cooperative management agreements with local communities which will ensure the long-term survival of the more vulnerable species. Prevention of the establishment of new settlements within protected areas is the most important practical management measure, mainly to prevent large new areas being overhunted. This is an effective measure because only for very few, specific purposes do people penetrate forest more than half a day's walk from their village (Berkmüller et al. 1993). If new village formation is to be prevented, development projects should avoid improving access by road within protected areas. Threats from larger-scale commercial development can only be overcome by high-level political commitment to the protected area system.

For Acute Priority species habitat protection is important, but the overriding need is to minimise hunting pressure. This will be challenging since hunting is such a fundamental aspect of Lao culture, and wild birds are not widely perceived to have other significant values. Poster-based conservation education campaigns are being conducted to encourage the voluntary cessation of hunting of the most vulnerable species. Strictly protected core areas within the National Biodiversity Conservation Areas are being considered, but the key habitats, such as wetlands, are dispersed and human populations are dependent on these areas for their livelihoods, so this approach cannot be the complete solution. The designation of "Non-hunting Areas", as used in Thailand, could be experimented with. The development of ecotourism to provide revenue for local people is a future possibility. The perception by local people of living wildlife as a monetary resource to be protected could benefit many species.

Legal protection of wildlife in Laos is covered by a number of conflicting decrees. The selection of birds protected including, as it does, all drongos and many common mynas - was eccentric, and many of the species for which Laos has major international importance remain unprotected (e.g. White-shouldered Ibis). Salter (1993) reviewed the recent legal status of wildlife in Laos. Deficiencies in existing laws might hinder effective protection of species in the new protected areas. However, all current conservation and natural resource use legislation is under revision. The information in the current review would form an appropriate basis for assigning categories of legal protection. Laos is likely soon to become signatory to CITES and debate about accession to other international conservation treaties is likely to follow.

Improved national strategies are needed to protect the outstanding riverine habitats, which are under increasing pressure from human use and the hydroelectric power sector. A national rivers inventory, detailing extent of bankside and catchment forest cover, associated static wetlands, rates of flow, river course characteristics and, most importantly, human use, would be a valuable first move to addressing this problem. Riverine habitats are under-represented in existing or proposed protected areas, and those rivers that are included seem still to be under threat from hydropower development. A national assessment of hydropower projects should consider the level of detrimental impact to the country's environmental and wildlife heritage. All projects should include independent Environmental Impact Assessments at a sufficiently early stage in planning to have real influence on project selection and design. Consideration should be given to the possibility of designating a protected river system, with restrictions 
on commercial development, a sustainable-use management strategy with local communities, and restricted-use areas of high conservation importance. Two major river systems have particularly high potential for this approach: the Nam Theun/Kading and the Xe Kong. The former has several hydropower projects under way, which would make designation difficult and will greatly reduce the value of the rivers once complete. The latter is also threatened by several projects, but they are at less advanced stages.

Local projects could be instigated in some heavily used areas such as the Seephandon area of the Mekong, to protect nesting sites of sandbar species and reduce local hunting pressure. A project protecting sustainable fisheries and Irrawaddy Dolphins Orcaella brevirostris in this area is having positive results (I. Baird verbally 1996).

\section{Further survey needs}

All fieldworkers in Laos should continue to report in detail records of key species. To date, in internal reports to the Lao government, all species in this review have been treated as key species. In future, we recommend that all species we list as At Risk in Laos, Potentially At Risk in Laos, Little Known in Laos, Globally Threatened or Globally Near-Threatened are treated as key species. This results in a list of 112 key species and the removal of 23 former key species from the list. For simplicity the list of these key species is presented in Appendix 2. A comprehensive review of all these species should occur approximately every five years.

The status of many species remains obscure or only partially known. Species for which information-gathering is a high priority are indicated in Table 3 within the Action Priority column. To improve understanding of the distributions of those species of the highest conservation concern, further survey work will be needed in the following areas, in rough order of priority:

1. The lowland wetlands in the most southerly parts of Laos for large waterbirds (including Giant and White-shouldered Ibises), particularly looking for nesting areas. Surveys for suitable areas followed by searches for birds (perhaps by air as in 1996) are the highest priority for future ornithological fieldwork.

2. Areas where Green Peafowl do or may occur which have not been surveyed yet (especially, open areas in lowland deciduous forest of the eastern part of Savannakhet Province: see Evans and Timmins 1996).

3. Areas with populations of White-winged Ducks (see species account) and two areas potentially retaining them: south-eastern Khammouan Province and the Xe Kong basin in Attapu and Xekong Provinces (see Evans et al. 1997).

4. Xe Sap PPA, Hin Namno NBCA, Nakay-Nam Theun Extension PPA, Nam Chouan PPA, and Nam Xam NBCA. These areas are likely to support species restricted to evergreen forest of the Annamites, including some until recently believed endemic to Vietnam. Further species of high importance are likely to be found.

5. Other parts of the Xe Kong basin and the adjoining southern Annamites in Dong Ampham NBCA, Phou Kathong PPA and Phou Theung PPA, as all areas surveyed within the basin support notable assemblages of key species. 
6. The entire length of the Mekong (boat-based census), especially in southern Champasak Province and upstream of Vientiane to Ban Houayxai, to allow comparison with the past and expand on Salter's (1993) records. Wet and dry season work is needed, because records demonstrate that some species were resident, some were dry-season visitors, and others occurred during the rains.

7. All National Biodiversity Conservation Areas in North Laos.

8. The areas covered by David-Beaulieu (1944), where new fieldwork would allow consideration as to whether the species he documented are declining, and give a useful picture of the long-term prospects for species in areas affected by shifting cultivation.

As well as site surveys of general avifauna some questions of species status need addressing with directed fieldwork; Spot-billed Pelican (for which wet-season surveys on the lower Mekong are required) and Wire-tailed Swallow (for which wet- and dry-season surveys along the Mekong and Xe Banghiang in Savannakhet Province are required) are two clear cases. There is also a pressing need for ecological information about many species. Two notable examples are the extent to which Sooty Babblers rely on tall forest and the wet-season location of Jerdon's Bushchat, River Lapwing and other species which breed in the Mekong channel.

Note: Between the final date for records included in this paper (31 December 1996) and its publication, surveys or reconnaissances have already been undertaken in some of these areas, including several north of $18^{\circ} 40^{\prime} \mathrm{N}$.

\section{Acknowledgements}

We are very grateful to the Department of Forestry of the Ministry of Agriculture and Forestry in Vientiane of the government of the Lao PDR, particularly $\mathrm{Mr}$ Khampheune Kingsada, Mr Silavanh Sawathvong, Mr Chanthaviphone Inthavong, Mr Venevongphet, Mr Saleumsy Phithayaphone and the many provincial and district officials, for granting permission to conduct the fieldwork.

We thank all the people who have given us practical advice and assistance before, during and after fieldwork. Tim Inskipp provided regular updated drafts of his Indochina bibliography, and advice and access to references, throughout all stages of the project. Particular thanks for sustained advice and practical assistance over several years of survey go to Klaus and Unchai Berkmüller, William Bleisch, Stuart Chape, Peter Colston (NHM), Bouaphanh Phanthavong, Alan Rabinowitz, Bill Robichaud, Philip Round, Sivannavong Sawathvong, George Schaller and all the staff of the Centre for Protected Areas and Watershed Management of the Department of Forestry, Vientiane. Thanks also go to our Lao field companions Boonhong Mounsouphom, Bounhom Sounthala, Chainoi Sisomphone, Chanthaphone Phon-asa, Chantavi Vongkhamheng, Khamkhoun Khounboline, Padith Vanalatsmy, Pheng Phaengsintham, Somphong Souliyavong and Viengxay. The following field companions provided records unacknowledged in the text: Guy Anderson, Jeb Barzen, Katherine Cozza, Michael Dvorak, Matt Etter, Charles Francis, Mike Leven, Erwin Nemeth, Bill Robichaud, Tony Stones, Robert Tizard, Howard Towll, Roger Wilkinson and James Wolstencroft. Assistance was also received from Ian Baird, H.-M. Brechtel, Robert 
Dobias, Nick Dymond, Jonathan Eames, Walter Ehrhardt, Mike Evans, Joost Foppes, Mary O'Sullivan, Craig Robson, Nancy Ruggeri and Richard Salter. Regina Pfaff at the BirdLife Secretariat helped format the tables and appendices. The enthusiastic support and interest of Nigel Collar was of great value throughout and especially during the preparation of the manuscript.

The survey of Dong Hua Sao (1993) was funded by a grant from the British Embassy in Bangkok. The Phou Xang He survey was carried out under contract to the Lao-Swedish Forest Resources Conservation Project. The surveys of Nakay-Nam Theun (1994 and 1996), Nakay-Nam Theun Extension (1994), Nakay Plateau (1994), Khammouan Limestone (1995), Xe Bang-Nouan, Phou Khaokhoay, Hin Namno and Xe Sap were funded through the Wildlife Conservation Society with grants from the MacArthur Foundation. Nam Kading was surveyed under contract to Norplan A.S. and Electrowatt Engineering Services, Xe Namnoy under contract to Electrowatt Engineering Services, and the Nakay Plateau under contract to TEAM Consulting Engineers Ltd. Surveys in Nakay-Nam Theun Extension (1996), Nakay Plateau (1995 and 1996) and Khammouan Limestone (1996) were funded by the Nam Theun 2 Project Development Group. The Xe Pian and Houay Nhang surveys were funded by a variety of bodies with major donations from: the British Ornithologists' Union, BP (through BirdLife International/Fauna and Flora International), the People's Trust for Endangered Species, the Wildfowl and Wetlands Trust, and the World Pheasant Association. The surveys of Dong Hua Sao (1996) and Phou Xiang Thong were conducted under contract to the Biodiversity Conservation Project, funded by the Dutch government and implemented by the Lao Forestry Department with technical assistance from IUCN. The surveys of Dong Khanthung and some parts of the Mekong River were funded by the Wildlife Conservation Society and the International Crane Foundation. Sangthong Training and Model Forest was surveyed under contract to the Lao-German Forestry Team project for the Promotion of Education at Vientiane Forestry College with funding from GTZ. The 1995 visit to Phou Dendin was funded by a grant from the Hanus Trust to the Cedar Grove Ornithological Research Station, Inc., U.S.A.

Data for this paper were synthesised and the paper drafted in Vientiane while RMT, RJT and JWD were supported by the Wildlife Conservation Society. Publication costs were met by the Wildlife Conservation Society (we particularly thank Joshua Ginsburg and Bill Robichaud) and the Dutch Embassy in Bangkok (we particularly thank Astrid Zonneveld).

\section{References}

Anderson, G. (1993) Laos expedition finds Giant Ibis. Oriental Bird Club Bull, 17: 12-13.

Baird, I. G. and Mounsouphom, B. (1994) Irrawaddy Dolphins (Orcaella brevirostris) in southern Lao PDR and northeastern Cambodia. Nat. Hist. Bull. Siam Soc. 42: 159-175.

Baker, E. C. S. (1920) Description of new genera of species and subspecies from a collection of birds collected by Mr E. G. Herbert in Siam. Bull. Brit. Orn. Club 41: 10-11.

Baker, E. C. S. (1921) Diagnosis of the genus Nigravis. Bull. Brit. Orn. Club 41: 101.

van Balen, B., Suwelo, I. S., Hadi, D. S., Soepomo, D., Arlon, R. M. and Mutiarina (1993) The decline of the Brahminy Kite Haliastur indus on Java. Forktail 8: 83-88.

Bangs, O. and van Tyne, J. (1930) Descriptions of five new Indo-Chinese birds. Publ. Field Mus. Nat. Hist. (Zool. Ser.) 18: 1-4. 
Bangs, O. and van Tyne, J. (1931) Birds of the Kelley-Roosevelts expedition to French Indochina. Publ. Field Mus. Nat. Hist. (Zool. Ser.) 18: 33-119.

Barzen, J. (1997) Preliminary report of a survey of Sarus Cranes and other wildlife in the Dong Khanthung area, Champasak Province, Lao PDR, August 1996. Baraboo, Wisconsin, USA: International Crane Foundation, Wildlife Conservation Society and CPAWM.

Bennett, E. L., Nyaoi, A. J. and Sompud, J. (1997) Hornbills Buceros spp. and culture in northern Borneo: can they continue to co-exist? Biol. Conserv. 82: 41-46.

Berkmüller, K. (1995) Hydropower development and protected areas: problem analysis. Unpublished report to Lao-Swedish Forestry Co-operation Programme.

Berkmüller, K., Bouaphanh Phantavong and Venevongphet (1993) Protected areas system planning and management in Lao PDR: status report to mid-1993. Unpublished report to Lao-Swedish Forestry Co-operation Programme.

Berkmüller, K., Sangthong Southammakoth and Vene Vongphet (1995a) Protected areas system planning and management in Lao PDR: status report to mid-1995. Unpublished report to Lao-Swedish Forestry Co-operation Programme.

Berkmüller, K., Evans, T., Timmins, R. and Vene Vongphet (1995b) Recent advances in nature conservation in the Lao PDR. Oryx 29: 253-260.

Berkmüller, K. and Vilawong, W. (1996) A rapid wildlife and habitat survey of Dong Khanthung Conservation Forest and its environs. Agriculture and Forestry Office, Champasak: Biodiversity Conservation Project, IUCN (unpublished).

Bourret, R. (1943) Liste des oiseaux récemment entrés dans les collections du Laboratoire de Zoologie. Notes et travaux de l'Ecole supérieure des Sciences de l'Université Indochinoise, Hanoi 2: 18-37.

CCB (1992) Rapid assessment of forest, wildlife and river ecology in the area affected by the Kaeng Sua Taen Dam. Bangkok: Center for Conservation Biology, Mahidol University.

Cheng Tso-hsin (1987) A synopsis of the avifauna of China. Beijing: Science Press.

Claridge, G. F. (compiler) (1996) An inventory of wetlands of the Lao P.D.R. Bangkok: IUCN.

Collar, N. J. and Andrew, P. (1988) Birds to watch: the ICBP world checklist of threatened birds. Cambridge, U.K.: International Council for Bird Preservation (Tech. Publ. 8).

Collar, N. J., Crosby, M. J. and Stattersfield, A. J. (1994). Birds to watch 2: the world list of threatened birds. Cambridge, U.K.: BirdLife International (Conservation Series no. 4).

Collins N. M., Sayer J. A. and Whitmore T. C. (1991) Conservation atlas of tropical forests: Asia and the Pacific. London and Basingstoke: Macmillan with BP, IUCN and WCMC.

Cox, R., Sivannavong Sawathvong and Khampaey Louanglath (1991) Report of a survey for Kouprey and other wild cattle in the southern Lao P.D.R. provinces of Champassak and Attapeu. Unpublished report to the Kouprey Conservation Trust.

David-Beaulieu, A. (1939) Liste complémentaire des oiseaux du Tranninh. Oiseau et R.F.O. 9: $183-186$.

David-Beaulieu, A. (1944) Les oiseaux du Tranninh. Hanoi: Université Indochinoise.

David-Beaulieu, A. (1948) Note sur quelques oiseaux nouveaux pour le Tranninh et même pour l'Indochine. Oiseau et R.F.O. 18: 133-140.

David-Beaulieu, A. (1949-1950) Les oiseaux de la Province de Savannakhet (Bas-Laos). L'Oiseau R.F.O. 19: 41-84, 153-194; 20: 9-50.

Deignan, H. G. (1964) Subfamily Timaliinae. Pp. 240-427 in E. Mayr and R. A. Paynter, eds. Check-list of the birds of the world, 10. Cambridge, Massachusetts, U.S.A.: Museum of Comparative Zoology.

Delacour, J. (1926) Descriptions of thirty-one new species and sub-species from Annam and Laos, Indo-China. Bull. Brit. Orn. Club 47: 8-22.

Delacour, J. (1929) On the birds collected during the fourth expedition to French Indochina. Ibis (12)5: 193-220, 403-429.

Delacour, J. (1932) Etude systématique de quelques oiseaux nouveaux ou intéressants obtenus par la VIe expédition en Indochine. Oiseau et R.F.O. 2: 419-438. 
Delacour, J. (1948) The subspecies of Lophura nycthemera. Amer. Mus. Novit. 1377.

Delacour, J. (1977) Pheasants of the world. Third edition. Hindhead, Surrey, U.K.: Spur Publications in conjunction with the World Pheasant Association.

Delacour, J. and Greenway, J. C. (1940) Liste des oiseaux receuillis dans la province du Haut-Mekong et le royaume de Luang-Prabang. Oiseau et R.F.O. 10: $25^{-59}$.

Delacour, J. and Greenway, J. C. (1941) A new timaliid from Laos, French Indo-China. Proc. New England Zool. Club 18: 47-48.

Delacour, J. and Jabouille, P. (1927) Recherches ornithologiques dans les provinces $d u$ Tranninh (Laos), de Thua-Thien et de Kontoum (Annam) et quelques autres régions de l'Indochine française. Paris: Société Nationale d'Acclimatation de France (Archives d'Histoire Naturelle).

Delacour, J. and Jabouille, P. (1931) Les oiseaux de l'Indochine française, 1-4. Paris: Exposition Coloniale Internationale.

Delacour, J. and Jabouille, P. (1940) Liste des oiseaux de l'Indo-chine française, complété et mise à jour. Oiseau et R.F.O. 10: 89-220.

Desai, A. and Lic Vuthy (1996) Status and distribution of large mammals in eastern Cambodia. Phnom Penh: IUCN/FFI/WWF Large Mammal Conservation Project.

Dickinson, E. C. (1970a) Birds of the Legendre Indochina expedition 1931-1932. Amer. Mus. Novit. 2423.

Dickinson, E. C. (1970b) Notes upon a collection of birds from Indochina. Ibis 112: 481487 .

Dickinson, E. C. (1973) A study of the orange-breasted niltavas represented on mainland South-East Asia. Nat. Hist. Bull. Siam Soc, 24: 409-430.

Duckworth, J. W. (1996) Bird and mammal records from the Sangthong District, Vientiane Municipality, Laos, in 1996. Nat. Hist. Bull. Siam Soc. 44: 217-242.

Duckworth, J. W. (1997a) Small carnivores in Laos: a status review with notes on ecology, behaviour and conservation. Small Carnivore Conserv. 16: 1-21.

Duckworth, J. W. (1997b) Observations on a population of Jerdon's Bushchat Saxicola jerdoni in the Mekong channel, Laos. Bull. Brit. Orn. Club 117: 210-220.

Duckworth, J. W. (in press) A survey of large mammals in the central Annamite mountains of Laos. Z. Säugetierkunde.

Duckworth, J. W. and Hedges, S. (1998) Bird records from Cambodia in 1997, including records of sixteen species new for the country. Forktail 14: 29-36.

Duckworth, J. W., Timmins, R. J., Thewlis, R. M., Evans, T. D. and Anderson, G. Q. A. (1994) Field observations of mammals in Laos, 1992-1993. Nat. Hist. Bull. Siam Soc. 42: $177-205$.

Duckworth, J. W., Timmins, R. J., Anderson, G. Q. A., Thewlis, R. M., Nemeth, E., Evans, T. D., Dvorak, M. and Cozza, K. E. A. (1995) Notes on the status and conservation of the gibbon Hylobates (Nomascus) gabriellae in Laos. Trop. Biodiversity 3: 15-27.

Duckworth, J. W., Evans, T. D., Robichaud, W. G., Thewlis, R. M., Timmins, R. J. and Tizard, R. J. (1998a) Bird records from Laos, October 1994-August 1995. Forktail 13: 33-68.

Duckworth, J. W., Timmins, R. J. and Evans, T. D. (1998b) The conservation status of the River Lapwing Vanellus duvaucelii in southern Laos. Biol. Conserv. 84: 215-222.

Eames, J. C., Lambert, F. R. and Nguyen Cu (1994a) A survey of the Annamese Lowlands, Vietnam, and its implications for the conservation of Vietnamese and Imperial Pheasants Lophura hatinhensis and L. imperialis. Bird Conserv. Internatn. 4: 343-382.

Eames, J. C., Robson, C. R. and Nguyen Cu (1994b) A new subspecies of Spectacled Fulvetta Alcippe ruficapilla from Vietnam. Forktail 10: 141-158.

Eames, J. C., Lambert, F. R. and Nguyen Cu (1995) Rediscovery of the Sooty Babbler Stachyris herberti in Central Vietnam. Bird Conserv. Internatn. 5: 129-135.

Edmond-Blanc, F. (1944) A propos du trois soui-mangas de Tranninh. Oiseau et R.F.O. 14: 1-4. 
Engelbach, P. (1927a) Une collection d'oiseaux du Bas Laos. Bull. Soc. Zool. France 52: 239250.

Engelbach, P. (1927b) Pterocyanea scuturala [sic] et Carpococcyx renauldi au Laos. Rev. franç. Orn. 11: 27.

Engelbach, P. (1929) Observations d'oiseaux sur le Mékong. Oiseau 10: 672 .

Engelbach, P. (1932) Les Oiseaux du Laos méridional. Oiseau et R.F.O: 2: 439-498.

Evans, T. D. and Timmins, R. J. (1994) Survey results from Nakai-Nam Theun. Oriental Bird Club Bull. 20: 15-16.

Evans, T. D. and Timmins, R. J. (1996) The status of the Green Peafowl Pavo muticus in Laos. Forktail 11: 11-32.

Evans, T. D. and Timmins, R. J. (1998) Records of birds from Laos during January-July 1994. Forktail 13: 69-96.

Evans, T. D. Tizard, R. J and Robichaud, W. G. (1997) The White-winged Duck Cairina scutulata in Laos. Wildfowl 47: 81-96.

Evans, T. D., Towll, H. C., Timmins, R. J., Thewlis, R. M., Stones, A. J., Robichaud, W. G. and Barzen, J. (in prep.) Ornithological records from the lowlands of southern Laos during December 1995-May 1996, including areas on the Thai and Cambodian borders.

Foppes, J. (1995) Farming and forest use systems survey and recommendations for community forestry in the Sang Tong Training and Model Forest. Vientiane: unpublished report to Vientiane Forestry College.

Foreign Investment Management Committee (1995) Lao PDR in the Greater Mekong subregion. Vientiane: FIMC.

Fujisaka, S. (1991) A diagnostic survey of shifting cultivation in northern Laos: targeting research to improve sustainability and productivity. Agroforestry Systems 13: 95-109.

Heath, P. (1996) Birdwatching areas: Chiang Saen, northern Thailand. Oriental Bird Club Bull. 23: 24-26.

Holmes, D. A. (1991) Note on the status of the White-shouldered Ibis in Kalimantan. Kukila 5: 145-147.

Inskipp, T., Lindsey, N. and Duckworth, W. (1996) An annotated checklist of the birds of the Oriental Region. Sandy, Bedfordshire, U.K.: Oriental Bird Club.

IUCN Species Survival Commission (1994) IUCN Red List categories. Gland, Switzerland: IUCN-The World Conservation Union.

Japan International Co-operation Agency (1993) Master plan study on hydroelectric power development in the Se Kong basin. Interim report. Vientiane: unpublished report to Ministry of Industry and Handicraft.

Kerr, A. F. G. (1933) A trip to Pu Bia in French Laos. J. Siam Soc., Nat. Hist. Suppl. 9: 193223.

King, B. F., Woodcock, M. and Dickinson, E. C. (1975) A field guide to the birds of South-East Asia. London: Collins.

Kloss, C. B. (1921) Amendments to locality descriptions of birds recently described by W. L. Sclater and E. C. S. Baker. Bull. Brit. Orn. Club 41: 75-76.

Lao-Swedish Forestry Co-operation Programme (1992) Forest cover and land-use in Lao PDR: final report of the nationwide reconnaissance survey. Vientiane: unpublished Forest Inventory Report No. 5 to the Ministry of Agriculture and Forestry.

Le Xuan Canh, Pham Trong Anh, Duckworth, J. W., Vu Ngoc Thanh and Lic Vuthy (1997). A survey of large mammals in Dak Lak Province, Vietnam. Hanoi: World Wide Fund for Nature / IUCN-The World Conservation Union.

Lekagul, B. and Round, P. D. (1991) A guide to the birds of Thailand. Bangkok: Saha Karn Bhaet.

Lloyd, C., Tasker, M. and Partridge, K. (1991) The status of seabirds in Britain and Ireland. London: T. and A. D. Poyser. 
Ludlow, F. and Kinnear, N. B. (1937) The birds of Bhutan and adjacent territories of Sikkim and Tibet. Ibis (14)1: 1-46, 249-293, 467-503.

MacKinnon, J. and MacKinnon, K. (1986) Review of the protected area system in the IndoMalayan Realm. Gland, Switzerland, and Cambridge, U.K.: International Union for Conservation of Nature and Natural Resources.

Marshall, J. T. (1978) Systematics of smaller Asian night birds based on voice. Kansas: American Ornithologists' Union (Orn. Monogr. 25).

McGowan, P. J. K. and Garson, P. J. (1995) Pheasants: status survey and conservation action plan 1995-1999. Gland, Switzerland: IUCN-The World Conservation Union.

McGowan, P. J. K. and Panchen, A. L. (1994) Plumage variation and geographical distribution in the Kalij and Silver Pheasants. Bull. Brit. Orn. Club 114: 113-123.

Mlikovsky, J. and Inskipp, T. P. (in prep.) An annotated checklist and bibliography of the birds of Indochina.

Mundkur, T., Carr, P., Sun Hean and Chhim Somean (1995) Surveys for large waterbirds in Cambodia, March-April 1994. Gland, Switzerland and Cambridge, U.K.: IUCN Species Survival Commission.

Murray, A. (1995) An annotated list of birds recorded in the Bhumiphol dam area, Tak Province, Thailand. Nat. Hist. Bull. Siam Soc. 43: 85-107.

Nam Theun 2 Electricity Consortium (1997) Background to the proposed Nam Theun 2 hydroelectric project in Laos. Vientiane: Nam Theun 2 Electricity Consortium Development Group.

National Statistical Centre (1995) Lao Census 1995, Preliminary Report 2 (results on the province and district level). Unpublished report. Vientiane: Committee for Planning and Co-operation, Government of the Lao PDR.

Oustalet, E. (1898) Catalogue des oiseaux recueillis par M. le Comte de Barthélemy dans le cours de son dernier voyage en Indo-Chine. Bull. Mus. Hist. Nat. Paris 4: 11-19.

Oustalet, E. (1899-1903) Les oiseaux du Cambodge, du Laos, de l'Annam et du Tonkin. Nouv. Arch. Mus. Hist. Nat. Paris (4)1: 221-296; (4)5: 1-94.

Parr, J. W. K., Pongpan Laothong and Gorrerk Ruangsree (1994) The status of Whitewinged Wood Duck Cairina scutulata in Thailand. Tigerpaper 21(1): 1-7.

Parr, J. W. K., Eames, J. C., Sun Hean, Chamnan Hong, Som Han, Vi La Pich and Kim Hout Seng (1996) Biological and socio-economic aspects of waterbird exploitation and natural resource utilization at Prek Toal, Tonle Sap Lake, Cambodia. Bangkok: IUCN Species Survival Commission.

Perennou, C. and Mundkur, T. (1991) Asian waterfowl census 1991. Mid-winter waterfowl counts, January 1991. Slimbridge, U.K.: IWRB.

Perennou, C., Rose, P. M. and Poole, C. (1990) Asian waterfowl census 1990. Mid-winter waterfowl counts in southern and eastern Asia, January 1990. Slimbridge, U.K.: International Waterfowl Research Bureau.

Rank, M. (1996) New Short-tailed Parrotbill site found in S. China. Oriental Bird Club Bull. 23: 11.

Robichaud, W. (1992) Report on bird surveys, Houei Nhang forest reserve. Vientiane: unpublished report to Forest Resources Conservation Sub-programme.

Robinson, H. C. and Kloss, C. B. (1931) Some birds from Siam and Laos (Middle Mekong). Ibis (13)1: 319-341.

Robson, C. R. (comp.) (1995) From the field. Oriental Bird Club Bull. 22: 57-62.

Robson, C. R. (comp.) (1997) From the field. Oriental Bird Club Bull. 26: 60-66.

Robson, C. R., Eames, J. C., Wolstencroft, J. A., Nguyen Cu and Truong Van La (1989) Recent records of birds from Viet Nam. Forktail 5: 71-97.

Robson, C. R., Eames, J. C., Newman, M., Nguyen Cu and Truong Van La (1991) Forest bird surveys in Vietnam 1989/1990. Unpublished report to the International Council for Bird Preservation. 
Robson, C. R., Eames, J. C., Nguyen Cu and Truong Van La (1993a) Further recent records of birds from Viet Nam. Forktail 8: 25-52.

Robson, C. R., Eames, J. C., Nguyen Cu and Truong Van La (1993b) Birds recorded during the third BirdLife/Forest Birds Working Group expedition in Viet Nam. Forktail 9: 89119.

Round, P. D. (1984) The status and conservation of the bird community in Doi Suthep-Pui National Park, north-west Thailand. Nat. Hist. Bull. Siam Soc. 32: 21-46.

Round, P. D. (1988) Resident forest birds in Thailand. Cambridge, U.K.: International Council for Bird Preservation (Monograph 2).

Round, P. (compiler) (1995) Recent reports. Bird Conserv. Soc. Thailand Bull. 12(5): 9.

Round, P. (compiler) (1996) Recent reports: March-May 1996. Bird Conserv. Soc. Thailand Bull. 13(7): 15-16.

Round, P. D., Amget, B., Jintanugol, J. and Treesucon, U. (1988) A summary of the larger waterbirds in Thailand. Tigerpaper 15: 1-9.

Rozendaal, F. and Nguyen Cu (1989) Status of Elliot's Pitta in Viet Nam. Dutch Birding 11: 16-18.

Ruggeri, N. and Timmins, R. J. (1996) An initial survey of diurnal primate status in Laos. Asian Primates 5 (3-4): 1-3.

Salter, R. E. (1993) Wildlife in Lao PDR. A status report. Vientiane: IUCN-The World Conservation Union.

Schaller, G. B. (1995) A wildlife survey of the Annamite Mountains of Laos, December 1994-January 1995. Vientiane: Wildlife Conservation Society (unpublished report to CPAWM).

Scott, D. A., ed. (1989) A directory of Asian wetlands. Gland, Switzerland and Cambridge, U.K.: IUCN-The World Conservation Union.

Scott, D. A. (1992) Survey of Cambodian wetlands. Unpublished typescript.

Scott, D. A. and Rose, P. M. (1989) Asian waterfowl census 1989. Mid-winter waterfowl counts in southern and eastern Asia, January 1989. Slimbridge, U.K.: International Waterfowl Research Bureau.

Sibley, C. G. and Monroe, B. L. (1990) Distribution and taxonomy of birds of the world. New Haven: Yale University Press (as updated 1993).

Smythies, B. E. (1981) The birds of Borneo. Kota Kinabalu: Sabah Society; and Kuala Lumpur: Malayan Nature Society.

Smythies, B. E. (1986) The birds of Burma. Liss, U.K.: Nimrod Press.

Sözer, R. and van der Heijden, A. J. W. J. (1997) An overview of the distribution, status and behavioural ecology of the White-shouldered Ibis in East Kalimantan. Kukila 9: 126-140.

Srikosamatara, S., Siripholdedej, B. and Suteethorn, V. (1992) Wildlife trade in Lao P.D.R. and between Lao P.D.R. and Thailand. Nat. Hist. Bull. Siam Soc. 40: 1-47.

Srikosamatara, S. and Suteethorn, V. (1994) Wildlife conservation along the Thai-Lao border. Nat. Hist. Bull. Siam Soc. 42: 3-21.

Thewlis, R. M., Duckworth, J. W., Anderson, G. Q. A., Dvorak, M., Evans, T. D., Nemeth, E., Timmins, R. J. and Wilkinson, R. J. (1996) Ornithological records from Laos, 19921993. Forktail 11: 47-100.

Thewlis, R. M. and Timmins, R. J. (1996) The rediscovery of Giant Ibis Pseudibis gigantea with a review of previous records. Bird Conserv. Internatn. 6: 317-324.

Thomas, W. W. (1964) A preliminary list of the birds of Cambodia. Unpublished.

Timmins, R. J. (1996a) A preliminary wildlife and habitat survey of Xe Sap Proposed Protected Area and mountains to the south, Salavan and Sekong, Lao P.D.R. Vientiane: Wildlife Conservation Society (unpublished report to CPAWM).

Timmins, R. J. (1996b) A preliminary wildlife and habitat survey of the Dong Khanthung area, Champasak, Lao P.D.R. Vientiane: Wildlife Conservation Society (unpublished report to CPAWM). 
Timmins, R. J., Evans, T. D., Khamkhoun Khounboline and Chainoi Sisomphone (1998) Status and conservation of the giant muntjac Megamuntiacus vuquangensis and notes on other muntjac species in Laos. Oryx 32: 59-67.

Tizard, R. J., Robichaud, W. G. and Timmins, R. J. (in prep.) Ornithological records in Laos, 1996.

Treesucon, U. and Round, P. D. (1990) Report on threatened birds in Thailand. Tigerpaper 17(3): 1-9.

Usher, A. D. (1996) Damming the Theun river: Nordic companies in Laos. Ecologist 26(3): $85-92$.

Wells, D. R. and Medway, Lord (1976) Taxonomic and faunistic notes on the birds of the Malay Peninsula. Bull. Brit. Orn. Club 96: 20-34.

Wildlife Conservation Society (1995a) A preliminary survey of Phou Khao Khouay National Biodiversity Conservation Area. Vientiane: Wildlife Conservation Society (unpublished report CPAWM).

Wildlife Conservation Society (1995b) A survey of terrestrial wildlife in the area to be affected by the proposed Xe Nam Noy-Xe Pian Hydroelectric Project. Vientiane: Wildlife Conservation Society (unpublished report to the Committee for Planning and Cooperation of the Government of the Lao P.D.R. and Electrowatt Engineering Services).

Wildlife Conservation Society (1995c) A wildlife and habitat assessment of the TheunHinboun hydropower project area. Vientiane: Wildlife Conservation Society (unpublished report to the Hydropower Office of the Lao P.D.R. Ministry of Industry and Handicrafts and to Norplan A/S).

Wildlife Conservation Society (1995d) A preliminary wildlife and habitat assessment of the Nam Theun 2 hydropower project area. Vientiane: Wildlife Conservation Society (unpublished report to the Committee for Planning and Cooperation of the Government of the Lao P.D.R. and the Project Development Group of the Nam Theun 2 Hydropower project).

Williamson, W. (1945) On some birds from Thailand, etc. Ibis 87: 52-69.

R. M. THEWLIS

52 Long Reach Road, Chesterton, Cambridge CB4 IUJ, U.K.

R. J. TIMMINS

25 Cradley Road, Cradley Heath, Warley, West Midlands B64 6AG, U.K.

T. D. EVANS

11 Yeoman Lane, Bearsted, Maidstone, Kent ME14 4BX, U.K.

J. W. DUCKWORTH

East Redham Farm, Pilning, Bristol, BS35 4JG, U.K.

\section{Notes added in proof}

1. As this paper went to press, the observer of the Greater Adjutant records listed on p. 88 for Dong Khanthung proposed NBCA (DKT) re-considered their identification. Following subsequent experience of adjutants in various zoos, he concluded the birds in DKT were more likely to have been Lesser Adjutants. They should therefore be treated as adjutant sp. Thus, there are no records, even provisional, of Greater Adjutant in Dong Khanthung. This reassignment affects the text in various places, as indicated by asterisks with footnotes. It also affects the categorisation of the species in Table 3, and subsequent discussion of this table, again as indicated by asterisks. The Lao population of Greater Adjutant should be listed in Table 3 as of uncertain global 
importance and of action priority "inf/acute". The species remains on the Lao list on the basis of Engelbach's (1932) records, and of provisional recent occurrence in the country on the strength of Salter (1993).

2. Ban Tongphe is the local name for a village marked on the maps as Ban Nape (3). Two other villages nearby are marked as Ban Nape (1) and Ban Nape (2). Together they and their surroundings form the area historically referred to as Nape.

3. The Ban Navang Logging Road is called the High-altitude Logging Road in the gazetteer.

4. The entry for Khon (which includes the Khonphapeng Falls) was omitted from the gazetteer. It should read:

Khon (historical, $13^{\circ} 55^{\prime}-13^{\circ} 58^{\prime} \mathrm{N} 105^{\circ} 57^{\prime}-106^{\circ} 00^{\prime} \mathrm{E} \quad$ Not named ${ }^{1,2}$, Khone $^{25}, \quad 80 ; \mathrm{S} ; 10 \mathrm{a}$ SMK) (waterfalls) Chutes de Khône ${ }^{22,25}$

5. Historical records from Nam Theun probably refer to the area on the Nakay Plateau around Ban Namtheun.

6. The Ban Nahoua Logging Road is called the Wet Forest Logging Road in the gazetteer.

Appendix 1. Gazetteer of localities in Laos mentioned in the text.

All localities are listed in alphabetical order, but the gazetteer is broken into two parts, the first for study sites and protected areas, the second for all other localities.

Geographical coordinates and altitudes have been standardised to follow the République Democratique Populaire Lao Service Geographique d'Etat (SGE) 1:100,000 map series. Coordinates are rounded to the nearest minute. Areas are taken where possible from Berkmüller et al. (1995a) supplemented by examination of maps. Province, site locality, NBCA and PPA name spellings have also been standardised to follow the same map series, except where stated (usually only for popular and widely used names). Map names do not always follow names in local use. If no map name exists, the local name is used, transliterated with the help of Lao personnel; where we decide to use an alternative name, the map spelling is given in parentheses after the alternative in the gazetteer, and local names are given in column 3. All NBCAs and PPAs are listed in Berkmüller et al. (1995b), with the exception of Dong Khanthung PPA, which was proposed later (Berkmüller and Vilawong 1996, Timmins 1996b). Coordinates are given as a point for small sites and a range for rivers and specific areas. Where a range is quoted, this is the range over which the feature extends, not the range over which observations were made. Xe Kong and Bolikhamxai Provinces are not marked on the Lao SGE 1 : 100,00o series: therefore for all province spellings and geographical coordinates we have followed the RDP Lao SGN 1:1,750,000 administrative map sheet.

Alternative spellings given in parentheses after site names relate to the following references indicated by superscript numbers: the Times Atlas of the World (1993) ${ }^{1}$; Nelles 1 : 1,500,000 map of Vietnam, Laos and Kampuchea ${ }^{2}$, Baker (1920) ${ }^{3}$; Baker $(1921)^{4}$; Bangs and van Tyne (1930 $)^{5}$; Bangs and van Tyne (1931 $)^{6}$; Bourret $(1943)^{7}$; David-Beaulieu (1939) ${ }^{8}$; David-Beaulieu (1944) $)^{9}$; David-Beaulieu $\quad(1948)^{10}$; David-Beaulieu (1949-50) ${ }^{11}$; Delacour (1926) ${ }^{12}$; Delacour (1929) ${ }^{13}$; Delacour (1932) ${ }^{14}$; Delacour and Greenway (1940) ${ }^{15}$; Delacour and Greenway (1941) ${ }^{16}$; Delacour and Jabouille (1927) ${ }^{17}$; Delacour and Jabouille $(1931)^{18}$; Delacour and Jabouille (1940) ${ }^{19}$; 
Dickinson (1970a) ${ }^{20}$; Edmond-Blanc (1944) ${ }^{21}$; Engelbach (1927a) ${ }^{22}$; Engelbach $(1927 \mathrm{~b})^{23}$; Engelbach (1929) ${ }^{24}$; Engelbach (1932) ${ }^{25}$; Oustalet (1898) ${ }^{26}$; Oustalet (18991903 ${ }^{27}$; Robinson and Kloss (1931 $)^{28}$; Williamson $(1945)^{29}$.

Underneath the locality name a category is given to the placing of that locality within the main text, which is: Historical (if it is referred to in pre-1980 references); a major study site abbreviation (e.g. BSW or TMF); or "Other" if a recent record does not relate to a major study site. Some localities which actually lie just outside a major study site are listed under that study site heading: this is the most convenient way of listing them, rather than as "Other", which would prevent the reader from quickly grasping where the locality is; where this is so, it is clearly stated.

"Not named" means a locality is marked on the map but it is not named. "Not marked" means a locality is not marked on the maps (e.g. district areas). "Not located" means a locality has not been located on the maps. NBCAs visited are shown on Fig. 1 and all provinces are shown on Fig. 2. "Not covered" means a locality is not within the national boundaries of the Lao PDR.

Glossary of Lao language elements in place names (many are often incorporated into village names): angkep, reservoir; ban, village; don, island; dong, forest; doy, mountain; houay, stream; keng, rapids; lak, kilometre; muang, town; nam, river; nong, pool, small lake; $p a$, forest; pak, river mouth; pha, exposed rocky peak (usually limestone); phou, mountain; phouphiang, plateau; sayphou, ridge, escarpment; sop, river mouth; thong, open area; vang, deep river pool; xe, river. The prefix muang literally translates as "district"; on the Lao SGE 1:100,000 map series, it is used to prefix district headquarter towns, replacing ban. However, in many historical sources it appears to be generally used to refer to the district area rather than the town. Such district boundaries are not shown on the Lao SGE 1 : 100,000 map series. Similar confusion can arise from provinces which are often named after a town or city of the same name. Furthermore, in some cases villages, towns or regions take on the name of a river, for example the Xe Pon has given rise to both a district and its administrative capital.

Localities are listed according to two biogeographical classifications; firstly the division of Laos into North (N), Central (C) and South (S) employed by King et al. (1975). Secondly, the classification of MacKinnon and MacKinnon (1986), who divided Laos into the three sub-units of Central Indochina (10a), North Indochina (1ob) and Annam (5b), is also given in the table.

Part 1. Major study sites and other existing and proposed protected areas

\begin{tabular}{|c|c|c|c|}
\hline Locality & Geographical coordinates & Area $\left(\mathrm{km}^{2}\right)$, Province & $\begin{array}{l}\text { Altitude range }(\mathrm{m}) \text {; } \\
\text { Biogeographic } \\
\text { subunits }\end{array}$ \\
\hline \multicolumn{4}{|c|}{ National Biodiversity Conservation Areas Source: Berkmüller et al. (1995b) } \\
\hline Dong Ampham & $14^{\circ} 38^{\prime}-15^{\circ} 18^{\prime} \mathrm{N} 107^{\circ} 08^{\prime}-107^{\circ} 39^{\prime} \mathrm{E}$ & 1,975 Attapu & $150-2,052 ; S, 5 b, 10 a$ \\
\hline $\begin{array}{l}\text { Dong Hua Sao } \\
\text { (DHS) }\end{array}$ & $14^{\circ} 50^{\prime}-15^{\circ} 11^{\prime} \mathrm{N} 105^{\circ} 55^{\prime}-106^{\circ} 18^{\prime} \mathrm{E}$ & 910 Champasak & $150-1,336 ; S, 10 a$ \\
\hline Hin Namno (HNN) & $17^{\circ} 15^{\prime}-17^{\circ} 40^{\prime} \mathrm{N} 105^{\circ} 43^{\prime}-106^{\circ} 09^{\prime} \mathrm{E}$ & 865 Khammouan & $180-1,017 ; \mathrm{C}, 5 \mathrm{~b}$ \\
\hline $\begin{array}{l}\text { Khammouan } \\
\text { Limestone (KML) }\end{array}$ & $17^{\circ} 26^{\prime}-18^{\circ} 05^{\prime} \mathrm{N} 104^{\circ} 25^{\prime}-105^{\circ} 10^{\prime} \mathrm{E}$ & 1,580 Khammouan & $200-1,146 ; C, 10 a$ \\
\hline $\begin{array}{l}\text { Nakay-Nam Theun } \\
\text { (NNT) }\end{array}$ & $17^{\circ} 36^{\prime}-18^{\circ} 23^{\prime} \mathrm{N} 10502^{\prime}-105^{\circ} 46^{\prime} \mathrm{E}^{1}$ & $\begin{array}{l}\text { 3,710 Khammouan, } \\
\text { Bolikhamxai }\end{array}$ & $350-2,288 ; C, 5 b, 10 a$ \\
\hline Nam Et & $20^{\circ} 09^{\prime}-20^{\circ} 50^{\prime} \mathrm{N} 103^{\circ} 21^{\prime}-103^{\circ} 53^{\prime} \mathrm{E}$ & 1,915 Houaphanh & $600-2,052 ; N, 10 b$ \\
\hline Nam Ha (East) & $20^{\circ} 32^{\prime}-20^{\circ} 53^{\prime} \mathrm{N} 101^{\circ} 10^{\prime}-101^{\circ} 28^{\prime} \mathrm{E}$ & 445 Louang-Namtha & $600-1,518 ; N, 10 b$ \\
\hline
\end{tabular}


Part 1. cont.

\begin{tabular}{|c|c|c|c|}
\hline Locality & Geographical coordinates & Area $\left(\mathrm{km}^{2}\right)$, Province & $\begin{array}{l}\text { Altitude range (m) } \\
\text { Biogeographic } \\
\text { subunits }\end{array}$ \\
\hline Nam Kading (NK) & $18^{\circ} 11^{\prime}-18^{\circ} 39^{\prime} \mathrm{N} 103^{\circ} 54^{\prime}-104^{\circ} 44^{\prime} \mathrm{E}$ & 1,740 Bolikhamxai & $180-1,432 ; N, 10 a$ \\
\hline Nam Phoun & $18^{\circ} 12^{\prime}-18^{\circ} 47^{\prime} \mathrm{N} 101^{\circ} 04^{\prime}-101^{\circ} 29^{\prime} \mathrm{E}$ & 1,150 Xaignabouli & $380-1,365 ; \mathrm{N}, 10 \mathrm{a}$ \\
\hline Nam Xam & $20^{\circ} 02^{\prime}-20^{\circ} 14^{\prime} \mathrm{N} 104^{\circ} 18^{\prime}-104^{\circ} 53^{\prime} \mathrm{E}$ & 580 Houaphanh & $200-1,741 ; \mathrm{N}, 5 \mathrm{~b}$ \\
\hline Phou Dendin (PDD) & $21^{\circ} 40^{\prime}-22^{\circ} 18^{\prime} \mathrm{N} 102^{\circ} \mathrm{OO}^{\prime}-102^{\circ} 4^{\circ} \mathrm{O}$ & 1,310 Phongsali & $500-1,914 ; N, 10 b$ \\
\hline $\begin{array}{l}\text { Phou Khaokhoay } \\
\text { (PKK) }\end{array}$ & $18^{\circ} 14^{\prime}-18^{\circ} 34^{\prime} \mathrm{N} 102^{\circ} 44^{\prime}-103^{\circ} 29^{\prime} \mathrm{E}$ & $\begin{array}{l}\text { 1,390 Vientiane, } \\
\text { Bolikhamxai }\end{array}$ & $200-1,666 ; \mathrm{N}, 10 a$ \\
\hline Phou Loeuy & $19^{\circ} 50^{\prime}-20^{\circ} 29^{\prime} \mathrm{N} 103^{\circ} 00^{\prime}-104^{\circ} 23^{\prime} \mathrm{E}$ & $\begin{array}{l}\text { 1,430 Houaphan, } \\
\text { Louangphabang }\end{array}$ & $500-2,257 ; N, 10 b$ \\
\hline Phou Phanang & $18^{\circ} 02^{\prime}-18^{\circ} 35^{\prime} \mathrm{N} 102^{\circ} 12^{\prime}-102^{\circ} 23^{\prime} \mathrm{E}$ & $\begin{array}{l}400 \text { Vientiane } \\
\text { Prefecture/Province }\end{array}$ & $180-790 ; \mathrm{N}, 10 a$ \\
\hline $\begin{array}{l}\text { Phou Xang He } \\
\text { (PXH) }\end{array}$ & $16^{\circ} 4^{\prime}-17^{\circ} 04^{\prime} \mathrm{N} 105^{\circ} 19^{\prime}-106^{\circ} 06^{\prime} \mathrm{E}$ & 1,06o Savannakhet & $200-818 ; C, 10 a$ \\
\hline $\begin{array}{l}\text { Phou Xiang Thong } \\
\text { (PXT) }\end{array}$ & $15^{\circ} 19^{\prime}-15^{\circ} 56^{\prime} \mathrm{N} 105^{\circ} 25^{\prime}-105^{\circ} 47^{\prime} \mathrm{E}$ & 995 Salavan & $150-716 ; 5,10 a$ \\
\hline $\begin{array}{l}\text { Xe Bang-Nouan } \\
(\mathrm{XBN})\end{array}$ & $15^{\circ} 44^{\prime}-16^{\circ} 01^{\prime} \mathrm{N} 105^{\circ} 33^{\prime}-106^{\circ} 18^{\prime} \mathrm{E}$ & $\begin{array}{l}\text { 1,260 Savannakhet, } \\
\text { Salavan }\end{array}$ & $180-1,239 ; \mathrm{S}, 10 a$ \\
\hline Xe Pian (XP) & $13^{\circ} 55^{\prime}-14^{\circ} 47^{\prime} \mathrm{N} 105^{\circ} 54^{\prime}-106^{\circ} 29^{\prime} \mathrm{E}$ & $\begin{array}{l}\text { 2,665 Champasak } \\
\text { Attapu }\end{array}$ & $150-844 ; S, 10 a$ \\
\hline
\end{tabular}

Proposed National Biodiversity Conservation Areas Sources: Berkmüller et al. (1995b), Berkmüller and Vilawong (1996), Timmins (1996a,b).

\begin{tabular}{|c|c|c|c|}
\hline Bolaven Northeast & $15^{\circ} 00^{\prime}-15^{\circ} 24^{N} 106^{\circ} 23^{\prime}-106^{\circ} 49^{\prime} \mathrm{E}$ & $\begin{array}{l}935 \text { Champasak, } \\
\text { Attapu }\end{array}$ & 200-1,716; S,10a \\
\hline $\begin{array}{l}\text { Bolaven Southwest } \\
\text { (BSW) }\end{array}$ & 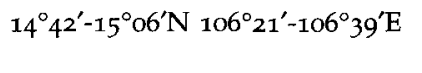 & $\begin{array}{l}\text { 620 Champasak, } \\
\text { Attapu }\end{array}$ & 190-1,092; S,10a \\
\hline $\begin{array}{l}\text { Dong Khanthung } \\
\text { (DKT) }\end{array}$ & $14^{\circ} \mathrm{O} 7^{\prime}-14^{\circ} 32^{\prime} \mathrm{N} 105^{\circ} 12^{\prime}-105^{\circ} 45^{\prime} \mathrm{E}$ & $\begin{array}{l}\text { approx. 1,000 } \\
\text { Champasak }\end{array}$ & $80-502 ; \mathrm{S}, 10 a$ \\
\hline $\begin{array}{l}\text { Nakay-Nam Theun } \\
\text { Extension (NTX) }\end{array}$ & $18^{\circ} 21^{\prime}-18^{\circ} 4^{\prime} \mathrm{N} 104^{\circ} 45^{\prime}-105^{\circ} 12^{\prime} \mathrm{E}$ & 645 Bolikhamxai & $700-1,697 ; N, 5 b$ \\
\hline Nam Chouan & $18^{\circ} 45^{\prime}-19^{\circ} 16^{\prime} \mathrm{N} 103^{\circ} 5^{\circ}-104^{\circ} 47^{\prime} \mathrm{E}$ & $\begin{array}{l}\text { 1,610 Xiangkhouang, } \\
\text { Bolikhamxai }\end{array}$ & $200-2,711 ; \mathrm{N}, 5 \mathrm{~b}$ \\
\hline Nam Ha (West) & $20^{\circ} 39^{\prime}-21^{\circ} 03^{\prime} \mathrm{N} 100^{\circ} 52^{\prime}-101^{\circ} 23^{\prime} \mathrm{E}$ & 1,025 Louang-Namtha & $500-2,094 ; N, 10 b$ \\
\hline Nam Kan & $20^{\circ} 20^{\prime}-20^{\circ} 46^{\prime} \mathrm{N} 100^{\circ} 38^{\prime}-100^{\circ} 54^{\prime} \mathrm{E}$ & 775 Bokeo & $400-1,358 ; N, 10 b$ \\
\hline $\begin{array}{l}\text { Nam Theun } \\
\text { Corridor }\end{array}$ & $17^{\circ} 46^{\prime}-18^{\circ} 10^{\prime} \mathrm{N} 104^{\circ} 48^{\prime}-105^{\circ} 06^{\prime} \mathrm{E}$ & $\begin{array}{l}620 \text { Khammouan, } \\
\text { Khammouan }\end{array}$ & $180-1,320 ; N, C, 10 a$ \\
\hline Phou Kathong & $14^{\circ} 54^{\prime}-15^{\circ} 19^{\prime} \mathrm{N} 106^{\circ} 47^{\prime}-107^{\circ} 14^{\prime} \mathrm{E}$ & 88o Attapu, Xekong & $110-1,022 ; S, 10 a$ \\
\hline Phou Theung & $15^{\circ} 25^{\prime}-15^{\circ} 54^{\prime} \mathrm{N} 106^{\circ} 29^{\prime}-106^{\circ} 51^{\prime} \mathrm{E}$ & 1,130 Salavan, Xekong & $180-926 ; 5,10 a$ \\
\hline Xe Khampho & $14^{\circ} 35^{\prime}-15^{\circ} 00^{\prime} \mathrm{N} 106^{\circ} 11^{\prime}-106^{\circ} 35^{\prime} \mathrm{E}$ & $\begin{array}{l}780 \text { Champasak, } \\
\text { Attapu }\end{array}$ & $80-750 ; S, 10 a$ \\
\hline Xe Sap (XS) & $15^{\circ} 57^{\prime}-16^{\circ} 19^{\prime} \mathrm{N} 106^{\circ} 42^{\prime}-107^{\circ} 28^{\prime} \mathrm{E}^{2}$ & $\begin{array}{l}1,335 \text { (XS) }+1,700 \\
\text { (Phou Ajol extension) } \\
\text { Salavan, Xekong }\end{array}$ & $600-2,193 ; S, 5 b$ \\
\hline
\end{tabular}

Study sites outside the NBCA system

Houay Nhang $\quad 18^{\circ} 06^{\prime} \mathrm{N} 102^{\circ} 40^{\prime} \mathrm{E}$

Nature Reserve (HN)

Nakay Plateau (NP) $17^{\circ} 36^{\prime}-18^{\circ} 00^{\prime} \mathrm{N} 104^{\circ} 52^{\prime}-105^{\circ} 32^{\prime} \mathrm{E}$

8 Vientiane Prefecture $180 ; \mathrm{N}, 10 a$

(a portion of this is within NNT)

1,250 Khammouan

$500-600 ; C, 10 a$

( 450 in NNT)

$192 \mathrm{~km}$ length

$50-90 ; \mathrm{S}, 10 a$

Section of Mekong
river in Champasak

$13^{\circ} 55^{\prime}-15^{\circ} 20^{\prime} \mathrm{N} 105^{\circ} 34^{\prime}-106^{\circ} 00^{\prime} \mathrm{E}$

Champasak

Province (SMK)

Sangthong Training $18^{\circ} 12^{\prime}-18^{\circ} 26^{\prime} \mathrm{N} 102^{\circ} 02^{\prime}-102^{\circ} 15^{\prime} \mathrm{E}$ and Model Forest

355 Vientiane

Prefecture

170-609; $\mathrm{N}, 10 a$ 
Part 1. cont.

\begin{tabular}{llll}
\hline Locality & Geographical coordinates & Area $\left(\mathrm{km}^{2}\right)$, Province & $\begin{array}{l}\text { Altitude range }(\mathrm{m}) ; \\
\text { Biogeographic } \\
\text { subunits }\end{array}$ \\
\hline $\begin{array}{l}\text { Xe Namnoy } \\
\text { drainage basin } \\
(\mathrm{XNN})\end{array}$ & $14^{\circ} 55^{\prime}-15^{\circ} 15^{\prime} \mathrm{N} 106^{\circ} 32^{\prime}-106^{\circ} 50^{\prime} \mathrm{E}$ & $\begin{array}{l}\text { approx. 800 } \\
\text { Champasak, Attapu }\end{array}$ & 150-1,300; S,10a \\
\hline
\end{tabular}

'Includes the portion of the Nakay Plateau which is within the protected area, but not NTX.

2 Proposed Phou Ajol extension: $15^{\circ} 30^{\prime}-16^{\circ} 00^{\prime} \mathrm{N} 107^{\circ} 00^{\prime}-107^{\circ} 25^{\prime} \mathrm{E}$.

Part 2. All other localities mentioned in the text ${ }^{*}$

\begin{tabular}{|c|c|c|c|}
\hline $\begin{array}{l}\text { Locality name } \\
\text { following Lao SGN } \\
\text { I : 10o,ooo Series } \\
\text { Category within main } \\
\text { text (e.g: Historical } \\
\text { "Other") }\end{array}$ & $\begin{array}{l}\text { Geographical } \\
\text { coordinates (locality } \\
\text { type: town/river/ } \\
\text { region) }\end{array}$ & $\begin{array}{l}\text { Alternative names in } \\
\text { references, and local } \\
\text { names }\end{array}$ & $\begin{array}{l}\text { Altitude; } \\
\text { Biogeographic } \\
\text { subunits }\end{array}$ \\
\hline $\begin{array}{l}\text { Annamite range (Map } \\
\text { name Sayphou } \\
\text { Louang) }\end{array}$ & $\begin{array}{l}\text { approx. } 14^{\circ} 30^{\prime}-19^{\circ} 00^{\prime} \mathrm{N} \\
103^{\circ} 30^{\prime}-107^{\circ} 30^{\prime} \mathrm{E} \\
\text { (coordinates for within } \\
\text { Laos; major mountain } \\
\text { range) }\end{array}$ & $\begin{array}{l}\text { Not named }{ }^{1} \text {; Annam } \\
\text { Highlands }^{2}\end{array}$ & $500-2,711 ; \mathrm{N}, \mathrm{C}, \mathrm{S}, 5 \mathrm{~b}$ \\
\hline $\begin{array}{l}\text { Attapu Province (Not } \\
\text { marked) }\end{array}$ & $\begin{array}{l}14^{\circ} 20^{\prime}-15^{\circ} 15^{\prime} \mathrm{N} \\
106^{\circ} 15^{\prime}-107^{\circ} 40^{\prime} \mathrm{E} \\
\text { (Province) }\end{array}$ & Not marked ${ }^{1,2}$ & $70-1,683, S, 5 b, 10 a$ \\
\hline $\begin{array}{l}\text { Attapu (Historical; } \\
\text { "Other") }\end{array}$ & $\begin{array}{l}14^{\circ} 4^{\prime} \mathrm{N} 106^{\circ} 50^{\prime} \mathrm{E} \\
\text { (town) }\end{array}$ & $\begin{array}{l}\text { Attopeu }{ }^{1,18,22,25,27} ; \\
\text { Attapu }^{2} ; \text { Attapeu }\end{array}$ & $110 ;$ S,10a \\
\hline Ban Boung (SMK) & $\begin{array}{l}14^{\circ} 24^{\prime} \mathrm{N} 105^{\circ} 5 \mathrm{I}^{\prime} \mathrm{E} \\
\text { (village) }\end{array}$ & Not marked ${ }^{1,2}$ & $80 ; S, 10 a$ \\
\hline Ban Boungbao (SMK) & $\begin{array}{l}14^{\circ} 29^{\prime} \mathrm{N} 105^{\circ} 51^{\prime} \mathrm{E} \\
\text { (village) }\end{array}$ & Not marked ${ }^{1,2}$ & $80 ; S, 10 a$ \\
\hline $\begin{array}{l}\text { Ban Bo-Tai (NNT and } \\
\text { NP) }\end{array}$ & $\begin{array}{l}17^{\circ} 49^{\prime} \mathrm{N} 105^{\circ} 09^{\prime} \mathrm{E} \\
\text { (village) }\end{array}$ & $\begin{array}{l}\text { Not marked }{ }^{1,2} \text { (local } \\
\text { name Ban Soupen) }\end{array}$ & 520; C,10a \\
\hline $\begin{array}{l}\text { Ban Boun-Tai } \\
\text { (Historical) }\end{array}$ & $\begin{array}{l}21^{\circ} 24^{\prime} \mathrm{N} 101^{\circ} 58^{\prime} \mathrm{E} \\
\text { (village) }\end{array}$ & 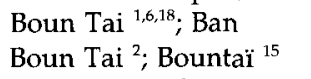 & $580 ; \mathrm{N}, \mathrm{Iob}$ \\
\hline Ban Chanto ("Other") & $\begin{array}{l}14^{\circ} 41^{\prime} \mathrm{N} 106^{\circ} 18^{\prime} \mathrm{E} \\
\text { (village) }\end{array}$ & Not marked ${ }^{1,2}$ & $80 ;$ S,10a \\
\hline $\begin{array}{l}\text { Ban Chomthong } \\
\text { ("Other" - outside } \\
\text { NK) }\end{array}$ & $\begin{array}{l}18^{\circ} 43^{\prime} \mathrm{N} 104^{\circ} 16^{\prime} \mathrm{E} \\
\text { (village) }\end{array}$ & Not marked $^{1,2}$ & $280 ; N, 10 a$ \\
\hline Ban Dakchung (XS) & $\begin{array}{l}15^{\circ} 28^{\prime} \mathrm{N} 107^{\circ} 16^{\prime} \mathrm{E} \\
\text { (village) }\end{array}$ & $\begin{array}{l}\text { Not marked }{ }^{1} \text {; Ban } \\
\text { Dakchung }^{2}\end{array}$ & 1,$100 ; S, 5 b$ \\
\hline $\begin{array}{l}\text { Ban Don (NP, just } \\
\text { outside NNT) }\end{array}$ & $\begin{array}{l}17^{\circ} 40^{\prime} \mathrm{N} 105^{\circ} 17^{\prime} \mathrm{E} \\
\text { (village) }\end{array}$ & Not marked $^{1,2}$ & 520; C,10a \\
\hline Ban Donhet (SMK) & $\begin{array}{l}14^{\circ} 11^{\prime} \mathrm{N} 105^{\circ} 45^{\prime} \mathrm{E} \\
\text { (village) }\end{array}$ & Not marked ${ }^{1,2}$ & $80 ;$ S, IOa \\
\hline Ban Donkoum (PXT) & $\begin{array}{l}15^{\circ} 24^{\prime} \mathrm{N} 105^{\circ} 34^{\prime} \mathrm{E} \\
\text { (village) }\end{array}$ & Not marked $^{1,2}$ & I10; S, IOa \\
\hline Ban Donme (NK) & 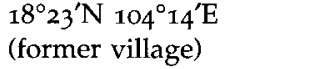 & Not marked ${ }^{1,2}$ & $180 ; N, 10 a$ \\
\hline $\begin{array}{l}\text { Ban Gnommalat } \\
\text { ("Other") }\end{array}$ & $\begin{array}{l}17^{\circ} 36^{\prime} \mathrm{N} 105^{\circ} 10^{\prime} \mathrm{E} \text { (large } \\
\text { village) }\end{array}$ & $\begin{array}{l}\text { Nhommarath }{ }^{1} \text {, Muang } \\
\text { Gnommarat }^{2}\end{array}$ & $180 ; C, 5 b, 10 a$ \\
\hline
\end{tabular}

*see notes added in proof 2-6, p.132. 
Part 2. cont.

\begin{tabular}{|c|c|c|c|}
\hline $\begin{array}{l}\text { Locality name } \\
\text { following Lao SGN } \\
1: \text { 1oo,ooo Series } \\
\text { Category within main } \\
\text { text (e.g: Historical } \\
\text { "Other") }\end{array}$ & $\begin{array}{l}\text { Geographical } \\
\text { coordinates (locality } \\
\text { type: town/river/ } \\
\text { region) }\end{array}$ & $\begin{array}{l}\text { Alternative names in } \\
\text { references, and local } \\
\text { names }\end{array}$ & $\begin{array}{l}\text { Altitude; } \\
\text { Biogeographic } \\
\text { subunits }\end{array}$ \\
\hline $\begin{array}{l}\text { Ban Guner (Not } \\
\text { marked) (NNT) }\end{array}$ & $\begin{array}{l}17^{\circ} 51^{\prime} \mathrm{N} 105^{\circ} 35^{\prime} \mathrm{E} \\
\text { (village) }\end{array}$ & Not marked ${ }^{1,2}$ & $600 ; C, 5 b, 10 a$ \\
\hline Ban Hangkhon (SMK) & $\begin{array}{l}13^{\circ} 56^{\prime} \mathrm{N} 105^{\circ} 56^{\prime} \mathrm{E} \\
\text { (village) }\end{array}$ & Not marked ${ }^{1,2}$ & $70 ; S, 10 a$ \\
\hline Ban Hat Xa (PDD) & $\begin{array}{l}21^{\circ} 44^{\prime} \mathrm{N} 102^{\circ} 13^{\prime} \mathrm{E} \\
\text { (village) }\end{array}$ & Not marked ${ }^{1,2}$ & $54^{\circ} ; \mathrm{N}, 5 \mathrm{~b}$ \\
\hline $\begin{array}{l}\text { Ban Hatxeno (Not } \\
\text { marked) (PXT) }\end{array}$ & $\begin{array}{l}15^{\circ} 38^{\prime} \mathrm{N} 105^{\circ} 38^{\prime} \mathrm{E} \\
\text { (village) }\end{array}$ & Not marked 1,2 & $110 ; S, 10 a$ \\
\hline Ban Hinlat (BSW) & $\begin{array}{l}14^{\circ} 45^{\prime} \mathrm{N} 106^{\circ} 29^{\prime} \mathrm{E} \\
\text { (village) }\end{array}$ & Not marked ${ }^{1,2}$ & $80 ;$ S,10a \\
\hline $\begin{array}{l}\text { Ban Hoi Mak (not } \\
\text { located: locality } \\
\text { between Ban Na Sao } \\
\text { and Ban Pak-Hinboun) } \\
\text { (Historical) }\end{array}$ & $\begin{array}{l}\text { approx. } 17^{\circ} 55^{\prime} \mathrm{N} \\
104^{\circ} 35^{\prime} \mathrm{E} \text { (village) }\end{array}$ & $\begin{array}{l}\text { Not marked }{ }^{1,2} \text {; Ban } \\
\text { Hoi Mak }^{3,28}\end{array}$ & $200 ; C, 10 a$ \\
\hline $\begin{array}{l}\text { Ban Houadonxai } \\
(\mathrm{SMK})\end{array}$ & $\begin{array}{l}14^{\circ} 34^{\prime} \mathrm{N} 105^{\circ} 51^{\prime} \mathrm{E} \\
\text { (village) }\end{array}$ & Not marked ${ }^{1,2}$ & $90 ; S, 10 a$ \\
\hline $\begin{array}{l}\text { Ban Houakhamao } \\
\text { (SMK) }\end{array}$ & $\begin{array}{l}14^{\circ} \mathrm{o} 8^{\prime} \mathrm{N} 105^{\circ} 4^{\prime} \mathrm{E} \\
\text { (village) }\end{array}$ & Not marked ${ }^{1,2}$ & $80 ; S, 10 a$ \\
\hline Ban Houaychot (BSW) & $\begin{array}{l}15^{\circ} \mathrm{O} 2^{\prime} \mathrm{N} 106^{\circ} 31^{\prime} \mathrm{E} \\
\text { (village) }\end{array}$ & Not marked ${ }^{1,2}$ & $760 ; S, 10 a$ \\
\hline Ban Houayko (BSW) & $\begin{array}{l}14^{\circ} 56^{\prime} \mathrm{N} 106^{\circ} 28^{\prime} \mathrm{E} \\
\text { (village) }\end{array}$ & $\begin{array}{l}\text { Not marked }{ }^{1,2} \text { (local } \\
\text { name Ban Don } \\
\text { Kong) }\end{array}$ & $340 ; S, 10 a$ \\
\hline $\begin{array}{l}\text { Ban Houaymanpa } \\
\text { (SMK) }\end{array}$ & $\begin{array}{l}14^{\circ} 42^{\prime} \mathrm{N} 105^{\circ} 55^{\prime} \mathrm{E} \\
\text { (village) }\end{array}$ & Not marked ${ }^{1,2}$ & $90 ; S, 10 a$ \\
\hline $\begin{array}{l}\text { Ban Houay Phoung } \\
\text { (not marked) (DHS) }\end{array}$ & $\begin{array}{l}15^{\circ} \mathrm{OO}{ }^{\prime} \mathrm{N} 106^{\circ} \mathrm{o} 7^{\prime} \mathrm{E} \\
\text { (village) }\end{array}$ & Not marked ${ }^{1,2}$ & 3oo; S,10a \\
\hline Ban Houayxai (DKT) & $\begin{array}{l}14^{\circ} 27^{\prime} \mathrm{N} 105^{\circ} 32^{\prime} \mathrm{E} \\
\text { (village) }\end{array}$ & Not marked ${ }^{1,2}$ & $94 ; S, 10 a$ \\
\hline $\begin{array}{l}\text { Ban Houayxai } \\
\text { (Historical) }\end{array}$ & $\begin{array}{l}20^{\circ} 17^{\prime} \mathrm{N} 100^{\circ} 25^{\prime} \mathrm{E} \\
\text { (village) }\end{array}$ & $\begin{array}{l}\text { Ban Houei Sai }{ }^{1} \text {; Ban } \\
\text { Houayxay }{ }^{2} \text {; Ban } \\
\text { Houeisai }{ }^{15,18}\end{array}$ & $300 ; N, 10 b$ \\
\hline $\begin{array}{l}\text { Ban Hua Chang (not } \\
\text { located locality along } \\
\text { Mekong between } \\
\text { Mukdahan and Ban } \\
\text { Pak-Hinboun) } \\
\text { (Historical) }\end{array}$ & $\begin{array}{l}\text { Coordinates unknown } \\
\text { (village) }\end{array}$ & $\begin{array}{l}\text { Not marked }{ }^{1,2} ; \text { Ban } \\
\text { Hua Chang }{ }^{28}\end{array}$ & 200; C,10a \\
\hline $\begin{array}{l}\text { Ban Huang (not } \\
\text { located: locality along } \\
\text { Nam Huang river) } \\
\text { (Historical) }\end{array}$ & $\begin{array}{l}\text { Coordinates unknown } \\
\text { (village) }\end{array}$ & $\begin{array}{l}\text { Not marked }{ }^{1,2} ; \text { Ban } \\
\text { Huang }^{28}\end{array}$ & $170 ; \mathrm{N}, 10 a$ \\
\hline $\begin{array}{l}\text { Ban Kadan (Not } \\
\text { marked) (DKT) }\end{array}$ & $\begin{array}{l}14^{\circ} 22^{\prime} \mathrm{N} 105^{\circ} 40^{\prime} \mathrm{E} \\
\text { (village) }\end{array}$ & Not marked ${ }^{1,2}$ & $95 ; S, 10 a$ \\
\hline Ban Kadian (DKT) & $\begin{array}{l}14^{\circ} 26^{\prime} \mathrm{N} 105^{\circ} 42^{\prime} \mathrm{E} \\
\text { (village) }\end{array}$ & $\begin{array}{l}\text { Ban Kadiene }{ }^{1} \text {; Ban } \\
\text { Kadian }^{2}\end{array}$ & $93 ;$ S,10a \\
\hline $\begin{array}{l}\text { Ban Kalon-Dong (Not } \\
\text { located) ("Other") }\end{array}$ & $\begin{array}{l}\text { Coordinates unknown } \\
\text { (village) }\end{array}$ & $\begin{array}{l}\text { Not marked }{ }^{1,2} ; \text { locality } \\
\text { in Savannakhet }\end{array}$ & ?; S,10a \\
\hline
\end{tabular}


Part 2. cont.

\begin{tabular}{lll}
\hline Locality name & $\begin{array}{l}\text { Geographical } \\
\text { coordinates (locality } \\
\text { following Lao SGN }\end{array}$ & $\begin{array}{l}\text { Alternative names in } \\
\text { references, and local } \\
\text { names }\end{array}$ \\
$\begin{array}{l}\text { Category } 100 \text {, oo Series } \\
\text { text (e.g: Historical }\end{array}$ & region) & \\
"Other") & &
\end{tabular}

Altitude;

Biogeographic subunits

\begin{tabular}{|c|c|c|c|}
\hline Ban Kanluang (DKT) & $\begin{array}{l}14^{\circ} \mathrm{og}{ }^{\prime} \mathrm{N} 105^{\circ} 35^{\prime} \mathrm{E} \\
\text { (village) }\end{array}$ & $\begin{array}{l}\text { Province } \\
\text { Not marked }{ }^{1,2} \text { (local } \\
\text { name Ban Tahin) }\end{array}$ & $90 ; S, 10 a$ \\
\hline $\begin{array}{l}\text { Ban Katok (HNN just } \\
\text { outside) }\end{array}$ & $\begin{array}{l}17^{\circ} \mathrm{O} 5^{\prime} \mathrm{N} 106^{\circ} \mathrm{O} 3^{\prime} \mathrm{E} \\
\text { (village) }\end{array}$ & Not marked ${ }^{1,2}$ & $420 ; C, 5 b$ and Ioa \\
\hline Ban Khame (PXH) & $\begin{array}{l}16^{\circ} 46^{\prime} \mathrm{N} 105^{\circ} 55^{\prime} \mathrm{E} \\
\text { (village) }\end{array}$ & $\begin{array}{l}\text { Not marked }{ }^{1,2} \text { (local } \\
\text { name Ban } \\
\text { Nomsamlane) }\end{array}$ & 220; C,10a \\
\hline Ban Khiam (DKT) & $\begin{array}{l}14^{\circ} 13^{\prime} \mathrm{N} 105^{\circ} 19^{\prime} \mathrm{E} \\
\text { (village) }\end{array}$ & Not marked ${ }^{1,2}$ & 110; S,10a \\
\hline Ban Konglu (XBN) & $\begin{array}{l}15^{\circ} 55^{\prime} \mathrm{N} 105^{\circ} 5^{\prime} \mathrm{E} \\
\text { (village) }\end{array}$ & Not marked ${ }^{1,2}$ & $160 ; S, 10 a$ \\
\hline $\begin{array}{l}\text { Ban Kengbit (just } \\
\text { outside NK) }\end{array}$ & $\begin{array}{l}18^{\circ} 15^{\prime} \mathrm{N} 104^{\circ} 34^{\prime} \mathrm{E} \\
\text { (village) }\end{array}$ & Not marked ${ }^{1,2}$ & $380 ; \mathrm{N}, 10 a$ \\
\hline $\begin{array}{l}\text { Ban Kengcheng (Ban } \\
\text { Hang) (NNT and NP) }\end{array}$ & $\begin{array}{l}17^{\circ} 44^{\prime} \mathrm{N} 105^{\circ} 20^{\prime} \mathrm{E} \\
\text { (village) }\end{array}$ & $\begin{array}{l}\text { Not marked }{ }^{1,2} \\
\text { (local name Ban } \\
\text { Kha-oy) }\end{array}$ & $520 ; C, 10 a$ \\
\hline $\begin{array}{l}\text { Ban Kengkok } \\
\text { (Historical) }\end{array}$ & $\begin{array}{l}16^{\circ} 27^{\prime} \mathrm{N} 105^{\circ} 12^{\prime} \mathrm{E} \\
\text { (village) }\end{array}$ & $\begin{array}{l}\text { Keng Kok }{ }^{1} \text {; } \\
\text { Ban Kèngkok }{ }^{2} \text {; } \\
\text { Keng-kok }{ }^{11}\end{array}$ & 140; C,10a \\
\hline Ban Keoleuk ("Other') & $\begin{array}{l}19^{\circ} 49^{\prime} \mathrm{N} 103^{\circ} 45^{\prime} \mathrm{E} \\
\text { (village) }\end{array}$ & Not marked ${ }^{1,2}$ & 1,$000 ; \mathrm{N}, 10 a$ \\
\hline $\begin{array}{l}\text { Ban Khantoungxai } \\
\text { (Not marked) (PXT) }\end{array}$ & $\begin{array}{l}15^{\circ} 33^{\prime} \mathrm{N} 105^{\circ} 37^{\prime} \mathrm{E} \\
\text { (village) }\end{array}$ & Not marked ${ }^{1,2}$ & $140 ; \mathrm{S}, 10 a$ \\
\hline Ban Keun ("Other") & $\begin{array}{l}18^{\circ} 22^{\prime} \mathrm{N} 102^{\circ} 35^{\prime} \mathrm{E} \\
\text { (village) }\end{array}$ & $\begin{array}{l}\text { Not marked }{ }^{1} \text {; Ban } \\
\text { Keun }^{2}\end{array}$ & $170 ; N, 10 a$ \\
\hline $\begin{array}{l}\text { Ban Khuang-Gnai } \\
\text { (BSW) }\end{array}$ & $\begin{array}{l}15^{\circ} 06^{\prime} \mathrm{N} 106^{\circ} 26^{\prime} \mathrm{E} \\
\text { (village) }\end{array}$ & Not marked ${ }^{1,2}$ & $940 ; \mathrm{S}, 10 a$ \\
\hline $\begin{array}{l}\text { Ban Kuai (Not named) } \\
\text { (TMF) }\end{array}$ & $\begin{array}{l}18^{\circ} 18^{\prime} \mathrm{N} 107^{\circ} 07^{\prime} \mathrm{E} \\
\text { (village) }\end{array}$ & Not marked ${ }^{1,2}$ & $200 ; \mathrm{N}, 10 a$ \\
\hline Ban La (PDD) & $\begin{array}{l}22^{\circ} 05^{\prime} \mathrm{N} 102^{\circ} 20^{\prime} \mathrm{E} \\
\text { (village) }\end{array}$ & Not marked ${ }^{1,2}$ & $600 ; \mathrm{N}, 10 \mathrm{~b}$ \\
\hline $\begin{array}{l}\text { Ban Lahanam-Thong } \\
\text { (Historical) }\end{array}$ & $\begin{array}{l}16^{\circ} 16^{\prime} \mathrm{N} 105^{\circ} 16^{\prime} \mathrm{E} \\
\text { (village) }\end{array}$ & $\begin{array}{l}\text { Not marked 1; Ban } \\
\text { Lahanam }^{2} \text {; La } \\
\text { Ha-Nam }^{11}\end{array}$ & 130; C,10a \\
\hline Ban Lak (20) ("Other") & $\begin{array}{l}18^{\circ} 11^{\prime} \mathrm{N} 104^{\circ} 58^{\prime} \mathrm{E} \\
\text { (village) }\end{array}$ & $\begin{array}{l}\text { Lak Sao }{ }^{1} \text {; Not } \\
\text { marked }^{2} \text { (local name } \\
\text { Lak Sao or } \\
\text { Lak Xao) }\end{array}$ & $520 ; C, 10 a$ \\
\hline Ban Lak (52) ("Other") & $\begin{array}{l}18^{\circ} 21^{\prime} \mathrm{N} 102^{\circ} 26^{\prime} \mathrm{E} \\
\text { (village) }\end{array}$ & $\begin{array}{l}\text { Not marked }{ }^{1,2} \text { (local } \\
\text { name Ban } \\
\text { Lak-Hasipsong) }\end{array}$ & $190 ; \mathrm{N}, 10 a$ \\
\hline $\begin{array}{l}\text { Ban Laogna (just } \\
\text { outside DHS) }\end{array}$ & $\begin{array}{l}14^{\circ} 53^{\prime} \mathrm{N} 106^{\circ} 05^{\prime} \mathrm{E} \\
\text { (village) }\end{array}$ & Not marked ${ }^{1,2}$ & $160 ; S, 10 a$ \\
\hline $\begin{array}{l}\text { Ban Lavay (just } \\
\text { outside PXH) }\end{array}$ & $\begin{array}{l}16^{\circ} 41^{\prime} \mathrm{N} 105^{\circ} 5^{\prime} \mathrm{E} \\
\text { (village) }\end{array}$ & Not marked ${ }^{1,2}$ & 200; C,10a \\
\hline $\begin{array}{l}\text { Ban Louk (just outside } \\
\text { HNN) }\end{array}$ & $\begin{array}{l}17^{\circ} 34^{\prime} \mathrm{N} 105^{\circ} 51^{\prime} \mathrm{E} \\
\text { (village) }\end{array}$ & $\begin{array}{l}\text { Not marked }{ }^{1,2} \text { (local } \\
\text { name Ban } \\
\text { Vangngnow) }\end{array}$ & $500 ; C, 5 b, 10 a$ \\
\hline
\end{tabular}


Part 2. cont.

\begin{tabular}{|c|c|c|c|}
\hline $\begin{array}{l}\text { Locality name } \\
\text { following Lao SGN } \\
\text { 1 : 100,000 Series } \\
\text { Category within main } \\
\text { text (e.g: Historical } \\
\text { "Other") }\end{array}$ & $\begin{array}{l}\text { Geographical } \\
\text { coordinates (locality } \\
\text { type: town/river/ } \\
\text { region) }\end{array}$ & $\begin{array}{l}\text { Alternative names in } \\
\text { references, and local } \\
\text { names }\end{array}$ & $\begin{array}{l}\text { Altitude; } \\
\text { Biogeographic } \\
\text { subunits }\end{array}$ \\
\hline $\begin{array}{l}\text { Ban Maka (not } \\
\text { marked) (NNT) }\end{array}$ & $\begin{array}{l}17^{\circ} 56^{\prime} \mathrm{N} 105^{\circ} 31^{\prime} \mathrm{E} \\
\text { (village) }\end{array}$ & Not marked ${ }^{1,2}$ & $600 ; C, 5 b, 10 a$ \\
\hline $\begin{array}{l}\text { Ban Manau (not } \\
\text { located; locality lies } \\
\text { along Mekong } \\
\text { between Ban Paksa } \\
\text { and Ban Pak-Hinboun) } \\
\text { (Historical) }\end{array}$ & $\begin{array}{l}\text { Coordinates unknown } \\
\text { (village) }\end{array}$ & $\begin{array}{l}\text { Not marked }{ }^{1,2} ; \text { Ban } \\
\text { Manau }^{28}\end{array}$ & $160 ; \mathrm{N}$ or $\mathrm{C}, 10 a$ \\
\hline Ban Mixai (XNN) & $\begin{array}{l}15^{\circ} 05^{\prime} \mathrm{N} 106^{\circ} 51^{\prime} \mathrm{E} \\
\text { (village) }\end{array}$ & $\begin{array}{l}\text { Not marked }{ }^{1,2} \text { (local } \\
\text { name Ban Kagnuk) }\end{array}$ & $140 ; S, 10 a$ \\
\hline $\begin{array}{l}\text { Ban Mounlapamok } \\
\text { (SMK) }\end{array}$ & $\begin{array}{l}14^{\circ} 20^{\prime} \mathrm{N} 105^{\circ} 52^{\prime} \mathrm{E} \\
\text { (village) }\end{array}$ & $\begin{array}{l}\text { Not marked }{ }^{1}, \\
\text { Mounlapamok }^{2}\end{array}$ & $90 ; \mathrm{S}, 10 a$ \\
\hline $\begin{array}{l}\text { Ban Muanghat-Hin } \\
\text { (PDD) }\end{array}$ & $\begin{array}{l}22^{\circ} \mathrm{O} 4^{\prime} \mathrm{N} 102^{\circ} 06^{\prime} \mathrm{E} \\
\text { (village) }\end{array}$ & $\begin{array}{l}\text { Muong Hat Hin }{ }^{1} \text {, } \\
\text { Muang Hat } \text { Hin }^{2}\end{array}$ & $560 ; N, 10 b$ \\
\hline $\begin{array}{l}\text { Ban Muangliap } \\
\text { (Historical) }\end{array}$ & $\begin{array}{l}18^{\circ} 29^{\prime} \mathrm{N} 101^{\circ} 39^{\prime} \mathrm{E} \\
\text { (village) }\end{array}$ & $\begin{array}{l}\text { Muang Liep }{ }^{1,3,28} ; \text { Not } \\
\text { marked }{ }^{2}\end{array}$ & 200; N,10a \\
\hline $\begin{array}{l}\text { Ban Muang-Ngat } \\
\text { (Historical) }\end{array}$ & $\begin{array}{l}19^{\circ} 05^{\prime} \mathrm{N} 104^{\circ} 04^{\prime} \mathrm{E} \\
\text { (village) }\end{array}$ & $\begin{array}{l}\text { Not marked }{ }^{1,2} ; \text { Muang } \\
\text { Ngat }{ }^{9}\end{array}$ & 1,$300 ; N, 5 b$ \\
\hline $\begin{array}{l}\text { Ban Muangsen (just } \\
\text { outside PXH) }\end{array}$ & $\begin{array}{l}16^{\circ} 53^{\prime} \mathrm{N} 105^{\circ} 52^{\prime} \mathrm{E} \\
\text { (village) }\end{array}$ & $\begin{array}{l}\text { Not marked }{ }^{1} \text {; Ban } \\
\text { Muangsen }^{2}\end{array}$ & 250; C,10a \\
\hline $\begin{array}{l}\text { Ban Muangva } \\
\text { ("Other") }\end{array}$ & $\begin{array}{l}21^{\circ} 54^{\prime} \mathrm{N} 102^{\circ} 19^{\prime} \mathrm{E} \\
\text { (village) }\end{array}$ & $\begin{array}{l}\text { Muong } \mathrm{Va}^{\mathrm{T}} \text {; Muang } \\
\mathrm{Va}^{2}\end{array}$ & $540 ; \mathrm{N}, 10 \mathrm{ob}$ \\
\hline $\begin{array}{l}\text { Ban Muangyo } \\
\text { (Historical) }\end{array}$ & $\begin{array}{l}21^{\circ} 30^{\prime} \mathrm{N} 101^{\circ} 50^{\prime} \mathrm{E} \\
\text { (village) }\end{array}$ & $\begin{array}{l}\text { Not marked }{ }^{1,2} ; \\
\text { Muang-Yo } \\
\text { Yo }^{6,18} \text {; Muong }\end{array}$ & $840 ; N, 10 b$ \\
\hline Ban $\mathrm{Na}$ (SMK) & $\begin{array}{l}14^{\circ} 24^{\prime} \mathrm{N} 105^{\circ} 5^{1} \mathrm{E} \\
\text { (village) }\end{array}$ & Not marked ${ }^{1,2}$ & $85 ; S, 10 a$ \\
\hline $\begin{array}{l}\text { Ban Nabon (just } \\
\text { outside DHS) }\end{array}$ & $\begin{array}{l}14^{\circ} 53^{\prime} \mathrm{N} 106^{\circ} \mathrm{or} 1^{\prime} \mathrm{E} \\
\text { (village) }\end{array}$ & Not marked ${ }^{1,2}$ & $155 ; S, 10 a$ \\
\hline $\begin{array}{l}\text { Ban Nadi (NK, } \\
\text { although actually just } \\
\text { outside) }\end{array}$ & $\begin{array}{l}18^{\circ} 20^{\prime} \mathrm{N} 104^{\circ} 31^{\prime} \mathrm{E} \\
\text { (village) }\end{array}$ & Not marked ${ }^{1,2}$ & $440 ; \mathrm{N}, 10 \mathrm{a}$ \\
\hline $\begin{array}{l}\text { Ban Nakadok (just } \\
\text { outside NNT) }\end{array}$ & $\begin{array}{l}{ }^{1} 8^{\circ} 09^{\prime} \mathrm{N} 105^{\circ} 08^{\prime} \mathrm{E} \\
\text { (village) }\end{array}$ & Not marked ${ }^{1,2}$ & $580 ; C, 10 a, 5 b$ \\
\hline $\begin{array}{l}\text { Ban Nakay (Historical, } \\
\text { NP) }\end{array}$ & $\begin{array}{l}17^{\circ} 45^{\prime} \mathrm{N} 105^{\circ} 07^{\prime} \mathrm{E} \\
\text { (Three adjoining } \\
\text { villages, suffixed: } \\
\text {-Nua,-Kang and } \\
\text {-Tai) }\end{array}$ & $\begin{array}{l}\text { Not marked }{ }^{1,2} ; \\
\text { Nakay }{ }^{13} ; \text { Na Kay }{ }^{18} ; \\
\text { Nakai }{ }^{20}\end{array}$ & $540 ; C, 10 a$ \\
\hline $\begin{array}{l}\text { Ban Nakhay (just } \\
\text { outside PKK) }\end{array}$ & $\begin{array}{l}18^{\circ} 15^{\prime} \mathrm{N} 102^{\circ} 4^{\prime} \mathrm{E} \\
\text { (village) }\end{array}$ & Not marked ${ }^{1,2}$ & $190 ; \mathrm{N}, 10 a$ \\
\hline $\begin{array}{l}\text { Ban Na Khang (Not } \\
\text { located) (Historical) }\end{array}$ & $\begin{array}{l}\text { Approx. } 19^{\circ} 45^{\prime} \mathrm{N} \\
103^{\circ} 32^{\prime} \mathrm{E} \text { (village) }\end{array}$ & $\begin{array}{l}\text { Not marked }{ }^{1,2} \text {; Ban } \mathrm{Na} \\
\text { Khang }{ }^{10}\end{array}$ & $1400-1500 ; N, 10 b$ \\
\hline $\begin{array}{l}\text { Ban Nalay (just } \\
\text { outside PXH) }\end{array}$ & $\begin{array}{l}16^{\circ} 43^{\prime} \mathrm{N} 105^{\circ} 40^{\prime} \mathrm{E} \\
\text { (village) }\end{array}$ & Not marked ${ }^{1,2}$ & $180 ; C, 10 a$ \\
\hline Ban Nameuy (NNT) & $\begin{array}{l}17^{\circ} 5^{\prime} \mathrm{N} 105^{\circ} 33^{\prime} \mathrm{E} \\
\text { (village) }\end{array}$ & Not marked ${ }^{1,2}$ & $600 ; C, 5 b, 10 a$ \\
\hline Ban Namiang (TMF) & $\begin{array}{l}18^{\circ} 20^{\prime} \mathrm{N} 102^{\circ} 12^{\prime} \mathrm{E} \\
\text { (village) }\end{array}$ & Not marked ${ }^{1,2}$ & $190 ; N, 10 a$ \\
\hline
\end{tabular}


Part 2. cont.

\begin{tabular}{|c|c|c|c|}
\hline $\begin{array}{l}\text { Locality name } \\
\text { following Lao SGN } \\
\text { I : 100,000 Series } \\
\text { Category within main } \\
\text { text (e.g: Historical } \\
\text { "Other") }\end{array}$ & $\begin{array}{l}\text { Geographical } \\
\text { coordinates (locality } \\
\text { type: town/river/ } \\
\text { region) }\end{array}$ & $\begin{array}{l}\text { Alternative names in } \\
\text { references, and local } \\
\text { names }\end{array}$ & $\begin{array}{l}\text { Altitude; } \\
\text { Biogeographic } \\
\text { subunits }\end{array}$ \\
\hline $\begin{array}{l}\text { Ban Namkeung-Kao } \\
\text { (Historical) }\end{array}$ & $\begin{array}{l}20^{\circ} 24^{\prime} \mathrm{N} 100^{\circ} 15^{\prime} \mathrm{E} \\
\text { (village) }\end{array}$ & $\begin{array}{l}\text { Not marked }{ }^{1,2} \text {; Nam } \\
\text { Khueng }{ }^{15,19}\end{array}$ & $360 ; \mathrm{N}, 1 \mathrm{ob}$ \\
\hline $\begin{array}{l}\text { Ban Namnian (not } \\
\text { marked) (NP, just } \\
\text { outside NNT) }\end{array}$ & $\begin{array}{l}17^{\circ} 57^{\prime} \mathrm{N} 105^{\circ} 03^{\prime} \mathrm{E} \\
\text { (village) }\end{array}$ & Not marked ${ }^{1,2}$ & 540; C,10a \\
\hline Ban Nam Tang (XNN) & $\begin{array}{l}15^{\circ} 08^{\prime} \mathrm{N} 106^{\circ} 31^{\prime} \mathrm{E} \\
\text { (village) }\end{array}$ & Not marked $^{1,2}$ & $880 ;$ S, Ioa \\
\hline $\begin{array}{l}\text { Ban Namtheun (NP, } \\
\text { outside NNT) }\end{array}$ & $\begin{array}{l}17^{\circ} 51^{\prime} \mathrm{N} 105^{\circ} 03^{\prime} \mathrm{E} \\
\text { (village) }\end{array}$ & $\begin{array}{l}\text { Not marked }{ }^{1} \text {, Nam } \\
\text { Theun }^{2}\end{array}$ & $520 ; C, 10 a$ \\
\hline $\begin{array}{l}\text { Ban Namxot (NNT } \\
\text { and NP) }\end{array}$ & $\begin{array}{l}17^{\circ} 53^{\prime} \mathrm{N} 105^{\circ} 05^{\prime} \mathrm{E} \\
\text { (village) }\end{array}$ & Not marked ${ }^{1,2}$ & $520 ; C, 10 a$ \\
\hline $\begin{array}{l}\text { Ban Nape* Note: on } \\
\text { the map there are } \\
\text { three closely located } \\
\text { villages of this name, } \\
\text { suffixed (1), (2) and } \\
\text { (3). (Historical, outside } \\
\text { NNT and NTX) }\end{array}$ & $\begin{array}{l}18^{\circ} 18^{\prime} \mathrm{N} 105^{\circ} 04^{\prime} \mathrm{E} \\
\text { (village) }\end{array}$ & $\begin{array}{l}\text { Nape }{ }^{1} ; \text { Ban Napè }{ }^{2} \\
\text { Napé }^{6,13,20} ; \text { Na Pé }\end{array}$ & $560 ; C, 5 b$ \\
\hline $\begin{array}{l}\text { Ban Napo (not } \\
\text { marked) (TMF) }\end{array}$ & $\begin{array}{l}18^{\circ} 17^{\prime} \mathrm{N} 102^{\circ} 11^{\prime} \mathrm{E} \\
\text { (village) }\end{array}$ & Not marked ${ }^{1,2}$ & $240 ; N, 10 a$ \\
\hline $\begin{array}{l}\text { Ban Na Sao (not } \\
\text { marked) (Historical) }\end{array}$ & $\begin{array}{l}17^{\circ} 53^{\prime} \mathrm{N} 104^{\circ} 37^{\prime} \mathrm{E} \\
\text { (village) }\end{array}$ & $\begin{array}{l}\text { Not marked }{ }^{1,2} \text {; Ban } \\
\text { Sao }{ }^{3,4} ; \text { Ban Na Sao }^{28} ; \\
\text { Ban-na-sao }\end{array}$ & 7oo; C,10a \\
\hline Ban Nasa (TMF) & $\begin{array}{l}18^{\circ} 13^{\prime} \mathrm{N} 102^{\circ} 10^{\prime} \mathrm{E} \\
\text { (village) }\end{array}$ & Not marked ${ }^{1,2}$ & $180 ; \mathrm{N}, 10 \mathrm{a}$ \\
\hline $\begin{array}{l}\text { Ban Nasenphan (just } \\
\text { outside XP) }\end{array}$ & $\begin{array}{l}14^{\circ} 13^{\prime} \mathrm{N} 105^{\circ} 54^{\prime} \mathrm{E} \\
\text { (village) }\end{array}$ & Not marked ${ }^{1,2}$ & $80 ; S, I 0 a$ \\
\hline Ban Navang (NNT) & $\begin{array}{l}17^{\circ} 5^{\prime} \mathrm{N} 105^{\circ} 14^{\prime} \mathrm{E} \\
\text { (village) }\end{array}$ & Not marked ${ }^{1,2}$ & $600 ; C, 5 b, 10 a$ \\
\hline $\begin{array}{l}\text { Ban Ngay-Nua } \\
\text { ("Other") }\end{array}$ & $\begin{array}{l}21^{\circ} 50^{\prime} \mathrm{N} 101^{\circ} 54^{\prime} \mathrm{E} \\
\text { (village) }\end{array}$ & $\begin{array}{l}\text { Not marked }{ }^{1} \text {; Ngay } \\
\text { Nua }^{2}\end{array}$ & $900 ; N, 10 b$ \\
\hline $\begin{array}{l}\text { Ban Ngay-Tai } \\
(\text { "Other") }\end{array}$ & $\begin{array}{l}21^{\circ} 51^{\prime} \mathrm{N} 102^{\circ} \mathrm{O} 2^{\prime} \mathrm{E} \\
\text { (village) }\end{array}$ & Not marked ${ }^{1,2}$ & $840 ; \mathrm{N}, 10 \mathrm{~b}$ \\
\hline $\begin{array}{l}\text { Ban Ngoun (Not } \\
\text { located) (Historical) }\end{array}$ & $\begin{array}{l}\text { Coordinates unknown } \\
\text { (village) } \\
\text { (NE of the plain of } \\
\text { Savannakhet) }\end{array}$ & $\begin{array}{l}\text { Not marked }{ }^{1,2} ; \text { Ban } \\
\text { Ngoun }^{11}\end{array}$ & $? ; \mathrm{C}, ?$ \\
\hline Ban Ngoy (Historical) & $\begin{array}{l}20^{\circ} 42^{\prime} \mathrm{N} 102^{\circ} 40^{\prime} \mathrm{E} \\
\text { (village) }\end{array}$ & $\begin{array}{l}\text { Muong Ngoi }{ }^{1,20} \text {; } \\
\text { Muang Ngoy }^{2}\end{array}$ & $780 ; N, 10 b$ \\
\hline $\begin{array}{l}\text { Ban Nondinxay (PXT, } \\
\text { just outside) }\end{array}$ & $\begin{array}{l}15^{\circ} 50^{\prime} \mathrm{N} 105^{\circ} 39^{\prime} \mathrm{E} \\
\text { (village) }\end{array}$ & Not marked ${ }^{1,2}$ & $200 ; S, 10 a$ \\
\hline $\begin{array}{l}\text { Ban Nongboua Note: } \\
\text { present site of village }\end{array}$ & $\begin{array}{l}17^{\circ} 44^{\prime} \mathrm{N} 105^{\circ} 12^{\prime} \mathrm{E} \\
\text { (village) }\end{array}$ & Not marked ${ }^{1,2}$ & $520 ; C, 10 a$ \\
\hline
\end{tabular}
is at position marked "Hn.L" on the map; a village no longer exists at the mapped location

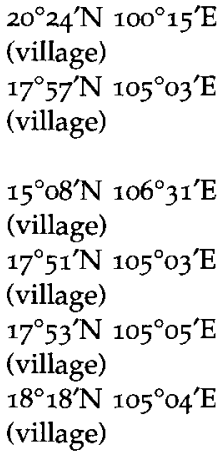

Not marked ${ }^{1,2}$; Nam

Khueng ${ }^{15,19}$

Not marked ${ }^{1,2}$

Not marked ${ }^{1,2}$

Not marked ${ }^{1}$, Nam

Theun ${ }^{2}$

Nape ${ }^{1}$; Ban Napè ${ }^{2}$

Napé ${ }^{6,13,20} ; \mathrm{Na}$ Pé ${ }^{18}$

*see note added in proof 2, p.132. 
Part 2. cont.

\begin{tabular}{|c|c|c|c|}
\hline $\begin{array}{l}\text { Locality name } \\
\text { following Lao SGN } \\
1 \text { : 100,000 Series } \\
\text { Category within main } \\
\text { text (e.g: Historical } \\
\text { "Other") }\end{array}$ & $\begin{array}{l}\text { Geographical } \\
\text { coordinates (locality } \\
\text { type: town/river/ } \\
\text { region) }\end{array}$ & $\begin{array}{l}\text { Alternative names in } \\
\text { references, and local } \\
\text { names }\end{array}$ & $\begin{array}{l}\text { Altitude; } \\
\text { Biogeographic } \\
\text { subunits }\end{array}$ \\
\hline \multicolumn{4}{|l|}{$\begin{array}{l}\text { of Ban Nongboua. } \\
\text { (NP, outside NNT) }\end{array}$} \\
\hline $\begin{array}{l}\text { Ban Nondeng (outside } \\
\text { DKT) }\end{array}$ & $\begin{array}{l}14^{\circ} 33^{\prime} \mathrm{N} 105^{\circ} 43^{\prime} \mathrm{E} \\
\text { (village) }\end{array}$ & Not marked ${ }^{1,2}$ & 100; S,10a \\
\hline $\begin{array}{l}\text { Ban Nonghet } \\
\text { (Historical) }\end{array}$ & $\begin{array}{l}19^{\circ} 30^{\prime} \mathrm{N} 103^{\circ} 59^{\prime} \mathrm{E} \\
\text { (village) }\end{array}$ & $\begin{array}{l}\text { Nong Het }{ }^{1,9} \text {; Nong } \\
\text { Hèt }{ }^{2} \text {; Nonghet }{ }^{15,18} ; \\
\text { Nong-Het }{ }^{17} ; \\
\text { Nong-het }^{7}\end{array}$ & $1,45^{\circ} ; N, 10 b$ \\
\hline $\begin{array}{l}\text { Ban Nongkhe (Not } \\
\text { marked) (DHS) }\end{array}$ & $\begin{array}{l}15^{\circ} 03^{\prime} \mathrm{N} 106^{\circ} 06^{\prime} \mathrm{E} \\
\text { (village) }\end{array}$ & Not marked ${ }^{1,2}$ & $250 ; S, 10 a$ \\
\hline $\begin{array}{l}\text { Ban Nongpop (outside } \\
\text { DHS) }\end{array}$ & $\begin{array}{l}14^{\circ} 54^{\prime} \mathrm{N} 106^{\circ} 05^{\prime} \mathrm{E} \\
\text { (village) }\end{array}$ & $\begin{array}{l}\text { Not marked }^{1,2} \\
\text { (local name Ban } \\
\text { Somsup) }\end{array}$ & $180 ; 5,10 a$ \\
\hline Ban Paam (“Other") & $\begin{array}{l}14^{\circ} 55^{\prime} \mathrm{N} 107^{\circ} 03^{\prime} \mathrm{E} \\
\text { (village) }\end{array}$ & Not marked ${ }^{1,2}$ & $120 ; S, 10 a$ \\
\hline Ban Pakbo (XP) & $\begin{array}{l}14^{\circ} 38^{\prime} \mathrm{N} 106^{\circ} 17^{\prime} \mathrm{E} \\
\text { (village) }\end{array}$ & Not marked ${ }^{1,2}$ & $80 ; 5,10 a$ \\
\hline $\begin{array}{l}\text { Ban Pak-Hinboun } \\
\text { (Historical) }\end{array}$ & $\begin{array}{l}17^{\circ} 35^{\prime} \mathrm{N} 104^{\circ} 37^{\prime} \mathrm{E} \\
\text { (village) }\end{array}$ & $\begin{array}{l}\text { Pak Hin Boun }{ }^{1,18,28} \\
\text { Muang Hinboun }\end{array}$ & 155; C, $10 a$ \\
\hline $\begin{array}{l}\text { Ban Pakkading bridge } \\
\text { (Not named) ("Other") }\end{array}$ & $\begin{array}{l}18^{\circ} 20^{\prime} \mathrm{N} 103^{\circ} 59^{\prime} \mathrm{E} \\
\text { (bridge over Nam } \\
\text { Kading river) }\end{array}$ & Not marked $^{1,2}$ & 150; N,10a \\
\hline $\begin{array}{l}\text { Ban Pakmet } \\
\text { (Historical) }\end{array}$ & $\begin{array}{l}18^{\circ} 49^{\prime} \mathrm{N} 101^{\circ} 50^{\prime} \mathrm{E} \\
\text { (village) }\end{array}$ & $\begin{array}{l}\text { Not marked }{ }^{1,2} \text {; Pak } \\
\text { Mat } 18,28\end{array}$ & $400 ; N, 10 a$ \\
\hline Ban Paksa (Historical) & $\begin{array}{l}18^{\circ} 21^{\prime} \mathrm{N} 103^{\circ} 56^{\prime} \mathrm{E} \\
\text { (village) }\end{array}$ & $\begin{array}{l}\text { Not marked } \\
\text { Ban Paksa } \\
\text { Ban Pak-Sa }^{28}\end{array}$ & $160 ; N, 10 a$ \\
\hline Ban Paksi (Historical) & $\begin{array}{l}19^{\circ} 46^{\prime} \mathrm{N} 101^{\circ} 58^{\prime} \mathrm{E} \\
\text { (village) }\end{array}$ & Not marked ${ }^{1,2} ;$ Pak $S i^{6}$ & $190 ; N, 10 b$ \\
\hline $\begin{array}{l}\text { Ban Pak Tung } \\
\text { (Historical) }\end{array}$ & $\begin{array}{l}19^{\circ} 46^{\prime} \mathrm{N} 101^{\circ} 58^{\prime} \mathrm{E} \\
\text { (village) }\end{array}$ & $\begin{array}{l}\text { Not marked }{ }^{1,2} ; \text { Ban } \\
\text { Pak Tung }\end{array}$ & $300 ; \mathrm{N}, 10 \mathrm{~b}$ \\
\hline Ban Paling (DKT) & $14^{\circ} \mathrm{O} 7^{\prime} \mathrm{N} 105^{\circ} 25^{\prime} \mathrm{E}$ & Not marked ${ }^{1,2}$ & 110; S,I0a \\
\hline $\begin{array}{l}\text { Ban Phapho (just } \\
\text { outside XP) }\end{array}$ & $\begin{array}{l}14^{\circ} 44^{\prime} \mathrm{N} 106^{\circ} 05^{\prime} \mathrm{E} \\
\text { (village) }\end{array}$ & Not marked ${ }^{1,2}$ & 150; S,10a \\
\hline $\begin{array}{l}\text { Ban Phongsavang } \\
(\mathrm{PXH})\end{array}$ & $\begin{array}{l}16^{\circ} 49^{\prime} \mathrm{N} 105^{\circ} 52^{\prime} \mathrm{E} \\
\text { (village) }\end{array}$ & Not marked ${ }^{1,2}$ & 210; C,IOa \\
\hline Ban Phonsaat (XP) & $\begin{array}{l}14^{\circ} 35^{\prime} \mathrm{N} 106^{\circ} 21^{\prime} \mathrm{E} \\
\text { (village) }\end{array}$ & Not marked ${ }^{1,2}$ & $80 ; 5,10 a$ \\
\hline $\begin{array}{l}\text { Ban Phonsavan } \\
\text { ("Other") }\end{array}$ & $\begin{array}{l}19^{\circ} 27^{\prime} \mathrm{N} 103^{\circ} 13^{\prime} \mathrm{E} \\
\text { (Provincial town of } \\
\text { Xiangkhouang } \\
\text { Province, replacing } \\
\text { Xiangkhouang } \\
\text { town) }\end{array}$ & $\begin{array}{l}\text { Not marked }{ }^{1} ; \text { Muang } \\
\text { Phônsavan }{ }^{2}\end{array}$ & 1,$150 ; N, 10 b$ \\
\hline $\begin{array}{l}\text { Ban Phonsi (NK, } \\
\text { although actually just } \\
\text { outside) }\end{array}$ & $\begin{array}{l}18^{\circ} 18^{\prime} \mathrm{N} 104^{\circ} 06^{\prime} \mathrm{E} \text { (large } \\
\text { village) }\end{array}$ & Not marked ${ }^{1,2}$ & 150; N,10a \\
\hline $\begin{array}{l}\text { Ban Phontiou (just } \\
\text { outside KML) }\end{array}$ & $\begin{array}{l}17^{\circ} 53^{\prime} \mathrm{N} 104^{\circ} 37^{\prime} \mathrm{E} \\
\text { (village) }\end{array}$ & Not marked ${ }^{1,2}$ & 160; C, Іоа \\
\hline
\end{tabular}


Part 2. cont.

\begin{tabular}{|c|c|c|c|}
\hline $\begin{array}{l}\text { Locality name } \\
\text { following Lao SGN } \\
1: 100,000 \text { Series } \\
\text { Category within main } \\
\text { text (e.g: Historical } \\
\text { "Other") }\end{array}$ & $\begin{array}{l}\text { Geographical } \\
\text { coordinates (locality } \\
\text { type: town/river/ } \\
\text { region) }\end{array}$ & $\begin{array}{l}\text { Alternative names in } \\
\text { references, and local } \\
\text { names }\end{array}$ & $\begin{array}{l}\text { Altitude; } \\
\text { Biogeographic } \\
\text { subunits }\end{array}$ \\
\hline $\begin{array}{l}\text { Ban Phonvisai (just } \\
\text { outside } X P \text { ) }\end{array}$ & $\begin{array}{l}14^{\circ} 11^{\prime} \mathrm{N} 105^{\circ} 57^{\prime} \mathrm{E} \\
\text { (village) }\end{array}$ & Not marked ${ }^{1,2}$ & $100 ; S, 10 a$ \\
\hline $\begin{array}{l}\text { Ban Phu Soung } \\
\text { (Not located) } \\
\text { (Historical) }\end{array}$ & $\begin{array}{l}\text { Coordinates unknown } \\
\text { (village) }\end{array}$ & $\begin{array}{l}\text { Not marked }{ }^{1,2} \text {; Ban } \\
\text { Phu Soung }{ }^{9}\end{array}$ & ?; N,1ob \\
\hline Ban Poung ("Other") & $\begin{array}{l}18^{\circ} 13^{\prime} \mathrm{N} 104^{\circ} 50^{\prime} \mathrm{E} \\
\text { (village) }\end{array}$ & Not marked ${ }^{1,2}$ & 510; C,10a \\
\hline Ban Samkhang (SMK) & $\begin{array}{l}14^{\circ} 08^{\prime} \mathrm{N} 105^{\circ} 52^{\prime} \mathrm{E} \\
\text { (village) }\end{array}$ & Not marked ${ }^{1,2}$ & $80 ; 5,10 a$ \\
\hline $\begin{array}{l}\text { Ban San (just outside } \\
\text { HNN) }\end{array}$ & $\begin{array}{l}17^{\circ} 13^{\prime} \mathrm{N} 106^{\circ} 10^{\prime} \mathrm{E} \\
\text { (village) }\end{array}$ & $\begin{array}{l}\text { Not marked }{ }^{1,2} \text { (local } \\
\text { name Ban Nongma, } \\
\text { although the map } \\
\text { shows a village called } \\
\text { Ban Nongma at } \\
\text { another locality } \\
\text { nearby) }\end{array}$ & $560 ; C, 5 b, 10 a$ \\
\hline Ban Sa Ngao & $18^{\circ}{ }_{4}^{\prime} \mathrm{N} 101^{\circ} 5^{\prime} \mathrm{E}$ & Not marked ${ }^{1}$; Ban Sa & 160; adjacent to \\
\hline (Historical) & (village in Thailand) & $\mathrm{Ngao}^{2} ; \mathrm{Sa} \mathrm{Ngao}{ }^{28}$ & $\mathrm{~N}$, roa \\
\hline $\begin{array}{l}\text { Ban Seula (Not } \\
\text { marked) (PXT) }\end{array}$ & $\begin{array}{l}15^{\circ} 23^{\prime} \mathrm{N} 105^{\circ} 30^{\prime} \mathrm{E} \\
\text { (village) }\end{array}$ & Not marked ${ }^{1,2}$ & 180; S, 10a \\
\hline Ban So (TMF) & $\begin{array}{l}18^{\circ} 18^{\prime} \mathrm{N} 105^{\circ} 06^{\prime} \mathrm{E} \\
\text { (village) }\end{array}$ & Not marked ${ }^{1,2}$ & 195; N,10a \\
\hline $\begin{array}{l}\text { Ban Songkhon } \\
\text { (Historical) }\end{array}$ & $\begin{array}{l}16^{\circ} 15^{\prime} \mathrm{N} 105^{\circ} 18^{\prime} \mathrm{E} \\
\text { (village) }\end{array}$ & $\begin{array}{l}\text { Muang Song Khone }{ }^{1} \text {; } \\
\text { Muang Sonkhon }{ }^{2} \text {; } \\
\text { Song-Khone }^{11}\end{array}$ & 130; C,10a \\
\hline Ban Sopchat ("Other") & $\begin{array}{l}18^{\circ} 27^{\prime} \mathrm{N} 104^{\circ} 53^{\prime} \mathrm{E} \\
\text { (village) }\end{array}$ & $\begin{array}{l}\text { Not marked }{ }^{1} \text {; Ban } \\
\text { Sopchat }^{2}\end{array}$ & $440 ; \mathrm{N}, 10 a$ \\
\hline $\begin{array}{l}\text { Ban Sop Kan (Not } \\
\text { marked) (PDD) }\end{array}$ & $\begin{array}{l}22^{\circ} 08^{\prime} \mathrm{N} 102^{\circ} 14^{\prime} \mathrm{E} \\
\text { (village) }\end{array}$ & Not marked ${ }^{1,2}$ & $700 ; N, 5^{b}$ \\
\hline $\begin{array}{l}\text { Ban Sopkhom } \\
\text { ("Other") }\end{array}$ & $\begin{array}{l}18^{\circ} 17^{\prime} \mathrm{N} 104^{\circ} 52^{\prime} \mathrm{E} \\
\text { (village) }\end{array}$ & Not marked $^{1,2}$ & $420 ; N, 10 a$ \\
\hline $\begin{array}{l}\text { Ban Sopngom (NK, } \\
\text { although actually just } \\
\text { outside) }\end{array}$ & $\begin{array}{l}18^{\circ} 28^{\prime} \mathrm{N} 104^{\circ} 20^{\prime} \mathrm{E} \\
\text { (abandoned village) }\end{array}$ & Not marked ${ }^{1,2}$ & $400 ; \mathrm{N}, 10 \mathrm{a}$ \\
\hline $\begin{array}{l}\text { Ban Sopnian (Not } \\
\text { marked) (NP, outside } \\
\text { NNT) }\end{array}$ & $\begin{array}{l}17^{\circ} 58^{\prime} \mathrm{N} 104^{\circ} 59^{\prime} \mathrm{E} \\
\text { (village) }\end{array}$ & Not marked ${ }^{1,2}$ & $500 ; C, 10 a$ \\
\hline $\begin{array}{l}\text { Ban Sop-On (NP, just } \\
\text { outside NNT) }\end{array}$ & $\begin{array}{l}17^{\circ} 42^{\prime} \mathrm{N} 105^{\circ} 15^{\prime} \mathrm{E} \\
\text { (village) }\end{array}$ & Not marked ${ }^{1,2}$ & $520 ; C, 10 a$ \\
\hline $\begin{array}{l}\text { Ban Soptong ("Other", } \\
\text { outside NTX) }\end{array}$ & $\begin{array}{l}18^{\circ} 20^{\prime} \mathrm{N} 104^{\circ} 55^{\prime} \mathrm{E} \\
\text { (village) }\end{array}$ & Not marked ${ }^{1,2}$ & $440 ; \mathrm{N}, 10 a$ \\
\hline Ban Souy (Historical) & $\begin{array}{l}19^{\circ} 32^{\prime} \mathrm{N} 102^{\circ} 52^{\prime} \mathrm{E} \\
\text { (town) }\end{array}$ & 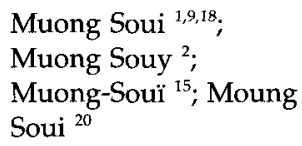 & 1,$200 ; N, 10 b$ \\
\hline $\begin{array}{l}\text { Ban Talung (Not } \\
\text { marked) (PDD) }\end{array}$ & $\begin{array}{l}22^{\circ} 08^{\prime} \mathrm{N} 102^{\circ} 15^{\prime} \mathrm{E} \\
\text { (village) }\end{array}$ & Not marked ${ }^{1,2}$ & 1,$000 ; \mathrm{N}, 5 \mathrm{~b}$ \\
\hline Ban Tangyoun (XS) & $\begin{array}{l}15^{\circ} 38^{\prime} \mathrm{N} 107^{\circ} 12^{\prime} \mathrm{E} \\
\text { (village) }\end{array}$ & $\begin{array}{l}\text { Not marked }{ }^{1,2} \text { (local } \\
\text { name Ban Ayun) }\end{array}$ & $800 ; S, 5 b$ \\
\hline
\end{tabular}


Part 2. cont.

\begin{tabular}{|c|c|c|c|}
\hline $\begin{array}{l}\text { Locality name } \\
\text { following Lao SGN } \\
1 \text { : 10o,ooo Series } \\
\text { Category within main } \\
\text { text (e.g: Historical } \\
\text { "Other") }\end{array}$ & $\begin{array}{l}\text { Geographical } \\
\text { coordinates (locality } \\
\text { type: town/river/ } \\
\text { region) }\end{array}$ & $\begin{array}{l}\text { Alternative names in } \\
\text { references, and local } \\
\text { names }\end{array}$ & $\begin{array}{l}\text { Altitude; } \\
\text { Biogeographic } \\
\text { subunits }\end{array}$ \\
\hline $\begin{array}{l}\text { Ban Tasang (not } \\
\text { marked) (just outside } \\
\text { HNN) }\end{array}$ & $\begin{array}{l}17^{\circ} 29^{\prime} \mathrm{N} 105^{\circ} 51^{\prime} \mathrm{E} \\
\text { (village) }\end{array}$ & Not marked ${ }^{1,2}$ & $183 ; \mathrm{C}, 5 \mathrm{~b}, 10 \mathrm{a}$ \\
\hline $\begin{array}{l}\text { Ban Thabak (just } \\
\text { outside NK) }\end{array}$ & $\begin{array}{l}18^{\circ} 19^{\prime} \mathrm{N} 104^{\circ} 40^{\prime} \mathrm{E} \\
\text { (town) }\end{array}$ & Not marked ${ }^{1,2}$ & $400 ; C, 10 a$ \\
\hline Ban Thadua ("Other") & $\begin{array}{l}17^{\circ} 53^{\prime} \mathrm{N} 102^{\circ} 44^{\prime} \mathrm{E} \\
\text { (village) }\end{array}$ & Not marked ${ }^{1,2}$ & 165; N,10a \\
\hline $\begin{array}{l}\text { Ban Thakhanxomxua } \\
\text { (PXT) }\end{array}$ & $\begin{array}{l}15^{\circ} 47^{\prime} \mathrm{N} 105^{\circ} 25^{\prime} \mathrm{E} \\
\text { (village) }\end{array}$ & Not marked ${ }^{1,2}$ & $160 ; S, 10 a$ \\
\hline $\begin{array}{l}\text { Ban Than (Not } \\
\text { marked) (PDD) }\end{array}$ & $\begin{array}{l}22^{\circ} \mathrm{o} 6^{\prime} \mathrm{N} 102^{\circ} 19^{\prime} \mathrm{E} \\
\text { (village) }\end{array}$ & Not marked ${ }^{1,2}$ & I,010; N,1ob \\
\hline $\begin{array}{l}\text { Ban Thangbeng; } \\
\text { (just outside XP) }\end{array}$ & $\begin{array}{l}14^{\circ} 47^{\prime} \mathrm{N} 105^{\circ} 58^{\prime} \mathrm{E} \\
\text { (village) }\end{array}$ & Not marked ${ }^{1.2}$ & 100; S,10a \\
\hline $\begin{array}{l}\text { Ban Thangon } \\
\text { (Historical) }\end{array}$ & $\begin{array}{l}1^{\circ} \mathrm{o} 8^{\prime} \mathrm{N} 102^{\circ} 37^{\prime} \mathrm{E} \\
\text { (village) }\end{array}$ & $\begin{array}{l}\text { Not marked }{ }^{1,2} ; \text { Tha } \\
\text { Ngon }{ }^{6}\end{array}$ & $180 ; N, 10 a$ \\
\hline Ban Thakho (SMK) & $\begin{array}{l}13^{\circ} 58^{\prime} \mathrm{N} 105^{\circ} 59^{\prime} \mathrm{E} \\
\text { (village) }\end{array}$ & Not marked ${ }^{1,2}$ & $70 ; S, 10 a$ \\
\hline $\begin{array}{l}\text { Ban Thangon reservoir } \\
\text { (Not named) ("Other') }\end{array}$ & $\begin{array}{l}18^{\circ} \mathrm{o}^{\prime} \mathrm{N} 102^{\circ} 39^{\prime} \mathrm{E} \\
\text { (reservoir) }\end{array}$ & Not marked ${ }^{1,2}$ & 160; N,10a \\
\hline $\begin{array}{l}\text { Ban Thateng } \\
\text { (Historical) }\end{array}$ & $\begin{array}{l}15^{\circ} 26^{\prime} \mathrm{N} 106^{\circ} 23^{\prime} \mathrm{E} \\
\text { (village) }\end{array}$ & $\begin{array}{l}\text { Ban Thateng }{ }^{1} \text {; Not } \\
\text { marked }{ }^{2} \text {; Tha Teng }{ }^{18} \text {; } \\
\text { Tha-teng }{ }^{22} \text {; } \\
\text { Thateng }{ }^{25}\end{array}$ & $842 ; \mathrm{S}, 10 a$ \\
\hline $\begin{array}{l}\text { Ban Thathom } \\
\text { (Historical) }\end{array}$ & $\begin{array}{l}{ }_{1}^{\circ} 59^{\prime} \mathrm{N} 103^{\circ} 36^{\prime} \mathrm{E} \\
\text { (village) }\end{array}$ & $\begin{array}{l}\text { Not marked }{ }^{1} \text {; Muang } \\
\text { Thathôm }{ }^{2 ;} \text { Tha } \\
\text { Thom }^{9,10}\end{array}$ & $420 ; \mathrm{N}, 10 \mathrm{~b}$ \\
\hline $\begin{array}{l}\text { Ban Thaviang } \\
\text { (Historical) }\end{array}$ & $\begin{array}{l}19^{\circ} \mathrm{O} 2^{\prime} \mathrm{N} 103^{\circ} 24^{\prime} \mathrm{E} \\
\text { (village) }\end{array}$ & $\begin{array}{l}\text { Ban Ta Viang }{ }^{1,2} \text {; Tha } \\
\text { Vieng } 9\end{array}$ & $460 ; N, 10 b$ \\
\hline $\begin{array}{l}\text { Ban Thenkhen } \\
\text { (Historical) }\end{array}$ & $\begin{array}{l}20^{\circ} 28^{\prime} \mathrm{N} 102^{\circ} 32^{\prime} \mathrm{E} \\
\text { (village) }\end{array}$ & $\begin{array}{l}\text { Not marked }{ }^{1,2} \text {; Ban } \\
\text { Ten Khen }{ }^{6}\end{array}$ & $660 ; N, 10 b$ \\
\hline $\begin{array}{l}\text { Ban Tongphe* (Map } \\
\text { name Ban Nape (3) } \\
\text { (just outside NNT and } \\
\text { NTX) }\end{array}$ & $\begin{array}{l}18^{\circ} 19^{\prime} \mathrm{N} 105^{\circ} 05^{\prime} \mathrm{E} \\
\text { (village) }\end{array}$ & Not marked ${ }^{1,2}$ & $560 ; C, 10 a, 5 b$ \\
\hline Ban Tou (HNN) & $\begin{array}{l}17^{\circ} 05^{\prime} \mathrm{N} 106^{\circ} 09^{\prime} \mathrm{E} \\
\text { (village) }\end{array}$ & $\begin{array}{l}\text { Not marked }{ }^{1,2} \\
\text { (local name } \\
\text { Ban San) }\end{array}$ & $560 ; C, 5 b, 10 a$ \\
\hline $\begin{array}{l}\text { Ban T'Woi (not } \\
\text { located; locality lies } \\
\text { along Mekong } \\
\text { between Ban Paksa } \\
\text { and Ban Pak-Hinboun) } \\
\text { (Historical) }\end{array}$ & $\begin{array}{l}\text { Coordinates unknown } \\
\text { (village) }\end{array}$ & $\begin{array}{l}\text { Not marked }{ }^{1,2} ; \\
\text { BanT'Woi }^{28}\end{array}$ & $160 ; \mathrm{N}$ or $\mathrm{C}, 10 \mathrm{a}$ \\
\hline $\begin{array}{l}\text { Ban Vangdao (just } \\
\text { outside KML) }\end{array}$ & $\begin{array}{l}{ }^{1} 8^{\circ} 05^{\prime} \mathrm{N} 104^{\circ} 32^{\prime} \mathrm{E} \\
\text { (village) }\end{array}$ & Not marked ${ }^{1,2}$ & $160 ; C, 10 a$ \\
\hline Ban Vin-Tai (DKT) & $\begin{array}{l}14^{\circ} 14^{\prime} \mathrm{N} 105^{\circ} 26^{\prime} \mathrm{E} \\
\text { (village) }\end{array}$ & $\begin{array}{l}\text { Not marked }{ }^{1,2} \\
\text { (local name Ban Po) }\end{array}$ & $115 ; S, 10 a$ \\
\hline
\end{tabular}

*see note added in proof 2, p.132. 
Part 2. cont.

\begin{tabular}{|c|c|c|c|}
\hline $\begin{array}{l}\text { Locality name } \\
\text { following Lao SGN } \\
1: 100,000 \text { Series } \\
\text { Category within main } \\
\text { text (e.g: Historical } \\
\text { "Other") }\end{array}$ & $\begin{array}{l}\text { Geographical } \\
\text { coordinates (locality } \\
\text { type: town/river/ } \\
\text { region) }\end{array}$ & $\begin{array}{l}\text { Alternative names in } \\
\text { references, and local } \\
\text { names }\end{array}$ & $\begin{array}{l}\text { Altitude; } \\
\text { Biogeographic } \\
\text { subunits }\end{array}$ \\
\hline Ban Wangma (TMF) & $\begin{array}{l}18^{\circ} 23^{\prime} \mathrm{N} 105^{\circ} 05^{\prime} \mathrm{E} \\
\text { (village) }\end{array}$ & Not marked ${ }^{1,2}$ & $235 ; N, 10 a$ \\
\hline $\begin{array}{l}\text { Ban Xekaman } \\
\text { ("Other") }\end{array}$ & $\begin{array}{l}14^{\circ} 4^{8^{\prime} \mathrm{N}} 106^{\circ} 50^{\prime} \mathrm{E} \\
\text { (village) }\end{array}$ & Not marked ${ }^{1,2}$ & $110 ; S, 10 a$ \\
\hline Ban Xeng (SMK) & $\begin{array}{l}14^{\circ} 45^{\prime} \mathrm{N} 106^{\circ} 56^{\prime} \mathrm{E} \\
\text { (village) }\end{array}$ & Not marked ${ }^{1,2}$ & $90 ;$ S,10a \\
\hline Ban Xepon (Historical) & $\begin{array}{l}16^{\circ} 41^{\prime} \mathrm{N} 106^{\circ} 14^{\prime} \mathrm{E} \\
\text { (village) }\end{array}$ & $\begin{array}{l}\text { Not marked }{ }^{1} \text {, Muang } \\
\text { Xepon }^{2}\end{array}$ & $180 ; C, 10 a$ \\
\hline Ban Xot (XP) & $\begin{array}{l}14^{\circ} \mathrm{O} 2^{\prime} \mathrm{N} 106^{\circ} \mathrm{o} 7^{\prime} \mathrm{E} \\
\text { (village) }\end{array}$ & $\begin{array}{l}\text { Not marked }{ }^{1} \text {, Ban } \\
\text { Xot }^{2}\end{array}$ & $80 ; S, 10 a$ \\
\hline $\begin{array}{l}\text { Ban Yoi Hai (not } \\
\text { located; locality lies } \\
\text { along Mekong } \\
\text { between Vientiane and } \\
\text { Phon Phisai) } \\
\text { (Historical) }\end{array}$ & $\begin{array}{l}\text { Coordinates unknown } \\
\text { (village) }\end{array}$ & $\begin{array}{l}\text { Not marked }{ }^{1,2} \text {; Ban Yoi } \\
\text { Hai }^{28}\end{array}$ & $150 ; \mathrm{N}, 10 \mathrm{a}$ \\
\hline Bokeo Province & 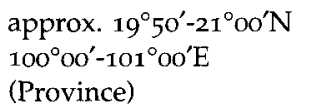 & Not marked ${ }^{1,2}$ & $300-1,688 ; \mathrm{N}, 10 \mathrm{~b}$ \\
\hline $\begin{array}{l}\text { Bolaven Plateau (map } \\
\text { name is Phouphiang } \\
\text { Bolaven) (Historical, } \\
\text { DHS, BSW, XNN and } \\
\text { "Other") }\end{array}$ & $\begin{array}{l}14^{\circ} 42^{\prime}-15^{\circ} 30^{\prime} \mathrm{N} \\
106^{\circ} 15^{\prime}-106^{\circ} 50^{\prime} \mathrm{E} \\
\text { (Plateau area) }\end{array}$ & 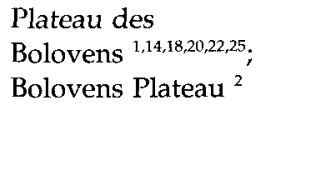 & $600-1,716 ; S, 10 a$ \\
\hline $\begin{array}{l}\text { Bolikhamxai Province } \\
\text { ("Other") }\end{array}$ & $\begin{array}{l}\text { Approx. } 17^{\circ} 50^{\prime}-19^{\circ} 00^{\prime} \mathrm{N} \\
102^{\circ} 50^{\prime}-105^{\circ} 30^{\prime} \mathrm{E} \\
\text { (Province) }\end{array}$ & Not marked ${ }^{1,2}$ & $\begin{array}{l}160-1,841 ; \\
N, C, 5 b, 10 a, 10 b\end{array}$ \\
\hline $\begin{array}{l}\text { Boungkham (Not } \\
\text { located) (Historical) }\end{array}$ & $\begin{array}{l}\text { Coordinates unknown } \\
\text { (village on Bolaven } \\
\text { Plateau) }\end{array}$ & $\begin{array}{l}\text { Not marked }{ }^{1} ; \\
\text { Boungkham }^{25}\end{array}$ & ?; S,10a \\
\hline $\begin{array}{l}\text { Bung Gnai-Kiatngong } \\
\text { (XP) }\end{array}$ & $\begin{array}{l}14^{\circ} 05^{\prime}-14^{\circ} 06^{\prime} \mathrm{N} \\
106^{\circ} 02^{\prime}-106^{\circ} 05^{\prime} \mathrm{E} \\
\text { (wetland area) }\end{array}$ & Not marked ${ }^{1,2}$ & $100 ; S, 10 a$ \\
\hline $\begin{array}{l}\text { "Central Forest" (Not } \\
\text { named) (DKT) }\end{array}$ & $\begin{array}{l}14^{\circ} 10^{\prime}-14^{\circ} 25^{\prime} \mathrm{N} \\
105^{\circ} 29^{\prime}-105^{\circ} 40^{\prime} \mathrm{E} \\
\text { (lowland forest of DKT) }\end{array}$ & Not marked ${ }^{1,2}$ & $C, 5 b, 10 a$ \\
\hline $\begin{array}{l}\text { "Central Hills" (Not } \\
\text { named) (XBN) }\end{array}$ & $\begin{array}{l}15^{\circ} 50^{\prime}-15^{\circ} 58^{\prime} \mathrm{N} \\
106^{\circ} 48^{\prime}-106^{\circ} 05^{\prime} \mathrm{E} \\
\text { (Central hilly portion } \\
\text { of XBN) }\end{array}$ & Not marked ${ }^{1,2}$ & $250-858 ; 5,10 a$ \\
\hline $\begin{array}{l}\text { "Central Mountains" } \\
\text { (Not named) (NNT) }\end{array}$ & $\begin{array}{l}17^{\circ} 45^{\prime}-18^{\circ} 12^{\prime} \mathrm{N} \\
105^{\circ} 07^{\prime}-105^{\circ} 37^{\prime} \mathrm{E} \\
\text { (mountains) }\end{array}$ & Not marked ${ }^{1,2}$ & $580-2,286 ; C, 5 b, 10 a$ \\
\hline Champasak Province & $\begin{array}{l}13^{\circ} 59^{\prime}-15^{\circ} 30^{\prime} \mathrm{N} \\
105^{\circ} 20^{\prime}-106^{\circ} 45^{\prime} \mathrm{E} \\
\text { (Province) }\end{array}$ & Not marked ${ }^{1,2}$ & $80-1,162 ; S, 10 a$ \\
\hline $\begin{array}{l}\text { Champasak (Historical } \\
\text { and "Other") }\end{array}$ & $\begin{array}{l}14^{\circ} 54^{\prime} \mathrm{N} 106^{\circ} 53^{\prime} \mathrm{E} \\
\text { (town) }\end{array}$ & $\begin{array}{l}\text { Not marked }{ }^{1 ;} \\
\text { Champasak }^{2} ; \\
\text { Bassac }^{18,25}\end{array}$ & $100 ; S, 10 a$ \\
\hline
\end{tabular}


Part 2. cont.

\begin{tabular}{|c|c|c|c|}
\hline $\begin{array}{l}\text { Locality name } \\
\text { following Lao SGN } \\
\text { I : 1oo,ooo Series } \\
\text { Category within main } \\
\text { text (e.g: Historical } \\
\text { "Other") }\end{array}$ & $\begin{array}{l}\text { Geographical } \\
\text { coordinates (locality } \\
\text { type: town/river/ } \\
\text { region) }\end{array}$ & $\begin{array}{l}\text { Alternative names in } \\
\text { references, and local } \\
\text { names }\end{array}$ & $\begin{array}{l}\text { Altitude; } \\
\text { Biogeographic } \\
\text { subunits }\end{array}$ \\
\hline $\begin{array}{l}\text { Chiang Khan (Not } \\
\text { covered) (Historical) }\end{array}$ & $\begin{array}{l}17^{\circ} 5^{\prime} \mathrm{N} 101^{\circ} 40^{\prime} \mathrm{E} \\
\text { (town in Thailand) }\end{array}$ & $\begin{array}{l}\text { Muang Chiang } \\
\text { Khan }{ }^{1 ;} \text { Chiang } \\
\text { Khan }{ }^{2} \text {; Xieng- } \\
\text { Khan }{ }^{28}\end{array}$ & $\begin{array}{l}160 \text {; adjacent to } \\
\mathrm{N}, 10 a\end{array}$ \\
\hline $\begin{array}{l}\text { Chiang Saen (Not } \\
\text { covered) ("Other") }\end{array}$ & $\begin{array}{l}20^{\circ} 15^{\prime} \mathrm{N} 100^{\circ} \mathrm{o}^{\prime} \mathrm{E} \\
\text { (town in Thailand) }\end{array}$ & $\begin{array}{l}\text { Chiang Saen }{ }^{1} \text {; Not } \\
\text { marked }^{2}\end{array}$ & $\begin{array}{l}300 \text {; adjacent to } \\
\mathrm{N}, 10 a\end{array}$ \\
\hline $\begin{array}{l}\text { Dakchung Plateau } \\
\text { (Not named) (outside } \\
\text { XS) }\end{array}$ & $\begin{array}{l}\text { approx. } 15^{\circ} 10^{\prime}-15^{\circ} 35^{\prime} \mathrm{N} \\
105^{\circ} 50^{\prime}-107^{\circ} 20^{\prime} \mathrm{E} \\
\text { (plateau) }\end{array}$ & Not marked ${ }^{1,2}$ & $95^{\circ}-1,44^{\circ} ; \mathrm{S}, 5 \mathrm{~b}$ \\
\hline Don Chat (SMK) & $\begin{array}{l}15^{\circ} 14^{\prime} \mathrm{N} 105^{\circ} 39^{\prime} \mathrm{E} \\
\text { (island) }\end{array}$ & Not marked ${ }^{1,2}$ & $100 ; \mathrm{S}, 10 \mathrm{a}$ \\
\hline Don Che (SMK) & $\begin{array}{l}15^{\circ} 15^{\prime} \mathrm{N} 105^{\circ} 39^{\prime} \mathrm{E} \\
\text { (island) }\end{array}$ & Not marked ${ }^{1,2}$ & $100 ; \mathrm{S}, 10 a$ \\
\hline $\begin{array}{l}\text { Don Chuan Sandbank } \\
\text { (Not named) } \\
\text { ("Other") }\end{array}$ & $\begin{array}{l}17^{\circ} 57^{\prime} \mathrm{N} 102^{\circ} 36^{\prime} \mathrm{E} \\
\text { (sandbank) }\end{array}$ & Not marked ${ }^{1,2}$ & $165 ; N, 10 a$ \\
\hline Don Deng (SMK) & $\begin{array}{l}14^{\circ} 50^{\prime}-14^{\circ} 54^{\prime} \mathrm{N} \\
105^{\circ} 53^{\prime}-105^{\circ} 54^{\prime} \mathrm{E} \\
\text { (island) }\end{array}$ & Not marked ${ }^{1,2}$ & $100 ; S, 10 a$ \\
\hline $\begin{array}{l}\text { Don Dong (not } \\
\text { named) (SMK) }\end{array}$ & $\begin{array}{l}14^{\circ} 08^{\prime} \mathrm{N} 105^{\circ} 46^{\prime} \mathrm{E} \\
\text { (island) }\end{array}$ & Not marked ${ }^{1,2}$ & $80 ; S, 10 a$ \\
\hline Don Het (SMK) & $\begin{array}{l}14^{\circ} 11^{\prime} \mathrm{N} 105^{\circ} 45^{\prime} \mathrm{E} \\
\text { (island) }\end{array}$ & Not marked ${ }^{1,2}$ & $80 ; S, 10 a$ \\
\hline Don Kho (SMK) & $\begin{array}{l}15^{\circ} 09^{\prime} \mathrm{N} 105^{\circ} 45^{\prime} \mathrm{E} \\
\text { (island) }\end{array}$ & Not marked ${ }^{1,2}$ & $100 ; S, 10 a$ \\
\hline $\begin{array}{l}\text { Don Khong (Historical, } \\
\text { SMK) }\end{array}$ & $\begin{array}{l}14^{\circ} 04^{\prime}-14^{\circ} 14^{\prime} \mathrm{N} \\
105^{\circ} 38^{\prime}-105^{\circ} 42^{\prime} \mathrm{E} \\
\text { (island) }\end{array}$ & Khong ${ }^{1.18,25}$; Không ${ }^{2}$ & $80-239 ; \mathrm{S}, 10 a$ \\
\hline Don Koy (SMK) & $\begin{array}{l}14^{\circ} 10^{\prime}-14^{\circ} 11^{\prime} \mathrm{N} \\
105^{\circ} 45^{\prime}-105^{\circ} 46^{\prime} \mathrm{E} \\
\text { (island) }\end{array}$ & Not marked ${ }^{1,2}$ & $80 ; S, 10 a$ \\
\hline Don Loppadi (SMK) & $\begin{array}{l}13^{\circ} 59^{\prime}-14^{\circ} 02^{\prime} \mathrm{N} \\
105^{\circ} 50^{\prime}-105^{\circ} 52^{\prime} \mathrm{E} \\
\text { (island) }\end{array}$ & Not marked ${ }^{1,2}$ & $80 ; S, 10 a$ \\
\hline Don Nangloy (SMK) & $\begin{array}{l}14^{\circ} 23^{\prime}-14^{\circ} 26^{\prime} \mathrm{N} \\
105^{\circ} 51^{\prime}-105^{\circ} 51^{\prime} \mathrm{E} \\
\text { (island) }\end{array}$ & Not marked ${ }^{1,2}$ & $85 ; S, 10 a$ \\
\hline Don Ngiou (SMK) & $\begin{array}{l}14^{\circ} 59^{\prime} \mathrm{N} 105^{\circ} 53^{\prime} \mathrm{E} \\
\text { (island) }\end{array}$ & Not marked ${ }^{1,2}$ & $100 ; S, 10 a$ \\
\hline Don Phaling (SMK) & $\begin{array}{l}15^{\circ} 08^{\prime} \mathrm{N} 105^{\circ} 44^{\prime} \mathrm{E} \\
\text { (island) }\end{array}$ & Not marked $^{1,2}$ & $100 ; S, 10 a$ \\
\hline Don Phakan (SMK) & $\begin{array}{l}14^{\circ} 55^{\prime} \mathrm{N} 105^{\circ} 54^{\prime} \mathrm{E} \\
\text { (island) }\end{array}$ & Not marked ${ }^{1,2}$ & $100 ; \mathrm{S}, 10 a$ \\
\hline $\begin{array}{l}\text { Don Pong (Not } \\
\text { named) (SMK) }\end{array}$ & $\begin{array}{l}15^{\circ} 11^{\prime} \mathrm{N} 105^{\circ} 43^{\prime} \mathrm{E} \\
\text { (island) }\end{array}$ & Not marked ${ }^{1,2}$ & $100 ; S, 10 a$ \\
\hline Don Puay (SMK) & $\begin{array}{l}14^{\circ} 27^{\prime} \mathrm{N} 105^{\circ} 51^{\prime} \mathrm{E} \\
\text { (village) }\end{array}$ & Not marked ${ }^{1,2}$ & $90 ; S, 10 a$ \\
\hline Don Tan (SMK) & $\begin{array}{l}14^{\circ} 05^{\prime} \mathrm{N} 105^{\circ} 44^{\prime} \mathrm{E} \\
\text { (island) }\end{array}$ & Not marked ${ }^{1,2}$ & $80 ;$ S,10a \\
\hline
\end{tabular}


Part 2. cont.

\begin{tabular}{|c|c|c|c|}
\hline $\begin{array}{l}\text { Locality name } \\
\text { following Lao SGN } \\
1: \text { 100,o0o Series } \\
\text { Category within main } \\
\text { text (e.g: Historical } \\
\text { "Other") }\end{array}$ & $\begin{array}{l}\text { Geographical } \\
\text { coordinates (locality } \\
\text { type: town/river/ } \\
\text { region) }\end{array}$ & $\begin{array}{l}\text { Alternative names in } \\
\text { references, and local } \\
\text { names }\end{array}$ & $\begin{array}{l}\text { Altitude; } \\
\text { Biogeographic } \\
\text { subunits }\end{array}$ \\
\hline Don Xang (SMK) & $\begin{array}{l}13^{\circ} 59^{\prime} \mathrm{N} 105^{\circ} 53^{\prime} \mathrm{E} \\
\text { (island) }\end{array}$ & Not marked ${ }^{1,2}$ & $80 ; S, 10 a$ \\
\hline $\begin{array}{l}\text { Dong Kalo (not } \\
\text { named) (XP) }\end{array}$ & $\begin{array}{l}14^{\circ} \mathrm{O} 2^{\prime}-14^{\circ} 20^{\prime} \mathrm{N} \\
105^{\circ} 55^{\prime}-106^{\circ} 11^{\prime} \mathrm{E} \\
\text { (southern part of XP) }\end{array}$ & Not marked ${ }^{1,2}$ & $90-282 ; S, 10 a$ \\
\hline $\begin{array}{l}\text { Fokienia Forest Area } \\
\text { (Not marked) (NNT) }\end{array}$ & $\begin{array}{l}18^{\circ} 07^{\prime}-18^{\circ} 10^{\prime} \mathrm{N} \\
105^{\circ} 23^{\prime}-105^{\circ} 25^{\prime} \mathrm{E} \\
\text { (Fokienia Forest of } \\
\text { NNT) }\end{array}$ & Not marked ${ }^{1,2}$ & $\begin{array}{l}1,500-2,286 \\
C, 5 b, 10 a\end{array}$ \\
\hline $\begin{array}{l}\text { High-altitude logging } \\
\text { road* (Not marked) }^{*}(\mathrm{NNT})\end{array}$ & $\begin{array}{l}17^{\circ} 57^{\prime}-17^{\circ} 59^{\prime} \mathrm{N} \\
105^{\circ} 18^{\prime}-105^{\circ} 20^{\prime} \mathrm{E}(\mathrm{road})\end{array}$ & Not marked ${ }^{1,2}$ & $950-1,200 ; C, 5 b, 10 a$ \\
\hline $\begin{array}{l}\text { Hoi King (not located; } \\
\text { locality lies along } \\
\text { Mekong between Ban } \\
\text { Pakmet and Chiang } \\
\text { Khan) (Historical) }\end{array}$ & $\begin{array}{l}\text { Coordinates unknown } \\
\text { (village) }\end{array}$ & $\begin{array}{l}\text { Not marked }{ }^{1,2} \text {; Hoi } \\
\text { King }{ }^{28}\end{array}$ & 160; N, 10a \\
\hline Houaphan Province & $\begin{array}{l}\text { Approx } 19^{\circ} 30^{\prime}-21^{\circ} 00^{\prime} \mathrm{N} \\
103^{\circ} 00^{\prime}-105^{\circ} 00^{\prime} \mathrm{E} \\
\text { (Province) }\end{array}$ & Not marked 1,2 & $350-2,079 ; \mathrm{N}, 5 \mathrm{~b}, 1 \mathrm{ob}$ \\
\hline Houay Apa (NNT) & $\begin{array}{l}17^{\circ} 59^{\prime} \mathrm{N} 105^{\circ} 21^{\prime} \mathrm{E} \\
\text { (river) }\end{array}$ & $\begin{array}{l}\text { Not marked }{ }^{1,2} \\
\text { (local name Houay } \\
\text { Satun) }\end{array}$ & 1,$050 ; C, 5 b, 10 a$ \\
\hline $\begin{array}{l}\text { Houay Bangliang } \\
\text { (DHS) }\end{array}$ & $\begin{array}{l}14^{\circ} 58^{\prime}-15^{\circ} 10^{\prime} \mathrm{N} \\
105^{\circ} 54^{\prime}-106^{\circ} 14^{\prime} \mathrm{E} \text { (river) }\end{array}$ & Not marked ${ }^{1,2}$ & $100-1,320 ; S ; 10 a$ \\
\hline $\begin{array}{l}\text { Houay Basong (Not } \\
\text { named) (NK) }\end{array}$ & $\begin{array}{l}18^{\circ} 17^{\prime}-18^{\circ} 19^{\prime} \mathrm{N} \\
104^{\circ} 18^{\prime}-104^{\circ} 25^{\prime} \mathrm{E} \text { (river) }\end{array}$ & Not marked ${ }^{1,2}$ & $320-1,000 ; \mathrm{N}, 10 a$ \\
\hline $\begin{array}{l}\text { Houay Be (Not } \\
\text { named) (NTX) }\end{array}$ & $\begin{array}{l}18^{\circ} 40^{\prime} \mathrm{N} 104^{\circ} 45^{\prime} \mathrm{E} \\
\text { (river) }\end{array}$ & Not marked ${ }^{1,2}$ & $500 ; \mathrm{N}, 5 \mathrm{~b}$ \\
\hline $\begin{array}{l}\text { Houay Clocc (Not } \\
\text { marked) (HNN) }\end{array}$ & $\begin{array}{l}17^{\circ} 25^{\prime} \mathrm{N} 105^{\circ} 56^{\prime} \mathrm{E} \\
\text { (stream) }\end{array}$ & Not marked ${ }^{1,2}$ & $630 ; \mathrm{C}, 5 \mathrm{~b}, 10 \mathrm{a}$ \\
\hline Houay Dua (PXT) & $\begin{array}{l}15^{\circ} 38^{\prime}-15^{\circ} 39^{\prime} \mathrm{N} \\
105^{\circ} 38^{\prime}-105^{\circ} 44^{\prime} \mathrm{E} \text { (river) }\end{array}$ & Not marked $^{1,2}$ & $110-250 ; S, 10 a$ \\
\hline Houay Kaliang (XP) & $\begin{array}{l}14^{\circ} 04^{\prime}-14^{\circ} \mathrm{O} 7^{\prime} \mathrm{N} \\
106^{\circ} \mathrm{O} 3^{\prime}-106^{\circ} 10^{\prime} \mathrm{E} \text { (river) }\end{array}$ & Not marked ${ }^{1,2}$ & $80 ;$ S,10a \\
\hline $\begin{array}{l}\text { Houay Kanik (NP, } \\
\text { outside NNT) }\end{array}$ & $\begin{array}{l}17^{\circ} 54^{\prime} \mathrm{N} 104^{\circ} 59^{\prime} \mathrm{E} \\
\text { (river) }\end{array}$ & Not marked ${ }^{1,2}$ & $520 ; C, 10 a$ \\
\hline $\begin{array}{l}\text { Houay Kechayer (Not } \\
\text { named) (NP, outside } \\
\text { NNT) }\end{array}$ & $\begin{array}{l}17^{\circ} 52^{\prime}-17^{\circ} 55^{\prime} \mathrm{N} \\
104^{\circ} 55^{\prime}-104^{\circ} 58^{\prime} \mathrm{E} \text { (river) }\end{array}$ & Not marked ${ }^{1,2}$ & $500-600 ; C, 10 a$ \\
\hline Houay Kua (XP) & $\begin{array}{l}14^{\circ} 34^{\prime} \mathrm{N} 106^{\circ} 13^{\prime} \mathrm{E} \\
\text { (river) }\end{array}$ & Not marked ${ }^{1,2}$ & $180 ; S, 10 a$ \\
\hline $\begin{array}{l}\text { Houay Maloua (Not } \\
\text { named) (NNT and NP) }\end{array}$ & $\begin{array}{l}17^{\circ} 40^{\prime} \mathrm{N} 105^{\circ} 24^{\prime} \mathrm{E} \\
\text { (river) }\end{array}$ & Not marked ${ }^{1,2}$ & $520 ; C, 10 a$ \\
\hline Houay Meuy (XP) & $\begin{array}{l}14^{\circ} 36^{\prime}-14^{\circ} 39^{\prime} \mathrm{N} \\
106^{\circ} 08^{\prime}-106^{\circ} \text { og } 9^{\prime} \mathrm{E} \text { (river) }\end{array}$ & Not marked ${ }^{1,2}$ & $200 ; S, 10 a$ \\
\hline
\end{tabular}

*see note added in proof 3, p.132. 
Part 2. cont.

Locality name
following Lao SGN
I : 100,000 Series
Category within main
text (e.g: Historical
"Other")

Geographical coordinates (locality type: town/river/ region)
Alternative names in references, and local names
Altitude;

Biogeographic subunits

\begin{tabular}{|c|c|c|c|}
\hline $\begin{array}{l}\text { Houay Morrow (Not } \\
\text { named) (NNT) }\end{array}$ & $\begin{array}{l}18^{\circ} 01^{\prime}-18^{\circ} 05^{\prime} \mathrm{N} \\
105^{\circ} 21^{\prime}-105^{\circ} 21^{\prime} \mathrm{E} \text { (river) }\end{array}$ & $\begin{array}{l}\text { Not marked }{ }^{1,2} \text { (local } \\
\text { name: Houay } \\
\text { Morrow) }\end{array}$ & $\begin{array}{l}1,040-1,160 \\
C, 10 a, 5 b\end{array}$ \\
\hline $\begin{array}{l}\text { Houay Namphak } \\
\text { (lower) (DHS) }\end{array}$ & $\begin{array}{l}15^{\circ} 03^{\prime}-15^{\circ} 04^{\prime} \mathrm{N} \\
106^{\circ} 06^{\prime}-106^{\circ} \mathrm{O} 4^{\prime} \mathrm{E} \text { (river) }\end{array}$ & Not marked ${ }^{1,2}$ & $\mathrm{~S}, 10 \mathrm{a}, 210-25^{\circ}$ \\
\hline $\begin{array}{l}\text { Houay Namphak } \\
\text { (upper) (DHS) }\end{array}$ & $\begin{array}{l}15^{\circ} 04^{\prime}-15^{\circ} 06^{\prime} \mathrm{N} \\
106^{\circ} 08^{\prime}-106^{\circ} 09^{\prime} \mathrm{E} \text { (river) }\end{array}$ & Not marked ${ }^{1,2}$ & $S, 10 a, 920-1,050$ \\
\hline Houay $\operatorname{Nan}(X B N)$ & $\begin{array}{l}15^{\circ} 50^{\prime}-15^{\circ} 52^{\prime} \mathrm{N} \\
105^{\circ} 57^{\prime}-105^{\circ} 58^{\prime} \mathrm{E} \text { (river) }\end{array}$ & Not marked ${ }^{1,2}$ & $180-400 ; S, 10 a$ \\
\hline $\begin{array}{l}\text { Houay Nyat (Not } \\
\text { named) (DHS tributary } \\
\text { of Houay Namphak) }\end{array}$ & $\begin{array}{l}15^{\circ} 03^{\prime}-15^{\circ} 03^{\prime} \mathrm{N} \\
106^{\circ} 08^{\prime}-106^{\circ} 09^{\prime} \mathrm{E} \text { (river) }\end{array}$ & Not marked ${ }^{1,2}$ & $280-360 ; S, 10 a$ \\
\hline $\begin{array}{l}\text { Houay Packha (Not } \\
\text { marked) (HNN) }\end{array}$ & $\begin{array}{l}17^{\circ} 26^{\prime}-17^{\circ} 27^{\prime} \mathrm{N} \text { 10 } 5^{\circ} 52^{\prime}- \\
105^{\circ} 54^{\prime} \mathrm{E} \text { (river) }\end{array}$ & Not marked $^{1,2}$ & $300 ; C, 5 b, 10 a$ \\
\hline Houay Sadam (XBN) & $\begin{array}{l}15^{\circ} 51^{\prime}-15^{\circ} 54^{\prime} \mathrm{N} \\
106^{\circ} 43^{\prime}-106^{\circ} 43^{\prime} \mathrm{E} \\
\text { (river) }\end{array}$ & Not marked ${ }^{1,2}$ & $190-230 ; S, 10 a$ \\
\hline $\begin{array}{l}\text { Houay Saoe (Not } \\
\text { named; another stream } \\
\text { nearby, not visited has } \\
\text { the same name) (XP) }\end{array}$ & $\begin{array}{l}14^{\circ} 37^{\prime} \mathrm{N} 106^{\circ} \mathrm{o} 8^{\prime} \mathrm{E} \\
\text { (river) }\end{array}$ & $\begin{array}{l}\text { Not marked }{ }^{1,2} \text { (local } \\
\text { name: Houay Saoe is a } \\
\text { tributary of Houay } \\
\text { Meuy) }\end{array}$ & $200 ; S, 10 a$ \\
\hline $\begin{array}{l}\text { Houay Soymong (Not } \\
\text { named) (BSW) }\end{array}$ & $\begin{array}{l}14^{\circ} 44^{\prime} \mathrm{N} 106^{\circ} 26^{\prime} \mathrm{E} \\
\text { (river) }\end{array}$ & Not marked ${ }^{1,2}$ & 140; S,10a \\
\hline Houay Takit (DHS) & $\begin{array}{l}15^{\circ} \mathrm{O} 2^{\prime}-15^{\circ} 05^{\prime} \mathrm{N} \\
106^{\circ} 00^{\prime}-106^{\circ} 01^{\prime} \mathrm{E} \\
\text { (river) }\end{array}$ & Not marked $^{1,2}$ & $180-260 ; S, 10 a$ \\
\hline $\begin{array}{l}\text { Houay Talee (not } \\
\text { marked) (HNN) }\end{array}$ & $\begin{array}{l}17^{\circ} 36^{\prime} \mathrm{N} 105^{\circ} 49^{\prime} \mathrm{E} \\
\text { (river) }\end{array}$ & Not marked ${ }^{1,2}$ & $400 ; C, 5 b, 10 a$ \\
\hline $\begin{array}{l}\text { Houay Tapkua (Not } \\
\text { named) (XP) }\end{array}$ & $\begin{array}{l}14^{\circ} 36^{\prime}-14^{\circ} 37^{\prime} \mathrm{N} \\
105^{\circ} 56^{\prime}-105^{\circ} 58^{\prime} \mathrm{E} \\
\text { (river) }\end{array}$ & Not marked ${ }^{1,2}$ & $120-400 ; S, 10 a$ \\
\hline Houay Tauang (XP) & $\begin{array}{l}14^{\circ} 38^{\prime} \mathrm{N} 106^{\circ} \mathrm{o} 7^{\prime} \mathrm{E} \\
\text { (river) }\end{array}$ & Not marked ${ }^{1,2}$ & $200 ; S, 10 a$ \\
\hline $\begin{array}{l}\text { Houay Touay-Gnai } \\
\text { (DHS) }\end{array}$ & $\begin{array}{l}14^{\circ} 55^{\prime}-15^{\circ} 05^{\prime} \mathrm{N} \\
105^{\circ} 5^{\prime}-106^{\circ} 14^{\prime} \mathrm{E} \\
\text { (river) }\end{array}$ & Not marked ${ }^{1,2}$ & $120-1,020 ; S, 10 a$ \\
\hline Houay Tsapsaet (TMF) & $\begin{array}{l}18^{\circ} 20^{\prime}-18^{\circ} 21^{\prime} \mathrm{N} 102^{\circ} 11^{\prime}- \\
102^{\circ} 12^{\prime} \mathrm{E} \text { (river) }\end{array}$ & Not marked ${ }^{1,2}$ & $190-230 ; \mathrm{N}, 10 \mathrm{a}$ \\
\hline Houay Xan (PXT) & $\begin{array}{l}15^{\circ} 40^{\prime}-15^{\circ} 43^{\prime} \mathrm{N} \\
105^{\circ} 38^{\prime}-105^{\circ} 40^{\prime} \mathrm{E} \\
\text { (river) }\end{array}$ & Not marked ${ }^{1,2}$ & $110-200 ; S, 10 a$ \\
\hline $\begin{array}{l}\text { Keng Itat (Not named) } \\
\text { (NK) }\end{array}$ & $\begin{array}{l}18^{\circ} 21^{\prime} \mathrm{N} 104^{\circ} 09^{\prime} \mathrm{E} \\
\text { (rapids) }\end{array}$ & Not marked ${ }^{1,2}$ & 180; N,roa \\
\hline $\begin{array}{l}\text { Keng Maiha (Not } \\
\text { named) (NK) }\end{array}$ & $\begin{array}{l}18^{\circ} 15^{\prime} \mathrm{N} 104^{\circ} 31^{\prime} \mathrm{E} \\
\text { (rapids) }\end{array}$ & Not marked ${ }^{1,2}$ & $380 ; N, 10 a$ \\
\hline $\begin{array}{l}\text { Keng Sung (Not } \\
\text { named) (XBN) }\end{array}$ & $\begin{array}{l}15^{\circ} 58 \mathrm{~N} 105^{\circ} 35^{\prime} \mathrm{E} \\
\text { (rapids) }\end{array}$ & Not marked ${ }^{1,2}$ & $140 ; S, 10 a$ \\
\hline $\begin{array}{l}\text { Keng Luang (on Nam } \\
\text { Xot) (Not named) (NP) }\end{array}$ & $\begin{array}{l}17^{\circ} 55^{\mathrm{N}} 105^{\circ} 07^{\prime} \mathrm{E} \\
\text { (rapids) }\end{array}$ & Not marked ${ }^{1,2}$ & $480 ; C, 10 a$ \\
\hline
\end{tabular}


Part 2. cont.

\begin{tabular}{|c|c|c|c|}
\hline $\begin{array}{l}\text { Locality name } \\
\text { following Lao SGN } \\
1 \text { : 100,0oo Series } \\
\text { Category within main } \\
\text { text (e.g: Historical } \\
\text { "Other") }\end{array}$ & $\begin{array}{l}\text { Geographical } \\
\text { coordinates (locality } \\
\text { type: town/river/ } \\
\text { region) }\end{array}$ & $\begin{array}{l}\text { Alternative names in } \\
\text { references, and local } \\
\text { names }\end{array}$ & $\begin{array}{l}\text { Altitude; } \\
\text { Biogeographic } \\
\text { subunits }\end{array}$ \\
\hline $\begin{array}{l}\text { Keng Luang (on Nam } \\
\text { Theun) (Not named) } \\
\text { ("Other") }\end{array}$ & $\begin{array}{l}18^{\circ} 11^{\prime} \mathrm{N} 104^{\circ} 44^{\prime} \mathrm{E} \\
\text { (rapids) }\end{array}$ & Not marked ${ }^{1,2}$ & 520; C,10a \\
\hline Khammouan Province & $\begin{array}{l}17^{\circ} \mathrm{OO}^{\prime}-18^{\circ} 10^{\prime} \mathrm{N} 104^{\circ} 20^{\prime}- \\
106^{\circ} 15^{\prime} \mathrm{E} \text { (Province) }\end{array}$ & Not marked ${ }^{1,2}$ & $150-2,286 ; C, 5 b, 10 a$ \\
\hline $\begin{array}{l}\text { Khuadhin (not } \\
\text { marked) (KML) }\end{array}$ & $\begin{array}{l}17^{\circ} 5^{\circ} \mathrm{N} 104^{\circ} 50^{\prime} \mathrm{E} \\
\text { (forest area on } \\
\text { limestone) }\end{array}$ & Not marked $^{1,2}$ & 400; C, Ioa \\
\hline $\begin{array}{l}\text { Khonphapheng Falls* } \\
\text { (map name: N. Th. } \\
\text { Khonphapheng) } \\
\text { (Historical, SMK) }\end{array}$ & $\begin{array}{l}13^{\circ} 57^{\prime} \mathrm{N} 105^{\circ} 59^{\prime} \mathrm{E} \\
\text { (waterfalls) }\end{array}$ & Not marked ${ }^{1,2}$ & $70 ; 5,10 a$ \\
\hline $\begin{array}{l}\text { Kong Kok (Not } \\
\text { located) (Historical) }\end{array}$ & $\begin{array}{l}\text { Coordinates unknown } \\
\text { (village) }\end{array}$ & $\begin{array}{l}\text { Not marked }{ }^{1,2} \text {; Kong } \\
\text { Kok }{ }^{11}\end{array}$ & ?; C, 1oa \\
\hline $\begin{array}{l}\text { Kouys (Not located) } \\
\text { Iname has been found } \\
\text { on an old map with } \\
\text { several Kouys in } \\
\text { Cambodia and } \\
\text { Thailand but not } \\
\text { Laos]. (Historical) }\end{array}$ & $\begin{array}{l}\text { Coordinates unknown } \\
\text { (region) }\end{array}$ & $\begin{array}{l}\text { Not marked }{ }^{1,2} \text {; land of } \\
\text { the Kouys }{ }^{27}\end{array}$ & ?; S,Ioa \\
\hline $\begin{array}{l}\text { Lao Pako (Not } \\
\text { marked) ("Other") }\end{array}$ & $\begin{array}{l}18^{\circ} \mathrm{og}{ }^{\prime} \mathrm{N} 102^{\circ} 51^{\prime} \mathrm{E} \\
\text { (tourist resort) }\end{array}$ & Not marked ${ }^{1,2}$ & $170 ; \mathrm{N}, 10 \mathrm{a}$ \\
\hline $\begin{array}{l}\text { Logging camp (Not } \\
\text { marked) (NTX) }\end{array}$ & $\begin{array}{l}18^{\circ} 28^{\prime} \mathrm{N} 105^{\circ} 05^{\prime} \mathrm{E} \\
\text { (campsite used by } \\
\text { logging crews) }\end{array}$ & Not marked ${ }^{1,2}$ & $960 ; \mathrm{N} / \mathrm{C}, 5 \mathrm{~b}$ \\
\hline $\begin{array}{l}\text { Lo-Tiao (not located) } \\
\text { (Historical) }\end{array}$ & $\begin{array}{l}\text { approx. } 20^{\circ} 25^{\prime} \mathrm{N} \\
100^{\circ} 30^{\prime} \mathrm{E} \text { (village or } \\
\text { town) }\end{array}$ & $\begin{array}{l}\text { Not marked }{ }^{1,2,9} ; \\
\text { Lo-Tiao }{ }^{15}\end{array}$ & approx.1,000; N,10b \\
\hline $\begin{array}{l}\text { Louang-Namtha } \\
\text { Province ("Other") }\end{array}$ & $\begin{array}{l}20^{\circ} 30^{\prime}-21^{\circ} 30^{\prime} \mathrm{N} 100^{\circ} 25^{\prime}- \\
101^{\circ} 40^{\prime} \mathrm{E} \text { (Province) }\end{array}$ & Not marked $^{1,2}$ & $45^{0}-2,094 ; \mathrm{N}, 10 \mathrm{~b}$ \\
\hline $\begin{array}{l}\text { Louang-Namtha } \\
\text { ("Other") }\end{array}$ & $\begin{array}{l}20^{\circ} 57^{\prime} \mathrm{N} 101^{\circ} 24^{\prime} \mathrm{E} \\
\text { (town) }\end{array}$ & $\begin{array}{l}\text { Muong Luong Nam } \\
\text { Tha'; Louang Namtha }{ }^{2}\end{array}$ & $590 ; \mathrm{N}, 10 \mathrm{~b}$ \\
\hline $\begin{array}{l}\text { Louangphabang } \\
\text { Province }\end{array}$ & $\begin{array}{l}20^{\circ} 30^{\prime}-21^{\circ} 30^{\prime} \mathrm{N} 100^{\circ} 25^{\prime}- \\
101^{\circ} 40^{\prime} \mathrm{E} \text { (Province) }\end{array}$ & Not marked ${ }^{1,2}$ & $300-2,212 ; \mathrm{N}, 10 \mathrm{~b}$ \\
\hline $\begin{array}{l}\text { Louangphabang } \\
\text { (Historical and } \\
\text { "Other") }\end{array}$ & $\begin{array}{l}19^{\circ} 53^{\prime} \mathrm{N} 102^{\circ} 08^{\prime} \mathrm{E} \\
\text { (town) }\end{array}$ & $\begin{array}{l}\text { Luang Prabang }{ }^{1,6,18,20} \text {; } \\
\text { Louangphrabang }^{2} ; \\
\text { Luang-Prabang }{ }^{15}\end{array}$ & $300 ; \mathrm{N}, 10 \mathrm{~b}$ \\
\hline Mekong (Map name & $13^{\circ} 59^{\prime}-21^{\circ} 40^{\prime} \mathrm{N} 100^{\circ} 15^{\prime}-$ & Mekong ${ }^{1}$; Mae Nam & $80-350$ \\
\hline Nam Khong) & $\begin{array}{l}105^{\circ} 53^{\prime} \mathrm{E} \text { (coordinates } \\
\text { for within Laos; major } \\
\text { river) }\end{array}$ & Khong $^{2}$ & $\mathrm{~N}, \mathrm{C}, \mathrm{S}, 10 \mathrm{a}, 10 \mathrm{~b}$ \\
\hline $\begin{array}{l}\text { Muang Hom (Not } \\
\text { marked) (just outside } \\
\text { PKK) }\end{array}$ & $\begin{array}{l}{ }^{1} 8^{\circ} 33^{\prime} \mathrm{N} 103^{\circ} \circ 1^{\prime} \mathrm{E} \\
\text { (village) }\end{array}$ & Not marked ${ }^{1,2}$ & $300 ; \mathrm{N}, 10 a$ \\
\hline Muang Koa ("Other") & $\begin{array}{l}21^{\circ} \mathrm{O} 5^{\prime} \mathrm{N} 102^{\circ} 35^{\prime} \mathrm{E} \\
\text { (town) }\end{array}$ & $\begin{array}{l}\text { Muong Khoua '; } \\
\text { Muang Khoua }^{2}\end{array}$ & $300 ; \mathrm{N}, 10 \mathrm{~b}$ \\
\hline
\end{tabular}

${ }^{*}$ see note added in proof 4, p.132. 
Part 2. cont.

\begin{tabular}{|c|c|c|c|}
\hline $\begin{array}{l}\text { Locality name } \\
\text { following Lao SGN } \\
1 \text { : 1oo,ooo Series } \\
\text { Category within main } \\
\text { text (e.g: Historical } \\
\text { "Other") }\end{array}$ & $\begin{array}{l}\text { Geographical } \\
\text { coordinates (locality } \\
\text { type: town/river/ } \\
\text { region) }\end{array}$ & $\begin{array}{l}\text { Alternative names in } \\
\text { references, and local } \\
\text { names }\end{array}$ & $\begin{array}{l}\text { Altitude; } \\
\text { Biogeographic } \\
\text { subunits }\end{array}$ \\
\hline $\begin{array}{l}\text { Muang Phin } \\
\text { (Historical, outside } \\
\text { PXH) }\end{array}$ & $\begin{array}{l}16^{\circ} 32^{\prime} \mathrm{N} 106^{\circ} 01^{\prime} \mathrm{E} \\
\text { (town also a district) }\end{array}$ & $\begin{array}{l}\text { Not marked }{ }^{1} \text {; Muang } \\
\text { Phin }{ }^{2} \text {; Muong-Phine }{ }^{11}\end{array}$ & $180 ; C, 10 a$ \\
\hline $\begin{array}{l}\text { Muang Sansai (Not } \\
\text { marked) ("Other") }\end{array}$ & $\begin{array}{l}14^{\circ} 55^{\prime} \mathrm{N} 107^{\circ} 05^{\prime} \mathrm{E} \\
\text { (town) }\end{array}$ & Not marked ${ }^{1,2}$ & $120 ; S, 10 a$ \\
\hline $\begin{array}{l}\text { Muang Somoy (Not } \\
\text { marked) (Historical) }\end{array}$ & $\begin{array}{l}16^{\circ} 05^{\prime}-16^{\circ} 25^{\prime} \mathrm{N} \\
106^{\circ} 40^{\prime}-107^{\circ} 10^{\prime} \mathrm{E} \\
\text { (district of Salavan } \\
\text { Province) }\end{array}$ & ${ }_{11}^{\text {Not marked }}{ }^{1,2}$; Samoï & $300-1,362 ; C, 10 a$ \\
\hline $\begin{array}{l}\text { Muang Taoy (referred } \\
\text { to in next entry) }\end{array}$ & $\begin{array}{l}16^{\circ} \mathrm{o} 3^{\prime} \mathrm{N} 106^{\circ} 35^{\prime} \mathrm{E} \\
\text { (town) }\end{array}$ & Not marked ${ }^{1,2}$ & $450 ;$ S,10a \\
\hline $\begin{array}{l}\text { Muang Taoy } \\
\text { (Historical) }\end{array}$ & $\begin{array}{l}15^{\circ} 30^{\prime}-16^{\circ} 03^{\prime} \mathrm{N} \\
106^{\circ} 20^{\prime}-107^{\circ} 15^{\prime} \mathrm{E} \\
\text { (district; also a town) }\end{array}$ & $\begin{array}{l}\text { Not marked }{ }^{1,2} \text {; } \\
\text { Tahoi }{ }^{22,23,25}\end{array}$ & $45^{0-1,300 ; S, 10 a, 5 b}$ \\
\hline $\begin{array}{l}\text { Mukdahan (Not } \\
\text { covered) (Historical) }\end{array}$ & $\begin{array}{l}16^{\circ} 32^{\prime} \mathrm{N} 104^{\circ} 32^{\prime} \mathrm{E} \\
\text { (town in Thailand) }\end{array}$ & $\begin{array}{l}\text { Mukdahan }{ }^{1,2} ; \text { Mouc } \\
\text { Dahan }^{28}\end{array}$ & $\begin{array}{l}\text { 150; adjacent to } \\
\text { C,10a }\end{array}$ \\
\hline $\begin{array}{l}\text { Nadi limestone area } \\
(\mathrm{NK})\end{array}$ & $\begin{array}{l}18^{\circ} 17^{\prime}-18^{\circ} 25^{\prime} \mathrm{N} \\
104^{\circ} 32^{\prime}-104^{\circ} 43^{\prime} \mathrm{E} \\
\text { (Limestone Area) }\end{array}$ & Not marked ${ }^{1,2}$ & $400-1,078 ; N, 10 a$ \\
\hline $\begin{array}{l}\text { Nam An (Nam Ao on } \\
\text { map: local name used } \\
\text { to reduce confusion } \\
\text { with Nam Ao below) } \\
\text { (NK) }\end{array}$ & $\begin{array}{l}18^{\circ} 23^{\prime} \mathrm{N} 104^{\circ} 17^{\prime} \mathrm{E} \\
\text { (river) }\end{array}$ & Not marked ${ }^{t, 2}$ & $180 ; \mathrm{N}, 10 a$ \\
\hline Nam Ao $(\mathrm{NK})$ & $\begin{array}{l}18^{\circ} 15^{\prime} \mathrm{N} 104^{\circ} 34^{\prime} \mathrm{E} \\
\text { (river) }\end{array}$ & Not marked ${ }^{1,2}$ & $380 ; \mathrm{N}, 10 \mathrm{a}$ \\
\hline $\begin{array}{l}\text { Nam Ao forest area } \\
\text { (Not named) (NK) }\end{array}$ & $\begin{array}{l}18^{\circ} \mathrm{J} 5^{\prime}-18^{\circ} 18^{\prime} \mathrm{N} \\
104^{\circ} 31^{\prime}-104^{\circ} 36^{\prime} \mathrm{E} \text { (forest } \\
\text { area) }\end{array}$ & Not marked ${ }^{1,2}$ & $390-432 ; \mathrm{N} / \mathrm{C}, 10 a$ \\
\hline Nam Cham (NTX) & $\begin{array}{l}18^{\circ} 41^{\prime}-18^{\circ} 46^{\prime} \mathrm{N} \\
104^{\circ} 46^{\prime}-104^{\circ} 55^{\prime} \mathrm{E} \\
\text { (river) }\end{array}$ & Not marked 1,2 & $720-1,000$ \\
\hline $\begin{array}{l}\text { Nam Cham } \\
\text { headwaters (NTX) }\end{array}$ & $\begin{array}{l}18^{\circ} 46^{\prime} \mathrm{N} 104^{\circ} 55^{\prime} \mathrm{E} \\
\text { (river) }\end{array}$ & Not marked ${ }^{1,2}$ & $800-1,000$ \\
\hline $\begin{array}{l}\text { Nam Chouan } \\
\text { ("Other") }\end{array}$ & $\begin{array}{l}18^{\circ} 48^{\prime}-18^{\circ} 54^{\prime} \mathrm{N} \\
104^{\circ} 15^{\prime}-104^{\circ} 30^{\prime} \mathrm{E} \text { (river) }\end{array}$ & $\begin{array}{l}\text { Not marked }{ }^{1} \text {, Not } \\
\text { named }{ }^{2}\end{array}$ & $320-400 ; N, 5 b$ \\
\hline $\begin{array}{l}\text { Nam Gnouang (NTX } \\
\text { and NK, although } \\
\text { actually just outside } \\
\text { both) }\end{array}$ & $\begin{array}{l}18^{\circ} 15^{\prime}-18^{\circ} 27^{\prime} \mathrm{N} \\
104^{\circ} 38^{\prime}-104^{\circ} 55^{\prime} \mathrm{E} \text { (river) }\end{array}$ & $\begin{array}{l}\text { Not marked }{ }^{1} \text {, Nam } \\
\text { Nhuong }^{2}\end{array}$ & $380-430 ; N, 10 a$ \\
\hline $\begin{array}{l}\text { Nam Hai (outside NK } \\
\text { and "Other") }\end{array}$ & $\begin{array}{l}18^{\circ} 05^{\prime}-18^{\circ} 11^{\prime} \mathrm{N} \\
104^{\circ} 32^{\prime}-104^{\circ} 42^{\prime} \mathrm{E} \text { (river) }\end{array}$ & $\begin{array}{l}\text { Not marked }{ }^{1}, \text { Not } \\
\text { named }^{2}\end{array}$ & $165-1,000 ; N, 10 a$ \\
\hline $\begin{array}{l}\text { Nam Hai - Nam } \\
\text { Hinboun plain } \\
\text { (outside NK and } \\
\text { "Other") (Not named) }\end{array}$ & $\begin{array}{l}18^{\circ} 02^{\prime}-18^{\circ} 13^{\prime} \mathrm{N} \\
104^{\circ} 31^{\prime}-104^{\circ} 39^{\prime} \mathrm{E} \text { (plain) }\end{array}$ & Not marked ${ }^{1,2}$ & $165 ; \mathrm{N}, 10 a$ \\
\hline Nam Heung (NTX) & $\begin{array}{l}18^{\circ} 27^{\prime}-18^{\circ} 37^{\prime} \mathrm{N} \\
104^{\circ} 49^{\prime}-104^{\circ} 53^{\prime} \mathrm{E} \\
\text { (river) }\end{array}$ & Not marked ${ }^{1,2}$ & $500-560 ; N, 5 b$ \\
\hline
\end{tabular}


Part 2. cont.

Locality name
following Lao SGN
$1: 100,000$ Series
Category within main
text (e.g: Historical
"Other")

Nam Hinboun (outside

KML, "Other")

Nam Hiang (Not

marked) (XNN)

Nam Him (TMF)

Nam Huang

(Historical)

Nam Kading (NK)

Nam Kata (NNT)

Nam Kang (PDD)

Nam Khang (PDD)

Nam Khao (Historical)

Nam Kong

(catchment) ("Other")

Nam Kwai (Not

named) (NTX)

Nam La (PDD)

Nam La, mouth of:

(PDD)

Nam Lepou (DKT, SMK)

Nam Leuk (NNT and NP)

Nam Leuk (PKK)

Nam Leuk dam site

(Not marked) (PKK)

Nam Malou (NP, outside NNT,

Nam Mang (PKK)

Nam Mat (Historical)

Nam Mo (Historical)
Geographical coordinates (locality type: town/river/ region)
Alternative names in references, and local names
Altitude;

Biogeographic subunits

\begin{tabular}{|c|c|}
\hline $17^{\circ} 35^{\prime}-18^{\circ} 05^{\prime} \mathrm{N}$ & Not marked ${ }^{3}$, Nam \\
\hline $104^{\circ} 25^{\prime}-104^{\circ} 50^{\prime} \mathrm{E}$ (river) & Hinboun $^{2}$ \\
\hline $\begin{array}{l}14^{\circ} 55^{\prime} \mathrm{N} 106^{\circ} 45^{\prime} \mathrm{E} \\
\text { (stream) }\end{array}$ & Not marked ${ }^{1,2}$ \\
\hline $\begin{array}{l}18^{\circ} 21^{\prime}-18^{\circ} 22^{\prime} \mathrm{N} 102^{\circ} 11^{\prime} \\
102^{\circ} 12^{\prime} \mathrm{E} \text { (river) }\end{array}$ & Not marked ${ }^{1,2}$ \\
\hline $\begin{array}{l}17^{\circ} 28^{\prime}-17^{\circ} 50^{\prime} \mathrm{N} \\
101^{\circ} 10^{\prime}-101^{\circ} 35^{\prime} \mathrm{E} \text { (river }\end{array}$ & $\begin{array}{l}\text { Not marked ', Nam } \\
\text { Huang }{ }^{2}\end{array}$ \\
\hline
\end{tabular}

forming part of border with Thailand)

$18^{\circ} 14^{\prime}-18^{\circ} 25^{\prime} \mathrm{N}$

$103^{\circ} 59^{\prime}-104^{\circ} 35^{\prime} \mathrm{E}$ (river)

$18^{\circ} \mathrm{o} 8^{\prime}-18^{\circ} 10^{\prime} \mathrm{N}$

$105^{\circ} 08^{\prime}-105^{\circ} 13^{\prime} \mathrm{E}$

(river)

$22^{\circ} 06^{\prime}-22^{\circ} \mathrm{O} 7^{\prime} \mathrm{N} 102^{\circ} 15^{\prime}-$ $102^{\circ} 19^{\prime} \mathrm{E}$ (river)

$22^{\circ} 06^{\prime}-22^{\circ} 22^{\prime} \mathrm{N}$

$102^{\circ} 00^{\prime}-102^{\circ} 15^{\prime} \mathrm{E}$ (river)

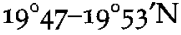

$103^{\circ} 15^{\prime}-103^{\circ} 30^{\prime} \mathrm{E}$ (river)

$14^{\circ} 27^{\prime}-14^{\circ} 4 o^{\prime} \mathrm{N}$

$106^{\circ} 35^{\prime}-107^{\circ} 05^{\prime} \mathrm{E}$

(catchment area)

$18^{\circ} 22^{\prime}-18^{\circ} 24^{\prime} \mathrm{N}$

$105^{\circ} 08^{\prime}-105^{\circ} 09^{\prime} \mathrm{E}$ (river)

$22^{\circ} 04^{\prime}-22^{\circ} \circ 9^{\prime} \mathrm{N}$

$102^{\circ} 16^{\prime}-102^{\circ} 21^{\prime} \mathrm{E}$ (river)

$22^{\circ} \mathrm{O} 4^{\prime} \mathrm{N} 102^{\circ} 16^{\prime} \mathrm{E}$ (river mouth)

$14^{\circ} 06^{\prime}-14^{\circ} 10^{\prime} \mathrm{N}$

$105^{\circ} 16^{\prime}-105^{\circ} 4^{\prime} \mathrm{E}$ (river)

$17^{\circ} 38^{\prime} \mathrm{N} 105^{\circ} 21^{\prime} \mathrm{E}$

(river)

$18^{\circ} 11^{\prime}-18^{\circ} 22^{\prime} \mathrm{N}$

$102^{\circ} 50^{\prime}-103^{\circ} 09^{\prime} \mathrm{E}$ (river)

$18^{\circ} 26^{\prime} \mathrm{N} 103^{\circ} \mathrm{oo}^{\prime} \mathrm{E}$ (site

of proposed dam)

$17^{\circ} 4^{\prime}-17^{\circ} 52^{\prime} \mathrm{N}$

$104^{\circ} 57^{\prime}-104^{\circ} 59^{\prime} \mathrm{E}$ (river)

$18^{\circ} 24^{\prime}-18^{\circ} 32^{\prime} \mathrm{N}$

$103^{\circ} \mathrm{Og}^{\prime}-103^{\circ} 12^{\prime} \mathrm{E}$ (river)

$19^{\circ} 35^{\prime}-19^{\circ} 42^{\prime} \mathrm{N}$

$103^{\circ} 30^{\prime}-104^{\circ} \mathrm{O} 2^{\prime} \mathrm{E}$ (river)

$19^{\circ} \mathrm{O} 2^{\prime}-19^{\circ} 20^{\prime} \mathrm{N}$

$103^{\circ} 49^{\prime}-104^{\circ} \mathrm{O} 7^{\prime} \mathrm{E}$ (river)
Nam Ca Dinh ${ }^{1}$; Nam

Kading $^{2}$

Not marked ${ }^{1,2}$

Not marked ${ }^{1,2}$

Not marked ${ }^{1,2}$

Not marked ${ }^{1}$; Not

named ${ }^{2}$; Nam

Khao $^{9}$

Not marked ${ }^{1,}$ Not

named $^{2}$

Not marked ${ }^{1,2}$

Not marked ${ }^{1,2}$

Not marked 1,2

Tonle Repou ${ }^{1}$, Not

named ${ }^{2}$ (local name

Xe Lamphao)

Not marked ${ }^{1,2}$ (local

name Houay Leuk)

Not marked ", Not

named $^{2}$

Not marked 1,2

Not marked ${ }^{1,2}$ (local

name Nam Nyalong)

Not marked ${ }^{1,}$ Not

named ${ }^{2}$

Nam Mat ${ }^{1,2,9}$

Not marked ${ }^{1}$; Not

named ${ }^{2}$; Nam Mo ${ }^{9}$;

Nam Mô ${ }^{27} ;$ Nam-mo ${ }^{7}$
150-160; C,10a

$850 ;$ S,10a

190-230; N,10a

approx. 200-600;

N,ioa

150-360; N,10a

550; C,5b,10a,

$500-840 ; \mathrm{N}, 10 b$

$580-740 ; \mathrm{N}, 10 \mathrm{~b}$

550-1,000; N,10b

$90-520 ; S, 10 a$

$640-800 ; N, 5 b$

560-1,200; N,10b

$560 ; \mathrm{N}, 10 \mathrm{~b}$

$80-100 ; 5,10 a$

520; C,10a

160-600; N, 10a

310; N,10a

$520-560 ; C, 5 b, 10 a$

$154-350 ; N, 10 a$

$480-600 ; \mathrm{N}, 5 \mathrm{~b}$

$350-600 ; \mathrm{N}, 5 \mathrm{~b}$ 
Part 2. cont.

\begin{tabular}{|c|c|c|c|}
\hline $\begin{array}{l}\text { Locality name } \\
\text { following Lao SGN } \\
1 \text { : 10o,ooo Series } \\
\text { Category within main } \\
\text { text (e.g: Historical } \\
\text { "Other") }\end{array}$ & $\begin{array}{l}\text { Geographical } \\
\text { coordinates (locality } \\
\text { type: town/river/ } \\
\text { region) }\end{array}$ & $\begin{array}{l}\text { Alternative names in } \\
\text { references, and local } \\
\text { names }\end{array}$ & $\begin{array}{l}\text { Altitude; } \\
\text { Biogeographic } \\
\text { subunits }\end{array}$ \\
\hline $\begin{array}{l}\text { Nam Mon (tributary of } \\
\text { Nam Xot) (NNT and } \\
\text { NP) }\end{array}$ & $\begin{array}{l}17^{\circ} 53^{\prime}-17^{\circ} 54^{\prime} \mathrm{N} \\
105^{\circ} 06^{\prime}-105^{\circ} 09^{\prime} \mathrm{E} \text { (river) }\end{array}$ & $\begin{array}{l}\text { Not marked }{ }^{1} \text { Nam } \\
\text { Mon }{ }^{2}\end{array}$ & $520 ; C, 10 a$ \\
\hline $\begin{array}{l}\text { Nam Mon (tributary of } \\
\text { Nam Yang) (NNT and } \\
\text { NP) }\end{array}$ & $\begin{array}{l}17^{\circ} 41^{\prime}-17^{\circ} 47^{\prime} \mathrm{N} 105^{\circ} 25^{\prime}- \\
105^{\circ} 30^{\prime} \mathrm{E} \text { (river) }\end{array}$ & Not marked ${ }^{1,2}$ & $520 ; C, 10 a$ \\
\hline $\begin{array}{l}\text { Nam Mouan (NK and } \\
\text { "Other") }\end{array}$ & $\begin{array}{l}18^{\circ} 24^{\prime}-18^{\circ} 51^{\prime} \mathrm{N} \\
104^{\circ} 12^{\prime}-104^{\circ} 20^{\prime} \mathrm{E} \text { (river) }\end{array}$ & $\begin{array}{l}\text { Nam Muone }{ }^{1,} \text { Nam } \\
\text { Muan }^{2}\end{array}$ & $220-420 ; \mathrm{N}, 10 a$ \\
\hline Nam Neun (Historical) & $\begin{array}{l}19^{\circ} 42^{\prime}-20^{\circ} 00^{\prime} \mathrm{N} \\
103^{\circ} 50^{\prime}-104^{\circ} 02^{\prime} \mathrm{E} \text { (river) }\end{array}$ & $\begin{array}{l}\text { Nam Neun }{ }^{1,2} ; \text { Nam } \\
\text { Neune }^{9} ; \text { Nam-neune }{ }^{7}\end{array}$ & $480-520 ; N, 5 b$ \\
\hline Nam Ngo (HNN) & $\begin{array}{l}17^{\circ} 29^{\prime}-17^{\circ} 33^{\prime} \mathrm{N} 105^{\circ} 42^{\prime}- \\
105^{\circ} 52^{\prime} \mathrm{E} \text { (river) }\end{array}$ & $\begin{array}{l}\text { Not marked }{ }^{1,} \text { Not } \\
\text { named }{ }^{2} \text { (local name } \\
\text { Nam Ngor) }\end{array}$ & $180-190 ; \mathrm{C}, 5 \mathrm{~b}, 10 \mathrm{a}$ \\
\hline Nam Ngay ("Other") & $\begin{array}{l}21^{\circ} 47^{\prime}-21^{\circ} 53^{\prime} \mathrm{N} \\
101^{\circ} 44^{\prime}-102^{\circ} 12^{\prime} \mathrm{E} \text { (river) }\end{array}$ & Not marked ${ }^{1,2}$ & $540-1,000 ; \mathrm{N}, 10 \mathrm{~b}$ \\
\hline $\begin{array}{l}\text { Nam Ngoy ("Other" } \\
\text { near Nam Theun) }\end{array}$ & $\begin{array}{l}18^{\circ} 03^{\prime}-18^{\circ} 11^{\prime} \mathrm{N} \\
104^{\circ} 41^{\prime}-104^{\circ} 55^{\prime} \mathrm{E} \text { (river) }\end{array}$ & Not marked ${ }^{1,2}$ & $400-520 ; S, 10 a$ \\
\hline $\begin{array}{l}\text { Nam Noy (NP and } \\
\text { NNT) }\end{array}$ & $\begin{array}{l}17^{\circ} 43^{\prime}-17^{\circ} 50^{\prime} \mathrm{N} \\
105^{\circ} 19^{\prime}-105^{\circ} 27^{\prime} \mathrm{E} \text { (river) }\end{array}$ & Not marked 1,2 & $500-560 ; C, 5 b, 10 a$ \\
\hline $\begin{array}{l}\text { Nam Ngum } \\
\text { (Historical) }\end{array}$ & $\begin{array}{l}18^{\circ} 00^{\prime}-19^{\circ} 35^{\prime} \mathrm{N} \\
102^{\circ} 30^{\prime}-103^{\circ} 15^{\prime} \mathrm{E} \text { (river) }\end{array}$ & $\begin{array}{l}\text { Nam Ngum }{ }^{1,2} ; \text { Nam } \\
\text { Ngeum }^{9}\end{array}$ & $\begin{array}{l}220-1,100 \\
N, 10 a, 10 b\end{array}$ \\
\hline $\begin{array}{l}\text { Nam Ngum reservoir } \\
\text { (Angkep Nam Ngum) } \\
\text { ("Other") }\end{array}$ & $\begin{array}{l}18^{\circ} 25^{\prime}-18^{\circ} 37^{\prime} \mathrm{N} \\
102^{\circ} 30^{\prime}-102^{\circ} 54^{\prime} \mathrm{E}\end{array}$ & $\begin{array}{l}\text { Not marked }{ }^{1} ; \text { Nam } \\
\text { Ngum reservoir }{ }^{2}\end{array}$ & $220 ; \mathrm{N}$, IOa \\
\hline $\begin{array}{l}\text { Nam Ou (Historical, } \\
\text { PDD) }\end{array}$ & $\begin{array}{l}20^{\circ} 05^{\prime}-22^{\circ} 03^{\prime} \mathrm{N} \\
101^{\circ} 4^{\prime}-102^{\circ} 13^{\prime} \mathrm{E} \text { (river) }\end{array}$ & $\begin{array}{l}\text { Nam Ou }{ }^{1} ; \\
\text { Nam Hou }^{2,18}\end{array}$ & $320-800 ; N, 10 b$ \\
\hline Nam Pan (NTX) & $\begin{array}{l}18^{\circ} 27^{\prime}-18^{\circ} 30^{\prime} \mathrm{N} \\
104^{\circ} 55^{\prime}-105^{\circ} 06^{\prime} \mathrm{E} \text { (river) }\end{array}$ & Not marked ${ }^{1,2}$ & $520-840 ; \mathrm{N}, 5 \mathrm{~b}$ \\
\hline $\begin{array}{l}\text { Nam Pan Noy (Not } \\
\text { named) (NTX) }\end{array}$ & $\begin{array}{l}18^{\circ} 29^{\prime}-18^{\circ} 29^{\prime} \mathrm{N} \\
105^{\circ} 05^{\prime}-105^{\circ} 06^{\prime} \mathrm{E} \text { (river, } \\
\text { tributary of Nam Noy) }\end{array}$ & Not marked ${ }^{1,2}$ & $95^{0-1,160 ; N, 5 b}$ \\
\hline $\begin{array}{l}\text { Nam Phao (NTX, } \\
\text { NNT) }\end{array}$ & $\begin{array}{l}18^{\circ} 03^{\prime}-18^{\circ} 22^{\prime} \mathrm{N} \\
104^{\circ} 57^{\prime}-105^{\circ} 09^{\prime} \mathrm{E} \text { (river) }\end{array}$ & $\begin{array}{l}\text { Not marked }{ }^{1,} \text { Not } \\
\text { named }^{2}\end{array}$ & $510-920 ; C, 5 b$ \\
\hline Nam Pheo (NNT) & $\begin{array}{l}17^{\circ} 49^{\prime}-17^{\circ} 52^{\prime} \mathrm{N} \\
105^{\circ} 27^{\prime}-105^{\circ} 36^{\prime} \mathrm{E} \text { (river) }\end{array}$ & Not marked 1,2 & $550-600 ; C, 10 a$ \\
\hline Nam Sa ("Other") & $\begin{array}{l}18^{\circ} 21^{\prime}-18^{\circ} 28^{\prime} \mathrm{N} \\
103^{\circ} 39^{\prime}-103^{\circ} 56^{\prime} \mathrm{E} \text { (river) }\end{array}$ & $\begin{array}{l}\text { Not marked }{ }^{1} \text {; Not } \\
\text { named }^{2}\end{array}$ & $160-150 ; N, 10 a$ \\
\hline Nam Sang (TMF) & $\begin{array}{l}18^{\circ} 13^{\prime}-18^{\circ} 26^{\prime} \mathrm{N} \\
102^{\circ} 06^{\prime}-102^{\circ} 09^{\prime} \mathrm{E} \text { (river) }\end{array}$ & Not marked ${ }^{1,2}$ & $180-210 ; \mathrm{N}, 10 a$ \\
\hline Nam Sin (PDD) & $\begin{array}{l}22^{\circ} \mathrm{O} 2^{\prime}-22^{\circ} \mathrm{O} 3^{\prime} \mathrm{N} \\
102^{\circ} \mathrm{O} 7^{\prime}-102^{\circ} 13^{\prime} \mathrm{E} \text { (river) }\end{array}$ & Not marked 1,2 & $350-1,000 ; \mathrm{N}, 10 \mathrm{~b}$ \\
\hline Nam Tang (HNN) & $\begin{array}{l}17^{\circ} 31^{\prime}-17^{\circ} 34^{\prime} \mathrm{N} 105^{\circ} 50^{\prime}- \\
105^{\circ} 51^{\prime} \mathrm{E} \text { (river) }\end{array}$ & $\begin{array}{l}\text { Not marked }{ }^{1,2} \text { (local } \\
\text { name Nam Huck) }\end{array}$ & $180-200 ; C, 5 b, 10 a$ \\
\hline $\begin{array}{l}\text { Nam Theun* } \\
\text { (Historical, NNT, NP } \\
\text { and "Other") }\end{array}$ & $\begin{array}{l}17^{\circ} 43^{\prime}-18^{\circ} 15^{\prime} \mathrm{N} \\
104^{\circ} 38^{\prime}-105^{\circ} 16^{\prime} \mathrm{E} \text { (river) }\end{array}$ & $\begin{array}{l}\text { Nam Theun }{ }^{1,2} ; \\
\text { Nam-Teun }{ }^{13} ; \text { Nam } \\
\text { Teun }{ }^{18}\end{array}$ & $380-550 ; C, 10 a$ \\
\hline
\end{tabular}

*see note added in proof 5, p.132. 
Part 2. cont

\begin{tabular}{|c|c|c|c|}
\hline $\begin{array}{l}\text { Locality name } \\
\text { following Lao SGN } \\
\text { 1 : 100,00o Series } \\
\text { Category within main } \\
\text { text (e.g: Historical } \\
\text { "Other") }\end{array}$ & $\begin{array}{l}\text { Geographical } \\
\text { coordinates (locality } \\
\text { type: town/river/ } \\
\text { region) }\end{array}$ & $\begin{array}{l}\text { Alternative names in } \\
\text { references, and local } \\
\text { names }\end{array}$ & $\begin{array}{l}\text { Altitude; } \\
\text { Biogeographic } \\
\text { subunits }\end{array}$ \\
\hline $\begin{array}{l}\text { Nam Theun I dam site } \\
\text { (Not marked) (NK) }\end{array}$ & $\begin{array}{l}18^{\circ} 21^{\prime} \mathrm{N} 104^{\circ} \mathrm{og} \mathrm{g}^{\prime} \mathrm{E} \text { (site } \\
\text { of proposed dam at } \\
\text { Keng Itat) }\end{array}$ & Not marked 1,2 & $180 ; N, 10 a$ \\
\hline $\begin{array}{l}\text { Nam Theun } 2 \text { dam site } \\
\text { (Not marked) (NP, } \\
\text { outside NNT) }\end{array}$ & $\begin{array}{l}18^{\circ} 00^{\prime} \mathrm{N} 104^{\circ} 59^{\prime} \mathrm{E} \text { (site } \\
\text { of proposed dam) }\end{array}$ & Not marked ${ }^{1,2}$ & $510 ; C, 10 a$ \\
\hline $\begin{array}{l}\text { Nam On (NNT and } \\
\text { NP) }\end{array}$ & $\begin{array}{l}17^{\circ} 38^{\prime}-17^{\circ} 43^{\prime} \mathrm{N} \\
105^{\circ} 16^{\prime}-105^{\circ} 27^{\prime} \mathrm{E} \\
\text { (river) }\end{array}$ & $\begin{array}{l}\text { Nam One }{ }^{1} ; \text { Not } \\
\text { named }^{2}\end{array}$ & $520 ; C, 5 b, 10 a$ \\
\hline $\begin{array}{l}\text { Nam Thie (Not } \\
\text { located) (Historical) }\end{array}$ & $\begin{array}{l}\text { approx. } 19^{\circ} 13^{\prime} \mathrm{N} \\
102^{\circ} 34^{\prime} \mathrm{E} \text { (river) }\end{array}$ & $\begin{array}{l}\text { Not marked }{ }^{1} ; \text { Not } \\
\text { named }{ }^{2} ; \text { Nam Thie }{ }^{9}\end{array}$ & approx. $900 ; \mathrm{N}, 10 \mathrm{~b}$ \\
\hline $\begin{array}{l}\text { Nam Thon (just } \\
\text { outside KML, NP) }\end{array}$ & $\begin{array}{l}17^{\circ} 53^{\prime}-17^{\circ} 56^{\prime} \mathrm{N} 104^{\circ} 4^{\prime}- \\
104^{\circ} 54^{\prime} \mathrm{E} \text { (river) }\end{array}$ & Not marked ${ }^{1,2}$ & $180-190 ; C, 10 a$ \\
\hline Nam Thon (TMF) & $\begin{array}{l}18^{\circ} 05^{\prime}-18^{\circ} 34^{\prime} \mathrm{N} \\
102^{\circ} 11^{\prime}-102^{\circ} 17^{\prime} \mathrm{E} \text { (river) }\end{array}$ & Not marked 1,2 & $180-250 ; N, 10 a$ \\
\hline $\begin{array}{l}\text { Nam Xot (NNT and } \\
\text { NP) }\end{array}$ & $\begin{array}{l}17^{\circ} 51^{\prime}-18^{\circ} 09^{\prime} \mathrm{N} \\
105^{\circ} 03^{\prime}-105^{\circ} 17^{\prime} \mathrm{E} \text { (river) }\end{array}$ & $\begin{array}{l}\text { Not marked }{ }^{1} \text {; Not } \\
\text { named }^{2}\end{array}$ & 520-60o; C,10a \\
\hline $\begin{array}{l}\text { Nam Xot (middle } \\
\text { reaches of) (NNT) }\end{array}$ & $\begin{array}{l}18^{\circ} 06^{\prime}-18^{\circ} 08^{\prime} \mathrm{N} \\
105^{\circ} 15^{\prime}-105^{\circ} 17^{\prime} \mathrm{E} \text { (river) }\end{array}$ & $\begin{array}{l}\text { Not marked }{ }^{1} \text {; Not } \\
\text { named }^{2}\end{array}$ & $600 ; C, 5 b, 10 a$ \\
\hline Nam Xouang (NK) & $\begin{array}{l}18^{\circ} 22^{\prime}-18^{\circ} 27^{\prime} \mathrm{N} \\
104^{\circ} 20^{\prime}-104^{\circ} 27^{\prime} \mathrm{E} \\
\text { (river) }\end{array}$ & Not marked ${ }^{1,2}$ & $200-320 ; N, 10 a$ \\
\hline $\begin{array}{l}\text { Nam Yang (NNT and } \\
\text { NP) }\end{array}$ & $\begin{array}{l}17^{\circ} 40^{\prime}-17^{\circ} 41^{\prime} \mathrm{N} \\
105^{\circ} 26^{\prime}-105^{\circ} 27^{\prime} \mathrm{E} \text { (river) }\end{array}$ & Not marked ${ }^{1,2}$ & $520 ; C, 10 a$ \\
\hline $\begin{array}{l}\text { Nong Boua (Not } \\
\text { named) (NP, just } \\
\text { outside NNT) }\end{array}$ & $\begin{array}{l}17^{\circ} 44^{\prime} \mathrm{N} 105^{\circ} 11^{\prime} \mathrm{E} \\
\text { (pool) }\end{array}$ & Not marked ${ }^{1,2}$ & $520 ; C, 10 a$ \\
\hline $\begin{array}{l}\text { Nong Bawa (not } \\
\text { marked) (DHS) }\end{array}$ & $\begin{array}{l}15^{\circ} \mathrm{O1}^{\prime} \mathrm{N} 106^{\circ} \mathrm{O} 4^{\prime} \mathrm{E} \\
\text { (pool) }\end{array}$ & Not marked ${ }^{1,2}$ & $210 ; S, 10 a$ \\
\hline $\begin{array}{l}\text { Nong Boua-ton (not } \\
\text { named) (DHS) }\end{array}$ & $\begin{array}{l}14^{\circ} 51^{\prime} \mathrm{N} 106^{\circ} 09^{\prime} \mathrm{E} \\
\text { (pool) }\end{array}$ & Not marked ${ }^{1,2}$ & $220 ; S, 10 a$ \\
\hline $\begin{array}{l}\text { Nong Hia (not named) } \\
\text { (DHS) }\end{array}$ & $\begin{array}{l}15^{\circ} \mathrm{O3}^{\prime} \mathrm{N} 106^{\circ} \mathrm{O} 4^{\prime} \mathrm{E} \\
\text { (pool) }\end{array}$ & Not marked ${ }^{1,2}$ & $210 ; S, 10 a$ \\
\hline $\begin{array}{l}\text { Nong Hin (Not } \\
\text { marked) (BSW) }\end{array}$ & $\begin{array}{l}14^{\circ} 53^{\prime} \mathrm{N} 100^{\circ} 26^{\prime} \mathrm{E} \\
\text { (pool) }\end{array}$ & Not marked ${ }^{1,2}$ & $270 ; S, 10 a$ \\
\hline $\begin{array}{l}\text { Nong Hou (Not } \\
\text { named) (DHS) }\end{array}$ & $\begin{array}{l}14^{\circ} 59^{\prime} \mathrm{N} 106^{\circ} 06^{\prime} \mathrm{E} \\
\text { (pool) }\end{array}$ & Not marked $^{1,2}$ & $240 ; S, 10 a$ \\
\hline $\begin{array}{l}\text { Nong Houay Soymong } \\
\text { (Not named) (BSW) }\end{array}$ & $\begin{array}{l}14^{\circ} 44^{\prime} \mathrm{N} 106^{\circ} 25^{\prime} \mathrm{E} \\
\text { (wetlands) }\end{array}$ & Not marked $^{1,2}$ & $140 ; S, 10 a$ \\
\hline $\begin{array}{l}\text { Nong Khai (Not } \\
\text { covered) (Historical) }\end{array}$ & $\begin{array}{l}17^{\circ} 51^{\prime} \mathrm{N} 102^{\circ} 43^{\prime} \mathrm{E} \\
\text { (town in Thailand) }\end{array}$ & $\begin{array}{l}\text { Nong Khai }{ }^{1,2,18} \text {; Nong } \\
\text { Kai }{ }^{28}\end{array}$ & $\begin{array}{l}\text { 160; adjacent to } \\
\mathrm{N}, 10 a\end{array}$ \\
\hline $\begin{array}{l}\text { Nong Leenphom (Not } \\
\text { named) (DHS) }\end{array}$ & $\begin{array}{l}14^{\circ} 5^{\prime} \mathrm{N} 106^{\circ} 06^{\prime} \mathrm{E} \\
\text { (pool) }\end{array}$ & Not marked ${ }^{\mathrm{t}, 2}$ & $260 ; S, 10 a$ \\
\hline Nong Lom (XNN) & $\begin{array}{l}15^{\circ} \mathrm{o} 2 \mathrm{~N}^{\prime} 106^{\circ} 34^{\prime} \mathrm{E} \\
\text { (pool) }\end{array}$ & Not marked ${ }^{1,2}$ & $780 ; S, 10 a$ \\
\hline $\begin{array}{l}\text { Nong Louang } \\
\text { ("Other") }\end{array}$ & $\begin{array}{l}16^{\circ} 14^{\prime}-16^{\circ} 16^{\prime} \mathrm{N} \\
105^{\circ} 22^{\prime}-105^{\circ} 24^{\prime} \mathrm{E} \text { (lake) }\end{array}$ & Not marked ${ }^{1,2}$ & $130 ; C, 10 a$ \\
\hline $\begin{array}{l}\text { Nong Loum (Not } \\
\text { named) }(X P)\end{array}$ & $\begin{array}{l}14^{\circ} 42^{\prime} \mathrm{N} 106^{\circ} 05^{\prime} \mathrm{E} \\
\text { (pool) }\end{array}$ & Not marked ${ }^{1,2}$ & 150; S,10a \\
\hline
\end{tabular}


Part 2. cont.

\begin{tabular}{|c|c|c|c|}
\hline $\begin{array}{l}\text { Locality name } \\
\text { following Lao SGN } \\
\text { I : Ioo,ooo Series } \\
\text { Category within main } \\
\text { text (e.g: Historical } \\
\text { "Other") }\end{array}$ & $\begin{array}{l}\text { Geographical } \\
\text { coordinates (locality } \\
\text { type: town/river/ } \\
\text { region) }\end{array}$ & $\begin{array}{l}\text { Alternative names in } \\
\text { references, and local } \\
\text { names }\end{array}$ & $\begin{array}{l}\text { Altitude; } \\
\text { Biogeographic } \\
\text { subunits }\end{array}$ \\
\hline $\begin{array}{l}\text { Nong Nyian (Not } \\
\text { named) (NP, just } \\
\text { outside NNT) }\end{array}$ & $\begin{array}{l}17^{\circ} 49^{\prime} \mathrm{N} 105^{\circ} 08^{\prime} \mathrm{E} \\
\text { (pool) }\end{array}$ & Not marked ${ }^{1,2}$ & $520 ; C, 10 a$ \\
\hline $\begin{array}{l}\text { Nong Puler (Not } \\
\text { named) (XP) }\end{array}$ & $\begin{array}{l}14^{\circ} 31^{\prime} \mathrm{N} 106^{\circ} 19^{\prime} \mathrm{E} \\
\text { (pool) }\end{array}$ & Not marked $^{1,2}$ & $80 ; S, 10 a$ \\
\hline Nong Tok (BSW) & $\begin{array}{l}14^{\circ} 56^{\prime} \mathrm{N} 106^{\circ} 28^{\prime} \mathrm{E} \\
\text { (pool) }\end{array}$ & Not marked ${ }^{1,2}$ & $330 ; 5,10 a$ \\
\hline $\begin{array}{l}\text { "Northern Mountains" } \\
\text { (Not named) (NNT) }\end{array}$ & $\begin{array}{l}18^{\circ} 00^{\prime}-18^{\circ} 22^{\prime} \mathrm{N} \\
105^{\circ} 03^{\prime}-105^{\circ} 20^{\prime} \mathrm{E} \\
\text { (mountains) }\end{array}$ & Not marked $^{1,2}$ & $600-1,642 ; C, 5 b, 10 a$ \\
\hline $\begin{array}{l}\text { "Northern Zone" (Not } \\
\text { named) (XP) }\end{array}$ & $\begin{array}{l}14^{\circ} 02^{\prime}-14^{\circ} 07^{\prime} \mathrm{N} 106^{\circ} 01^{\prime}- \\
106^{\circ} 13^{\prime} \mathrm{E} \text { (wetlands and } \\
\text { forest area partly } \\
\text { within XP) }\end{array}$ & Not marked ${ }^{1,2}$ & $150-165 ; S, 10 a$ \\
\hline Oudomxai Province & $\begin{array}{l}19^{\circ} 50^{\prime}-21^{\circ} 20^{\prime} \mathrm{N} 101^{\circ} 30^{\prime}- \\
102^{\circ} 20^{\prime} \mathrm{E} \text { (Province) }\end{array}$ & Not marked ${ }^{1,2}$ & $300-1,854 ; \mathrm{N}, 10 \mathrm{~b}$ \\
\hline Paklay (Historical) & $\begin{array}{l}18^{\circ} 12^{\prime} \mathrm{N} 101^{\circ} 30^{\prime} \mathrm{E} \\
\text { (town) }\end{array}$ & $\begin{array}{l}\text { Pak Lay }{ }^{1,18} ; \text { Muang } \\
\text { Pak-Lay }^{2} ; \text { Paklay }^{6} ; \\
\text { Paklaï }^{15} ; \text { Pak } \\
\text { Lai }^{28}\end{array}$ & $320 ; \mathrm{N}, 10 \mathrm{~b}$ \\
\hline $\begin{array}{l}\text { Paksang (not marked) } \\
\text { (TMF) }\end{array}$ & $\begin{array}{l}18^{\circ} 14^{\prime} \mathrm{N} 102^{\circ} 08^{\prime} \mathrm{E} \\
\text { (guard post hut at } \\
\text { river mouth) }\end{array}$ & Not marked ${ }^{1,2}$ & 180; N,10a \\
\hline Pakxan (Historical) & $\begin{array}{l}18^{\circ} 23^{\prime} \mathrm{N} 103^{\circ} 39^{\prime} \mathrm{E} \\
\text { (town) }\end{array}$ & $\begin{array}{l}\text { Pak Sane }{ }^{1,18} ; \text { Muang } \\
\text { Pakxan }^{2}\end{array}$ & 160; N,10a \\
\hline $\begin{array}{l}\text { Pakxan wetlands (not } \\
\text { named) ("Other") }\end{array}$ & $\begin{array}{l}18^{\circ} 23^{\prime} \mathrm{N} 103^{\circ} 42^{\prime} \mathrm{E} \\
\text { (wetlands) }\end{array}$ & Not marked ${ }^{1,2}$ & $160 ; N, 10 a$ \\
\hline Pakxe (Historical) & $\begin{array}{l}15^{\circ} \mathrm{O}^{\prime} \mathrm{N}_{105^{\circ}} 48^{\prime} \mathrm{E} \\
\text { (town) }\end{array}$ & $\begin{array}{l}\text { Pakse }{ }^{1} ; \text { Pakxé }{ }^{2} \\
\text { Paksé }^{14,18,22,24,25}\end{array}$ & 100; S,10a \\
\hline $\begin{array}{l}\text { Pakxong ( outside } \\
\text { XNN) }\end{array}$ & $\begin{array}{l}15^{\circ} 10^{\prime} \mathrm{N} 106^{\circ} 14^{\prime} \mathrm{E} \\
\text { (town) }\end{array}$ & $\begin{array}{l}\text { Pak Song }{ }^{1} \text {; Muang } \\
\text { Pakxong }{ }^{2}\end{array}$ & 1,$280 ; \mathrm{S}, 10 \mathrm{a}$ \\
\hline $\begin{array}{l}\text { Pha Khok (not named) } \\
\text { ("Other") }\end{array}$ & $\begin{array}{l}18^{\circ} 44^{\prime} \mathrm{N} 104^{\circ} 13^{\prime} \mathrm{E} \\
\text { (limestone mountain) }\end{array}$ & Not marked $^{1,2}$ & $500-1,200$ \\
\hline $\begin{array}{l}\text { Phon Phisai (Not } \\
\text { covered) (Historical) }\end{array}$ & $\begin{array}{l}18^{\circ} \mathrm{O} 3^{\prime} \mathrm{N} 103^{\circ} 05^{\prime} \mathrm{E} \\
\text { (town in Thailand) }\end{array}$ & Phon Phisai $1,2,28$ & $\begin{array}{l}\text { 170; adjacent to } \\
\mathrm{N}, 10 a\end{array}$ \\
\hline $\begin{array}{l}\text { Phongsali (Historical, } \\
\text { "Other") }\end{array}$ & $\begin{array}{l}21^{\circ} 41^{\prime} \mathrm{N} 102^{\circ} 06^{\prime} \mathrm{E} \\
\text { (town) }\end{array}$ & $\begin{array}{l}\text { Phong Saly }{ }^{1,6} \text {; } \\
\text { Phôngsali }{ }^{2} ; \\
\text { Phong-Saly }\end{array}$ & 1,$500 ; \mathrm{N}, 10 \mathrm{~b}$ \\
\hline Phongsali Province & $\begin{array}{l}21^{\circ} 10^{\prime}-23^{\circ} 00^{\prime} \mathrm{N} 101^{\circ} 35^{\prime}- \\
103^{\circ} 00^{\prime} \mathrm{E} \text { (Province) }\end{array}$ & Not marked ${ }^{1,2}$ & $720-1,842 ; \mathrm{N}, 10 \mathrm{~b}$ \\
\hline $\begin{array}{l}\text { Phou Ajol (Not } \\
\text { named) (XS) }\end{array}$ & $\begin{array}{l}15^{\circ} 43^{\prime} \mathrm{N} 105^{\circ} 11^{\prime} \mathrm{E} \\
\text { (mountain) }\end{array}$ & Not marked ${ }^{1,2}$ & 2,$193 ; S, 5 b$ \\
\hline Phou Alang (PXT) & $\begin{array}{l}15^{\circ} 24^{\prime} \mathrm{N} 105^{\circ} 36^{\prime} \mathrm{E} \\
\text { (hill) }\end{array}$ & Not marked ${ }^{1,2}$ & $300-440 ; S, 10 a$ \\
\hline Phou Bia (Historical) & $\begin{array}{l}1^{\circ} 59^{\prime} \mathrm{N} 103^{\circ} 09^{\prime} \mathrm{E} \\
\text { (mountain) }\end{array}$ & Phou Bia $1,2,9,10,16$ & $2,500-2,819 ; \mathrm{N}, 10 b$ \\
\hline $\begin{array}{l}\text { Phou Chong Vong } \\
\text { (Not located) } \\
\text { (Historical) }\end{array}$ & $\begin{array}{l}19^{\circ} 25^{\prime} \mathrm{N} 103^{\circ} 21^{\prime} \mathrm{E} \\
\text { (mountain) }\end{array}$ & $\begin{array}{l}\text { Not marked }{ }^{1,2} \text {; Phou } \\
\text { Chong Vong }{ }^{9}\end{array}$ & 1,$300 ; \mathrm{N}, 1 \mathrm{ob}$ \\
\hline
\end{tabular}


Part 2. cont.

\begin{tabular}{|c|c|c|c|}
\hline $\begin{array}{l}\text { Locality name } \\
\text { following Lao SGN } \\
\text { I : 1oo,ooo Series } \\
\text { Category within main } \\
\text { text (e.g: Historical } \\
\text { "Other") }\end{array}$ & $\begin{array}{l}\text { Geographical } \\
\text { coordinates (locality } \\
\text { type: town/river/ } \\
\text { region) }\end{array}$ & $\begin{array}{l}\text { Alternative names in } \\
\text { references, and local } \\
\text { names }\end{array}$ & $\begin{array}{l}\text { Altitude; } \\
\text { Biogeographic } \\
\text { subunits }\end{array}$ \\
\hline Phou Dendin (PDD) & $\begin{array}{l}22^{\circ} 09^{\prime} \mathrm{N} 102^{\circ} 23^{\prime} \mathrm{E} \\
\text { (mountain) }\end{array}$ & Not marked ${ }^{1,2}$ & 1,$948 ; \mathrm{N}_{, 10 b}$ \\
\hline Phou Etva (HNN) & $\begin{array}{l}17^{\circ} 35^{\prime} \mathrm{N} 105^{\circ} 4^{8^{\prime} \mathrm{E}} \\
\text { (mountain) }\end{array}$ & $\begin{array}{l}\text { Not marked }{ }^{1,2}, \\
\text { local name Phou } \\
\text { Tcheung }\end{array}$ & $\mathbf{1 , 4 9 2 ; C , 5 b , 1 0 a}$ \\
\hline Phou Hinho (PXH) & $\begin{array}{l}16^{\circ} 50^{\prime} \mathrm{N} 105^{\circ} 57^{\prime} \mathrm{E} \\
\text { (mountain) }\end{array}$ & Not marked ${ }^{1,2}$ & $300-618 ; C, 10 a$ \\
\hline $\begin{array}{l}\text { Phou Xang He (Not } \\
\text { named) (PXH) }\end{array}$ & $\begin{array}{l}16^{\circ} 54^{\prime} \mathrm{N} 105^{\circ} 47^{\prime} \mathrm{E} \\
\text { (mountain) }\end{array}$ & $\begin{array}{l}\text { Not marked }{ }^{1,2} \text { (Name } \\
\text { derived from the } \\
\text { Sayphou Xanghe } \\
\text { escarpment) }\end{array}$ & $300-730 ; C, 10 a$ \\
\hline Phou Kabo (Historical) & $\begin{array}{l}19^{\circ} 16^{\prime} \mathrm{N} 103^{\circ} 25^{\prime} \mathrm{E} \\
\text { (mountain) }\end{array}$ & $\begin{array}{l}\text { Not marked }{ }^{1} \text {; Not } \\
\text { named }{ }^{2} \text {; Phou } \\
\text { Kobo }^{9,21} \text {; Phu Kobo }{ }^{15,16}\end{array}$ & $1,800-2,166 ; \mathrm{N}, 10 \mathrm{~b}$ \\
\hline Phou Ko (NNT) & $\begin{array}{l}17^{\circ} 47^{\prime} \mathrm{N} 105^{\circ} 26^{\prime} \mathrm{E} \\
\text { (mountain) }\end{array}$ & Phu Co ${ }^{1}$; Not marked ${ }^{2}$ & $700-1,312 ; C, 5 b, 10 a$ \\
\hline Phou Laoko (NNT) & $\begin{array}{l}18^{\circ} 10^{\prime} \mathrm{N} 105^{\circ} 25^{\prime} \mathrm{E} \\
\text { (mountain) }\end{array}$ & Rao Go ${ }^{1}$; Not named ${ }^{2}$ & 2,$286 ; C, 5 b, 10 a$ \\
\hline $\begin{array}{l}\text { Phou Salar (not } \\
\text { named) (XBN) }\end{array}$ & $15^{\circ} 48^{\prime} \mathrm{N} 105^{\circ} 50^{\prime} \mathrm{E}$ (hill) & Not marked $^{1,2}$ & $400 ; S, 10 a$ \\
\hline $\begin{array}{l}\text { Phou Thauw (Not } \\
\text { named) (XBN) }\end{array}$ & $\begin{array}{l}15^{\circ} 56^{\prime} \mathrm{N} 106^{\circ} 09^{\prime} \mathrm{E} \\
\text { (mountain) }\end{array}$ & Not marked ${ }^{1,2}$ & $824 ; S, 10 a$ \\
\hline Phou Vang (NNT) & $\begin{array}{l}17^{\circ} 47^{\prime} \mathrm{N} 105^{\circ} 33^{\prime} \mathrm{E} \\
\text { (mountain) }\end{array}$ & Not marked ${ }^{1,2}$ & $\begin{array}{l}1,200-1,890 \\
C, 5 b, 10 a\end{array}$ \\
\hline Phou Yiatyo (NNT) & $\begin{array}{l}17^{\circ} 48^{\prime} \mathrm{N} 105^{\circ} 39^{\prime} \mathrm{E} \\
\text { (mountain) }\end{array}$ & Not marked ${ }^{1,2}$ & $\begin{array}{l}1,200-2,058 \\
C, 5 b, 10 a\end{array}$ \\
\hline $\begin{array}{l}\text { Plain of Jars (map } \\
\text { name: Thong Haihin) } \\
\text { (Historical) }\end{array}$ & $\begin{array}{l}19^{\circ} 20^{\prime}-19^{\circ} 30^{\prime} \mathrm{N} \text { 10301- } \\
103^{\circ} 15^{\prime} \mathrm{E} \text { (open plain) }\end{array}$ & $\begin{array}{l}\text { Plaine des Jarres }{ }^{1,9} ; \\
\text { not named }^{2}\end{array}$ & $1,050-1,100 ; N, 10 b$ \\
\hline Quan Mou (DHS) & $\begin{array}{l}14^{\circ} 56^{\prime} \mathrm{N} 106^{\circ} 09^{\prime} \mathrm{E} \\
\text { (seasonal pool) }\end{array}$ & $\begin{array}{l}\text { Not marked }{ }^{1,2} \text {; site } \\
\text { referred to as Quan } \\
\text { Moor in Thewlis et al. } \\
(1996) .\end{array}$ & $270 ; \mathrm{S}, 10 \mathrm{a}$ \\
\hline $\begin{array}{l}\text { Route } 8 \text { ("Other" and } \\
\text { outside NNT) }\end{array}$ & $\begin{array}{l}18^{\circ} 05^{\prime}-18^{\circ} 25^{\prime} \mathrm{N} \\
104^{\circ} 15^{\prime}-105^{\circ} 10^{\prime} \mathrm{E} \text { (major } \\
\text { road) }\end{array}$ & $\begin{array}{l}\text { Not marked }{ }^{1} \text {, Not } \\
\text { named }^{2}\end{array}$ & $150-600 ; N, C, 5 b, 10 a$ \\
\hline $\begin{array}{l}\text { Route } 13 \text { ("Other" and } \\
\text { outside XP) }\end{array}$ & $\begin{array}{l}13^{\circ} 55^{\prime}-18^{\circ} 25^{\prime} \mathrm{N} \\
102^{\circ} 40^{\prime}-106^{\circ} 00^{\prime} \mathrm{E} \text { (major } \\
\text { road) }\end{array}$ & $\begin{array}{l}\text { Not marked }{ }^{1}, \text { Not } \\
\text { named }^{2}\end{array}$ & $80-250 ; \mathrm{N}, \mathrm{C}, \mathrm{S}, 10 \mathrm{a}$ \\
\hline Route 18 ("Other") & $\begin{array}{l}14^{\circ} 42^{\prime}-14^{\circ} 4^{8} \mathrm{~N} 105^{\circ} 5^{\prime} \\
106^{\circ} 50^{\prime} \mathrm{E} \text { (major road) }\end{array}$ & $\begin{array}{l}\text { Not marked }{ }^{1} \text {, Not } \\
\text { named }{ }^{2}\end{array}$ & $100-130$ \\
\hline Salavan Province & $\begin{array}{l}15^{\circ} 22^{\prime}-16^{\circ} 30^{\prime} \mathrm{N} \\
105^{\circ} 20^{\prime}-107^{\circ} 15^{\prime} \mathrm{E} \\
\text { (Province) }\end{array}$ & Not marked ${ }^{1,2}$ & $130-1,588 ; S, 5 b, 10 a$ \\
\hline Salavan (Historical) & $\begin{array}{l}15^{\circ} 43^{\prime} \mathrm{N} 106^{\circ} 25^{\prime} \mathrm{E} \\
\text { (town) }\end{array}$ & $\begin{array}{l}\text { Saravane }^{1,11,13,14,18,19,20,22,23,25} \\
\text { Saravan }^{2}\end{array}$ & $186 ; S, 10 a$ \\
\hline Savannakhet Province & $\begin{array}{l}15^{\circ} 50^{\prime}-17^{\circ} 10^{\prime} \mathrm{N} \\
104^{\circ} 40^{\prime}-106^{\circ} 45^{\prime} \mathrm{E} \\
\text { (Province) }\end{array}$ & Not marked ${ }^{1,2}$ & $130-1,312 ; C, 5 b, 10 a$ \\
\hline
\end{tabular}


Part 2. cont.

\begin{tabular}{|c|c|c|c|}
\hline $\begin{array}{l}\text { Locality name } \\
\text { following Lao SGN } \\
\text { I : 100,o0o Series } \\
\text { Category within main } \\
\text { text (e.g: Historical } \\
\text { "Other") }\end{array}$ & $\begin{array}{l}\text { Geographical } \\
\text { coordinates (locality } \\
\text { type: town/river/ } \\
\text { region) }\end{array}$ & $\begin{array}{l}\text { Alternative names in } \\
\text { references, and local } \\
\text { names }\end{array}$ & $\begin{array}{l}\text { Altitude; } \\
\text { Biogeographic } \\
\text { subunits }\end{array}$ \\
\hline $\begin{array}{l}\text { Savannakhet } \\
\text { (Historical, "Other") }\end{array}$ & $\begin{array}{l}16^{\circ} 34^{\prime} \mathrm{N} 104^{\circ} 45^{\prime} \mathrm{E} \\
\text { (town) }\end{array}$ & $\begin{array}{l}\text { Savannakhet }{ }^{1,6,11,18} \text {; } \\
\text { Savannakhét }{ }^{2}\end{array}$ & 150; C,10a \\
\hline $\begin{array}{l}\text { Sayphou Ak (NNT, } \\
\text { NP) }\end{array}$ & $\begin{array}{l}17^{\circ} 35^{\prime}-17^{\circ} 52^{\prime} \mathrm{N} \\
104^{\circ} 52^{\prime}-105^{\circ} 45^{\prime} \mathrm{E} \\
\text { (escarpment) }\end{array}$ & $\begin{array}{l}\text { Not marked }{ }^{1} \text {; Not } \\
\text { named }^{2}\end{array}$ & $240-1,104 ; C, 10 a$ \\
\hline Sayphou Ao (NK) & $\begin{array}{l}18^{\circ} 16^{\prime}-18^{\circ} 22^{\prime} \mathrm{N} 104^{\circ} 24^{\prime}- \\
104^{\circ} 28^{\prime} \mathrm{E} \text { (ridge) }\end{array}$ & Not marked ${ }^{1,2}$ & $280-950 ; N, 10 a$ \\
\hline $\begin{array}{l}\text { Sayphou Damlek } \\
\text { (DKT, "Other") }\end{array}$ & $\begin{array}{l}14^{\circ} 20^{\prime}-15^{\circ} 00^{\prime} \mathrm{N} 105^{\circ} 10^{\prime}- \\
105^{\circ} 37^{\prime} \mathrm{E} \text { (mountain } \\
\text { range; coordinates are } \\
\text { for within Laos) }\end{array}$ & $\begin{array}{l}\text { Phanom des Raek }{ }^{1} \text {; } \\
\text { Chaine des } \\
\text { Dangrek }{ }^{1} \text {; } \\
\text { Chuor Phnum } \\
\text { Dangrek }^{2}\end{array}$ & $100-766 ; S, 10 a$ \\
\hline $\begin{array}{l}\text { Sayphou Hou-ong } \\
\text { (XBN) }\end{array}$ & $\begin{array}{l}15^{\circ} 57^{\prime}-15^{\circ} 59^{\prime} \mathrm{N} \\
106^{\circ} \mathrm{o1}-106^{\circ} 06^{\prime} \mathrm{E} \\
\text { (mountain) }\end{array}$ & Not marked ${ }^{1,2}$ & $400-1,239 ; S, 10 a$ \\
\hline Sayphou Kiou (XP) & $\begin{array}{l}14^{\circ} 04^{\prime}-14^{\circ} 07^{\prime} \mathrm{N} \\
106^{\circ} 00^{\prime}-106^{\circ} 10^{\prime} \mathrm{E} \text { (ridge } \\
\text { of hills) }\end{array}$ & Not marked ${ }^{1,2}$ & $100-282 ; S, 10 a$ \\
\hline $\begin{array}{l}\text { Sayphou Loyang } \\
\text { ("Other") }\end{array}$ & $\begin{array}{l}{ }^{1} 8^{\circ} 13^{\prime} \mathrm{N} 104^{\circ} 56^{\prime} \mathrm{E} \\
\text { (limestone mountains) }\end{array}$ & Not marked ${ }^{1,2}$ & $820 ; C, 10 a$ \\
\hline $\begin{array}{l}\text { Seephandon (Not } \\
\text { named) (SMK) }\end{array}$ & $\begin{array}{l}13^{\circ} 55^{\prime}-14^{\circ} 18^{\prime} \mathrm{N} \\
105^{\circ} 23^{\prime}-106^{\circ} \mathrm{oo}^{\prime} \mathrm{E} \text { (area } \\
\text { of islands) }\end{array}$ & $\begin{array}{l}\text { Not marked }{ }^{1} \text {, Not } \\
\text { named }^{2}\end{array}$ & $80 ; 5,10 a$ \\
\hline $\begin{array}{l}\text { Senamsai (Not } \\
\text { marked, although } \\
\text { probably Ban Hatgnao } \\
\text { (Muang Samakhixai)) } \\
(\text { "Other") }\end{array}$ & $\begin{array}{l}14^{\circ} 41^{\prime} \mathrm{N} 106^{\circ} 38^{\prime} \mathrm{E} \\
\text { (town) }\end{array}$ & Not marked ${ }^{1,2}$ & $80 ;$ S,I0a \\
\hline $\begin{array}{l}\text { Somphamit Falls } \\
\text { (SMK) }\end{array}$ & $\begin{array}{l}13^{\circ} 57^{\prime} \mathrm{N} 105^{\circ} 54^{\prime} \mathrm{E} \\
\text { (waterfall) }\end{array}$ & Not marked ${ }^{1,2}$ & $80 ; S, 10 a$ \\
\hline $\begin{array}{l}\text { "Southern } \\
\text { escarpment" (Not } \\
\text { named) (NNT) }\end{array}$ & $\begin{array}{l}17^{\circ} 34^{\prime}-17^{\circ} 40^{\prime} \mathrm{N} \\
105^{\circ} 20^{\prime}-105^{\circ} 45^{\prime} \mathrm{E} \\
\text { (escarpment at } \\
\text { southern fringe of } \\
\text { NNT) }\end{array}$ & Not marked ${ }^{1,2}$ & $400-1,104 ; C, 5 b, 10 a$ \\
\hline $\begin{array}{l}\text { "Southern Mountains" } \\
\text { (Not named) (NNT) }\end{array}$ & $\begin{array}{l}17^{\circ} 35^{\prime}-17^{\circ} 55^{\prime} \mathrm{N} \\
105^{\circ} 20^{\prime}-105^{\circ} 45^{\prime} \mathrm{E} \\
\text { (mountains) }\end{array}$ & Not marked ${ }^{1,2}$ & $600-2,058 ; C, 5 b, 10 a$ \\
\hline $\begin{array}{l}\text { Taloun (Not located) } \\
\text { (Historical) }\end{array}$ & $\begin{array}{l}19^{\circ} 54^{\prime} \mathrm{N} 102^{\circ} 18^{\prime} \mathrm{E} \\
\text { (village) }\end{array}$ & $\begin{array}{l}\text { Not marked }{ }^{1,2} ; \\
\text { Taloun }\end{array}$ & $500 ; \mathrm{N}, 10 \mathrm{~b}$ \\
\hline $\begin{array}{l}\text { Tasaeng Theung (Not } \\
\text { named) (NNT) }\end{array}$ & $\begin{array}{l}17^{\circ} 47^{\prime}-17^{\circ} 58^{\prime} \mathrm{N} \\
105^{\circ} 24^{\prime}-105^{\circ} 37^{\prime} \mathrm{E} \\
\text { (enclave of villages) }\end{array}$ & Not marked ${ }^{1,2}$ & $530-1,000 ; C, 5 b, 10 a$ \\
\hline Thakhek (Historical) & $\begin{array}{l}17^{\circ} 24^{\prime} \mathrm{N} 104^{\circ} 49^{\prime} \mathrm{E} \\
\text { (town) }\end{array}$ & $\begin{array}{l}\text { Thakhek }{ }^{1} \text {; Muang } \\
\text { Khammouan }{ }^{2} \text {; Tha } \\
\text { Khek }^{18}\end{array}$ & $150 ; C_{r} 10 a$ \\
\hline $\begin{array}{l}\text { Theun-Hinboun dam } \\
\text { site (Not marked) } \\
\text { (NK) }\end{array}$ & $\begin{array}{l}18^{\circ} 15^{\prime} \mathrm{N} 104^{\circ} 33^{\prime} \mathrm{E} \text { (site } \\
\text { of proposed dam) }\end{array}$ & Not marked ${ }^{1,2}$ & $380 ; \mathrm{N}, 10 a$ \\
\hline
\end{tabular}


Part 2, cont.

\begin{tabular}{|c|c|c|c|}
\hline $\begin{array}{l}\text { Locality name } \\
\text { following Lao SGN } \\
1 \text { : 100,000 Series } \\
\text { Category within main } \\
\text { text (e.g: Historical } \\
\text { "Other") }\end{array}$ & $\begin{array}{l}\text { Geographical } \\
\text { coordinates (locality } \\
\text { type: town/river/ } \\
\text { region) }\end{array}$ & $\begin{array}{l}\text { Alternative names in } \\
\text { references, and local } \\
\text { names }\end{array}$ & $\begin{array}{l}\text { Altitude; } \\
\text { Biogeographic } \\
\text { subunits }\end{array}$ \\
\hline $\begin{array}{l}\text { Tranninh (Not } \\
\text { marked) (Historical) }\end{array}$ & $\begin{array}{l}19^{\circ} 00^{\prime}-20^{\circ} 15^{\prime} \mathrm{N} \\
102^{\circ} 15^{\prime}-103^{\circ} 55^{\prime} \mathrm{E} \\
\text { (Historical region, } \\
\text { approximately } \\
\text { corresponding to } \\
\text { current province of } \\
\text { Xiangkhouang) }\end{array}$ & $\begin{array}{l}\text { Not named }{ }^{1,2} ; \\
\text { Tranninh } \\
9,8,17\end{array}$ & $300-2,819 ; \mathrm{N}, 5 \mathrm{~b}, 1 \mathrm{ob}$ \\
\hline $\begin{array}{l}\text { Upper Mekong } \\
\text { (Historical Province, } \\
\text { name no longer used, } \\
\text { precise area is } \\
\text { uncertain) }\end{array}$ & $\begin{array}{l}\text { approx. } 19^{\circ} 50^{\prime}-21^{\circ} 30^{\prime} \mathrm{N} \\
100^{\circ} 00^{\prime}-101^{\circ} 45^{\prime} \mathrm{E} \text { (the } \\
\text { predecessor, } \\
\text { approximating to } \\
\text { Provinces of } \\
\text { Louang-Namtha and } \\
\text { Bokeo) }\end{array}$ & $\begin{array}{l}\text { Not marked }{ }^{1,2} ; \text { Haut } \\
\text { Mekong }^{19}\end{array}$ & $300-2,094 ; \mathrm{N}, 5 \mathrm{~b}$ \\
\hline Vientiane Province & $\begin{array}{l}17^{\circ} 45^{\prime}-19^{\circ} 25^{\prime} \mathrm{N} 101^{\circ} 25^{\prime}- \\
103^{\circ} 50^{\prime} \mathrm{E} \text { (Province) }\end{array}$ & Not marked ${ }^{1,2}$ & $150-2,006 ; \mathrm{N}, 10 a$ \\
\hline $\begin{array}{l}\text { Vientiane (Historical, } \\
\text { "Other") }\end{array}$ & $\begin{array}{l}17^{\circ} 58^{\prime} \mathrm{N} 102^{\circ} 37^{\prime} \mathrm{E} \\
\text { (town) }\end{array}$ & $\begin{array}{l}\text { Vientiane }^{1,2,6,9,15,17} \\
\text { Viangchan }^{2} \text {; Vien } \\
\text { Tiane }^{18,27} \text {; Vien Chan }{ }^{28}\end{array}$ & $165 ; \mathrm{N}, 10 a$ \\
\hline Vientiane Prefecture & $\begin{array}{l}17^{\circ} 50^{\prime}-18^{\circ} 25^{\prime} \mathrm{N} 102^{\circ} 10^{\prime}- \\
103^{\circ} 15^{\prime} \mathrm{E} \\
\text { (administrative region } \\
\text { adjacent to Vientiane } \\
\text { Province) }\end{array}$ & Not marked ${ }^{1,2}$ & $165-180 ; N, 10 a$ \\
\hline $\begin{array}{l}\text { Wat Simuang } \\
(\text { "Other") }\end{array}$ & $\begin{array}{l}17^{\circ} 5^{\prime} \mathrm{N} 102^{\circ} 37^{\prime} \mathrm{E} \\
\text { (Buddhist temple) }\end{array}$ & Not marked ${ }^{1,2}$ & $165 ; \mathrm{N}, 10 \mathrm{a}$ \\
\hline $\begin{array}{l}\text { Wet forest logging } \\
\text { road }^{*} \text { (Not marked) } \\
(\mathrm{NTX})\end{array}$ & $\begin{array}{l}18^{\circ} 16^{\prime}-18^{\circ} 29^{\prime} \mathrm{N} \\
105^{\circ} \mathrm{O} 2^{\prime}-105^{\circ} \mathrm{o} 7^{\prime} \mathrm{E} \\
\text { (logging road) }\end{array}$ & Not marked ${ }^{1,2}$ & $540-1,100 ; \mathrm{N} / \mathrm{C}, 5 \mathrm{~b}$ \\
\hline $\begin{array}{l}\text { Xaignabouli Province } \\
\text { ("Other") }\end{array}$ & $\begin{array}{l}17^{\circ} 30^{\prime}-19^{\circ} 55^{\prime} \mathrm{N} \\
100^{\circ} 25^{\prime}-101^{\circ} 45^{\prime} \mathrm{E} \\
\text { (Province) }\end{array}$ & Not marked $^{1,2}$ & $\begin{array}{l}200-2,153 \\
N, 10 a, 10 b\end{array}$ \\
\hline $\begin{array}{l}\text { Xam-Nua (Historical, } \\
\text { "Other") }\end{array}$ & $\begin{array}{l}20^{\circ} 25^{\prime} \mathrm{N} 104^{\circ} 03^{\prime} \mathrm{E} \\
\text { (town) }\end{array}$ & $\begin{array}{l}\text { Sam Neua }{ }^{1,18} ; \text { Xam } \\
\text { Nua }^{2}\end{array}$ & 1,$000 ; \mathrm{N}, 1 \mathrm{ob}$ \\
\hline Xe Bangfai (HNN) & $\begin{array}{l}17^{\circ} 00^{\prime}-17^{\circ} 30^{\prime} \mathrm{N} 105^{\circ} 10^{\prime}- \\
106^{\circ} 20^{\prime} \mathrm{E} \text { (river) }\end{array}$ & $\begin{array}{l}\text { Se Bang } \mathrm{Fai}^{1}, \mathrm{Xe} \\
\text { Bangfai }^{2}\end{array}$ & $170-260 ; C, 5 b, 10 a$ \\
\hline $\begin{array}{l}\text { Xe Banghiang } \\
\text { (Historical) }\end{array}$ & $\begin{array}{l}16^{\circ} 03^{\prime}-16^{\circ} 54^{\prime} \mathrm{N} \\
105^{\circ} 15^{\prime}-106^{\circ} 27^{\prime} \mathrm{E} \text { (river) }\end{array}$ & $\begin{array}{l}\text { Se Bang Hieng }{ }^{1,2} ; \text { Se } \\
\text { Bang Hien }{ }^{18} ; \\
\text { Sé-Bang-Hieng }{ }^{11}\end{array}$ & $\begin{array}{l}\text { 130-220;border } \\
\text { between } C \text { and } \\
S, 5 b, 10 a\end{array}$ \\
\hline $\begin{array}{l}\text { Xe Bang-Nouan } \\
\text { (Historical, XBN) }\end{array}$ & $\begin{array}{l}15^{\circ} 51^{\prime}-15^{\circ} 54^{\prime} \mathrm{N} \\
106^{\circ} 12^{\prime}-106^{\circ} 26^{\prime} \mathrm{E} \text { (river) }\end{array}$ & $\begin{array}{l}\text { Not marked }{ }^{7} \text {; Not } \\
\text { named }{ }^{2} \text {; } \\
\text { Sé-Bang-Nhuân }^{11}\end{array}$ & $130-320 ; S, 10 a$ \\
\hline Xe Don (Historical) & 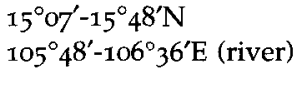 & $\begin{array}{l}\text { Se Done }{ }^{1} \text {; Xé Don }{ }^{2} \text {; Sé } \\
\text { Done }{ }^{18} \text {; Sédone }{ }^{22,25} \text {; } \\
\text { Sé-Don }{ }^{27}\end{array}$ & 100-180; S,10a \\
\hline Xe Kaman ("Other") & $\begin{array}{l}14^{\circ} 47^{\prime}-15^{\circ} 21^{\prime} \mathrm{N} \\
106^{\circ} 50^{\prime}-107^{\circ} 34^{\prime} \mathrm{E} \text { (river) }\end{array}$ & $\begin{array}{l}\text { Se Kamane }{ }^{1}, \mathrm{Xe} \\
\text { Kaman }^{2}\end{array}$ & $110-960 ; S, 10 a, 5 b$ \\
\hline
\end{tabular}

*see note added in proof 6, p.132. 
Part 2. cont.

\begin{tabular}{|c|c|c|c|}
\hline $\begin{array}{l}\text { Locality name } \\
\text { following Lao SGN } \\
\text { I : 1oo,ooo Series } \\
\text { Category within main } \\
\text { text (e.g: Historical } \\
\text { "Other") }\end{array}$ & $\begin{array}{l}\text { Geographical } \\
\text { coordinates (locality } \\
\text { type: town/river/ } \\
\text { region) }\end{array}$ & $\begin{array}{l}\text { Alternative names in } \\
\text { references, and local } \\
\text { names }\end{array}$ & $\begin{array}{l}\text { Altitude; } \\
\text { Biogeographic } \\
\text { subunits }\end{array}$ \\
\hline Xe Katam (XNN) & $\begin{array}{l}15^{\circ} 06^{\prime}-15^{\circ} 16^{\prime} \mathrm{N} \\
106^{\circ} 25^{\prime}-106^{\circ} 37^{\prime} \mathrm{E} \text { (river) }\end{array}$ & Not marked ${ }^{1,2}$ & $310-920 ; \mathrm{S}, 10 a$ \\
\hline Xe Khampho (XP) & $\begin{array}{l}14^{\circ} 02^{\prime}-14^{\circ} 31^{\prime} \mathrm{N} \\
106^{\circ} 13^{\prime}-106^{\circ} 21^{\prime} \mathrm{E} \text { (river) }\end{array}$ & $\begin{array}{l}\text { Se Khampho }{ }^{1} \text {; Not } \\
\text { named }^{2}\end{array}$ & $60-120 ; S, 10 a$ \\
\hline Xekong Province & $\begin{array}{l}15^{\circ} 00^{\prime}-16^{\circ} 15^{\prime} \mathrm{N} 106^{\circ} 15^{\prime}- \\
107^{\circ} 40^{\prime} \mathrm{E} \text { (Province) }\end{array}$ & Not marked ${ }^{1,2}$ & $180-2,500 ; S, 5 b, 10 a$ \\
\hline $\begin{array}{l}\text { Xe Kong (river) } \\
\text { (Historical, XNN, XP } \\
\text { and "Other") }\end{array}$ & $\begin{array}{l}14^{\circ} 27^{\prime}-16^{\circ} 01^{\prime} \mathrm{N} \\
106^{\circ} 20^{\prime}-107^{\circ} 01^{\prime} \mathrm{E} \text { (river) }\end{array}$ & $\begin{array}{l}\text { Se Kong }{ }^{1} \text {; Kong }{ }^{2} \text {; Sé } \\
\text { Kong }^{18} \text {; Sékong } 22,25\end{array}$ & $70-360 ; S, 10 a$ \\
\hline $\begin{array}{l}\text { Xe Kong plains (Not } \\
\text { named) (XP) }\end{array}$ & $\begin{array}{l}14^{\circ} 27^{\prime}-14^{\circ} 40^{\prime} \mathrm{N} \\
106^{\circ} 16^{\prime}-106^{\circ} 30^{\prime} \mathrm{E} \\
\text { (expanse of plains } \\
\text { within XP) }\end{array}$ & Not marked ${ }^{1,2}$ & 77-110; S,10a \\
\hline $\begin{array}{l}\text { Xe Namkok } \\
\text { (Historical) }\end{array}$ & $\begin{array}{l}16^{\circ} 42^{\prime}-16^{\circ} 52^{\prime} \mathrm{N} \\
106^{\circ} 03^{\prime}-106^{\circ} 13^{\prime} \mathrm{E} \text { (river) }\end{array}$ & $\begin{array}{l}\text { Not named }{ }^{1,2} ; \\
\text { Sé-Nam-Kok }^{11}\end{array}$ & $220-240 ; C, 10 a$ \\
\hline Xe Namnoy (XNN) & $\begin{array}{l}14^{\circ} 50^{\prime}-15^{\circ} 14^{\prime} \mathrm{N} \\
106^{\circ} 17^{\prime}-106^{\circ} 36^{\prime} \mathrm{E} \text { (river) }\end{array}$ & $\begin{array}{l}\text { Not marked }{ }^{1} \text {; Not } \\
\text { named }^{2}\end{array}$ & $100-800 ; S, 10 a$ \\
\hline $\begin{array}{l}\text { Xe Namnoy dam site } \\
\text { (Not marked) (XNN) }\end{array}$ & $\begin{array}{l}15^{\circ} 02^{\prime} \mathrm{N} 106^{\circ} 36^{\prime} \mathrm{E} \text { (site } \\
\text { of proposed dam) }\end{array}$ & Not marked ${ }^{1,2}$ & $750 ; S_{, 10 a}$ \\
\hline Xe Pian (BSW, XP) & $\begin{array}{l}14^{\circ} 27^{\prime}-15^{\circ} 06^{\prime} \mathrm{N} \\
106^{\circ} 20^{\prime}-106^{\circ} 32^{\prime} \mathrm{E} \text { (river) }\end{array}$ & $\begin{array}{l}\text { Not marked '; Not } \\
\text { named }^{2}\end{array}$ & $70-900 ; \mathrm{S}, 10 a$ \\
\hline Xe Pon (XS) & $\begin{array}{l}16^{\circ} 13^{\prime}-16^{\circ} 45^{\prime} \mathrm{N} \\
106^{\circ} 13^{\prime}-106^{\circ} 56^{\prime} \mathrm{E} \text { (river) }\end{array}$ & Se Pone ${ }^{1}$; Not named ${ }^{2}$ & $170-600 ; C, 5 b, 10 a$ \\
\hline $\begin{array}{l}\text { Xe Pon (Historical) } \\
\text { (not marked) }\end{array}$ & $\begin{array}{l}16^{\circ} 20^{\prime}-16^{\circ} 45^{\prime} \mathrm{N} \\
106^{\circ} 18^{\prime}-106^{\circ} 42^{\prime} \mathrm{E} \\
\text { (region) }\end{array}$ & $\begin{array}{l}\text { Not marked }{ }^{1,2} ; \\
\text { Tchéṕône }{ }^{11} ; \text { Tcephone }\end{array}$ & $170-500 ; C, 5 b, 10 a$ \\
\hline Xe Pon (Historical) & $\begin{array}{l}16^{\circ} 41{ }^{\prime} \mathrm{N} 106^{\circ} 14^{\prime} \mathrm{E} \\
\text { (town) }\end{array}$ & $\begin{array}{l}\text { Sepone }{ }^{1} \text {; Muang } \\
\text { Xéṕôn }{ }^{2} ; \text { Tchéṕône }{ }^{11} \text {; } \\
\text { Tcephone }^{6}\end{array}$ & $170 ; \mathrm{C}, 10 a$ \\
\hline Xe Xou ("Other") & $\begin{array}{l}14^{\circ} 40^{\prime}-14^{\circ} 50^{\prime} \mathrm{N} \\
106^{\circ} 55^{\prime}-107^{\circ} 34^{\prime} \mathrm{E} \text { (river) }\end{array}$ & $\begin{array}{l}\text { Not marked }{ }^{\mathrm{T}} \text {, not } \\
\text { named }^{2}\end{array}$ & $160-500 ; S, 5 b, 10 a$ \\
\hline $\begin{array}{l}\text { Xiangkhouang (Not } \\
\text { marked) (Historical) }\end{array}$ & $\begin{array}{l}19^{\circ} 20^{\prime} \mathrm{N} 103^{\circ} 22^{\prime} \mathrm{E} \\
\text { (former town } \\
\text { destroyed in } 1972 \text { ) }\end{array}$ & 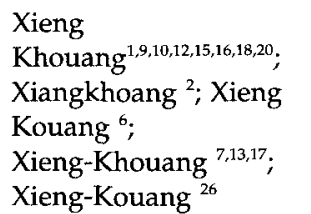 & 1,$100 ; \mathrm{N}, 10 \mathrm{~b}$ \\
\hline $\begin{array}{l}\text { Xiangkhouang } \\
\text { Province ("Other") }\end{array}$ & $\begin{array}{l}18^{\circ} 40^{\prime}-20^{\circ} 10^{\prime} \mathrm{N} \\
102^{\circ} 30^{\prime}-104^{\circ} 15^{\prime} \mathrm{E} \\
\text { (Province) }\end{array}$ & Not marked ${ }^{1,2}$ & $300-2,919 ; \mathrm{N}, 10 \mathrm{~b}$ \\
\hline
\end{tabular}


Appendix 2. Refined list of recommended Key Species for future workers in Laos.

\begin{tabular}{|c|c|}
\hline Species & Reason \\
\hline Siamese Fireback & GT, PARL \\
\hline Crested Argus & GT, ARL \\
\hline Green Peafowl & GT, ARL \\
\hline White-winged Duck & GT, ARL \\
\hline Comb Duck & PARL \\
\hline Yellow-crowned Woodpecker & PARL \\
\hline Crimson-breasted Woodpecker & LK \\
\hline White-bellied Woodpecker & PARL \\
\hline Streak-throated Woodpecker & PARL \\
\hline Red-collared Woodpecker & GT \\
\hline Great Hornbill & ARL \\
\hline Brown Hornbill & GNT, PARL \\
\hline Rufous-necked Hornbill & GT, ARL \\
\hline Wreathed Hornbill & ARL \\
\hline Blyth's Kingfisher & GT, PARL \\
\hline Ruddy Kingfisher & LK \\
\hline Pied Kingfisher & ARL \\
\hline Coral-billed Ground-cuckoo & GNT \\
\hline Alexandrine Parakeet & ARL \\
\hline Spot-bellied Eagle-owl & GNT, LK \\
\hline Tawny Fish-owl & GNT, LK \\
\hline Pale-capped Pigeon & GT, LK \\
\hline Pompadour Green-pigeon & ARL \\
\hline Yellow-footed Green-pigeon & ARL \\
\hline Yellow-vented Green-pigeon & GNT, LK \\
\hline White-bellied Green-pigeon & GNT, LK \\
\hline Green Imperial-pigeon & ARL \\
\hline Sarus Crane & GNT, ARL \\
\hline Masked Finfoot & GT, ARL \\
\hline Wood Snipe & GT, LK \\
\hline Great Thick-knee & ARL \\
\hline Long-billed Plover & GNT, LK \\
\hline River Lapwing & ARL \\
\hline Grey-headed Lapwing & GNT, PARL \\
\hline Small Pratincole & PARL \\
\hline Indian Skimmer & GT, ARL \\
\hline River Tern & ARL \\
\hline Black-bellied Tern & GT, ARL \\
\hline Little Tern & ARL \\
\hline Jerdon's Baza & GNT \\
\hline Black-eared Kite & ARL \\
\hline Brahminy Kite & ARL \\
\hline White-bellied Sea-eagle & ARL \\
\hline Lesser Fish-eagle & GNT, ARL \\
\hline Grey-headed Fish-eagle & GNT, ARL \\
\hline White-rumped Vulture & GNT, ARL \\
\hline Long-billed Vulture & GNT, ARL \\
\hline Red-headed Vulture & GNT, ARL \\
\hline Rufous-winged Buzzard & GNT, PARL \\
\hline Greater Spotted Eagle & GT, LK \\
\hline Imperial Eagle & GT, LK \\
\hline White-rumped Falcon & GNT, PARL \\
\hline Pied Falconet & GNT, LK \\
\hline
\end{tabular}


Appendix 2. cont.

\begin{tabular}{|c|c|}
\hline Species & Reason \\
\hline Lesser Kestrel & GT, LK \\
\hline Oriental Darter & GNT, ARL \\
\hline Little Cormorant & ARL \\
\hline Great Cormorant & ARL \\
\hline Grey Heron & PARL \\
\hline Purple Heron & PARL \\
\hline Malayan Night-heron & LK \\
\hline Schrenck's Bittern & GNT, LK \\
\hline Black-headed Ibis & GNT, ARL \\
\hline White-shouldered Ibis & GT, ARL \\
\hline Giant Ibis & GT, ARL \\
\hline Spot-billed Pelican & GT, ARL \\
\hline Painted Stork & GNT, ARL \\
\hline Asian Openbill & GNT, ARL \\
\hline Woolly-necked Stork & ARL \\
\hline Black-necked Stork & ARL \\
\hline Lesser Adjutant & GT, ARL \\
\hline Greater Adjutant & GT, ARL \\
\hline Blue-naped Pitta & GNT, LK \\
\hline Blue-rumped Pitta & GNT, PARL \\
\hline Bar-bellied Pitta & GNT, PARL \\
\hline White-winged Magpie & GNT, PARL \\
\hline Yellow-breasted Magpie & GNT, PARL \\
\hline Brown-rumped Minivet & GNT \\
\hline Yellow-bellied Fantail & LK \\
\hline Japanese Paradise-flycatcher & GNT, LK \\
\hline Brown Dipper & PARL \\
\hline Black-breasted Thrush & GNT, LK \\
\hline Grey-sided Thrush & GT, LK \\
\hline White-browed Shortwing & LK \\
\hline Fujian Niltava & GNT, PARL \\
\hline Blue-fronted Robin & GNT, LK \\
\hline Green Cochoa & GNT \\
\hline Jerdon's Bushchat & GNT, PARL \\
\hline Golden-crested Myna & PARL \\
\hline Yellow-billed Nuthatch & GT, LK \\
\hline Beautiful Nuthatch & GT, PARL \\
\hline Brown-throated Treecreeper & LK \\
\hline Plain Martin & ARL \\
\hline Wire-tailed Swallow & PARL \\
\hline Yellow-vented Warbler & GNT \\
\hline Broad-billed Warbler & GNT, LK \\
\hline Black-hooded Laughingthrush & GT, PARL \\
\hline Grey Laughingthrush & GNT \\
\hline Spot-breasted Laughingthrush & GNT, LK \\
\hline Red-tailed Laughingthrush & GNT \\
\hline Short-tailed Scimitar-babbler & GT, PARL \\
\hline Spotted Wren-babbler & GNT, PARL \\
\hline Sooty Babbler & GT, PARL \\
\hline Grey-faced Tit-babbler & GNT \\
\hline Yellow-throated Fulvetta & GNT, LK \\
\hline Spectacled Fulvetta & GNT \\
\hline Rufous-throated Fulvetta & GNT \\
\hline Spot-breasted Parrotbill & LK \\
\hline
\end{tabular}


Appendix 2. cont.

\begin{tabular}{ll}
\hline Species & Reason \\
\hline Short-tailed Parrotbill & GT, LK \\
Lesser Rufous-headed Parrotbill & GNT, LK \\
Greater Rufous-headed Parrotbill & GNT, LK \\
Yellow-bellied Flowerpecker & LK \\
Asian Golden Weaver & GNT, ARL \\
\hline
\end{tabular}

Also any further species newly recorded for the country which are listed by Collar et al. (1994) as Globally Threatened or Globally Near-Threatened. See Table 3 for explanation of abbreviations. 